\title{
GEORG-AUGUST-UNIVERSITÄT
}

GÖTTINGEN

\section{Effects of cold stress on reproductive biology and epigenetic profiles of the alpine plant Ranunculus kuepferi (Ranunculaceae)}

\author{
Dissertation \\ for the award of the degree \\ “Doctor rerum naturalium" (Dr. rer. nat.) \\ PhD Division of Mathematics and Natural Sciences \\ of the Georg-August-University Göttingen
}

Within the doctoral program Biology

of the Georg-August University School of Science (GAUSS)

Submitted by

Eleni Syngelaki

from Heraklion, Crete

Göttingen, 2021 


\section{Thesis Committee}

\section{Prof. Dr. Elvira Hörandl}

Department of Systematics, Biodiversity and Evolution of Plants

Albrecht-von-Haller Institute for Plant Sciences

Georg-August-University of Göttingen, Germany

\section{Prof. Dr. Stefan Scheu}

Department of Animal Ecology, Johann-Friedrich-Blumenbach Institute of Zoology and Anthropology

Georg-August-University of Göttingen, Germany

\section{Members of the Examination Board}

\section{1'st Reviewer: $\quad$ Prof. Dr. Elvira Hörandl}

Department of Systematics, Biodiversity and Evolution of Plants, Albrecht-von-Haller Institute for Plant Sciences, Georg-August-University of Göttingen, Germany

$2^{\text {st }}$ Reviewer: $\quad$ Prof. Dr. Stefan Scheu

Department of Animal Ecology, Johann-Friedrich-Blumenbach Institute of Zoology and Anthropology, Georg-August-University of Göttingen, Germany

\section{Further members of the Examination Board}

\section{Prof. Dr. Christoph Bleidorn}

Department of Animal Evolution and Biodiversity, Johann-Friedrich-Blumenbach Institute of Zoology and Anthropology, Georg-August-University of Göttingen, Germany

\section{Prof. Dr. Christiane Gatz}

Department of Plant Molecular Biology and Physiology, Schwann-Schleiden-ResearchCenter for Molecular Cell Biology, Georg-August-University of Göttingen, Germany

\section{PD Dr. Franz Hadacek}

Department of Plant Biochemistry, Albrecht-von-Haller Institute for Plant Sciences, Georg-August-University of Göttingen, Germany

\section{Prof. Dr. Jan de Vries}

Department of Applied Bioinformatics, Institute for Microbiology and Genetics, GeorgAugust-University of Göttingen, Germany

Date of the oral examination: 03.12.2021 
Table of Contents

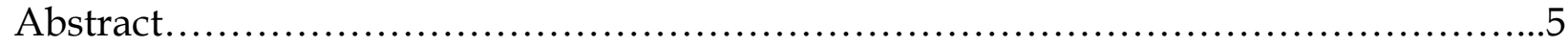

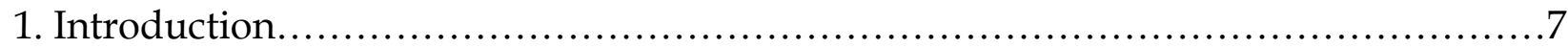

1.1 Temperature stress....................................................7

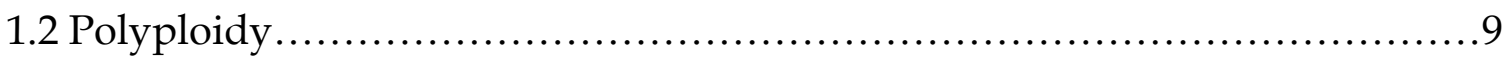

1.3 Apomixis........................................................... 10

1.4 Epigenetics and gene expression......................................12

1.5 Ranunculus kuepferi................................................... 14

1.6 Aims and scope.......................................................16

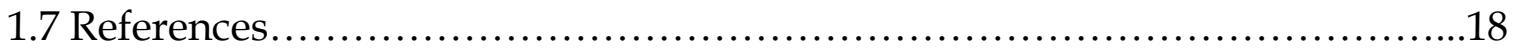

2. Chapter 2 - Effects of temperature treatments on cytosine-methylation profiles of diploid and autotetraploid plants of the alpine species Ranunculus kuepferi (Ranunculaceae)

Abstract................................................................... 30

2.1 Introduction.......................................................

2.2 Materials and Methods.........................................34

2.3 Results...................................................... 37

2.4 Discussion........................................................ 45

2.5 References.......................................................50

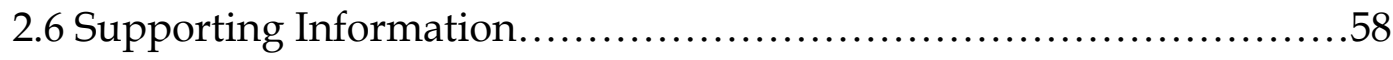

3. Chapter 3 - Phenotypic responses, reproduction mode and epigenetic patterns under temperature treatments in the alpine plant species Ranunculus kuepferi (Ranunculaceae)

Abstract...................................................................... 70

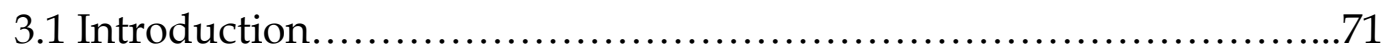

3.2 Materials and Methods...........................................74

3.3 Results........................................................... 


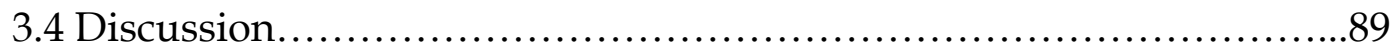

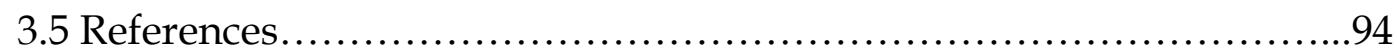

3.6 Supporting Information...........................................104

4. Chapter 4 - Gene expression profiles suggest a better cold acclimation of polyploids in the alpine species Ranunculus kuepferi (Ranunculaceae)

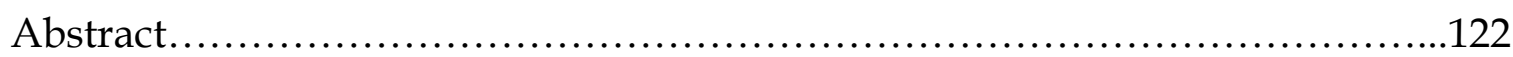

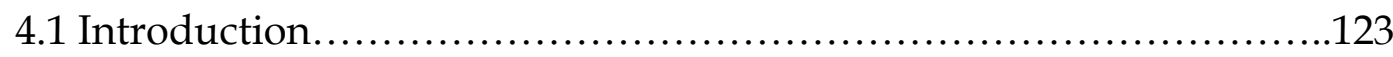

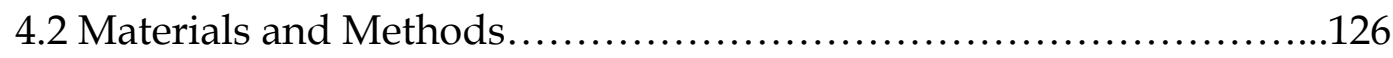

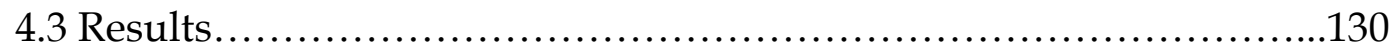

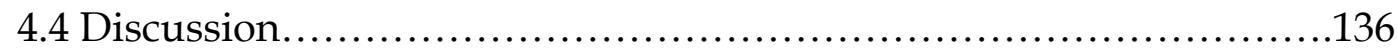

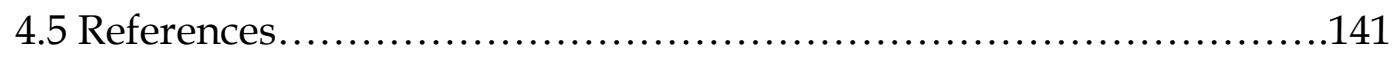

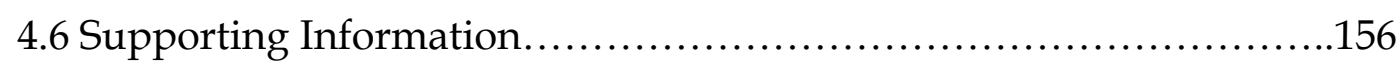

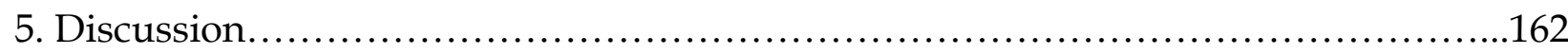

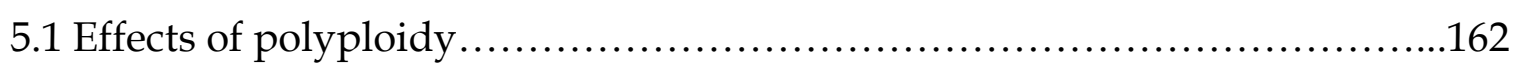

5.2 Effects of temperature treatments.......................................167

5.3 Correlations of epigenetic patterns with morphological traits and gene

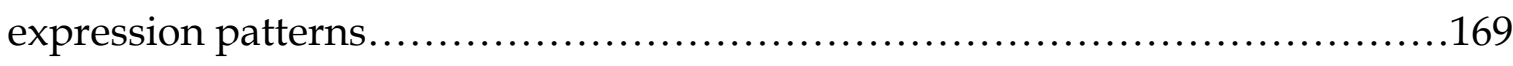

5.4 Conclusions and Prospects...............................................171

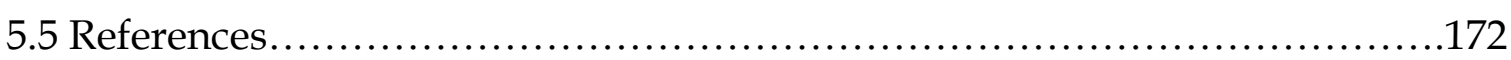

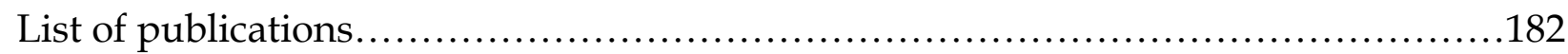

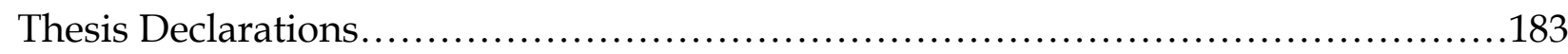

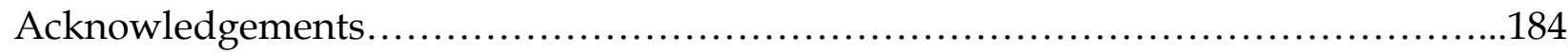

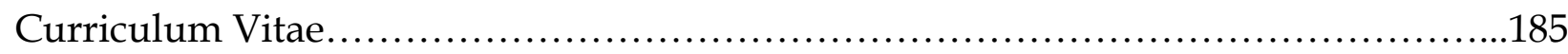




\section{Abstract}

Alpine habitats are shaped by harsh abiotic conditions and cold climates. Plant life in such habitats is challenging, as environmental influence can alter the conditions for development and reproduction.

More specifically, phenotypic plasticity of morphological traits can be influenced by temperature stress. Temperature stress can also affect epigenetic and gene expression profiles, which may have an impact on acclimation and adaptation of the species. Polyploidy seems to affect the DNA methylation profiles, while distribution patterns suggest that it could be advantageous under cold conditions.

Nevertheless, little is known about non-model plants, whether temperature stress can induce methylation changes depending on the cytotypes of the individuals, to what extent a treatment shift can induce epigenetic responses and how they are depicted in phenotypic plasticity and reproduction of the species. Furthermore, it remains vague how cold stress is translated in gene expression changes under different cytotypes and how such a putative response is framed through gene set pathways and epigenetic control.

The perennial alpine plant Ranunculus kuepferi was utilized to investigate the correlations of cold stress with polyploidy, mode of reproduction, phenotypic plasticity, epigenetics, gene expression and geographical parthenogenesis. The species is mainly found in the wild with diploid and autotetraploid cytotypes, which are mostly sexual and facultative apomicts, respectively.

Diploid and autotetraploid individuals were placed in two climate chambers and exposed to cold $\left(+7^{\circ} \mathrm{C}\right.$ day $/+2^{\circ} \mathrm{C}$ night, $-1^{\circ} \mathrm{C}$ cold shocks for three nights per week) and warm (control) $\left(+15^{\circ} \mathrm{C}\right.$ day $/+10^{\circ} \mathrm{C}$ night) temperature treatments in climate growth chambers for four consecutive flowering periods and shifted from one condition to the other after the first flowering period.

Methylation-sensitive amplified fragment-length polymorphism markers were applied for the first two years, to screen possible genome-wide methylation alterations triggered by temprerature treatments and treatment shifts. For the second year of temperature treatments, morphological traits (height, leaves and flowers) and the proportion of welldeveloped seeds were measured as fitness indicators, while flow cytometric seed screening (FCSS) was utilized to determine the reproduction mode. Subsequently, comparisons with patterns of methylation-sensitive amplified fragment-length polymorphisms (MS-AFLPs/MSAPs) regarding the same year of treatment were conducted. Finally, for the last year of treatment, both cytotypes were investigated for their gene expression profiles via transcriptome sequencing and qRT-PCR. The datasets 
were analyzed for four predefined groups with respect to treatment (Cold/Warm) and ploidy level (Diploid/Tetraploid).

DNA methylation profiles showed temperature sensitivity and propose a ploidy effect for both years of analysis. Likewise, the treatment shift had an impact on both cytotypes, resulting in significantly less epiloci, regardless of the shift's direction. Such correlations of ploidy level and epigenetic profiles may reflect DNA methylation dynamics during cold acclimation. The AMOVA results are in line with the hypothesis of cold stress influencing the epigenetic patterns, while they also depict the DNA methylation dynamics of tetraploids, as a response to temperature treatment shift.

Concerning the phenotypic plasticity of the species under temperature treatments, the potential of acclimation under environmental conditions is underlined, as diploids grow better under warm conditions and tetraploids perform better in cold treatments, while the expressed morphological traits are linked with epigenetic patterns. Moreover, cold stress reduced the reproduction fitness but did not induce apomixis in diploid individuals. These results confirm the different niche preferences of cytotypes in natural populations and empower the geographical parthenogenesis scenario, which is previously proposed for the species.

Cold acclimation of the cytotypes is further indicated by gene expression profiles. Overall, diploid individuals altered more gene set pathways than tetraploid ones, and suppressed pathways involved in ion/cation homeostasis. Gene Set Pathways mostly activated under tetraploids are related to cell wall and plasma membrane. Thus, tetraploids seem to be better acclimated to cold conditions, enabling them to colonize colder climatic areas in the Alps. Finally, an epigenetic background for gene regulation in response to temperature conditions is indicated. 


\section{Introduction}

\subsection{Temperature stress}

Abiotic and biotic environmental conditions are a major influence, alongside with the genotype, on the expression of phenotypes in plants (West-Eberhard, 2008). Changes in average temperature play a pivotal role in phenology as well as in defense capacity, growth and development of flowering plants, while they are supposed to affect the geographical distribution range of species (e.g. Hedhly, 2011; Lau et al., 2018; Fiorucci et al., 2020). Flowering plants evolved various adaptation strategies in order to survive and reproduce under adverse temperature conditions, such as plastic responses, which are highlighted as positive contributions to the colonization of novel habitats (e.g. Yeh \& Prince, 2004; Sol et al., 2005) and subsequent selection of fitting phenotypes over many generations (e.g. Schlichting \& Pigliucci, 1998; West-Eberhard, 2003; Chevin \& Lande, 2010).

Alpine habitats are shaped by short growth periods and cold spells, eventually with nocturnal frost during flowering time (spring or summer) (Körner, 2021). Such cold temperature stress conditions, which are further defined as chilling $\left(0-20^{\circ} \mathrm{C}\right)$ or freezing $\left(<0^{\circ} \mathrm{C}\right)$, represent a critical abiotic stress, threatening several growth and developmental procedures and activating adaptive traits (e.g. Chinnusamy et al., 2007; Nagy and Grabherr, 2009; Hedhly, 2011; Liu et al., 2017; Körner, 2021). The acquisition of increased freezing tolerance upon prior exposure to non-lethal low temperatures is defined as cold acclimation, which consists of sophisticated mechanisms to endure cold stress and is moderated via structural and functional remodeling (Guy, 1990; Thomashow, 1999; Ding et al., 2019). A reliable body of studies approaches the triggering role of environmental conditions and changes (Angers et al., 2010; Kooke et al., 2015) and the ability of individuals for phenotypic accommodation (West-Eberhard, 2003; Whitman \& Agrawal, 2009) as well as acclimation to the new conditions (Chevin \& Hoffmann, 2017).

The effect of phenotypic plasticity, i.e. the potential of an organism, as a single genotype, to differentially respond to environmental stimuli (Brandshaw, 1965; Schlichting, 1986), on plants does not have an adaptive value per se, as the beneficial plastic responses should be transmitted to the next generations (e.g. Schlichting, 1986; Kopp and Matuszewski, 2013; Chevin and Hoffmann, 2017). However, plastic responses of sessile organisms, such plants, are considered of great importance concerning the acclimation to environmental conditions (e.g. West-Eberhard, 2008; Nicotra et al., 2010; Richards et al., 2017). Such responses can be depicted in morphology, physiology, gene expression, as single changes or a combination of these characteristics (Price et al., 2003; West- 
Eberhard, 2008; Whitman and Agrawal, 2009; Munns, 2011; Laland et al., 2015) and estimation of the phenotypic plasticity of several fitness traits would outline the environmental tolerance of the individuals (Merilä and Hendry, 2013; Chevin and Hoffmann, 2017).

For alpine plants, reduction of stem height and dense and cushion-like growth are regarded as acclimation or even adaptation to short vegetation periods, lower temperature and exposure to freezing conditions (Syngelaki et al., 2020b; Körner, 2021). Moreover, cold stress conditions could affect polyploidization and mode of reproduction (Ramsey and Schemske, 1998; Klatt et al., 2018; Syngelaki et al., 2020b).

Furthermore, it is proposed that abiotic environmental parameters, like temperature and light, could have a direct impact on the reproduction modes of plants (Hörandl and Hadacek, 2013; Klatt et al., 2016; Klatt et al., 2018; Ulum et al., 2020), while experimental research suggest that with low temperatures possibly triggering apomictic seed formation, albeit at low frequencies (Klatt et al., 2018). Abiotic stress conditions are also demonstrated to trigger an immediate response of apomictic clonal dandelions, associated with the populations differentiation pattern across latitude (Preite et al., 2015) and linked to methylation patterns and heritability of traits (Verhoeven et al., 2010a,b; Verhoeven and Preite, 2013).

In the past decades, several studies on genetic and epigenetic backgrounds of phenotypic plasticity and the corresponding transcriptional differentiation pose interesting research questions on plasticity under extreme environmental conditions (e.g. Dolenson et al., 2017; Richards et al., 2017; Kelly et al., 2019; Syngelaki et al., 2020a, b). Such plasticity of plants to new environmental conditions is correlated further with DNA methylation variation (Mirouze and Paskozwski, 2011; Syngelaki et al., 2020b), which may lead to micro-evolutionary events in plants (Zhang et al., 2013).

Specifically, the effects of cold stress, as depicted in alterations on morphology, physiology, DNA methylation and gene expression (e.g. Price et al., 2003; Munns, 2011; Laland et al., 2015; Richards et al., 2017) are depending on timing, combination and intensity of the stress parameters (e.g. Suzuki et al., 2014). The genes involved in these procedures can be induced by cold per se or by the relative state of dehydration following cold stress (Griffith and Yaish, 2004). 


\subsection{Polyploidy}

Polyploidy represents a heritable condition of organisms, and refers to the possession of more than two complete sets of chromosomes (Comai, 2005). It is considered to have evolutionary consequences on angiosperms, as polyploidization events in plants seem to be correlated with phenotypic innovation and speciation (Madlung, 2013; Soltis et al., 2014).

Successful polyploidization events may have important side effects on general adaptation mechanisms to more extreme climates and to stress responses (Li et al., 2011). Uncovering the putative role of polyploidy in adaptation to extreme conditions, its effects on vigor, physiology, morphology and other adaptive traits can result in increased survival fitness under harsher environments (e.g. te Beest et al., 2012; Van de Peer et al., 2017; Wei et al., 2019). Moreover, polyploids are specifically more abundant in high latitudes and regions with colder climates (Rice et al., 2019).

In general, plants in alpine habitats tend to decrease their above-ground vegetative growth and plant height usually due to producing fewer cells, while cell size tends to remain stable, thus forming an alpine dwarfism phenotype (Körner, 2021). This morphology is adaptive to short vegetation periods, and reduces exposure to freezing and overheating (Ladinig et al., 2013).

Hence, it is hypothesized that under cold temperature conditions polyploid plants are adjusting their growth and exposure of reproductive tissues towards the putative adaptive morphology of alpine dwarfism (Körner, 2021) by reducing cell numbers and increasing cell size (te Beest et al., 2012), which requires even less cells for tissue formation.

This strategy can additionally help for rapid sprouting of the polyploid plants directly after snow melting (Körner, 2021). Furthermore, a shift to asexual reproduction modes in some polyploids (Comai, 2005) is suggested to further enhance their adaptation under stress conditions, as freezing temperatures during gamete formation can occur regularly during times of flower development (Körner, 2021). Cold shocks are observed to primarily affect species of average altitudes, which are not explicitly cold-adapted, but reach the alpine zone during upward migration (Hörandl, 2010; Hörandl et al., 2011). Freezing tolerance and degree of damage induced by freezing vary a lot among plant species (Ladinig et al., 2013). Epigenetic modifications are also thought to further improve the adaptation of polyploids to stress conditions (Osborn et al., 2003; Soltis et al., 2014; Körner, 2021), while genome duplication may induce genome-wide transcriptional rewiring linked to various cytogenetic, genetic and epigenetic changes (Madlung and Wendel, 2013). 


\subsection{Apomixis}

Phenotypic plasticity can also occur in mode of reproduction. Apomixis is defined as the asexual reproduction via seeds, i.e. agamospermy (Nogler, 1984), it is a heritable trait (e.g. Nogler, 1984; Ozias-Akins and van Dijk, 2007) and occurs in 78 families and more than 290 genera of angiosperms (Hojsgaard et al., 2014). Natural origins of apomixis happened mostly during climatic oscillations of the Pleistocene (Carman, 1997; Dobes et al., 2004; Paun et al., 2006). Apomictic plants are mostly perennials and apomixis is usually facultative, meaning that both sexual and apomictic seeds can be produced by the same plant, in variable proportions (Nogler, 1984; Hojsgaard et al., 2014; Schmidt, 2020), while an individual plant may express variation in sexual/apomictic seed formation in different years (Klatt et al., 2018).

The first step toward apomixis is the unreduced female gamete formation from unreduced embryo sacs (apomeiosis). An unreduced embryo sac can be formed from either a somatic cell of the nucellus tissue (apospory) or an unreduced megaspore after a restitutional meiosis of the megaspore mother cell (diplospory) (Asker and Jerling, 1992; Koltunow and Grossniklaus, 2003); thus, meiosis is still present in gametophytic apomixis. Following steps of gametophytic development are the parthenogenetic development of unreduced egg cells, and the formation of endosperm tissue after fertilization of the two polar nuclei with a sperm cell (pseudogamy) or without male contribution (autonomous endosperm) (Koltunow and Grossniklaus, 2003; Hand and Koltunow, 2014).

In flowering plants, apomicts are commonly polyploids/hybrids and genomic changes associated with polyploidization/hybridization events were thought to activate the induction of apomixis, although their role in the origin of apomixis is ambiguous (Carman, 1997; Koltunow and Grossniklaus, 2003; Comai 2005). A successful establishment of polyploids is often connected to a niche differentiation of cytotypes (Levin, 1975; Levin, 2003), which could benefit apomictic polyploid taxa to have a better colonization performance at high latitudes and altitudes, not observed among their diploid and sexual progenitors. Furthermore, several authors have stressed the relative abundance of apomictic populations in higher altitudes and latitudes, while they are able to colonize previously glaciated areas with greater success than the sexual populations (e.g. Kearney, 2005; Hörandl, 2006; Hörandl, 2011; Gregor, 2013).

This phenomenon of divergent distribution patterns between apomictic and sexual taxa is called geographical parthenogenesis and is described in plants as well as animals (e.g. Vandel, 1928; Bell, 1982; Bierzychudek, 1985; Kearney, 2005; Hörandl, 2006) and it is hypothesized to be associated with the climatic fluctuations during the Pleistocene (e.g. Carman, 1997; Paun et al., 2006). The colonization advantage of the apomictic taxa 
cannot fully interpret the distribution patterns implied by geographical parthenogenesis (e.g. Hörandl et al., 2011), indicating a multifactorial dependency of the phenomenon.

Polyploidy is abundant also in sexual plants (e.g. Cifuentes et al., 2010), while growing evidence suggests that apomixis can originate spontaneously, and sometimes occasionally, at low frequencies in diploid wild populations (e.g. Kantama et al., 2007; Siena et al., 2008; Aliyu et al., 2010; Schinkel et al., 2016) and in diploid populations under cold temperature stress (Klatt et al., 2018).

Hence, an additional factor must be acting for spontaneous origins of apomixis. Experimental research suggests that abiotic conditions like temperature and light (Hörandl and Hadacek, 2013; Klatt et al., 2018) can directly alter mode of apomictic vs. sexual mode reproduction in plants. Cold treatments are long known to trigger restitutional meiosis and consequently unreduced gamete formation (e.g. Gustafsson and Nygren, 1946; Ramsey and Schemske, 1998; De Storme and Geelen, 2013a,b; Bomblies et al., 2015). Recent research on model plants showed that extreme temperatures can have various effects on plant meiosis: a) lowering frequencies of double strand break formation at prophase I, which can affect correct segregation of chromosomes; b) failure of synapsis, c) or failure of spindle formation at meiosis I and II (De Storme and Geelen, 2013b; Bomblies et al., 2015).

Concerning the molecular background, apomixis appears to be a consequence of a temporal or spatial deregulation of genes regulating the sexual pathway (e.g. Carman, 1997; Koltunow and Grossniklaus, 2003; Bicknell and Koltunow, 2004; Sharbel et al., 2010; Grimanelli, 2012), but its genetic and epigenetic background and the environmental influence on the expression of that trait are rather complicated and remain enigmatic (Schmidt, 2020). 


\subsection{Epigenetics and gene expression}

Epigenetic studies examine the heritable changes in gene expression and function that cannot be linked to DNA sequence changes (Richards, 2006; Bird, 2007). There are four different mechanisms, i.e. sets of molecular processes, which can contribute to epigenetic changes: a) methylation of cytosine residues in the DNA, b) remodeling of chromatin structure through chemical modification of histone proteins, c) histone protein modification that can lead to alteration of DNA wrapping, and d) regulatory processes mediated by small and non-coding RNA molecules (miRNA). These processes do not act independently from each other and can produce epigenetic changes that affect genes expression, by e.g. activating, reducing or completely disabling the activity of particular genes (e.g. Grant-Downton and Dickinson, 2005; Berger, 2007) (Syngelaki et al., 2020a).

In plants, DNA methylation is the best understood epigenetic mechanism (Jaenisch and Bird, 2003; Bender, 2004) and several studies indicated it exhibits a transgenerational inheritance (e.g. Vaughn et al., 2007; Johannes et al., 2009; Finnegan, 2010; Hirsch et al., 2013). DNA methylation is defined as the addition, catalyzed by several methyltransferases, of a methyl group to the $5^{\prime} \mathrm{C}$ of a cytosine residue in the DNA sequence and associated with silencing of transposons, imprinting and silencing of both transgenes and endogenous genes (e.g. Miura et al., 2001; Grossniklaus et al., 2001; Lippman et al., 2004; Zilberman et al., 2007; Jones, 2012). It is well documented that DNA methylation can be dynamic, as biotic or abiotic environmental stimuli can trigger methylation changes and lead to different DNA methylation profiles (e.g. Sherman \& Talbert, 2002; Bossdorf et al., 2008; Dowen et al., 2012; Zhang et al., 2013), while DNA methylation could contribute to differentiation of populations according to latitudinal gradients (Preite et al., 2015) (Syngelaki et al., 2020a).

Phenotypic plasticity is thought to be under genetic and epigenetic control (e.g. Richards et al., 2017), which are regulated by various epigenetic molecular mechanisms, involving small RNAs, transposable elements, histone modifications and cytosine methylation (Nicotra et al., 2010) and often correlated with transcriptional differentiation (Donelson et al., 2017; Kelly, 2019). The molecular response of plants towards environmental conditions is dynamic and extremely complex, as a typical plant cell possesses more than 30,000 genes (Cramer et al., 2011), while epigenetic modifications, such as DNA methylation, histone modifications and chromatin rearrangement can directly or obliquely regulate gene expression (e.g. Bird, 2002; Law \& Jacobsen, 2010; Harris et al., 2018; Xiao et al., 2019).

Profound changes in gene expression profiles affect the composition of the transcriptome, proteome and metabolome (e.g. Chinnusamy et al., 2007; Jammohammadi et al., 2015), with biochemical, physiological, structural and morphological modifications 
(e.g. Nagy \& Grabherr, 2009; Wani et al., 2013; Wani et al., 2016; Banerjee et al., 2017; Körner, 2021), such as changes in light utilization, ROS production, carbon assimilation, photosynthesis rate, membrane permeability, fluidity and cell wall architecture, being induced (e.g. Garsed et al., 1987; Sanghera et al., 2011; Theocharis et al., 2012; Longo et al., 2017; Megha et al., 2018). Furthermore, DNA methylation is exhibited to mediate phenotypic plasticity within a single generation (Bossdorf et al., 2010) and between generations (Boyko et al., 2010).

Except for environmental stimuli, methylation profiles further change with genomic stresses, such as hybridization and polyploidization, which could induce DNA methylation changes (Adams and Wendel, 2005; Dong et al., 2006; Grant-Downton and Dickinson, 2005; Verhoeven et al., 2010b). A variation in the DNA methylation profiles of wild populations of polyploids putatively unravels their local adaptation and functional plasticity (Paun et al., 2010; Rois et al., 2013; Schulz et al., 2014) and may be advantageous for the invasion success of some species (Ainouche et al., 2009).

The adaptive dynamics triggered from DNA methylation may have evolutionary consequences to the potential selection of asexual genotypes (Latzel and Klimesova, 2010; Massicotte and Angers, 2012). Strikingly, morphological variation in apomictic plants is linked to methylation variation rather than to genetic variation (Rois et al., 2013). Previous experimental work on apomictic clonal dandelions demonstrated immediate responses of plants to abiotic stress conditions, correlations to methylation patterns and heritability of traits (Verhoeven et al., 2010a; Verhoeven and Preite, 2013). 


\subsection{Ranunculus kuepferi}

A suitable model system for studying the correlation of polyploidy, morphology, reproduction mode, DNA methylation and gene expression profiles under temperature treatment is the alpine plant Ranunculus kuepferi Greuter \& Burdet.

The species is a high-mountain perennial herb, occurring predominantly in diploid and autotetraploid cytotypes and exhibing a gradient distribution mainly across the European Alps and at altitudes between 1300 and 2800 m (Burnier et al., 2009; Cosendai and Hörandl, 2010; Cosendai et al., 2011; Kirchheimer et al., 2016). Concerning the mode of reproduction of the species, diploid plants of R. kuepferi are primarily sexual and tetraploid plants are facultative apomictic (aposporous), with varying proportions of sexual and asexual seeds (Burnier et al., 2009; Cosendai et al., 2013; Schinkel et al., 2016).

Seed formation in tetraploids is independent from pollinator visits, as they breakdown self-incompatibility and reproduce independently of pollinators and mating partners (Cosendai et al., 2013). Thus, their reproduction success could be related to adaptation to short vegetation periods, reduced or variable pollinator frequencies and pollen availability in cold climatic conditions (Wagner et al., 2016). Hence, the ability of uniparental reproduction in pseudogamous apomicts, which is a general advantage for colonization, was further supported (Hörandl, 2006; Hörandl, 2010). Moreover, diploid plants are restricted to the warmer Southwestern Alps, whereas autotetraploid plants colonize previously glaciated areas, i.e. the Northern, Central and Eastern Alps as well as the northern Apennines and Corsica (Küpfer, 1974; Burnier et al., 2009; Cosendai and Hörandl, 2010; Schinkel et al., 2016), along a pronounced geographical parthenogenesis scenario (Cosendai et al., 2013). Geographical Parthenogenesis in general describes related sexual and asexual organisms having different geographical distributions (Hörandl, 2006). Tetraploid populations exhibit a pronounced niche shift towards higher elevations and colder temperatures in the European Alps (Kirchheimer et al., 2016; Schinkel et al., 2016), which is associated with their reproduction mode and, in that regard, seem to provide asexual taxa with a distributional advantage (Kirchheimer et al., 2018).

Previous studies on the species focused on the origin of cytotypes, the geographical parthenogenesis, the population genetics, the correlations of ploidy and apomixis with alpine environmental gradients, the ecological aspects, the pathways to polyploidy of natural populations and the reproductive and vegetative responses of plants under controlled conditions (Cosendai and Hörandl, 2010; Cosendai et al., 2011; Cosendai et al., 2013; Schinkel et al., 2016; Schinkel et al., 2017; Kirchheimer et al., 2016; Kirchheimer et al., 2018; Klatt et al., 2018). 
Moreover, the tetraploid cytotype originated presumably by multiple and recurrent autopolyploidization events (Cosendai et al., 2011; Schinkel et al., 2017), which took place 10 - 80 kyears ago (Kirchheimer et al., 2018). The genetic differentiation between the cytotypes is very low and at a similar level within cytotypes $\left(F_{s t}\right.$ values $\sim 0.3$ for both cytotypes), while it is not depending on the reproduction mode. Under tetraploid cytotype a high individual genetic diversity is observed, following, thus, the respective frequencies of facultative sexuality (Cosendai et al., 2013). Ecological data suggested temperature as the most decisive environmental factor between cytotypes (Kirchheimer et al., 2016; Kirchheimer et al., 2018).

Concerning the influence of cold treatment on the reproduction mode of both cytotypes, the respective study showed a spontaneous emergence of apomixis among diploid plants that have been cultivated under cold conditions (Klatt et al., 2018). On the other hand, tetraploids remained facultative apomictic under cold conditions but the sexual seed formation is reduced to zero (Klatt et al., 2018). Previous studies on the epigenetic background of the species in natural populations proposed pronounced differences between cytotypes and a correlation of DNA methylation variation with abiotic environmental conditions (Schinkel et al., 2020). Thus, a putative epigenetic background of the niche shift of the tetraploids in the Alps is suggested, with epigenetic variation being associated with elevation in natural populations (Schinkel et al., 2020). 


\subsection{Aims and Scope}

In this thesis, I aimed to shed light on the temperature sensitivity of diploid and tetraploid plants of R. kuepferi, through DNA methylation patterns (MSAP profiling), reproduction mode, morphological traits and gene expression patterns. I investigated such unresolved evolutionary questions with experimental approaches from karyology, ecology, genetics and epigenetics, to entangle the effects of temperature treatment on the different ploidy levels and evaluate the phenotypic plasticity of their vegetative and reproductive traits. Thus, the enigmatic phenomenon of geographical parthenogenesis, which was previously proposed for the species (e.g. Kircheimer et al., 2018), would be further explored.

\section{Chapter 2 - Effects of temperature treatments on epigenetic patterns}

The overall aim of this chapter is to investigate the temperature sensitivity of the DNA methylation patterns of the two main cytotypes (di- and tetraploid) of the perennial species R. kuepferi, through their exposure to cold (stress) and warm (control) temperature treatment conditions, simulating natural conditions in the Alps. Cytosinemethylation was examined via the Methylation-Sensitive Amplified Fragment-Length Polymorphisms (MS-AFLP or MSAP) method (Paun et al., 2012), which is described as an informative tool to detect the potential of plants to respond rapidly towards stressful environments (e.g. Nicotra et al., 2010). After collection, the plants were placed in climate growth chambers, first acclimated for two years and then rotated (plants from warm were transferred to cold and vice versa). These treatment shifts were designed to simulate different seasonal weather conditions in the Alps. The patterns of epigenetic variation were explored separately for diploid and tetraploid individuals for warm/cold within the same year and comparisons for the same individuals after the shift of treatments were performed. Since the work described in this chapter is based on the same individuals under different treatments in consecutive years, results mainly reflect the phenotypic plasticity of perennial plants.

\section{Chapter 3 - Effects of temperature treatments on mode of reproduction and morphological traits and their correlation with DNA methylation}

In this chapter, I measured several morphological traits, together with reproductive fitness and the reproduction mode, in two cytotypes of R. kuepferi, which were exposed to cold and warm temperature treatment conditions, later to the treatment shift of 2017 (see Chapter 2). Seeds from 63 populations across the entire distribution area in the European Alps were analyzed to calculate the seed sets under each temperature 
treatment and to conclude on their reproductive pathways via the Flow Cytometric Seed Screening (FCSS) method (Dolezel et al., 2007), investigating, thus, the effect of treatment on the reproduction of the species and a putative positive correlation between cold temperature and induction of apomixis, as it was reported before by Klatt et al. (2018). Furthermore, the phenotypic responses of the two cytotypes under different temperature conditions were quantified and subsequently correlated with the epigenetic data of the same year, in order to disentangle the aspects of the molecular background of environmental response and phenotypic plasticity. Results would provide us insights into the potential of $R$. kuepferi to acclimate to cold conditions during the postglacial establishment of the species in the European Alps.

\section{Chapter 4 - Effects of temperature treatments on gene expression and their correlation with DNA methylation}

The diploid and tetraploid plants of R. kuepferi, which were exposed to different controlled temperature treatments in Chapter $2 \& 3$, were further employed to evaluate the gene expression profiles of individuals under cold temperature stress and get further insights into the expression dynamics. The gene expression profiles were further analyzed according to the ploidy level of the individuals and associated with DNA methylation, on a transcriptomic level. The extracted mRNAs from leaf material for three individuals (biological replicates) of each four predefined groups, regarding temperature and ploidy level (Cold Diploids: CD; Cold Tetraploids: CT; Warm Diploids: WD; Warm Tetraploids: WT) were sequenced on a HiSeq 4000 Illumina Sequencer at the Transcriptome and Genome Analysis Laboratory of the Microarray \& Deep-Sequencing Core Facility (UMG, Georg-August-Universität, Göttingen, Germany) and further analyzed regarding their differential gene expression, towards a $R$. kuepferi pseudoreference, assembled under Trinity. Moreover, gene annotation for functional inference and RTPCR validation of selected differentially expressed genes linked to DNA methylation were carried out, for the purpose of inquiring into the regulatory mechanisms of cold acclimation of alpine plants. Principally, I hypothesize that the observed niche shift of the tetraploid cytotype (Kirchheimer et al., 2018) has the physiological background of a better cold acclimation, as well as, the postglacial recolonization of the European Alps. 


\subsection{References}

Adams, K. L., and Wendel, J. F. (2005). Polyploidy and genome evolution in plants. Current Opinion in Plant Biology, 8, 135-141.

Ainouche, M. L., Fortune, P. M., Salmon, A., Parisod, C., Grandbastien, M-A., Fukunaga, K., Ricou, M., and Misset, M-T. (2009). Hybridization, polyploidy and invasion: lessons from Spartina (Poaceae). Biological Invasions, 11, 1159-1173.

Aliyu, O.E., Schranz, M.E., and Sharbel, T.F. (2010). Quantitative variation for apomictic reproduction in the genus Boechera (Brassicaceae). American Journal of Botany, 97, 1719-1731.

Angers, B., Castonguay, E., and Massicotte, R. (2010). Environmentally induced phenotypes and DNA methylation: how to deal with unpredictable conditions until the next generation and after. Molecular Ecology, 19, 1283-1295.

Asker, S.E., and Jerling, L. (1992). Apomixis in Plants. CRC Press, Boca Raton, FL.

Banerjee, A., Wani, S.H., and Roychoudhury, A. (2017). Epigenetic Control of Plant Cold Responses. Frontiers in Plant Science, 8, 1643.

Bell, G. (1982). The Masterpiece of Nature: The Evolution and Genetics of Sexuality. Croom Helm, London, UK: University of California Press, Berkeley.

Bender, J. (2004). DNA methylation and epigenetics. Annual Review of Plant Biology, 55, 41-68.

Berger, S. L. (2007). The complex language of chromatin regulation during transcription. Nature, 447, 407-412.

Bicknell, R.A., and Koltunow, A.M. (2004). Understanding apomixis: recent advances and remaining conundrums. Plant Cell, 16, 228-245.

Bierzychudek, P. (1985). Patterns in plant parthenogenesis. Experientia, 41, 1255-1264.

Bird, A. (2002). DNA methylation patterns and epigenetic memory DNA methylation patterns and epigenetic memory. Genes \& Development, 16, 6-21.

Bird, A. (2007). Perceptions of epigenetics. Nature, 447, 396-398.

Bomblies, K., Higgins, J.D., and Yant, L. (2015). Meiosis evolves: adaptation to external and internal environments. New Phytologist, 208, 306-323.

Bossdorf, O., Richards, C. L., and Pigliucci, M. (2008). Epigenetics for ecologists. Ecology Letters, 11, 106-115. 
Bossdorf, O., Arcuri, D., Richards, C. L., and Pigliucci, M. (2010). Experimental alteration of DNA methylation affects the phenotypic plasticity of ecologically relevant traits in Arabidopsis thaliana. Evolutionary Ecology, 24, 541-553.

Boyko, A., Blevins, T., Yao, Y., Golubov, A., Bilichak, A., Ilnytskyy, Y., Meins, F., and Kovalchuk, I. (2010). Transgenerational Adaptation of Arabidopsis to Stress Requires DNA Methylation and the Function of Dicer-Like Proteins. PLoS ONE 5(3): e9514. https:/ / doi.org/10.1371/journal.pone.0009514

Brandshaw, A.D. (1965). Evolutionary significance of phenotypic plasticity in plants. Adv. Genet., 13, 115-155.

Burnier, J., Buerki, S., Arrigo, N., Küpfer, P., and Alvarez, N. (2009). Genetic structure and evolution of Alpine polyploid complexes: Ranunculus kuepferi (Ranunculaceae) as a case study. Molecular Ecology, 18, 3730-3744.

Carman, J.G. (1997). Asynchronous expression of duplicate genes in angiosperms may cause apomixis, bispory, tetraspory and polyembryony. Biological Journal of the Linnean Society, 61, 51-94.

Chevin, L.M., and Lande, R. (2010). When do adaptive plasticity and genetic evolution prevent extinction of a density-regulated population? Evolution, 64, 1143-1150.

Chevin, L.M., and Hoffmann, A.A. (2017). Evolution of phenotypic plasticity in extreme environments. Philosophical Transactions of the Royal Society B: Biological Sciences, 372(1723), 20160138.

Chinnusamy, V., Zhu, J., and Zhu, J.K. (2007). Cold stress regulation of gene expression in plants. Trends in Plant Science, 12, 444-451.

Cifuentes, M., Grandont, L., Moore, G., Chevre, A.M., and Jenczewski, E. (2010). Genetic regulation of meiosis in polyploidy species: new insights into an old question. New Phytologist, 186, 29-36.

Comai, L. (2005). The advantages and disadvantages of being polyploid. Nature Reviews Genetics, 6, 836-846.

Cosendai, A-C., and Hörandl, E. (2010). Cytotype stability, facultative apomixis and geographical parthenogenesis in Ranunculus kuepferi (Ranunculaceae). Annals of Botany, $105,457-470$.

Cosendai, A-C., Rodewald, J., and Hörandl, E. (2011). Origin and distribution of autopolyploids via apomixis in the alpine species Ranunculus kuepferi (Ranunculaceae). Taxon, 60, 355-364. 
Cosendai, A-C., Wagner, J., Ladinig, U., Rosche, C., and Hörandl, E. (2013). Geographical parthenogenesis and population genetic structure in the alpine species Ranunculus kuepferi (Ranunculaceae). Heredity, 110, 560-569.

Cramer, G.R., Urano, K., Delrot, S., Pezzotti, M., and Shinozaki, K. (2011). Effects of abiotic stress on plants: a systems biology perspective. BMC Plant Biology, 11, 163.

De Storme, N., and Geelen, D. (2013a). Sexual polyploidization in plants: cytological mechanisms and molecular regulation. New Phytol., 198, 670-684.

De Storme, N., and Geelen, D. (2013b). The impact of environmental stress on male reproductive development in plants - biological processes and molecular mechanisms. Plant Cell Environm., doi: 10.1111/pce.12142.

Ding, Y., Shi, Y., and Yang, S. (2019). Advances and challenges in uncovering cold tolerance regulatory mechanisms in plants. New Phytologist, 222, 1690-1704.

Dobes, C.H., Mitchell-Olds, T., and Koch, M.A. (2004). Extensive chloroplast haplotype variation indicates Pleistocene hybridization and radiation of North American Arabis drummondii, A. divericarpa and A. hobloellii (Brassicaceae). Molecular Ecology, 13, 349-370.

Dolezel, J., Greilhuber, J., and Suda, J. (2007). Estimation of nuclear DNA content in plants using flow cytometry. Nature Protocols, 2, 2233-2244.

Donelson, J.M., Salinas, S., Munday, P.L., and Shama, L.N.S. (2017). Transgenerational plasticity and climate change experiments: Where do we go from here? Global Change Biology, 24, 13-24.

Dong, Z. Y., Wang, Y. M., Zhang, Z. J., Shen, Y., Lin, X. Y., Ou, X. F., Han, F. P., and Liu, B. (2006). Extent and pattern of DNA methylation alteration in rice lines derived from introgressive hybridization of rice and Zizania latifolia Griseb. Theoretical $\mathcal{E}$ Applied Genetics, 113, 196-205

Dowen, R. H., Pelizzola, M., Schmitz, R. J., Lister, R., Dowen, J. M., Nery, J. R., Dixon, J. E., and Ecker, J. R. (2012). Widespread dynamic DNA methylation in response to biotic stress. Proceedings of the National Academy of Sciences of the United States of America, 109, 2183-2191.

Finnegan, E. J. (2010). "DNA Methylation: a Dynamic Regulator of Genome Organization and Gene Expression in Plants,"in Plant Developmental Biology Biotechnological Perspectives: Vol. 2, eds E. C. Pua and M. R. Davey (Berlin, Germany: Springer-Verlag), 295-323. 
Fiorucci, A.S., Galvao, V.C., Ince, Y.C., Boccaccini, A., Goyal, A., Petrolati, L.A., Trevisan, M., and Fankhauser, C. (2020). PHYTOCHROME INTERACTING FACTOR 7 is important for early responses to elevated temperature in Arabidopsis seedlings. New Phytologist, 226, 50-58.

Garsed, S., Davey, H., and Galley, D. (1987). The effects of Light and Temperature on the Growth of and Balances of Carbon, Nitrogen and Potassium between Vicia faba L. and Aphis fabae Scop. New Phytologist, 107, 77-102.

Grant-Downton, R. T., and Dickinson, H. G. (2005). Epigenetics and its implications for Plant Biology: 1. The epigenetic network in plants. Annals of Botany, 96, 1143-1164.

Gregor, T. (2013). Apomicts in the vegetation of central Europe. Tuexenia, 33, 233-257.

Griffith, M., and Yaish, M.W.F. (2004). Antifreeze proteins in overwintering plants: a tale of two activities. Trends Plant Sci., 9, 399-405.

Grimanelli, D. (2012). Epigenetic regulation of reproductive development and the emergence of apomixis in angiosperms. Current Opin. Pl. Biol., 15, 57-62.

Grossniklaus, U., Nogler, G. A., and van Dijk, P. J.(2001). How to Avoid Sex: The Genetic Control of Gametophytic Apomixis. The Plant Cell, 13, 1491-1497.

Gustafsson, A., and Nygren, A.(1946). The temperature effect on pollen formation and meiosis in Hieracium robustum. Hereditas, 32, 1-14.

Guy, C.L. (1990) Cold acclimation and freezing stress tolerance: role of protein metabolism. Annual Review of Plant Physiology and Plant Molecular Biology, 41, 187-223.

Hand, M.L., and Koltunow, A.M.G. (2014). The genetic control of apomixis: asexual seed formation. Genetics, 197, 441-450.

Harris, C.J., Scheibe, M., Wongpalee, S.P., Liu, W.L., Cornett, E.M., Vaughan, R.M., Li, X.Q., Chen, W., Xue, Y., Zhong, Z.H., et al.(2018). A DNA methylation reader complex that enchances gene transcription. Science, 362, 1182-1186.

Hedhly, A. (2011). Sensitivity of flowering plant gametophytes to temperature fluctuations. Environmental and Experimental Botany, 74, 9-16.

Hirsch, S., Baumberger, R., and Grossniklaus, U. (2013). Epigenetic variation, inheritance, and selection in plant populations. Cold Spring Harbor Symposia on Quantitative Biology 77, 97-104. 
Hojsgaard, D., Klatt, S., Baier, R., Carman, J.G., and Hörandl, E. (2014). Taxonomy and Biogeography of Apomixis in Angiosperms and Associated Biodiversity Characteristics. Critical Reviews in Plant Sciences, 33, 414-427.

Hörandl, E. (2006). The complex causality of geographical parthenogenesis. New Phytologist 171, 525-538.

Hörandl, E. (2010). The evolution of self-fertility in apomictic plants. Sex.Pl. Repr., 23, 73-86.

Hörandl, E. (2011). Evolution and biogeography of alpine apomictic plants. Taxon, 60, 390-402.

Hörandl, E., Dobes, C., Suda, J., Vit, P., Urfus, T., Temsch, E.V., Cosendai, A-C., Wagner, J., and Ladinig, U. (2011). Apomixis is not prevalent in subnival to nival plants of the European Alps. Ann. Bot., 108, 381-390.

Hörandl, E., and Hadacek, F. (2013). The oxidative damage initiation hypothesis of meiosis. Plant Reproduction, 26, 351-367.

Jaenisch, R., and Bird, A. (2003). Epigenetic regulation of gene expression: how the genome intergrates intrinsic and environmental signals. Nature Genetics, 33, 245-254.

Jammohammadi, M., Zolla, L., and Rinalducci, S. (2015). Low temperature tolerance in plants: Changes at the protein level. Phytochemistry, 117, 76-89.

Johannes, F., Porcher, E., Teixeira, F. K., Saliba-Colombani, V., Simon, M.,Agier, N., Bulski, A., Albuisson, J., Heredia, F., Audigier, P., et al.(2009). Assessing the Impact of Transgenerational Epigenetic Variation on Complex Traits. PLoS Genetics, 5 (6), e1000530. doi: 10.1371/journal.pgen.1000530.

Jones, P. A. (2012). Functions of DNA methylation: islands, start sites, gene bodies and beyond. Nature Reviews Genetics, 13, 484-492.

Kantama, L., Sharbel, T.F., Schranz, M.E., Mitchell-Olds, T., de Vries, S., and de Jong, H.(2007). Diploid apomicts of the Boechera holboelli complex display large-scale chromosome substitutions and aberrant chromosomes. Proceedings of the National Academy of Sciences, 104, 14026-14031.

Kearney, M. (2005). Hybridization, glaciation and geographical parthenogenesis. Trends in Ecology E Evolution, 20, 495-502.

Kelly, M. (2019). Adaptation to climate change through genetic accommodation and assimilation of plastic phenotypes. Phil. Trans. R. Soc. B, 374, 20180176. 
Kirchheimer, B., Schinkel, C. C-F., Dellinger, A. S., Klatt, S., Moser, D., Winkler, M., Lenoir, J., Caccianiga, M., Guisan, A., Nieto-lugilde, D., et al. (2016). A matter of scale: apparent niche differentiation of diploid and tetraploid plants may depend on extent and grain of analysis. Journal of Biogeography, 43, 716-726.

Kirchheimer, B., Wessely, J., Gattringer, A., Hülber, K., Moser, D., Schinkel, C. C-F., Appelhans, M., Klatt, S., Caccianiga, M., Dellinger, A., et al.(2018). Reconstructing geographical parthenogenesis: effects of niche differentiation and reproductive mode on Holocene range expansion of an alpine plant. Ecology Letters, 21, 392-401.

Klatt, S., Hadacek, F., Hodac, L., Brinkmann, G., Eilerts, M., Hojsgaard, D., and Hörandl, E. (2016). Photoperiod extension enhances sexual megaspore formation and triggers metabolic reprogramming in facultative apomictic Ranunculus auricomus. Frontiers in Plant Science, 7, 728.

Klatt, S., Schinkel, C. C.-F., Kirchheimer, B., Dullinger, S., and Hörandl, E. (2018). Effects of cold treatments on fitness and mode of reproduction in the diploid and polyploid alpine plant Ranunculus kuepferi (Ranunculaceae). Annals of Botany, 121, 12871298.

Koltunow, A.M., and Grossniklaus, U. (2003). Apomixis: A developmental prespective. Annual Review of Plant Biology, 54, 547-574.

Kooke, R., Johannes, F., Wardenaar, R., Becker, F., Etcheverry, M., Colot, V., Vreugdenhil, D., and Keurentjes, J.B. (2015). Epigenetic Basis of Morphological Variation and Phenotypic Plasticity in Arabidopsis thaliana. The Plant Cell, 27, 337-348.

Kopp, M., and Matuszewski, S. (2013). Rapid evolution of quantitative traits: theoretical perspectives. Evol. Appl., 7, 169-191.

Körner, C.H. (2021). Alpine plant life 3nd edn. Cham, Switzerland: Springer Switzerland AG.

Küpfer, P. (1974). Recherches sur les liens de parente entre la flore orophile des Alpes et celle des Pyrenees. Boissiera, 23, 1-322.

Ladinig, U., Hacker, J., Neuner, G., and Wagner, J. (2013). How endangered is sexual reproduction of high-mountain plants by summer frosts? Frost resistance, frequency of frost events and risk assessments. Oecologia, 171, 743-760.

Laland, K.N., Uller, T., Feldman, M.W., Sterelny, K., Müller, G.B., Moczek, A., Jablinka, E., and Odling-Smee, J. (2015). The extended evolutionary synthesis: its structure, assumptions and predictions. Proc. R. Soc. B., 282, 20151019 
Latzel, V. and Klimesova, J. (2010). Transgenerational plasticity in clonal plants. Evolutionary Ecology, 24, 1537-1543.

Lau, O.S., Song, Z., Zhou, Z., Davies, K.A., Chang, J., Yang, X., Wang, S., Lucyshyn, D., Tay, I.H.Z., Wigge, P.A., et al.(2018). Direct control of SPEECHLESS by PIF4 in the hightemperature response of stomatal development. Current Biology, 28, 1273-1280.e3.

Law, J. A., and Jacobsen, S. E. (2010). Establishing, maintaining and modifying DNA methylation patterns in plants and animals. Nature Reviews Genetics, 11, 204-220.

Levin, D.A. (1975). Minority cytotype exclusion in local plant populations. Taxon, 24, 3543.

Levin, D.A. (2003). Ecological speciation: lessons from invasive species. Systematic Botany, 28, 643-650.

Li, Z. H., Lu, X., Gao, Y., Liu, S. J., Tao, M., Xiao, H., Qiao, Y. Q., Zhang, Y. P., and Luo J. (2011). Polyploidization and epigenetics. Chinese Science Bulletin, 3, 245-252.

Lippman, Z., Gendrel, A.V., Black, M., Vaughn, M.W., Dedhia, N., McCombie, W.R., Lavine, K., Mittal, V., May, B., Kasschau, K.D., Carrington, J.C., Doerge, R.W., Colot, V., and Martienssen, R. (2004). Role of transposable elements in heterochromatin and epigenetic control. Nature, 430, 471-476.

Liu, T., Li, Y., Duan, W., Huang, F., and Hou, X. (2017). Cold acclimation alters DNA methylation patterns and confers tolerance to heat and increases growth rate in Brassica rapa. Journal of Experimental Botany, 68, 1213-1224.

Longo, V., Kamran, R.V., Michaletti, A., Toorchi, M., Zolla, L., and Rinalducci, S. (2017). Proteomic and Physiological Response of Spring Barley Leaves to Cold Stress. Int. J Plant Biol. Res., 5, 1-10.

Madlung, A. (2013). Polyploidy and its effect on evolutionary success: old questions revisited with new tools. Heredity, 110, 99-104.

Madlung, A., and Wendel, J. F. (2013). Genetic and Epigenetic Aspects of Polyploid Evolution in Plants. Cytogenetic and Genome Research, 140, 270-285.

Massicotte, R., and Angers, B. (2012). General-purpose genotype or how epigenetics extend the flexibility of a genotype. Genetics Research International, 1-7.

Megha, S., Basu, U., and Kav, N.N.V. (2018). Regulation of low temperature stress in plants by microRNAs. Plant, Cell E Development, 41, 1-15. 
Merilä, J., and Hendry, P. (2013). Climate change, adaptation and phenotypic plasticity: the problem and the evidence. Evol. Appl., 7, 1-14.

Miura, A., Yonebayashi, S. Watanabe, K., Toyama, T., Shimada, H., and Kakutani, T. (2001). Mobilization of transposons by a mutation abolishing full DNA methylation in Arabidopsis. Nature, 411, 212-214.

Mirouze, M., and Paskzowski, J. (2011). Epigenetic contribution to stress adaptation in plants. Curr. Opin. Plant Biol.,14, 267-274.

Munns, R. (2011). Plant adaptations to salt and water stress: differences and commonalities. Advances in Botanical Research, 57, 1-32.

Nagy, L., and Grabherr, G. (2009). The Biology of Alpine Habitats. Oxford University Press.

Nicotra, A. B., Atkin, O. K., Bonser, S. P., Davidson, A. M., Finnegan, E. J., Mathesius, U., Poot, P., Purugganan, M. D., Richards, C. L., Valladares, F., and van Kleunen, M. (2010). Plant phenotypic plasticity in a changing climate. Trends in Plant Science, 15, 684692.

Nogler, G.A. (1984). Gametophytic apomixis. In Johri BM, ed. Embryology of angiosperms. Berlin, New York, Springer, 475-518.

Osborn, T.C., Pires, J.C., Birchler, J.A., Auger, D.L., Chen, Z.J., et al.(2003). Understanding mechanisms of novel gene expression in polyploids. Trends Genet., 19, 141-147.

Ozias-Akins, P., and van Dijk, P.J. (2007). Mendelian genetics of apomixis in plants. Annual Review of Genetics, 41, 509-537.

Paun, O., Stuetty, T.F. \& Hörandl, E. (2006). The role of hybridization, polyploidization and glaciation in the origin and evolution of the apomictic Ranunculus cassubicus complex. New Phytologist, 171, 223-236.

Paun, O., Bateman, R. M., Fay, M. F., Hedren, M., Civeyrel, L., and Chase, M. W. (2010). Stable epigenetic effects impact adaptation in allopolyploid orchids (Dactylorhiza: Orchidaceae). Molecular Biology and Evolution, 27, 2465-2473.

Paun, O., and Schönswetter, P. (2012). Amplified Fragment Length Polymorphism (AFLP) - an invaluable fingerprinting technique for genomic, transcriptomic and epigenetic studies. Methods in Molecular Biology, 862, 75-87. 
Preite, V., Snoek, L., Oplaat, C., Biere, A., Putten, W., and Verhoeven, K.J.F. (2015). The epigenetic footprint of poleward range-expanding plants in apomictic dantelions. Molecular Ecology, 24, 4406-4418.

Price, T.D., Qvarnström, A., and Irwin, D.E. (2003). The role of phenotypic plasticity in driving genetic evolution. Proceedings of the Royal Society of London Series B, 270, 14331440 .

Ramsey, J., and Schemske, D.W. (1998). Pathways, mechanisms and rates of polyploidy formation in flowering plants. Annual Review of Ecology, Evolution E Systematics, 29, 467501.

Rice, A., Smarda, P., Novosolov, M., Drori, M., Glick, L., Sabath, N., Meiri, S., Belmaker, J., and Mayrose, I. (2019). The global biogeography of polyploidy plants. Nature Ecology \& Evolution, 3: 265-273.

Richards, E. J. (2006). Inherited epigenetic variation-revisiting soft inheritance. Nature Reviews, 7, 395-402.

Richards, C. L., Alonso, C., Becker, C., Bossdorf, O., Bucher, E., Colome-Tatche, M., Durka, W., Engelhardt, J., Gaspar, B., Gogol-Döring, A., et al. (2017). Ecological plant epigenetics: Evidence from model and non-model species, and the way forward. Ecology Letters, 20, 1576-1590.

Rois, A. S., Rodriguez Lopez, C. M., Cortinhas, A., Erben, M., Espirito-Santo, D., Wilkinson, M. J., and Caperta, A. D. (2013). Epigenetic rather than genetic factors may explain phenotypic divergence between coastal populations of diploid and tetraploid Limonium spp. (Plumbaginaceae) in Portugal. BMC Plant Biolgy, 13, 205.

Sanghera, G.S., Wani, S.H., Hussain, W., and Singh, N.B. (2011). Engineering cold stress tolerance in crop plants. Current Genomics, 12, 30-43.

Schinkel, C. C-F., Kirchheimer, B., Dellinger, A. S., Klatt, S., Winkler, M., Dullinger, S., and Hörandl, E. (2016). Correlations of polyploidy and apomixis with elevation and associated environmental gradients in an alpine plant. AoB PLANTS, 8, plw064, doi:10.1093/aobpla/plw064.

Schinkel, C. C-F., Kirchheimer, B., Dullinger, S., Geelen, D., De Storme, N., and Hörandl, E. (2017). Pathways to polyploidy: indications of a female triploid bridge in the alpine species Ranunculus kuepferi (Ranunculaceae). Plant Systematics E Evolution, 303, 1093-1108. 
Schinkel, C.C-F., Syngelaki, E., Kirchheimer, B., Dullinger, S., Klatt, S., and Hörandl, E. (2020). Epigenetic patterns and geographical parthenogenesis in the alpine plant species Ranunculus kuepferi (Ranunculaceae). Int J MolSci, 21(9), 3318.

Schlichting, C.D. (1986). The evolution of phenotypic plasticity in plants. Annu. Rev. Ecol. Syst., 17, 667-693.

Schlichting, C.D., and Pigliucci, M. (1998). Phenotypic evolution: a reaction norm perspective. Sunderland, MA: Sinauer.

Schmidt, A. (2020). Controlling Apomixis: Shared features and distinct characteristics of gene regulation. Genes, 11(3), 329.

Schulz, B., Eckstein, R. L., and Durka, W. (2014). Epigenetic variation reflects dynamic habitat conditions in a rare floodplain herb. Molecular Ecology, 23, 3523-3537.

Sherman, J. D., and Talbert, L. E. (2002). Vernalization-induced changes of the DNA methylation pattern in winter wheat. Genome, 260, 253-260.

Sharbel, T.F., Voigt, M-L., Corral, J.M., Galla, G., Kumlehn, J., Klukas, C., Schreiber, F., Vogel, H., and Rotter, B. (2010). Apomictic and sexual ovules of Boechera display heterochronic global gene expression patterns. Pl. Cell, 22, 655-671.

Siena, L.A., Sartor, M.E., Espinoza, F., Quarin, C.1., and Ortiz, J.P.A. (2008). Genetic and embryological evidences of apomixis at the diploid level in Paspalum rufum support recurrent autopolyploidization in the species. Sexual Plant Reproduction, 21, 205-215.

Sol, D., Duncan, R.P., Blackburn, T.M., Cassey, P., and Lefebvre, L. (2005). Big brains, enhanced cognition and response of birds to novel environments. Proc. Natl Acad. Sci. USA, 102, 5460-6465.

Soltis, D. E., Visger, C. J., and Soltis, P. S. (2014). The polyploidy revolution then . . . and now: Stebbins revisited. American Journal of Botany, 101, 1057-1078.

Suzuki, N., Rivero, R.M., Shulaev, V., Blumwald, E., and Mittler, R. (2014). Abiotic and biotic stress combinations. New Phytologist, 203, 32-43.

Syngelaki, E., Schinkel, C.C-F., Klatt, S. and Hörandl, E. (2020a). Effects of temperature treatments on cytosine-methylation profiles of diploid and autotetraploid plants of the alpine species Ranunculus kuepferi (Ranunculaceae). Front. Plant Sci., 11, 435.

Syngelaki, E., Daubert, M., Klatt, S. and Hörandl, E. (2020b). Phenotypic responses, reproduction mode and epigenetic patterns under temperature treatments in the alpine plant species Ranunculus kuepferi (Ranunculaceae). Biology, 9(10), 315. 
te Beest, M., Le Roux, J. J., Richardson, D. M., Brysting, A. K., Suda, J., Kubesova, M., and Pysck, P. (2012). The more the better? The role of polyploidy in facilitating plant invasions. Annals of Botany, 109, 19-45.

Theocharis, A., Clement, C., and AitBarka, E. (2012). Physiolgical and molecular changes in plant growth at low temperatures. Planta, 235, 1091-1105.

Thomashow, M.F. (1999). Plant cold acclimation: freezing tolerance genes and regulatory mechanisms. Annual Review of Plant Physiology and Plant Molecular Biology, 50, 571-599.

Ulum, F.B., Castro, C.C., and Hörandl, E. (2020). Ploidy-dependent effects of light stress on the mode of reproduction in the Ranunculus auricomus complex (Ranunculaceae). Front. Plant Sci., 11, 104.

Van de Peer, Y., Mizrachi, E., and Marchal, K. (2017). The evolutionary significance of polyploidy. Nature Reviews: Genetics, 18, 411-424.

Vandel, A. (1928). La parthenogenese geographique: contribution a l'etude biologique et cytologique de la parthenogenese naturelle. Bull Biol France Belgique, 62, 164-281.

Vaughn, M. W., Tanurdzic, M., Lippman, Z., Jiang, H., Carrasquillo, R., Rabinowicz, P. D., Dedhia, N., McCombie, W. R., Agier, N., Bulski, A., et al. (2007). Epigenetic Natural Variation in Arabidopsis thaliana. PLoS Biology 5, 1617-1629.

Verhoeven, K. J. F., Jansen, J. J., van Dijk, P. J., and Biere, A. (2010a). Stress-induced DNA methylation changes and their heritability in asexual dandelions. New Phytologist, 185, 1108-1118.

Verhoeven, K. J. F., van Dijk, P. J., and Biere, A. (2010b). Changes in genomic methylation patterns during the formation of triploid asexual dandelion lineages. Molecular Ecology, 19, 315-324.

Verhoeven, K. J. F., and Preite, V. (2013). Epigenetic variation in asexually reproducing organisms. Evolution, 68, 644-655.

Wagner, J., Lechleitner, M., and Hosp, D. (2016). Pollen limitation is not the rule in nival plants: A study from the European Central Alps. American Journal of Botany, 103(3), 375-387.

Wani, S.H., Singh, N.B., Haribhushan, A., and Mir, J.I. (2013). Compatible solute engineering in plants for abiotic stress tolerance-Role of glycine betaine. Curr. Gen.,14, 157-165. 
Wani, S.H., Sah, S.K., Sanghera, G., Hussain, W., and Singh, N.B. (2016). Genetic engineering for cold stress tolerance in crop plants. In Advances in Genome Science. (Attaur-Rahman, eds). London, UK: Betham Science, 173-201.

Wei, N., Cronn, R., Liston, A., and Ashman, T.L. (2019). Functional trait divergence and trait plasticity confer polyploidy advantage in heterogeneous environments. New Phytologist, 221, 2286-2297.

West-Eberhard, M.J. (2003). Developmental Plasticity and Evolution. Oxford, UK: Oxford University Press.

West-Eberhard, M.J. (2008). Phenotypic plasticity. In Encyclopedia of Ecology. (Jorgensen, E. and Fath, B., eds). Amsterdam, Netherlands: Elsevier Science, 2701-2707.

Whitman, D.W., and Agrawal, A.A. (2009). What is phenotypic plasticity and why is it important? In Phenotypic Plasticity of Insects. (Ananthakrishnan, T.N., eds). Science Publishers, 1-63.

Xiao, X., Zhang, J., Li, T., Fu, X., Satheesh, V., Niu, Q., Lang, Z., Zhu, J.K. and Lei, M. (2019). A group of SUVH methyl-DNA binding proteins regulate expression of the DNA demethylase ROS1 in Arabidopsis. Journal of Intergrative Plant Biology, 61, 110-119.

Yeh, P.J., and Price, T.D. (2004). Adaptive phenotypic plasticity and the successful colonization of a novel environment. Am. Nat., 164, 531-542.

Zhang, Y., Fischer, M., Colot, V., and Bossdorf, O. (2013). Epigenetic variation creates potential for evolution of plant phenoty pic plasticity. New Phytologist, 197, 314-322.

Zilberman, D., Gehring, M., Tran, R. K., Ballinger, T., and Henikoff, S. (2007). Genome-wide analysis of Arabidopsis thaliana DNA methylation uncovers an interdependence between methylation and transcription. Nature Genetics, 39, 61-69. 


\section{Chapter 2}

Effects of temperature treatments on cytosine-methylation profiles of diploid and autotetraploid plants of the alpine species Ranunculus kuepferi (Ranunculaceae)

Eleni Syngelaki, Christoph C. F. Schinkel, Simone Klatt and Elvira Hörandl

Published in Frontiers of Plant Sciences (2020), 11, 435.

DOI $10.3389 /$ fpls.2020.00435

\section{Abstract}

The exposure to environmental stress can trigger epigenetic variation, which may have several evolutionary consequences. Polyploidy seems to affect the DNA methylation profiles. Nevertheless, it abides unclear whether temperature stress can induce methylations changes in different cytotypes and to what extent a treatment shift is translated to an epigenetic response. A suitable model system for studying these questions is Ranunculus kuepferi, an alpine perennial herb.

Diploid and tetraploid individuals of R.kuepferi were exposed to cold $\left[+7^{\circ} \mathrm{C}\right.$ day $/+2{ }^{\circ} \mathrm{C}$ night; frost treatment: $-1^{\circ} \mathrm{C}$ cold shocks for three nights per week ] and warm $\left[+15^{\circ} \mathrm{C}\right.$ day $/+10{ }^{\circ} \mathrm{C}$ night ] conditions in climate growth chambers for two consecutive flowering periods and shifted from one condition to the other after the first flowering period. Methylation-sensitive amplified fragment-length polymorphism markers were applied for both years, to track down possible alterations induced by the stress treatments.

Patterns of methylation suggested that cytotypes differed significantly in their profiles, independent from year of treatment. Likewise, the treatment shift had an impact on both cytotypes, resulting in significantly less epiloci, regardless the shift's direction. The AMOVAs reflect the DNA methylation dynamics of tetraploids, as a response to temperature's change, and follow up the hypothesis of cold stress affecting the epigenetic variation.

Results suggest that the temperature-sensitivityof DNA methylation patterns shows a highly dynamic phenotypic plasticity in R. kuepferi, as both cytotypes responded to temperature shifts. Furthermore, ploidy level has an important effect on epigenetic background variation, which may be correlated with the DNA methylation dynamics during cold acclimation. 


\subsection{Introduction}

Epigenetic studies try to explain the heritable changes in gene expression and function which determine the phenotype of an organism and cannot be linked to DNA sequence changes (Richards, 2006). There are mainly four different epigenetic mechanisms: a) methylation of cytosine residues in the DNA, b) remodeling of chromatin structure through chemical modification of histone proteins, c) histone proteins modification that can lead to extent alteration of DNA wrapping, and $\mathrm{d}$ ) regulatory processes mediated by small and non-coding RNA molecules (miRNA). These processes do not act independently from each other and can produce epigenetic changes that affect genes expression, by e.g. activating, reducing of completely disabling the activity of particular genes (Berger, 2007).

DNA methylation is defined as the addiction, catalyzed by several methyltransferases, of a methyl group to the 5' C of a cytosine residue in the DNA sequence, which is associated with silencing of transposons, imprinting and silencing of both transgenes and endogenous genes (e.g. Grossniklaus et al., 2001; Zilberman et al., 2007; Jones, 2012). In plants, DNA methylation is the best understood epigenetic mechanism and several studies intimate it exhibits a transgenerational inheritance (e.g. Vaughn et al., 2007; Johannes et al., 2009; Finnegan, 2010; Hirsch et al., 2013). It is well documented that DNA methylation can be dynamic, as biotic or abiotic environmental stimuli can trigger methylation changes and lead to different DNA methylation profiles (e.g.Sherman and Talbert, 2002; Dowen et al., 2012). Except for environmental stimuli, genomic stresses such as hybridization and polyploidization can induce DNA methylation changes (Adams and Wendel, 2005; Jones, 2012; Dong et al., 2006; Grant-Downton and Dickinson, 2005). Furthermore, DNA methylation has been exhibited to mediate phenotypic plasticity within a single generation (Bossdorf et al., 2010) and between generations (Boyko et al., 2010).

Polyploidy is a heritable condition of organisms that refers to the possession of more than two complete sets of chromosomes and is considered tohave evolutionary consequences on angiosperms (Comai, 2005), as polyploidization events in plants seem to be correlated with phenotypic innovation and speciation (Madlung, 2012; Soltis et al., 2014). During the formation of polyploids, several alterations in DNA methylation in allo- and autopolyploids are occurring (Li et al., 2011). As DNA methylation is related with regulation of gene expression (Bird 2002; Yan et al., 2010; Law and Jacobsen, 2010), it is implied the decisive role of epigenetic regulation in regaining the genomic balance and the structural and functional remodeling after polyploidization (Soltis et al., 2010; Hegarty et al., 2011; Madlung and Wendel, 2013; Alonso et al., 2016b). Several studies demonstrate that the epigenetic consequences of polyploidy can lead to gene expression alterations (e.g. gene silencing) and genome-wide transcriptional rewiring (Baubec et al., 
2010; Li et al., 2011; Song and Chen, 2016). However, most studies deal with polyploid hybrids (allopolyploids). Allopolyploids show more pronounced alterations in gene expression than autopolyploidsdue to effects of a hybrid genome additionally to genome duplication (e.g. Chen, 2007). Moreover, DNA methylation alterations can be ignited ad hoc by polyploidization during the first generations following the event (Paun et al., 2007). A variation in the patterns of cytosine methylation regarding wild populations of polyploids putatively unravels their local adaptation and functional plasticity (Paun et al., 2010; Rois et al., 2013; Schulz et al., 2014) and may be advantageous for the invasion success of some species (Ainouche et al., 2009).

Uncovering the putative role that polyploidy plays at adaptation to extreme conditions is correlated with the several effects of polyploidy on vigor, physiology, morphology and other adaptive traits (Li et al., 2011; te Beest et al., 2012). Successful polyploidization events can result in increased survival fitness in harsher environments and may have important side effects on mechanisms, which are related to stress response ( $\mathrm{Li}$ et al., 2011). Hence, it is hypothesized that polyploidy helpsplants to adjust their growth and exposure of reproductive tissues to cold temperatures by offering a putative adaptive advantage in alpine dwarfism (Körner, 2003), as polyploids achieve it by reducing cell number and increasing cell size (te Beest et al., 2012). This strategy can additionally help for rapid sprouting of the polyploidy plants directly after snow melting (Körner, 2003). According to Comai (2005), a selective advantage of polyploidy can be the way it may affect the mode of reproduction of the organism in absence of sexual mates, by favouring the establishment of asexual reproduction. The perpetuation of asexual reproduction mode on some polyploids is suggested that profits further their adaptation under stress conditions (Körner, 2003).

A suitable model system for studying the correlation of temperature effects, ploidy level and methylation profiles is Ranunculus kuepferi Greuter \& Burdet, a high-mountain perennial herb. The species occurs mainly with diploid and autotetraploid cytotypes and has a gradient distribution primarily across the European Alps and at altitudes between 1300 - 2800 m (Burnier et al., 2009; Cosendai and Hörandl, 2010; Cosendai et al., 2011; Kirchheimer et al., 2016; Schinkel et al., 2016). The comparison of diploid and autotetraploid cytotypes facilitates the study of effects of genome duplication without side-effects of hybridity. Regarding the reproduction mode of these cytotypes, diploid plants are predominantly sexual, whereas tetraploid plants are facultative apomictic (aposporous), with varying proportions of sexual and asexual seeds (Burnier et al., 2009; Schinkel et al., 2016).

Through the distribution of the species a pronounced geographical parthenogenesis in the European Alps (Cosendai et al., 2013) is indicated: diploid populations are restricted to the south-western Alps, while tetraploid populations colonize previously glaciated 
areas in the northern, central and eastern Alps (Küpfer 1974; Burnier et al., 2009; Cosendai and Hörandl, 2010) as well as the northern Apennines and Corsica. Tetraploid populations arise also at higher elevations in the European Alps than diploids and exhibit a pronounced niche shift towards colder temperatures (Kirchheimer et al., 2016; Schinkel et al., 2016). This niche differentiation between diploid and tetraploid cytotypes of R. kuepferi is associated with their reproduction mode, and asexual taxa seem to have a distributional advantage (Kirchheimer et al., 2018).

Previous population genetic studiesusing AFLPs throughout the range of the species revealed that sexual and apomictic populations show a very low genetic divergence, as only 3\% of AFLP fragments were specific for tetraploids, while all others wereshared with the diploid cytotype (Cosendai et al., 2011). Genetic differentiation and diversity measures within cytotypes were on a similar level (e.g. $\mathrm{F}_{\mathrm{st}} \mathrm{s}$ are around 0.3 for both cytotypes; Cosendai et al., 2013). Only diploids showed geographical structure in their refugial areas, comprising six genetic partitions, whereas tetraploid populations exhibited no geographical structure and comprised just three genetic partitions that were derived from the diploids' gene pool (Cosendai et al., 2013). Moreover, a high individual genetic diversity in tetraploids is observed and is in line with multiple origins, allelic diversity and high frequencies of facultative sexuality (Cosendai et al., 2013). A molecular dating revealed that the tetraploid cytotype originated only 10-80 kyears ago (Kirchheimer et al., 2018), probably by multiple and recurrentautopolyploidization events (Cosendai et al., 2011; Schinkel et al., 2017). Previous studies on methylation variation in natural populations suggested pronounced differences between cytotypes, and correlations of methylation variation to climatic gradients according to elevation, but not to spatial distribution (Schinkel et al., 2020). Hence, we hypothesize that the niche shift of tetraploids in the Alps has rather an epigenetic than a genetic background. However, in natural populations it is difficult to entangle various environmental factors, and to discriminate between phenotypic plasticity and heritable traits.

Herein, we employed the two main cytotypes of the perennial species R.kuepferi and we exposed plants collected in the Alps under different temperature treatments under controlled conditions, to appraise the putative DNA methylation changes. By assessing methylation variation with methylation-sensitive amplified fragment length polymorphisms (MS-AFLPs) we focus on entangling whether the methylation profiles of vegetative parts differentiate according to ploidy levels, and how the cytotypes are affected by a change in cold/warm conditions. We hypothesize a temperaturesensitivity of methylation patterns, as a potential to respond rapidly to stressful environments. We would expect that cytotypes respond differentially to stress treatments. Since we analyze here the same individuals under different treatments in consecutive years, we test here mainly for phenotypic plasticity of perennial plants. By 
differential analysis of types of epiloci we further try to get insights into the dynamics of epigenetic change. A detailed study on correlations of mode of reproduction and methylations will be presented elsewhere.

\subsection{Materials \& Methods}

\section{Plant material and experimental design}

Ranunculus kuepferi plants, representing diploid and tetraploid cytotypes were collected at 81 sampling sites throughout the distribution range of the species in the European Alps (Kirchheimer et al., 2016) during the growing seasons of 2013 \& 2014. These plants were re-potted in garden soil at the Old Botanical Garden of Göttingen University and overwintered outdoors, while their ploidy level was defined via flow cytometry measurements of silica gel dried leaf material collected in the field (Schinkel et al., 2016). To investigate the implied temperature preferences of the two cytotypes (Kirchheimer et al., 2016), an experiment based on the exposure to different temperature conditions, during the sprouting and flowering period, was designed and conductedfrom 2014 onwards (see Klatt et al., 2018). Hence, a subset of diploid and tetraploid individuals was placed in two climate chambers MC1000E (Snijders Scientific, Tilburg, Netherlands), where cold and warm temperature treatments were implemented, while light regime [photoperiod: $16 \mathrm{hs} ; 10 \mathrm{hs}$ full light $\left(700 \mu \mathrm{mol} \mathrm{m}^{-2} \mathrm{~s}^{-1}\right)$ ] and all other parameters were kept equal. In the first chamber a cold treatment was applied $\left(+7^{\circ} \mathrm{C}\right.$ day $/+2^{\circ} \mathrm{C}$ night; frost treatment: $-1^{\circ} \mathrm{C}$ cold shocks for three nights per week), mimicking the typical, harsh high alpine temperature conditions at the habitats of the tetraploid cytotype (Schinkel et al., 2016), while in the second chamber a warm treatment was applied $\left(+15^{\circ}\right.$ day $/+10^{\circ} \mathrm{C}$ night). In the cold treatment, the repeated moderate frost treatment is simulating temperature conditions occurring in high mountains and provokes frost injury in reproductive shoots, which subsequently could emerge in full fruit loss (Ladinig et al., 2013); similar damaging effects were observed by Klatt et al. (2018).

To elucidate further the effects of temperature treatments on cytotypes, a reciprocal test, by rotating the cold treated plants to the warm and vice versa, was performed. In spring of 2016 (third consecutive flowering period under first treatment) and 2017 (first flowering period after the rotation), leaf material was collected from the plants and was stored in silica gel. The individuals were categorized into four groups regarding their ploidy: Diploids 1, Tetraploids 1, Diploids 2 and Tetraploids 2 (from now on, mentioned as D1, T1, D2 and T2, respectively). The groups that are numbered with 1 were placed first under cold treatment, while the rest of them were first placed under warm treatment. A subset of 100 individuals (25 per group; Supplementary Data Table 1), originated from 57 populations, was selected to proceed with the molecular analysis for 
both years. The sampling was randomized and was targeted to cover as precisely as possible the distribution range of the species in the Alps (see map in Supplementary Data Figure 1).

\section{MS-AFLP analysis}

The DNA from the leaf material was isolated using the QiagenDNeasy Plant Mini Kit, with a slightly modified protocol. At the second step, $360 \mu$ AP1 Buffer and $40 \mu 1$ PVP $2.6 \%$ were added and incubation time for the elution is prolonged $30 \mathrm{~min}$. The PVP was added to remove polyphenolic compounds from plant DNA extracts as it forms hydrogen bonds with them, can deactivate proteins and hence can inhibit many downstream reactions e.g. PCR (Healey et al., 2014).

In order to investigate their epigenetic response, through the highlighting of the genome-wide patterns of epigenetic variation (e.g. Salmon et al., 2008; Massicotte et al., 2011; Herrera et al., 2012), methylation-sensitive amplified fragment-length polymorphisms (MS-AFLPs) were conducted. MS-AFLPs, as a methylation detecting approach, can be applied to non-model plants for which the genome has not been sequenced yet and assess cytosine methylation state in a large number of anonymous loci, which are randomly distributed over the genome (Schrey et al., 2013).

The extracted samples of 100 individuals for each treatment year were screened according to a slightly modified protocol of Paun et al. (2012). Restriction and ligation were carried out in two parallel reactions, each one with a different restriction enzyme. The restriction enzymes, which were used, are MspI \& HpaII. They are methylation sensitive restriction enzymes, i.e. isoschizomers, which recognize the same DNA sequence (CCGG), but differ in the sensitivity regarding the methylation state of $C$, and used as the frequent cutters, while EcoRI is used as the rare cutter. Ligation products were subjected to pre-selective amplification, whereupon selective amplification was performed with a set of three primer combinations with three selective nucleotides to each primer, used before for an AFLP analysis on the species (Cosendai et al., 2011). Ligation, pre-selective and selective amplification products went through a quality and quantity check on a $1.5 \%$ agarose gel and diluted 10 -fold dilution prior to pre-selective, selective amplification and fragment analyses, respectively.

The final selective-PCR products were prepared with GeneScan ROX 500 (Thermo Fisher Scientific, Waltham, MA, USA) as the internal size standard and fragment analyzed on the ABI Prism 3700/3730 (Applied Biosystems, Waltham, MA, USA) capillary sequencer. An attempt to increase the precision of the final results was performed, by tracking down genotyping errors and cleaning up the data sets (Bonin et al., 2004). The technical reproducibility of resulting electropherograms was checked by replicating $100 \%$ of accessions, i.e. duplicates were produced forevery sample used 
throughout the MSAP protocol steps, to minimize the false positive fragment peaks. Accounting for the modified lab protocol for our species to overcome the sensitivity of restriction enzymes, the guidelines of ASA for the importance of replicability and reproducibility of scientific work (Wasserstein and Lazar, 2016) and the optimization of fragment detection (Arrigo et al., 2009), the risk of false positive results was minimized.

\section{Fragment scoring}

The analysis of electropherograms and fragment scoring were performed using the following scoring pipeline: Peakscanner v.2 (Applied Biosystems, Life Technologies Corporation, Carlsbad, California, USA), RawGeno 2.0-1 (Arrigo et al., 2009) and MSAP_calc script (Schulz et al., 2013). We transformed electropherograms of raw data into a binary dominant-marker matrix. Peak Scanner2 was used to determine the height, width \& the area of all peaks. The output of the Peak Scanner2 was then imported to RawGeno 2.0-1 to proceed with the binning of detected peaks, the analysis of replication and the filtering of samples of low quality.

RawGeno handles a single dye color at a time, so presence/absence of fragments binary matrices were obtainedfor each of the three dyes (Blue; FAM, Green; HEX, Yellow; NED) and then they were merged in a final binary matrix. Fragments between 50 and 600 base pairs were scored. In order to optimize the dataset, a run of RawGeno with an R script (Arrigo et al., 2009) was performed, which checked stepwise ( 5760 steps) the binning and filtering parameters. Going through the resulting table, the optimal combination of the parameters waschosen for each dye (Supplementary Data Table 2) and the respective binary matrices were produced. The selection of parameters represents a balance between quality measures, e.g. the error rate and bin reproducibility, and informativity, measured with the data polymorphism.

The merged binary matrix of optimized dataset for each treatment year was dealt with MSAP_calc script in R (Schulz et al., 2013), to distinguish the four possible methylation conditions as they are described in Schulz et al. (2013), using the 'Mixed Scoring 2' approach for scoring the following conditions: I) no methylation (both MspI and HpaII cut the restriction site), II) holo- or hemi-methylation of internal cytosine ( $\mathrm{HMe} C \mathrm{C}$ or MeCG;MspI cuts the restriction site), III) hemimethylationof external cytosine ( ${ }^{\mathrm{HMe} C C G}$; HpaII cuts the restriction site) and IV) holomethylationof external cytosine or of both cytosines or hemi-methylation of both cytosines or mutations(none of them cuts the restriction site). In 'Mixed Scoring 2' condition I was scored as 100 (non-methylated), condition II as 010 (internally-methylated), condition III as 001 (externally methylated), and condition IV as ' 000 ' and refers to a non-distinguishable situation, e.g. an ambiguous methylation or a mutation status. Condition IV was, therefore, excluded from further statistical analyses. In 'Mixed Scoring 2' approach both group of fragments 
are comprised, so potential inadequacies of methylation- and non-methylation Scoring were avoided and more of the underlying information of the epiloci is utilized (Alonso et al., 2016a).

\section{Statistical analysis}

MSAP_calc script returned an epigenetic binary matrix, which presents the methylation condition (externally-, internally- and non-methylated) of each epilocus with the corresponding score and a matrix with descriptive parameters at the group level. The subsequent statistical analyses were mainly performed in $\mathrm{R}$ ( $\mathrm{R}$ Development Core Team 2019) under R Studio (RStudio Team 2016).

The descriptive parametersmatrices were adopted from the MSAP_calc script and used as input for barplots in ggplot2 (Wickham, 2009). In accordance with descriptive statistics, the percentages of each epilocus for each individual were calculated regarding the predefined groups for each year of analysis and the groups with some individuals through the years. These percentages were used to produce the respective boxplots with ggplot2 R package and were arcsine transformed in Excel 2016 to match a normal distribution of data. Based on the arcsine-transformed percentages, multiway ANOVAs regarding pairwise comparisons of the groups (ploidy versus treatments, year versus groups) and the non-parametric tests of Wilcoxon and Kruskal-Wallis were computed.

To estimate the epigenetic variances within and among the groups for each treatment year, the groups of same individuals through the treatment years, the cytotypes and the treatments as well as the respective epigenetic phenotypic differentiation $\left(\Phi_{\mathrm{ST}}\right)$, several global and locus-by-locus AMOVAs were conducted, using ARLEQUIN (Excoffier et al., 2010), version 3.5.2.2. Binary matrices were treated before with AFLPdat script (Ehrich, 2006) to get an output file in Arlequin format. Both modes of AMOVA were based on the option for haplotypic data computed with pairwise differences, a gamma value of 0 and a permutation number of 50.000. Measures as $F_{\text {ST }}$ (homologous to $\Phi_{\text {ST }}$ ), which describe genetic population structuring, should be equally applied to specify population or group differentiation at the epigenetic level (Bossdorf et al., 2008).

\subsection{Results}

\section{Epigenetic patterns of each year of treatment}

The MS-AFLP analysis was conducted on all (100) individuals for the 2017 treatment and on 99 of them for the 2016 treatment, as RawGeno scoring discarded one individual belonging to T2, because of its low quality. Across the 2016 analysis, 754 fragments were scored, while for 2017, the scorable fragments were 493. Furthermore, in the D1, T1, D2 
and T2 groups 401, 562, 485, 559 and260, 258, 266, 232polymorphic markers were detected for 2016 and 2017 analyses, respectively (see Table 1).

In 2016, all diversity measures (percentage of polymorphic loci, private loci and Shannon index) suggest an overall higher diversity for tetraploids, mostly due to internally-methylated and non-methylated markers. In 2017, this trait is reversed as diploids show a higher diversity of markers in these epiloci. All the described differences were consistent under cold treatment and more sporadic under warm treatment (Table 1). 
Table 1. Measures of epigenetic diversity within the four groups of Ranunculus kuepferi obtained for all the types of epiloci.

\section{Diploids 1 Tetraploids $1 \quad$ Diploids 2 Tetraploids 2}

(D1)

(T1)

(D2)

(T2)

\begin{tabular}{|c|c|c|c|c|}
\hline \multirow{2}{*}{ All (754 epiloci) } & \multicolumn{4}{|c|}{2016} \\
\hline & & & & \\
\hline Polymorphic epiloci (\%) & 53.18 & 74.54 & 64.32 & 74.14 \\
\hline Private epiloci & 32 & 43 & 32 & 44 \\
\hline Mean Shannon's diversity & 0.27 & 0.45 & 0.36 & 0.44 \\
\hline \multicolumn{5}{|l|}{$\begin{array}{l}\text { Externally-methylated (255 } \\
\text { epiloci) }\end{array}$} \\
\hline Polymorphic epiloci (\%) & 45.1 & 65.49 & 60.39 & 60.39 \\
\hline Private epiloci & 19 & 23 & 22 & 13 \\
\hline Mean Shannon's diversity & 0.17 & 0.38 & 0.27 & 0.31 \\
\hline \multicolumn{5}{|l|}{$\begin{array}{l}\text { Internally-methylated (254 } \\
\text { epiloci) }\end{array}$} \\
\hline Polymorphic epiloci (\%) & 72.05 & 67.72 & 74.41 & 74.02 \\
\hline Private epiloci & 12 & 7 & 8 & 22 \\
\hline Mean Shannon's diversity & 0.42 & 0.43 & 0.47 & 0.44 \\
\hline \multicolumn{5}{|c|}{ Non-methylated (245 epiloci) } \\
\hline Polymorphic epiloci (\%) & 42.04 & 91.02 & 57.96 & 88.57 \\
\hline Private epiloci & 1 & 13 & 2 & 9 \\
\hline \multirow[t]{2}{*}{ Mean Shannon's diversity } & 0.21 & 0.55 & 0.34 & 0.57 \\
\hline & \multicolumn{4}{|c|}{2017} \\
\hline \multicolumn{5}{|l|}{ All (493 epiloci) } \\
\hline Polymorphic epiloci (\%) & 52.74 & 52.33 & 53.96 & 47.06 \\
\hline Private epiloci & 52 & 41 & 96 & 27 \\
\hline Mean Shannon's diversity & 0.21 & 0.23 & 0.23 & 0.23 \\
\hline \multicolumn{5}{|l|}{$\begin{array}{l}\text { Externally-methylated (287 } \\
\text { epiloci) }\end{array}$} \\
\hline Polymorphic epiloci (\%) & 55.05 & 65.51 & 54.7 & 58.89 \\
\hline Private epiloci & 18 & 36 & 26 & 16 \\
\hline Mean Shannon's diversity & 0.22 & 0.29 & 0.25 & 0.32 \\
\hline \multicolumn{5}{|l|}{$\begin{array}{l}\text { Internally-methylated (119 } \\
\text { epiloci) }\end{array}$} \\
\hline Polymorphic epiloci (\%) & 48.74 & 26.89 & 50.42 & 30.25 \\
\hline Private epiloci & 26 & 2 & 38 & 11 \\
\hline Mean Shannon's diversity & 0.17 & 0.1 & 0.2 & 0.12 \\
\hline \multicolumn{5}{|l|}{ Non-methylated (87 epiloci) } \\
\hline Polymorphic epiloci (\%) & 50.57 & 43.68 & 56.32 & 31.03 \\
\hline Private epiloci & 8 & 3 & 32 & 0 \\
\hline Mean Shannon's diversity & 0.23 & 0.19 & 0.2 & 0.09 \\
\hline
\end{tabular}


The hypothesis of the ploidy effect is confirmed for both years of analysis, as the three different types of epiloci for diploids and tetraploids differed significantly under the same conditions (Fig. 1). More specifically, in externally-, non- and internallymethylated epiloci the ploidy levels under cold treatment (pairs: T1/D1 for 2016 and T2/D2 for 2017) differ significantly (p-values $2016<0.001,<0.001,<0.05 \&$ p-values2017 $<$ $0.05,<0.01,<0.001$ respectively). The ploidy effect is also observed under warm treatment for the non-methylated epiloci of 2016 analysis and externally- as well the internally-methylated epiloci of 2017 analysis (p-value $2016=<0.001 \&$ p-values $2017=$ $0.0373,0.04599$ respectively). A treatment effect within the same year and ploidy level is prominent only for the internally-methylated epiloci of the diploid individuals under 2017 analysis (p-value $2017<0.05)$.

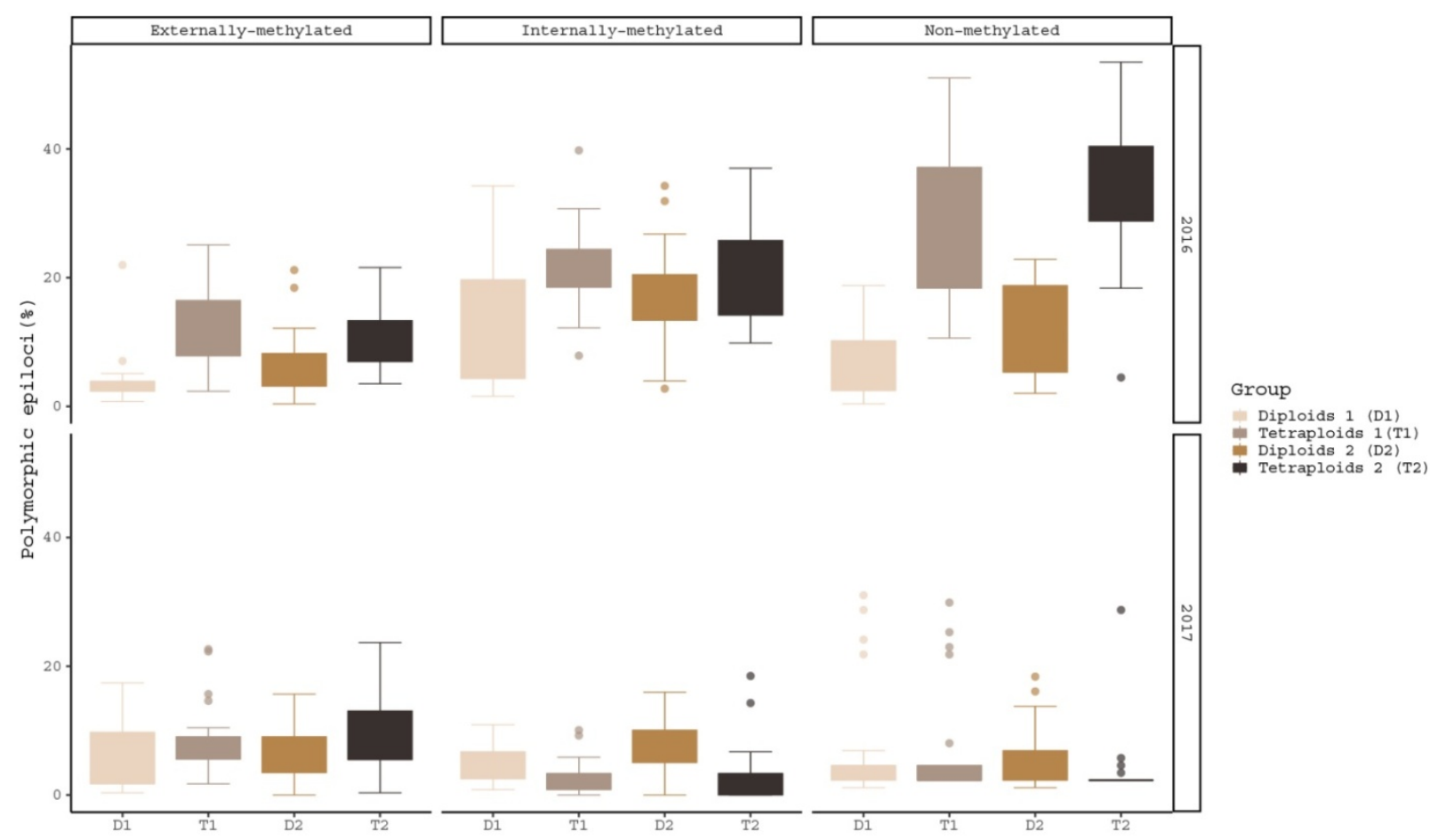

Figure 1. Boxplots of polymorphic epiloci (\%) of the four R. kuepferi groups for each year of treatment. For test statistics see Table S3.

Correlation of epigenetic patterns under the treatment shift

In order to test how the methylation patterns change with the reversed treatment, pairwise comparisons of same individuals between 2016 and 2017 treatment years were 
performed. The treatment shift, as for both directions (Warm to Cold \& Cold to Warm), affected the number and the proportion of polymorphic epilocifor the groups with same individuals (Fig. 2).

a)

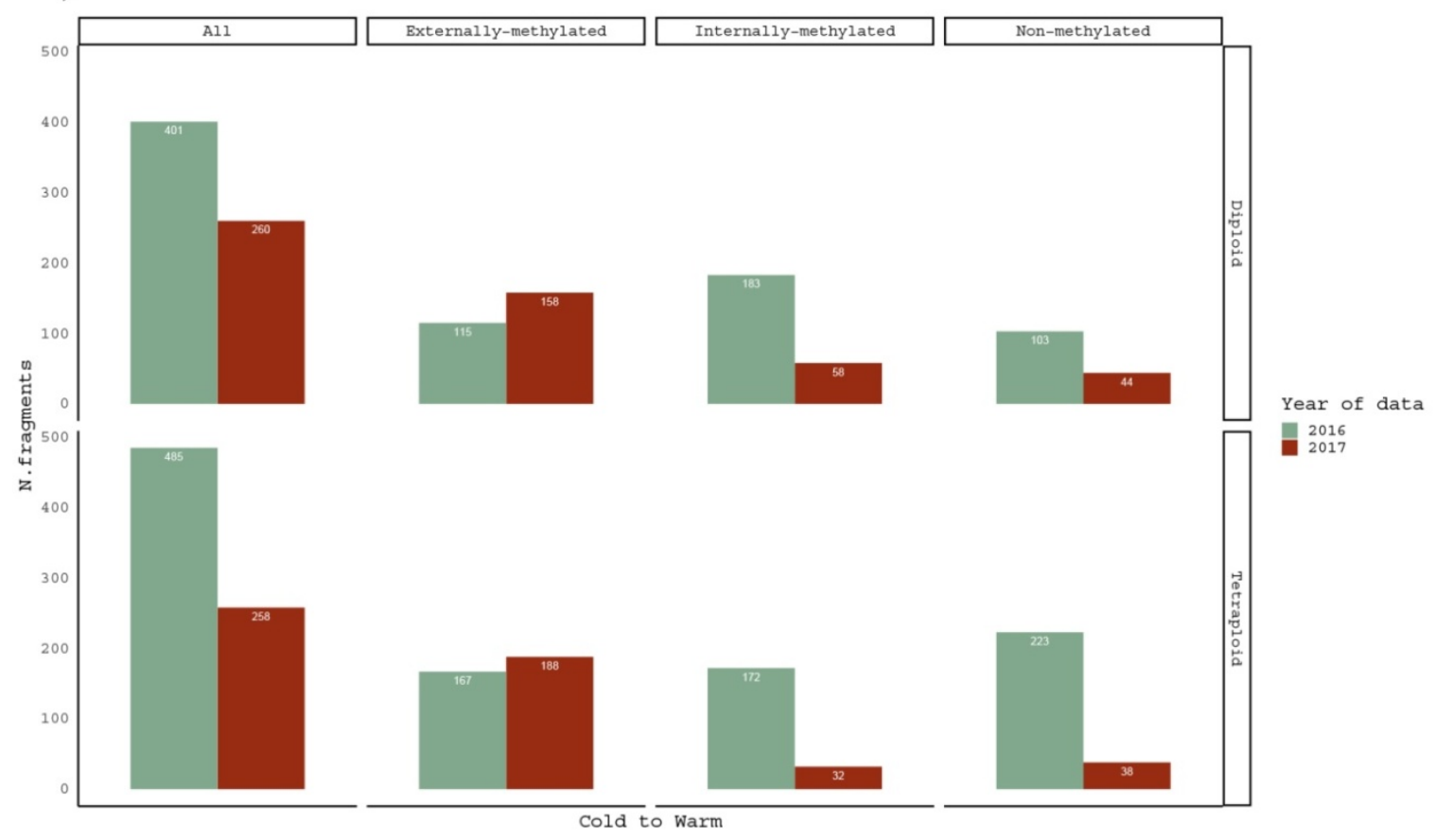

b)

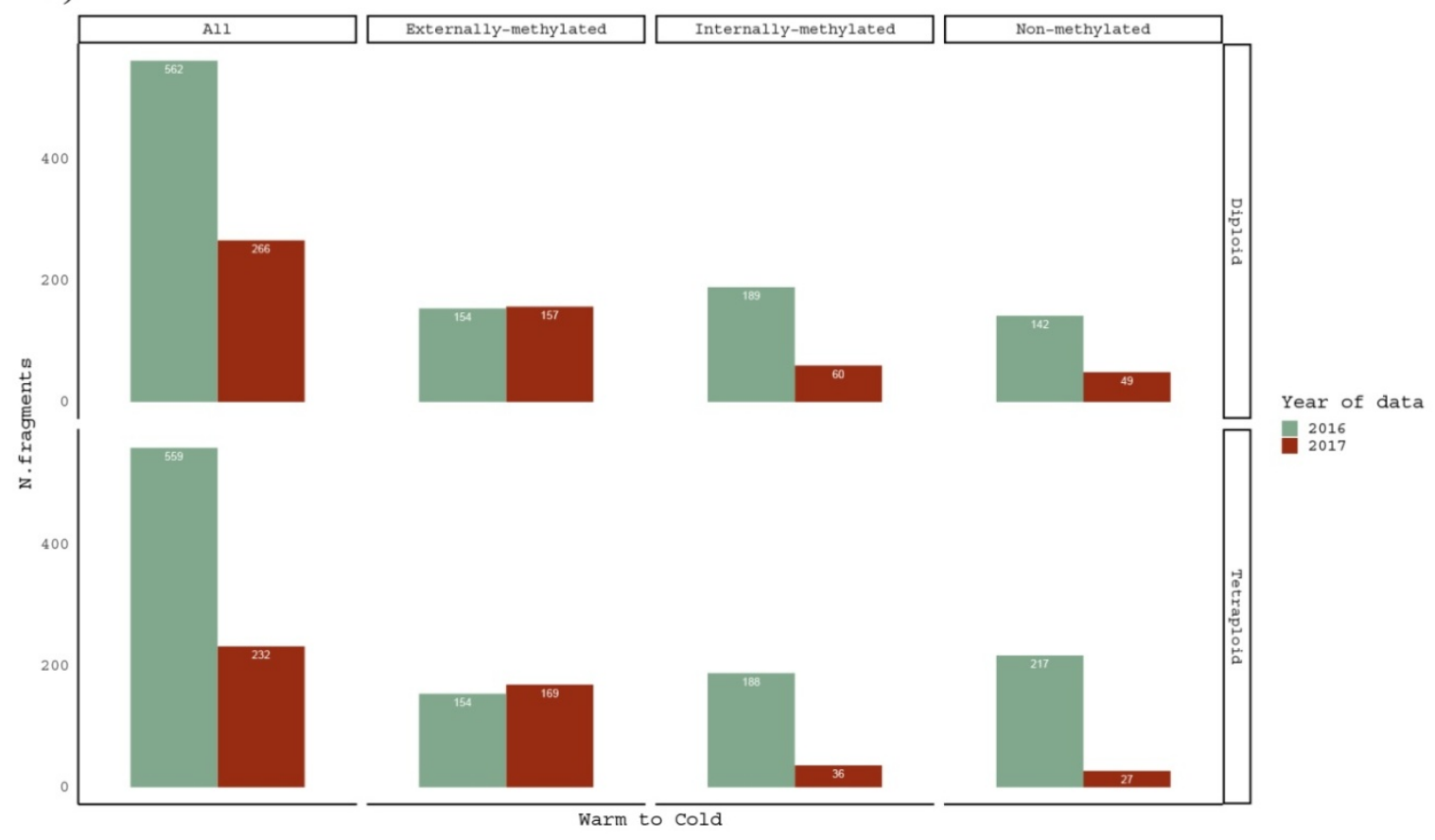


Figure 2. Barplots for comparison of scorable fragments, in absolute numbers (see data in Table 1), for a) Cold to Warm and b) Warm to Cold (vice versa) shift, among the same R. kuepferi individuals.

Regarding the treatment effect hypothesis through descriptive statistics, boxplots and statistical significant tests propose that both cytotypes changed significantly their methylations under Cold to Warm shift and vice versa, for non- and internallymethylated epiloci (Fig. 3).

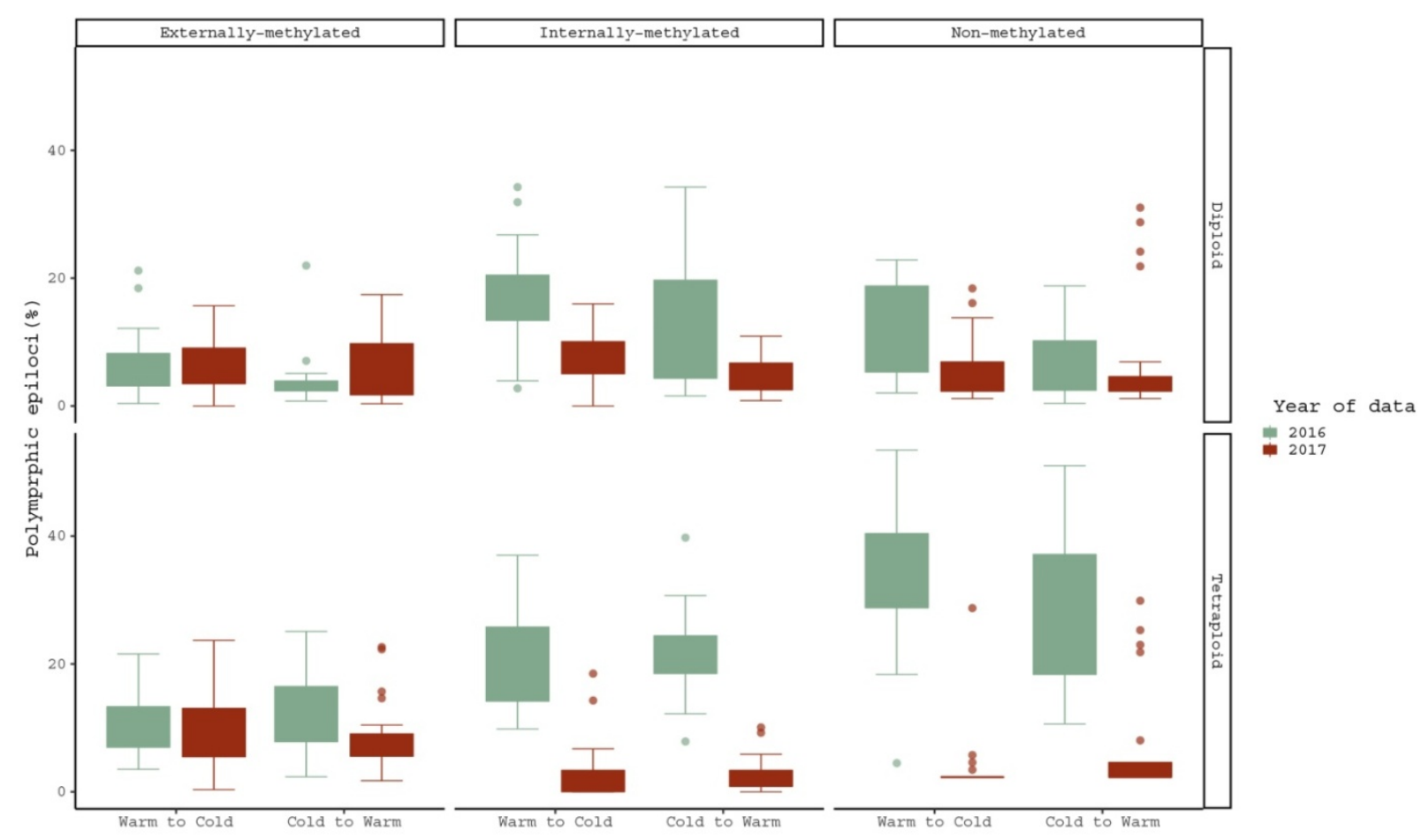

Figure 3. Pairwise comparison of polymorphic epiloci (\%) regarding the same $R$. kuepferi individuals, which went through the reciprocal treatment shift from 2016 to 2017. For test statistics see Table S3.

However, the cytotypes do not differ from each other in their response to the temperature changes. Furthermore, in non- and internally-methylated epiloci the pair D1/D2 differs significantly ( $\mathrm{p}$-values $<0.001$ from Warm to Cold and p-values $<0.005,<$ 0.001 from Cold to Warm), and as well does the T1/T2 pair ( $p$-values $<0.001$ for both directions). Moreover, the corresponding comparison of tetraploids under the shift from Cold to Warm treatment gavesignificant differences also for the case of externallymethylated epiloci $(\mathrm{p}$-value $=<0.005)$. 
Concerning the global AMOVA results, a higher epigenetic variation within than among the groups was found in the diploids for all types of epiloci. Regarding the groups of tetraploids, the epigenetic variation is greater among than within them for non- and internally-methylated epiloci, but not for externally-methylated ones (Table 2). These differences in variation were accounted for both directions of treatment shifts. The $\Phi_{S T}$ values are greater than 0.15 , except for the externally methylated epiloci of diploids that were alternated from Cold to Warm treatment. Values are ascending from externally- to non- and internally-methylated epiloci.

Similarly, locus-by-locus AMOVA revealed lowest percentages of significantly differentiated epiloci in externally methylated epiloci, followed by non-methylated epiloci, and highest percentages ininternally methylated epiloci, for both ploidy levels and treatment shifts. In addition, under the change from Warm to Cold both ploidy levels exhibit more significantly differentiated epiloci, than the ones for the reciprocal change. For this tendency we observed the exceptions of externally- and internallymethylated epilocifor diploids and tetraploids individuals, respectively (Table 2). 
Table 2. Analysis of Molecular Variance (AMOVA) of epiloci, overall and for each type, under both directions of treatment's shift, for the groups of the same individuals of Ranunculus kuepferi. 2x: Diploid, 4x: Tetraploid

\begin{tabular}{|c|c|c|c|c|c|c|c|c|c|c|c|c|c|c|c|c|}
\hline \multirow{3}{*}{$\begin{array}{l}\text { Epiloci } \\
\text { Shift's direction } \\
\text { Ploidy level } \\
\end{array}$} & \multicolumn{4}{|c|}{ Overall } & \multicolumn{4}{|c|}{ Externally-methylated } & \multicolumn{4}{|c|}{ Internally-methylated } & \multicolumn{4}{|c|}{ Non-methylated } \\
\hline & \multicolumn{2}{|c|}{$\begin{array}{l}\text { Warm to } \\
\text { Cold }\end{array}$} & \multicolumn{2}{|c|}{$\begin{array}{l}\text { Cold to } \\
\text { Warm }\end{array}$} & \multicolumn{2}{|c|}{$\begin{array}{l}\text { Warm to } \\
\text { Cold }\end{array}$} & \multicolumn{2}{|c|}{$\begin{array}{l}\text { Cold to } \\
\text { Warm }\end{array}$} & \multicolumn{2}{|c|}{$\begin{array}{l}\text { Warm to } \\
\text { Cold }\end{array}$} & \multicolumn{2}{|c|}{$\begin{array}{l}\text { Cold to } \\
\text { Warm }\end{array}$} & \multicolumn{2}{|c|}{$\begin{array}{l}\text { Warm to } \\
\text { Cold }\end{array}$} & \multicolumn{2}{|c|}{$\begin{array}{l}\text { Cold to } \\
\text { Warm }\end{array}$} \\
\hline & $2 x$ & $4 x$ & $2 x$ & $4 x$ & $2 x$ & $4 x$ & $2 x$ & $4 x$ & $2 x$ & $4 x$ & $2 x$ & $4 x$ & $2 x$ & $4 x$ & $2 x$ & $4 x$ \\
\hline \multicolumn{17}{|l|}{ AMOVA global } \\
\hline $\begin{array}{l}\text { Variation among } \\
\text { groups }(\%)\end{array}$ & $\begin{array}{c}33.3 \\
8\end{array}$ & $\begin{array}{c}40.0 \\
8\end{array}$ & $\begin{array}{c}31.6 \\
1\end{array}$ & $\begin{array}{c}36.0 \\
1\end{array}$ & $\begin{array}{c}10.2 \\
6\end{array}$ & $\begin{array}{c}22.7 \\
8\end{array}$ & $\begin{array}{c}19.2 \\
8\end{array}$ & 15.3 & $\begin{array}{c}48.2 \\
2\end{array}$ & $\begin{array}{c}55.9 \\
3\end{array}$ & $\begin{array}{c}31.6 \\
1\end{array}$ & 57.8 & 45 & $\begin{array}{c}57.1 \\
8\end{array}$ & $\begin{array}{c}49.5 \\
4\end{array}$ & $\begin{array}{c}51.6 \\
8\end{array}$ \\
\hline $\begin{array}{l}\text { Variation within } \\
\text { groups (\%) }\end{array}$ & $\begin{array}{c}66.6 \\
2\end{array}$ & $\begin{array}{c}59.9 \\
2\end{array}$ & $\begin{array}{c}68.3 \\
9\end{array}$ & $\begin{array}{c}63.9 \\
9\end{array}$ & $\begin{array}{c}89.7 \\
4\end{array}$ & $\begin{array}{c}77.2 \\
2\end{array}$ & $\begin{array}{c}80.7 \\
2\end{array}$ & 84.7 & $\begin{array}{c}51.7 \\
8\end{array}$ & $\begin{array}{c}44.0 \\
7\end{array}$ & $\begin{array}{c}68.3 \\
9\end{array}$ & 42.2 & 55 & $\begin{array}{c}42.8 \\
2\end{array}$ & $\begin{array}{c}50.4 \\
6\end{array}$ & $\begin{array}{c}48.3 \\
2\end{array}$ \\
\hline$\Phi_{\mathrm{ST}}$ & 0.33 & 0.4 & 0.32 & 0.36 & 0.1 & 0.23 & 0.19 & 0.15 & 0.48 & 0.56 & 0.32 & 0.58 & 0.45 & 0.57 & 0.5 & 0.52 \\
\hline P-value & $\begin{array}{c}< \\
0.00 \\
1\end{array}$ & $\begin{array}{c}< \\
0.00 \\
1\end{array}$ & $\begin{array}{c}< \\
0.00 \\
1\end{array}$ & $\begin{array}{c}< \\
0.00 \\
1\end{array}$ & $\begin{array}{c}< \\
0.00 \\
1\end{array}$ & $\begin{array}{c}< \\
0.00 \\
1\end{array}$ & $\begin{array}{c}< \\
0.00 \\
1\end{array}$ & $\begin{array}{c}< \\
0.00 \\
1\end{array}$ & $\begin{array}{c}< \\
0.00 \\
1\end{array}$ & $\begin{array}{c}< \\
0.00 \\
1\end{array}$ & $\begin{array}{c}< \\
0.00 \\
1\end{array}$ & $\begin{array}{c}< \\
0.00 \\
1\end{array}$ & $\begin{array}{c}< \\
0.00 \\
1\end{array}$ & $\begin{array}{c}< \\
0.00 \\
1\end{array}$ & $\begin{array}{c}< \\
0.00 \\
1\end{array}$ & $\begin{array}{c}< \\
0.00 \\
1\end{array}$ \\
\hline \multicolumn{17}{|l|}{$\begin{array}{l}\text { AMOVA locus- } \\
\text { by-locus }\end{array}$} \\
\hline $\begin{array}{l}\text { Significantly } \\
\text { differentiated loci }\end{array}$ & 30 & 41 & 24 & 38 & 7 & 19 & 8 & 18 & 16 & 10 & 8 & 12 & 6 & 12 & 6 & 9 \\
\hline $\begin{array}{l}\text { Significantly } \\
\text { differentiated loci } \\
(\%)\end{array}$ & $\begin{array}{c}30.9 \\
3\end{array}$ & $\begin{array}{c}38.6 \\
8\end{array}$ & 25 & $\begin{array}{c}34.8 \\
6\end{array}$ & $\begin{array}{c}12.9 \\
6\end{array}$ & $\begin{array}{c}30.6 \\
4\end{array}$ & $\begin{array}{c}15.3 \\
8\end{array}$ & $\begin{array}{c}27.6 \\
9\end{array}$ & $\begin{array}{c}66.6 \\
6\end{array}$ & 50 & $\begin{array}{c}33.3 \\
3\end{array}$ & 60 & $\begin{array}{c}31.5 \\
8\end{array}$ & 50 & 30 & 37.5 \\
\hline
\end{tabular}




\subsection{Discussion}

In the current study, patterns of epigenetic variation in two cytotypes of R. kuepferi along cold (stress) and warm (control) temperature treatments were explored and comparisons for the same individuals after the shift of treatments were performed. The results confirmed the correlation of methylation profiles with the ploidy level, under the same treatment conditions and for both years of analyses. Furthermore, tetraploids had significantly more epiloci than diploids, regarding overall, externally- and nonmethylated epiloci under cold treatment of 2016, while for the 2017 analyses the diploid individuals, have more internally-methylated epiloci under both treatments, more nonmethylated epiloci under cold treatment and less externally-methylated epiloci under both treatments.

The response to the reciprocal change of treatments is supported by the comparisons of methylation patterns of same individuals before and after the treatment shift. Overall, the treatment shift resulted in a drastic decrease of scorable fragments and, regardless of the shift's direction, a significantly lower number of internally- and non-methylated epiloci. Moreover, the significant higher number of internally-methylatedepiloci under cold treatment, compared to warm in the same year, indicates a temperature-sensitivity of DNA methylation patterns of 2017 among diploids.

Subsequently, we will attempt to interpret all results according to the two factors ploidy level and treatment.

\section{Epigenetic patterns and ploidy level}

The observed difference in methylation patterns of the ploidy levels, for both years of analysis, is in contrast to the very low genetic differentiation of cytotypes in wild populations in the AFLP study of Cosendai et al. (2011, 2013). Moreover, variation in DNA methylation patterns over short time scales appears to be spontaneous and independent from genetic background (Vidalis et al., 2016). The epigenetic differentiation of cytotypes was also observed in methylation patterns studied in wild populations of R. kuepferi (Schinkel et al., 2020). Since tetraploid R. kuepferi is autopolyploid, we can also rule out side-effects of hybridity on methylation patterns (e.g. Chen, 2007). The consistency of results suggests that polyploidization affects methylation variation independently from genetic background variation and environment. Strikingly, for 2016, tetraploids showed significantly more epiloci than diploids do.Other studies have shown that autopolyploidycan trigger de novo methylation in the model system Taraxacum officinale (Verhoeven et al., 2010a) and the endemic species of the Iberian Peninsula, Dianthus broteri (Alonso et al., 2016b) as well as increase the global cytosine methylation in six species of the grass species complex Cymbopogon (Lavania et al., 2012). 
Cold treatment conditions were quite similar to the natural habitat conditions of the tetraploid R. kuepferi plants in the Alps (see also Klatt et al., 2018). They have an extended biogeographical and altitudinal distribution (Cosendai and Hörandl, 2010; Schinkel et al., 2016; Kirchheimer et al., 2016), but neither geographical structure nor isolation-by-distance appearedin their gene pool (Cosendai et al., 2013). The lack of genetic structure in tetraploids is probably due to their recent origin and rapid postglacial colonization of the Alps (Kirchheimer et al., 2018). Kirchheimer et al. (2016) suggested that tetraploids' niche optimum is placed in the direction of cooler conditions than the one for diploid cytotype, probably due to the change in the reproductive system of an originally warm-adapted species during postglacial re-colonization of higher regions in the Alps (Kearney, 2005; Hörandl, 2006). Tolerance to cooler conditions allows tetraploids to surmount high elevation barriers and establish new populations throughout a greater distribution range (Kirchheimer et al., 2018). The shift to facultative apomixis may have additionally facilitated rapid colonization (Kirchheimer et al., 2018). Warm treatments rather reflected the natural temperature conditions of the diploids in the southwestern Alps. DNA methylation patterns in the wild populations indeed followed rather a temperature gradient than the biogeographical patternand they seem to correlate with reproduction mode of each cytotype (Schinkel et al.,2020). Previous cold/warm treatments by Klatt et al. (2018) in climate growth chambers suggested indeed some influence of temperature on mode of reproduction in diploids, and overall a high phenotypic plasticity in this trait. However, this earlier study did not include a reciprocal change of treatments. The potential correlations of reproduction mode and the epigenetic patterns of each cytotype regarding our experiments will be discussed elsewhere, as our main aim of the current study is to decipher the ploidy-treatment linked effects.

Hence, the results of the first treatment in 2016 may still reflect to a great extent the background methylation profiles from the natural habitats, potentially related to differential cold acclimation of diploids and tetraploids.Correlating these background studies with the dynamics of DNA methylation during cold acclimation (Liu et al., 2017), the findings of 2016, which represented the $3^{\text {rd }}$ year $(2014$ - 2016) of cultivation in growth chambers under the same conditions, are slightly deciphered.

The evolutionary aspects of stress-induced epigenetic variation as well as the epigenetic inheritance have been noteworthy discussed (e.g.Wendel et al., 2005; Richards, 2006; Bossdorf et al., 2008; Richards et al., 2017). The exposure to biotic or abiotic environmental stresses can trigger epigenetic changes that seem to persist even after the stress is relieved, resulting in a stress memory that can be stable throughout the lifetime of an organism or even across generations, especially in plants (Richards et al., 2012). The observed cytotype differentiation of methylation in $R$. kuepferi could reflect such a 
heritable pattern as ploidy levels, whichare highly stable within natural populations (Cosendai et al., 2010, Schinkel et al., 2016).

\section{Epigenetic patterns and treatment}

Regarding the treatment effect on the DNA methylation patterns, only after the reciprocal change of treatments for the same individuals we observed significant changes of the methylation profiles. We suggest that an extreme change of temperature is needed to alter methylation patterns independently from ploidy variation. However, such extreme temperature shifts do occur under natural weather conditions in the Alps, and alpine plants have to be tolerant to temperature extremes between day and night, extreme low temperatures down to $-24{ }^{\circ} \mathrm{C}$ in higher altitudes, as wellas different weather conditions and seasons (Körner, 2003). The high phenotypic plasticity in methylation patterns, which we observed in R. kuepferi, may be responsive to the fluctuating climatic conditions. Several studies insinuate increases in epigenetic variation in response to different environmental factors (Verhoeven et al., 2010b; Dowen et al., 2012; Verhoeven and Preite, 2013; Nicotra et al., 2015; Foust et al., 2016). The 2017 results for $R$. kuepferi may empower the argument of cold-induced DNA methylation changes, as described by e.g. Song et al. (2015) regarding the alpine to subnivale species Chorispora bungeana. Furthermore, in the alpine species Wahlenbergia ceracea, adaptive plasticity in methylation was observed in low-elevation plants (Nicotra et al., 2015), while forest trees set off several epigenetic mechanisms, including DNA methylation, to elicit rapid phenotypic variations, which help them respond to environmental changes (Mamadou et al., 2018). We cannot rule out that perennial plants like $R$. kuepferi change their methylation profile over their lifetime independently from environmental influence. However, it is unlikely that such a drastic shift from one year to another would be just an effect of ageing, as it occurred synchronously in plants from different origins. Our plants showed no signs of senescence.

Hereby, concerning the comparison of same individuals for the two years of analysis, fewer fragments were detected after the shift of treatments, i.e. 754 for 2016 in contrast to 493 for 2017. The "Mixed Scoring 2" approach used in the current study for fragment detection (Schulz et al., 2013) does score "000" for the condition IV, which refers to the uninformative state of fragments' absence due to methylation polymorphisms (Zhang et al., 2007) or restriction site polymorphisms/mutations. Methylation polymorphisms

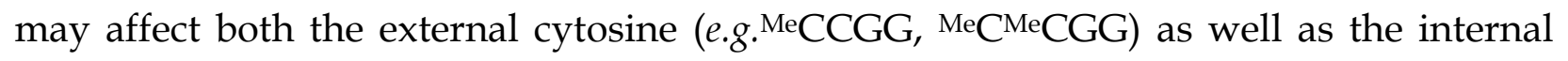
cytosine (e.g. $\left.{ }^{\mathrm{HMe}} \mathrm{C}^{\mathrm{HMe} C G G},{ }^{\mathrm{Me}}{ }^{\mathrm{Me}} \mathrm{CGG}\right)$, and correct interpretation of changes of methylation status from one to the other is often complicated (Fulnecek and Kovarik, 2014). Remarkably, the loss of epiloci appeared in both cytotypes of R. kuepferi and just affected internally-methylated and non-methylated loci. This observation may point at an inability of MspI to cut within the CG context. Hence, we cannot readily interpret our 
pattern as demethylation process, but rather as indicative of a high methylation dynamics, or even mutational changes in ce 5-methylcytosin can convert to a thymine via deamination. However, our results suggest that types of epiloci react differentially to abiotic stress, which is in line with involvement of differential methyltransferase families and positions in the genome (e.g. Alonso et al., 2016a).

Our speculations refer to the potential of DNA methylation mechanisms to respond to abiotic environmental stress (Richards et al., 2017) and the complex network of them with the other epigenetic mechanisms. It is known that DNA methylation, as an important epigenetic mechanism, is involved in diverse biological processes such as transposon proliferation, genomic imprinting and regulation of gene expression (e.g. Law and Jacobsen, 2010) and together with histone modifications and non-histone proteins, encompasses chromatin structure and accessibility (Zhang et al., 2018). The aforementioned phenotypic plasticity in methylations may improve the phenotypic response of plants during acclimation and adaptation to heterogeneous environments (Nicotra et al., 2010).

The lower number of internally- and non-methylated epiloci after the shift, referring to the methylation profiles of the same individuals, regardless the direction of treatment's change and the ploidy level, and the greater number of externally-methylated epiloci of tetraploid individuals, highlight likewise the response to the new abiotic conditionsafter the shift from cold to warm conditions. This epigenetic variation may depict the dynamics of DNA methylation under stress conditions (Bartels et al., 2018; Zhang et al., 2018) and the epigenetic control on the phenotypic plasticity of the species (Zhang et al., 2012; Richards et al., 2017).

Kooke et al. (2015) suggested that a DNA demethylation is responsible for variation of phenotypic plasticity by extending its environmental sensitivity. Furthermore, DNA methylation in response to abiotic environmental stress could regulate gene expression (e.g. Steward et al., 2002; Shan et al., 2013; Rakei et al., 2016), mostly by global demethylation of genomic DNA, while DNA methylation is believed to play a role in the maintenance of cell stability under stress (Song et al., 2015). However, since the interpretation of our methylation profiles is not straightforward we can just confer a high dynamics from our experiments.

Global AMOVA results for tetraploids reflect these DNA methylation dynamics as a response to the change of temperature, from warm to cold conditionsand vice versa. Interestingly, regarding the shift from warm to cold, the higher variation among the tetraploid groups for the non-methylated epiloci may underline the, hypothetically, important role of methylation dynamics under cold treatment. The locus-by-locus AMOVA results, which indicate the epigenetic phenotypic differentiation at each locus, 
support the hypothesis of cold stress affecting the epigenetic variation, as there were overall more significantly differentiated epiloci for the shift from warm to cold, also for the diploid groups.

To summarize, the current study demonstrates a ploidy effect on the DNA methylation profiles, mainly under cold treatment, and a significant differentiation of themas a response to the reciprocal temperature treatment experiments. This phenotypic plasticity may affect the potential of the two cytotypes, and therefore also the two different reproduction modes, to tolerate cold stress. Differential response of the different types of epiloci suggests a high epimutational dynamics. 


\subsection{References}

Adams, K. L., and Wendel, J. F. (2005). Polyploidy and genome evolution in plants. Current Opinion in Plant Biology, 8, 135-141.

Ainouche, M. L., Fortune, P. M., Salmon, A., Parisod, C., Grandbastien, M-A., Fukunaga, K., Ricou, M., and Misset, M-T. (2009). Hybridization, polyploidy and invasion: lessons from Spartina (Poaceae). Biological Invasions, 11, 1159-1173.

Alonso, C., Perez, R., Bazaga, P., Medrano, M., and Herrera, C. M.(2016a). MSAP markers and global cytosine methylation in plants: a literature survey and comparative analysis for a wild growing species. Molecular Ecology Resources, 16, 80 -90.

Alonso, C., Balao, F., Bazaga, P., and Perez, R. (2016b). Epigenetic contribution to successful polyploidizations: variation in glabal cytosine methylation along an extensive ploidy series in Dianthus broteri (Caryophyllaceae). New Phytologist, 212, 571-576.

Arrigo, N., Tuszynski, J. W., Ehrich, D., Gerdes, T., and Alvarez, N. (2009). Evaluating the impact of scoring parameters on the structure of intra-specific genetic variation using RawGeno, an R package for automating AFLP scoring. BMC Bioinformatics, 10, 1033.

Bartels, A., Han, Q., Nair, P., Stacey, L., Gaynier, H., Mosley, M., Huang, Q. Q., Pearson, J. K., Hsieh, T., An, Y. C., et al. (2018). Dynamic DNA Methylation in Plant Growth and Development. International Journal of Molecular Sciences, 19, 2144. doi:10.3390/ijms19072144.

Baubec, T., Dinh, H. Q., Pecinka, A., Rakic, B., Rozhon, W., Wohlrab, B., von Haeseler, A., and Scheid, O. M. (2010). Cooperation of Multiple Chromatin Modifications Can Generate Unanticipated Stability of Epigenetic States in Arabidopsis. Plant Cell, 22, 34-47.

Berger, S. L. (2007). The complex language of chromatin regulation during transcription. Nature, 447, 407-412.

Bird, A. (2002). DNA methylation patterns and epigenetic memory DNA methylation patterns and epigenetic memory. Genes E Development, 16, 6-21.

Bonin, A., Bellemain, E., Bronken Eidesen, P., Pompano, F., Brochmann, C., and Taberlet, P. (2004). How to track and assess genotyping errors in population genetics studies. Molecular Ecology, 13, 3261-3273.

Bossdorf, O., Richards, C. L., and Pigliucci, M. (2008). Epigenetics for ecologists. Ecology Letters, 11, 106-115. 
Bossdorf, O., Arcuri, D., Richards, C. L., and Pigliucci, M. (2010). Experimental alteration of DNA methylation affects the phenotypic plasticity of ecologically relevant traits in Arabidopsis thaliana. Evolutionary Ecology, 24, 541-553.

Boyko, A., Blevins, T., Yao, Y., Golubov, A., Bilichak, A., Ilnytskyy, Y., Meins, F., and Kovalchuk, I. (2010). Transgenerational Adaptation of Arabidopsis to Stress Requires DNA Methylation and the Function of Dicer-Like Proteins. PLoS ONE, 5(3), e9514. https:/ / doi.org/10.1371/journal.pone.0009514

Burnier, J., Buerki, S., Arrigo, N., Küpfer, P., and Alvarez, N. (2009). Genetic structure and evolution of Alpine polyploid complexes: Ranunculus kuepferi (Ranunculaceae) as a case study. Molecular Ecology, 18, 3730-3744.

Chen, Z. J. (2007). Genetic and epigenetic mechanisms for gene expression and phenotypic variation in plant polyploids. Annual Review of Plant Biology, 58, 377-406.

Comai, L. (2005). The advantages and disadvantages of being polyploid. Nature Reviews Genetics, 6, 836-846.

Cosendai, A. C., and Hörandl, E. (2010). Cytotype stability, facultative apomixis and geographical parthenogenesis in Ranunculus kuepferi (Ranunculaceae). Annals of Botany, $105,457-470$.

Cosendai, A. C., Rodewald, J., and Hörandl, E. (2011). Origin and distribution of autopolyploids via apomixis in the alpine species Ranunculus kuepferi (Ranunculaceae). Taxon, 60, 355-364.

Cosendai, A. C., Wagner, J., Ladinig, U., Rosche, C., and Hörandl, E. (2013). Geographical parthenogenesis and population genetic structure in the alpine species Ranunculus kuepferi (Ranunculaceae). Heredity, 110, 560-569.

Dong, Z. Y., Wang, Y. M., Zhang, Z. J., Shen, Y., Lin, X. Y., Ou, X. F., Han, F. P., and Liu, B. (2006). Extent and pattern of DNA methylation alteration in rice lines derived from introgressive hybridization of rice and Zizania latifolia Griseb. Theoretical $\mathcal{E}$ Applied Genetics, 113, 196-205.

Dowen, R. H., Pelizzola, M., Schmitz, R. J., Lister, R., Dowen, J. M., Nery, J. R., Dixon, J. E., and Ecker, J. R. (2012). Widespread dynamic DNA methylation in response to biotic stress. Proceedings of the National Academy of Sciences of the United States of America, 109, 2183-2191.

Ehrich, D. (2006). AFLPDAT: a collection of R functions for convenient handling of AFLP data. Molecular Ecology Resources, 6, 603-604. 
Excoffier, L., and Lischer, H.E. (2010). Arlequin suite ver 3.5: a new series of programs to perform population genetics analyses under Linux and Windows. Molecular Ecology Resources, 10, 564-567.

Finnegan, E. J. (2010). "DNA Methylation: a Dynamic Regulator of Genome Organization and Gene Expression in Plants,"inPlant Developmental Biology Biotechnological Perspectives: Vol. 2, eds E. C. Pua and M. R. Davey (Berlin, Germany: Springer-Verlag), 295-323.

Foust, C. M., Preite, V., Schrey, W., Alvarez, M., Robertson, M. H., Verhoeven, K. J. F., and Richards C. L. (2016). Genetic and epigenetic differences associated with environmental gradients in replicate populations of two salt marsh perennials. Molecular Ecology, 25, 1639-1652.

Fulnecek, J., and Kovarik, A. (2014). How to interpret Methylation Sensitive Amplified Polymorphism (MSAP) profiles? BMC Genetics, 15: 2.doi: 10.1186/1471-2156-15-2

Grant-Downton, R. T., and Dickinson, H. G. (2005). Epigenetics and its implications for Plant Biology: 1. The epigenetic network in plants. Annals of Botany, 96, 1143-1164.

Grossniklaus, U., Nogler, G. A., and van Dijk, P. J. (2001). How to Avoid Sex: The Genetic Control of Gametophytic Apomixis. The Plant Cell, 13, 1491-1497.

Hegarty, M. J., Batstone, T., Barker, G. L., Edwards, K. J., Abbott R. J., and Hiscock, S. J. (2011). Nonadditive changes to cytosine methylation as a consequence of hybridization and genome duplication in Senecio (Asteraceae). Molecular Ecology, 20, 105113.

Herrera, C. M., Pozo, M. I., and Bazaga, P. (2012). Jack of all nectars, master of most: DNA methylation and the epigenetic basis of niche width in a flower- living yeast. Molecular Ecology, 21, 2602-2616.

Hirsch, S., Baumberger, R., and Grossniklaus, U. (2013). Epigenetic variation, inheritance, and selection in plant populations. Cold Spring Harbor Symposia on Quantitative Biology, 77, 97-104.

Hörandl, E. (2006). The complex causality of geographical parthenogenesis. New Phytologist, 171, 525-538.

Johannes, F., Porcher, E., Teixeira, F. K., Saliba-Colombani, V., Simon, M., Agier, N., Bulski, A., Albuisson, J., Heredia, F., Audigier, P., et al. (2009). Assessing the Impact of Transgenerational Epigenetic Variation on Complex Traits. PLoS Genetics, 5 (6): e1000530. doi: 10.1371/journal.pgen.1000530. 
Jones, P. A. (2012). Functions of DNA methylation: islands, start sites, gene bodies and beyond. Nature Reviews Genetics, 13, 484-492.

Kearney, M. (2005). Hybridization, glaciation and geographical parthenogenesis. Trends in Ecology E Evolution, 20, 495-502.

Kirchheimer, B., Schinkel, C. C-F., Dellinger, A. S., Klatt, S., Moser, D., Winkler, M., Lenoir, J., Caccianiga, M., Guisan, A., Nieto-lugilde, D., et al. (2016). A matter of scale: apparent niche differentiation of diploid and tetraploid plants may depend on extent and grain of analysis. Journal of Biogeography, 43, 716-726.

Kirchheimer, B., Wessely, J., Gattringer, A., Hülber, K., Moser, D., Schinkel, C. C-F., Appelhans, M., Klatt, S., Caccianiga, M., Dellinger, A., et al. (2018). Reconstructing geographical parthenogenesis: effects of niche differentiation and reproductive mode on Holocene range expansion of an alpine plant. Ecology Letters, 21, 392-401.

Klatt, S., Schinkel, C. C.-F., Kirchheimer, B., Dullinger, S., and Hörandl, E. (2018). Effects of cold treatments on fitness and mode of reproduction in the diploid and polyploid alpine plant Ranunculus kuepferi (Ranunculaceae). Annals of Botany, 121, 12871298.

Kooke, R., Johannes, F., Wardenaar, R., Becker, F., Etcheverry, M., Colot, V., Vreugdenhil, D., and Keurentjes, J. B. (2015). Epigenetic Basis of Morphological Variation and Phenotypic Plasticity in Arabidopsis thaliana. The Plant Cell, 27, 337-348.

Körner, C. H. (2003). Alpine plant life, $2^{\text {nd }}$ Ed. Berlin, Germany: Springer-Verlag.

Küpfer, P. (1974). Recherches sur les liens de parente entre la flore orophile des Alpes et celle des Pyrenees. Boissiera, 23, 1-322.

Ladinig, U., Hacker, J., Neuner, G., and Wagner, J. (2013). How endangered is sexual reproduction of high-mountain plants by summer frosts? Frost resistance, frequency of frost events and risk assessments. Oecologia, 171, 743-760.

Lavania, U.C., Srivastava, S., Lavania. S., Basu, S., Misra, N.K., Mukai, Y. (2012). Autopolyploidy differentially influences body sizes in plants, but facilitates enhanced accumulation of secondary metabolites, causing increased cytosine methylation. Plant Journal, 71, 539 - 549.

Law, J. A., and Jacobsen, S. E. (2010). Establishing, maintaining and modifying DNA methylation patterns in plants and animals. Nature Reviews Genetics, 11, 204-220.

Li, Z. H., Lu, X., Gao, Y., Liu, S. J., Tao, M., Xiao, H., Qiao, Y. Q., Zhang, Y. P., and Luo J. (2011). Polyploidization and epigenetics. Chinese Science Bulletin, 3, 245-252. 
Liu, T., Li, Y., Duan, W., Huang, F., and Hou, X. (2017). Cold acclimation alters DNA methylation patterns and confers tolerance to heat and increases growth rate in Brassica rapa. Journal of Experimental Botany, 68, 1213-1224.

Madlung, A. (2013). Polyploidy and its effect on evolutionary success: old questions revisited with new tools. Heredity, 110, 99-104.

Madlung, A., and Wendel, J. F. (2013). Genetic and Epigenetic Aspects of Polyploid Evolution in Plants. Cytogenetic and Genome Research, 140, 270-285.

Mamadou, D. S., Allona, I., Ambroise, C., Conde, D., Fichot, R., Gribkova, S., Jorge, V., Le-Provost, G., Paques, L., Plomion, C., et al. (2018). "Epigenetic in Forest Trees: State of the Art and Potential Implications for Breeding and Management in a Context of Climate Change" in Advances in Botanical Research: Plant Epigenetics Coming of Age for Breeding Applications, Vol. 88, eds M. Mirouze, E. Bucher and P. Gallusci (London, UK: Academic Press LTD-Elsevier Science LTD), 387-453.

Massicotte, R., Whitelaw, E., and Angers, B. (2011). DNA methylation: A source of random variation in natural populations. Epigenetics, 6, 422-428.

Nicotra, A. B., Atkin, O. K., Bonser, S. P., Davidson, A. M., Finnegan, E. J., Mathesius, U., Poot, P., Purugganan, M. D., Richards, C. L., Valladares, F., and van Kleunen, M. (2010). Plant phenotypic plasticity in a changing climate. Trends in Plant Science, 15, 684692.

Nicotra, A. B., Segal, D. L., Hoyle, G. L., Schrey, A. W., Verhoeven, K. J. F., and Richards, C. L. (2015). Adaptive plasticity and epigenetic variation in response to warming in an Alpine plant. Ecology and Evolution, 5, 634-647.

Paun, O., Fay, M. F., Soltis, D. E., and Chase, M. W. (2007). Genetic and epigenetic alterations after hybridization and genome dupling. Taxon, 56, 649-656.

Paun, O., Bateman, R. M., Fay, M. F., Hedren, M., Civeyrel,L., and Chase, M. W. (2010). Stable epigenetic effects impact adaptation in allopolyploid orchids (Dactylorhiza: Orchidaceae). Molecular Biology and Evolution, 27, 2465-2473.

Paun, O., and Schönswetter, P. (2012). Amplified Fragment Length Polymorphism (AFLP) - an invaluable fingerprinting technique for genomic, transcriptomic and epigenetic studies. Methods in Molecular Biology, 862, 75-87.

R Core Team 2019. R: A language and environment for statistical computing. $R$ Foundation for Statistical Computing, Vienna, Austria. URL https://www.Rproject.org/ 
Rakei, A., Maali-amiri, R., Zeinali, H., and Ranjbar, M. (2016). DNA methylation and physio-biochemical analysis of chickpea in response to cold stress. Protoplasma, 253, 6176.

Richards, E. J. (2006). Inherited epigenetic variation-revisiting soft inheritance. Nature Reviews, 7, 395-402.

Richards, C. L., Schrey, A. W., and Pigliucci, M. (2012). Invasion of diverse habitats by few Japanese knotweed genotypes is correlated with epigenetic differentiation. Ecology Letters, 15, 1016-1025.

Richards, C. L., Alonso, C., Becker, C., Bossdorf, O., Bucher, E., Colome-Tatche, M., Durka, W., Engelhardt, J., Gaspar, B., Gogol-Döring, A., et al. (2017). Ecological plant epigenetics: Evidence from model and non-model species, and the way forward. Ecology Letters, 20, 1576-1590.

Rois, A. S., Rodriguez Lopez, C. M., Cortinhas, A., Erben, M., Espirito-Santo, D., Wilkinson, M. J., and Caperta, A. D. (2013). Epigenetic rather than genetic factors may explain phenotypic divergence between coastal populations of diploid and tetraploid Limonium spp. (Plumbaginaceae) in Portugal. BMC Plant Biology, 13, 205.

RStudio Team 2016. RStudio: Integrated Development for R. RStudio,Inc., Boston, MA URL http:/ / www.rstudio.com/

Salmon, A., Clotault, J., Jenczewski, E., Chable, V.,and Manzanares-dauleux, M. J. (2008). Brassica oleracea displays a high level of DNA methylation polymorphism. Plant Science, 174, 61-70.

Schinkel, C. C-F., Kirchheimer, B., Dellinger, A. S., Klatt, S., Winkler, M., Dullinger, S., and Hörandl, E. (2016). Correlations of polyploidy and apomixis with elevation and associated environmental gradients in an alpine plant. AoB PLANTS, 8, plw064, doi:10.1093/aobpla/plw064.

Schinkel, C. C-F., Kirchheimer, B., Dullinger, S., Geelen, D., De Storme, N., and Hörandl, E. (2017). Pathways to polyploidy: indications of a female triploid bridge in the alpine species Ranunculus kuepferi (Ranunculaceae). Plant Systematics E Evolution, 303, 1093-1108.

Schinkel, C.C-F., Syngelaki, E., Kirchheimer, B., Dullinger, S., Klatt, S., and Hörandl, E. (2020). Epigenetic patterns and geographical parthenogenesis in the alpine plant species Ranunculus kuepferi (Ranunculaceae). Int J MolSci, 21(9), 3318. 
Schrey, A. W., Alvarez, M., Foust, C. M., Kilvitis, H. J., Lee, J. D., Liebl, A. L., Martin, L. B., Richards, C. L., and Robertson, M. (2013). Ecological Epigenetics: Beyond MSAFLP. Integrative and Comparative Biology, 53, 340-350.

Schulz, B., Eckstein, R. L., and Durka, W. (2013). Scoring and analysis of methylationsensitive amplification polymorphisms for epigenetic population studies. Molecular Ecology Resources, 13, 642-653.

Schulz, B., Eckstein, R. L., and Durka, W. (2014). Epigenetic variation reflects dynamic habitat conditions in a rare floodplain herb. Molecular Ecology, 23, 3523-3537.

Shan, X., Wang, X., Yang, G., Wu, Y., Su, S., Li, S., Liu, H., and Yuan, Y. (2013). Analysis of the DNA Methylation of Maize (Zea mays L.) in response to cold stress Based on methylation-sensitive amplified polymorphisms. Journal of Plant Biology, 56, 32-38.

Sherman, J. D., and Talbert, L. E. (2002). Vernalization-induced changes of the DNA methylation pattern in winter wheat. Genome, 260, 253-260.

Song, Q., and Chen, Z. J. (2016). Epigenetic and developmental regulation in plant polyploids. Current Opinion in Plant Biology, 24, 101-109.

Song, Y., Liu, L., Feng, Y., Wei, Y., Yue, X., He, W., Zhang, H., and An, L. (2015). Chilling- and Freezing-Induced Alterations in Cytosine Methylation and Its Association with the Cold Tolerance of an Alpine Subnival Plant, Chorispora bungeana. PLOS one, doi:10.1371/journal.pone.0135485.

Soltis, D. E., Buggs, R. J. A., Doyle, J. J., and Soltis, P. S. (2010). What we still don't know about polyploidy. Taxon, 59, 1387-1403.

Soltis, D. E., Visger, C. J., and Soltis, P. S. (2014). The polyploidy revolution then . . and now: Stebbins revisited. American Journal of Botany, 101, 1057-1078.

Steward, N., Ito, M., Yamaguchi, Y., Koizumi, N., and Sano, H. (2002). DNA methylation in maize nucleosomes and demethylation by environmental stress. Journal of Biological Chemistry, 277, 37741-37746.

te Beest, M., Le Roux, J. J., Richardson, D. M., Brysting, A. K., Suda, J., Kubesova, M., and Pysck, P. (2012). The more the better? The role of polyploidy in facilitating plant invasions. Annals of Botany, 109, 19-45.

Vaughn, M. W., Tanurdzic, M., Lippman, Z., Jiang, H., Carrasquillo, R., Rabinowicz, P. D., Dedhia, N., McCombie, W. R., Agier, N., Bulski, A., et al.(2007). Epigenetic Natural Variation in Arabidopsis thaliana. PLoS Biology, 5, 1617-1629. 
Verhoeven, K. J. F., Jansen, J. J., van Dijk, P. J., and Biere, A. (2010a). Stress-induced DNA methylation changes and their heritability in asexual dandelions. New Phytologist, $185,1108-1118$.

Verhoeven, K. J. F., van Dijk, P. J., and Biere, A. (2010b). Changes in genomic methylation patterns during the formation of triploid asexual dandelion lineages. Molecular Ecology, 19, 315-324.

Verhoeven, K. J. F., and Preite, V. (2013).Epigenetic variation in asexually reproducing organisms. Evolution, 68, 644-655.

Vidalis, A., Zivkovic, D., Wardenaar, R., Roquis, D., Tellier, A., Johannes, F. (2016). Methylome evolution in plants. Genome Biology, 17, 264.

Wasserstein, R. L., and Lazar, N. A. (2016). The ASA' s statement on p-values: context, process and purpose. The American Statistician, doi:10.1080/00031305.2016.1154108.

Wendel, J. F., and Rapp, R. A. (2005). Epigenetics and plant evolution. New Phytologist, $168,81-91$.

Wickham, H. (2009). ggplot2: Elegant Graphics for Data Analysis. Springer-Verlag New York.

Yan, H., Kikuchi, S., Neumann, P., Zhang, W., Wu, Y., Chen, F., Jiang, J., and Creek, W. (2010). Genome-wide mapping of cytosine methylation revealed dynamic DNA methylation patterns associated with genes and centromeres in rice. The Plant Journal, 63, 353-365.

Zhang, Y., Fischer, M., Colot, V., and Bossdorf, O. (2012). Epigenetic variation creates potential for evolution of plant phenotypic plasticity. New Phytologist, 197, 314-322.

Zhang, H., Lang, Z., and Zhu, J. (2018). Dynamics and function of DNA methylation in plants. Nature Reviews, 19, 489-506.

Zhang, X., Richards, E. J., and Borevitz, J. O. (2007). Genetic and epigenetic dissection of cis regulatory variation. Current opinion in Plant Biology, 10, 142-148.

Zilberman, D., Gehring, M., Tran, R. K., Ballinger, T., and Henikoff, S. (2007). Genome-wide analysis of Arabidopsis thaliana DNA methylation uncovers an interdependence between methylation and transcription. Nature Genetics, 39, 61-69. 


\subsection{Supporting Information}

Data availability

The datasets generated for this study can be found in Dryad under: https://doi.org/10.5061/dryad.3n5tb2rcq

Table S1. List of individuals used for the laboratory work. Listed are the sampling ID, ploidy level, treatment, country, province and altitude (Schinkel et al., 2016; Klatt et al., 2018)

\begin{tabular}{|c|c|c|c|c|c|c|}
\hline $\begin{array}{c}\text { Sample } \\
\text { ID }\end{array}$ & $\begin{array}{c}\text { Leaf } \\
\text { ploidy }\end{array}$ & $\begin{array}{c}\text { Temperature } \\
\text { Treatment } \\
2016\end{array}$ & $\begin{array}{c}\text { Temperature } \\
\text { Treatment } \\
2017\end{array}$ & Country & Region & Altitude \\
\hline $3 / 2 / 3$ & diploid & cold & warm & France & $\begin{array}{l}\text { Provence- } \\
\text { Alpes-Côte } \\
\text { d'Azur }\end{array}$ & 2291 \\
\hline $23 / 4 / 1$ & diploid & cold & warm & France & $\begin{array}{l}\text { Provence- } \\
\text { Alpes-Côte } \\
\text { d'Azur }\end{array}$ & 1616 \\
\hline $24 / 4 / 3$ & diploid & cold & warm & France & $\begin{array}{l}\text { Provence- } \\
\text { Alpes-Côte } \\
\text { d'Azur }\end{array}$ & 1925 \\
\hline $25 / 3 / 2$ & diploid & cold & warm & France & $\begin{array}{l}\text { Provence- } \\
\text { Alpes-Côte } \\
\text { d'Azur }\end{array}$ & 1435 \\
\hline $26 / 3 / 3$ & diploid & cold & warm & France & $\begin{array}{l}\text { Provence- } \\
\text { Alpes-Côte } \\
\text { d'Azur }\end{array}$ & 1456 \\
\hline $27 / 2 / 1$ & diploid & cold & warm & France & $\begin{array}{l}\text { Rhônes- } \\
\text { Alpes }\end{array}$ & 1449 \\
\hline $28 / 3 / 1$ & diploid & cold & warm & Italy & Piemonte & 1685 \\
\hline $28 / 3 / 2$ & diploid & cold & warm & Italy & Piemonte & 1685 \\
\hline $29 / 1 / 2$ & diploid & cold & warm & Italy & Piemonte & 2020 \\
\hline $30 / 1 / 3$ & diploid & cold & warm & Italy & Piemonte & 1743 \\
\hline $31 / 3 / 3$ & diploid & cold & warm & Italy & Piemonte & 1937 \\
\hline $32 / 4 / 2$ & diploid & cold & warm & Italy & Piemonte & 2320 \\
\hline $33 / 3 / 3$ & diploid & cold & warm & Italy & Piemonte & 2328 \\
\hline $\begin{array}{l}112 / 3 / \\
1\end{array}$ & diploid & cold & warm & France & $\begin{array}{l}\text { Provence- } \\
\text { Alpes-Côte } \\
\text { d'Azur }\end{array}$ & 1626 \\
\hline $\begin{array}{l}112 / 3 / \\
2\end{array}$ & diploid & cold & warm & France & $\begin{array}{l}\text { Provence- } \\
\text { Alpes-Côte } \\
\text { d'Azur }\end{array}$ & 1626 \\
\hline
\end{tabular}




\begin{tabular}{|c|c|c|c|c|c|c|}
\hline $\begin{array}{l}\text { Sample } \\
\text { ID }\end{array}$ & $\begin{array}{l}\text { Leaf } \\
\text { ploidy }\end{array}$ & $\begin{array}{l}\text { Temperature } \\
\text { Treatment } \\
2016\end{array}$ & $\begin{array}{l}\text { Temperature } \\
\text { Treatment } \\
2017\end{array}$ & Country & Region & Altitude \\
\hline $\begin{array}{l}115 / 3 / \\
3\end{array}$ & diploid & cold & warm & France & $\begin{array}{l}\text { Provence- } \\
\text { Alpes-Côte } \\
\text { d'Azur }\end{array}$ & 1891 \\
\hline $\begin{array}{l}116 / 1 / \\
1\end{array}$ & diploid & cold & warm & France & $\begin{array}{l}\text { Provence- } \\
\text { Alpes-Côte } \\
\text { d'Azur }\end{array}$ & 1953 \\
\hline $\begin{array}{l}116 / 3 / \\
3\end{array}$ & diploid & cold & warm & France & $\begin{array}{l}\text { Provence- } \\
\text { Alpes-Côte } \\
\text { d'Azur }\end{array}$ & 1953 \\
\hline $\begin{array}{l}117 / 3 / \\
2\end{array}$ & diploid & cold & warm & France & $\begin{array}{l}\text { Provence- } \\
\text { Alpes-Côte } \\
\text { d'Azur }\end{array}$ & 1632 \\
\hline $\begin{array}{l}203 / 4 / \\
3\end{array}$ & diploid & cold & warm & France & $\begin{array}{l}\text { Provence- } \\
\text { Alpes-Côte } \\
\text { d'Azur }\end{array}$ & 1840 \\
\hline $\begin{array}{l}233 / 2 / \\
1\end{array}$ & diploid & cold & warm & France & $\begin{array}{l}\text { Provence- } \\
\text { Alpes-Côte } \\
\text { d'Azur }\end{array}$ & 2185 \\
\hline $\begin{array}{l}28 \mathrm{~B} / 3 / \\
1\end{array}$ & diploid & cold & warm & Italy & Piemonte & 1685 \\
\hline $\begin{array}{l}31 B / 1 / \\
3\end{array}$ & diploid & cold & warm & Italy & Piemonte & 1937 \\
\hline $\begin{array}{l}31 \mathrm{~B} / 2 / \\
2\end{array}$ & diploid & cold & warm & Italy & Piemonte & 1937 \\
\hline $\begin{array}{l}32 \mathrm{~B} / 1 / \\
2\end{array}$ & diploid & cold & warm & Italy & Piemonte & 2320 \\
\hline $17 / 4 / 3$ & $\begin{array}{l}\text { tetraploi } \\
\text { d }\end{array}$ & cold & warm & France & $\begin{array}{l}\text { Provence- } \\
\text { Alpes-Côte } \\
\text { d'Azur }\end{array}$ & 2357 \\
\hline $34 / 2 / 1$ & $\begin{array}{l}\text { tetraploi } \\
\mathrm{d}\end{array}$ & cold & warm & France & $\begin{array}{l}\text { Rhônes- } \\
\text { Alpes }\end{array}$ & 2120 \\
\hline $36 / 4 / 1$ & $\begin{array}{l}\text { tetraploi } \\
\text { d }\end{array}$ & cold & warm & France & $\begin{array}{l}\text { Rhônes- } \\
\text { Alpes }\end{array}$ & 2152 \\
\hline $37 / 1 / 2$ & $\begin{array}{l}\text { tetraploi } \\
\text { d }\end{array}$ & cold & warm & Italy & $\begin{array}{l}\text { Val } \\
\text { d'Aosta }\end{array}$ & 2115 \\
\hline $38 / 1 / 2$ & $\begin{array}{l}\text { tetraploi } \\
\text { d }\end{array}$ & cold & warm & France & $\begin{array}{l}\text { Rhônes- } \\
\text { Alpes }\end{array}$ & 2182 \\
\hline $41 / 4 / 3$ & $\begin{array}{l}\text { tetraploi } \\
\mathrm{d}\end{array}$ & cold & warm & Italy & $\begin{array}{l}\text { Val } \\
\text { d'Aosta }\end{array}$ & 2174 \\
\hline $42 / 1 / 2$ & $\begin{array}{l}\text { tetraploi } \\
\mathrm{d}\end{array}$ & cold & warm & $\begin{array}{l}\text { Switzerl } \\
\text { and }\end{array}$ & Valais & 1789 \\
\hline $47 / 3 / 3$ & $\begin{array}{l}\text { tetraploi } \\
\mathrm{d}\end{array}$ & cold & warm & $\begin{array}{l}\text { Switzerl } \\
\text { and }\end{array}$ & $\begin{array}{l}\text { Graubund } \\
\text { en }\end{array}$ & 2211 \\
\hline
\end{tabular}




\begin{tabular}{|c|c|c|c|c|c|c|}
\hline $\begin{array}{l}\text { Sample } \\
\text { ID }\end{array}$ & $\begin{array}{l}\text { Leaf } \\
\text { ploidy }\end{array}$ & $\begin{array}{l}\text { Temperature } \\
\text { Treatment } \\
2016\end{array}$ & $\begin{array}{l}\text { Temperature } \\
\text { Treatment } \\
2017\end{array}$ & Country & Region & Altitude \\
\hline $51 / 3 / 1$ & $\begin{array}{l}\text { tetraploi } \\
\text { d }\end{array}$ & cold & warm & Austria & Tirol & 2286 \\
\hline $53 / 1 / 3$ & $\begin{array}{l}\text { tetraploi } \\
\text { d }\end{array}$ & cold & warm & $\begin{array}{l}\text { Switzerl } \\
\text { and }\end{array}$ & $\begin{array}{l}\text { Graubund } \\
\text { en }\end{array}$ & 2456 \\
\hline $54 / 2 / 3$ & $\begin{array}{l}\text { tetraploi } \\
\text { d }\end{array}$ & cold & warm & Italy & Lombardia & 2303 \\
\hline $58 / 1 / 1$ & $\begin{array}{l}\text { tetraploi } \\
\mathrm{d}\end{array}$ & cold & warm & Italy & $\begin{array}{l}\text { Trentino } \\
\text { Alto } \\
\text { Adige/ } \\
\text { Südtirol }\end{array}$ & 2117 \\
\hline $58 / 3 / 3$ & $\begin{array}{l}\text { tetraploi } \\
\text { d }\end{array}$ & cold & warm & Italy & $\begin{array}{l}\text { Trentino } \\
\text { Alto } \\
\text { Adige/ } \\
\text { Südtirol }\end{array}$ & 2117 \\
\hline $74 / 1 / 2$ & $\begin{array}{l}\text { tetraploi } \\
\text { d }\end{array}$ & cold & warm & Austria & Osttirol & 2117 \\
\hline $78 / 3 / 2$ & $\begin{array}{l}\text { tetraploi } \\
\text { d }\end{array}$ & cold & warm & $\begin{array}{l}\text { Switzerl } \\
\text { and }\end{array}$ & Valais & 2000 \\
\hline $79 / 2 / 3$ & $\begin{array}{l}\text { tetraploi } \\
\text { d }\end{array}$ & cold & warm & $\begin{array}{l}\text { Switzerl } \\
\text { and }\end{array}$ & $\begin{array}{l}\text { Graubund } \\
\text { en }\end{array}$ & 2280 \\
\hline $85 / 4 / 1$ & $\begin{array}{l}\text { tetraploi } \\
\text { d }\end{array}$ & cold & warm & Austria & Kärnten & 2184 \\
\hline $88 / 3 / 1$ & $\begin{array}{l}\text { tetraploi } \\
\text { d }\end{array}$ & cold & warm & $\begin{array}{l}\text { Switzerl } \\
\text { and }\end{array}$ & $\begin{array}{l}\text { Graubund } \\
\text { en }\end{array}$ & 2300 \\
\hline $\begin{array}{l}103 / 4 / \\
2\end{array}$ & $\begin{array}{l}\text { tetraploi } \\
\text { d }\end{array}$ & cold & warm & Italy & Lombardia & 2290 \\
\hline $\begin{array}{l}106 / 4 / \\
1\end{array}$ & $\begin{array}{l}\text { tetraploi } \\
\mathrm{d}\end{array}$ & cold & warm & Italy & $\begin{array}{l}\text { Trentino } \\
\text { Alto } \\
\text { Adige/ } \\
\text { Südtirol }\end{array}$ & 2142 \\
\hline $\begin{array}{l}111 / 3 / \\
2\end{array}$ & $\begin{array}{l}\text { tetraploi } \\
\mathrm{d}\end{array}$ & cold & warm & France & $\begin{array}{l}\text { Provence- } \\
\text { Alpes-Côte } \\
\text { d'Azur }\end{array}$ & 2243 \\
\hline $\begin{array}{l}111 / 3 / \\
3\end{array}$ & $\begin{array}{l}\text { tetraploi } \\
\text { d }\end{array}$ & cold & warm & France & $\begin{array}{l}\text { Provence- } \\
\text { Alpes-Côte } \\
\text { d'Azur }\end{array}$ & 2243 \\
\hline $\begin{array}{l}116 / 4 / \\
1\end{array}$ & $\begin{array}{l}\text { tetraploi } \\
\text { d }\end{array}$ & cold & warm & France & $\begin{array}{l}\text { Provence- } \\
\text { Alpes-Côte } \\
\text { d'Azur }\end{array}$ & 1953 \\
\hline $\begin{array}{l}208 / 2 / \\
1\end{array}$ & $\begin{array}{l}\text { tetraploi } \\
\text { d }\end{array}$ & cold & warm & France & $\begin{array}{l}\text { Provence- } \\
\text { Alpes-Côte } \\
\text { d'Azur }\end{array}$ & 1924 \\
\hline
\end{tabular}




\begin{tabular}{|c|c|c|c|c|c|c|}
\hline $\begin{array}{l}\text { Sample } \\
\text { ID }\end{array}$ & $\begin{array}{l}\text { Leaf } \\
\text { ploidy }\end{array}$ & $\begin{array}{l}\text { Temperature } \\
\text { Treatment } \\
2016\end{array}$ & $\begin{array}{l}\text { Temperature } \\
\text { Treatment } \\
2017\end{array}$ & Country & Region & Altitude \\
\hline $3 \mathrm{~B} / 1 / 2$ & $\begin{array}{l}\text { tetraploi } \\
\mathrm{d}\end{array}$ & cold & warm & France & $\begin{array}{l}\text { Provence- } \\
\text { Alpes-Côte } \\
\text { d'Azur }\end{array}$ & 2291 \\
\hline $3 / 2 / 2$ & diploid & warm & cold & France & $\begin{array}{l}\text { Provence- } \\
\text { Alpes-Côte } \\
\text { d'Azur }\end{array}$ & 2291 \\
\hline $3 / 3 / 2$ & diploid & warm & cold & France & $\begin{array}{l}\text { Provence- } \\
\text { Alpes-Côte } \\
\text { d'Azur }\end{array}$ & 2291 \\
\hline $23 / 3 / 3$ & diploid & warm & cold & France & $\begin{array}{l}\text { Provence- } \\
\text { Alpes-Côte } \\
\text { d'Azur }\end{array}$ & 1616 \\
\hline $24 / 1 / 2$ & diploid & warm & cold & France & $\begin{array}{l}\text { Provence- } \\
\text { Alpes-Côte } \\
\text { d'Azur }\end{array}$ & 1925 \\
\hline $25 / 1 / 3$ & diploid & warm & cold & France & $\begin{array}{l}\text { Provence- } \\
\text { Alpes-Côte } \\
\text { d'Azur }\end{array}$ & 1435 \\
\hline $26 / 4 / 1$ & diploid & warm & cold & France & $\begin{array}{l}\text { Provence- } \\
\text { Alpes-Côte } \\
\text { d'Azur }\end{array}$ & 1456 \\
\hline $27 / 2 / 2$ & diploid & warm & cold & France & $\begin{array}{l}\text { Rhônes- } \\
\text { Alpes }\end{array}$ & 1449 \\
\hline $28 / 2 / 3$ & diploid & warm & cold & Italy & Piemonte & 1685 \\
\hline $29 / 4 / 2$ & diploid & warm & cold & Italy & Piemonte & 2020 \\
\hline $30 / 1 / 2$ & diploid & warm & cold & Italy & Piemonte & 1743 \\
\hline $31 / 2 / 3$ & diploid & warm & cold & Italy & Piemonte & 1937 \\
\hline $32 / 3 / 3$ & diploid & warm & cold & Italy & Piemonte & 2320 \\
\hline $33 / 4 / 2$ & diploid & warm & cold & Italy & Piemonte & 2328 \\
\hline $\begin{array}{l}112 / 1 / \\
2\end{array}$ & diploid & warm & cold & France & $\begin{array}{l}\text { Provence- } \\
\text { Alpes-Côte } \\
\text { d'Azur }\end{array}$ & 1626 \\
\hline $\begin{array}{l}115 / 4 / \\
2\end{array}$ & diploid & warm & cold & France & $\begin{array}{l}\text { Provence- } \\
\text { Alpes-Côte } \\
\text { d'Azur }\end{array}$ & 1891 \\
\hline $\begin{array}{l}116 / 1 / \\
3\end{array}$ & diploid & warm & cold & France & $\begin{array}{l}\text { Provence- } \\
\text { Alpes-Côte } \\
\text { d'Azur }\end{array}$ & 1953 \\
\hline $\begin{array}{l}116 / 3 / \\
1\end{array}$ & diploid & warm & cold & France & $\begin{array}{l}\text { Provence- } \\
\text { Alpes-Côte } \\
\text { d'Azur }\end{array}$ & 1953 \\
\hline
\end{tabular}




\begin{tabular}{|c|c|c|c|c|c|c|}
\hline $\begin{array}{l}\text { Sample } \\
\text { ID }\end{array}$ & $\begin{array}{l}\text { Leaf } \\
\text { ploidy }\end{array}$ & $\begin{array}{l}\text { Temperature } \\
\text { Treatment } \\
2016\end{array}$ & $\begin{array}{l}\text { Temperature } \\
\text { Treatment } \\
2017\end{array}$ & Country & Region & Altitude \\
\hline $\begin{array}{l}117 / 3 / \\
3\end{array}$ & diploid & warm & cold & France & $\begin{array}{l}\text { Provence- } \\
\text { Alpes-Côte } \\
\text { d'Azur }\end{array}$ & 1632 \\
\hline $\begin{array}{l}202 / 3 / \\
3\end{array}$ & diploid & warm & cold & France & $\begin{array}{l}\text { Provence- } \\
\text { Alpes-Côte } \\
\text { d'Azur }\end{array}$ & 1829 \\
\hline $\begin{array}{l}203 / 2 / \\
2\end{array}$ & diploid & warm & cold & France & $\begin{array}{l}\text { Provence- } \\
\text { Alpes-Côte } \\
\text { d'Azur }\end{array}$ & 1840 \\
\hline $\begin{array}{l}233 / 2 / \\
3\end{array}$ & diploid & warm & cold & France & $\begin{array}{l}\text { Provence- } \\
\text { Alpes-Côte } \\
\text { d'Azur }\end{array}$ & 2185 \\
\hline $\begin{array}{l}28 \mathrm{~B} / 1 / \\
2\end{array}$ & diploid & warm & cold & Italy & Piemonte & 1685 \\
\hline $\begin{array}{l}31 \mathrm{~B} / 3 / \\
3\end{array}$ & diploid & warm & cold & Italy & Piemonte & 1937 \\
\hline $\begin{array}{l}32 \mathrm{~B} / 1 / \\
1\end{array}$ & diploid & warm & cold & Italy & Piemonte & 2320 \\
\hline $\begin{array}{l}32 \mathrm{~B} / 2 / \\
1\end{array}$ & diploid & warm & cold & Italy & Piemonte & 2320 \\
\hline $17 / 4 / 2$ & $\begin{array}{l}\text { tetraploi } \\
\text { d }\end{array}$ & warm & cold & France & $\begin{array}{l}\text { Provence- } \\
\text { Alpes-Côte } \\
\text { d'Azur }\end{array}$ & 2357 \\
\hline $34 / 1 / 1$ & $\begin{array}{l}\text { tetraploi } \\
\mathrm{d}\end{array}$ & warm & cold & France & $\begin{array}{l}\text { Rhônes- } \\
\text { Alpes }\end{array}$ & 2120 \\
\hline $36 / 2 / 1$ & $\begin{array}{l}\text { tetraploi } \\
\text { d }\end{array}$ & warm & cold & France & $\begin{array}{l}\text { Rhônes- } \\
\text { Alpes }\end{array}$ & 2152 \\
\hline $37 / 4 / 1$ & $\begin{array}{l}\text { tetraploi } \\
\mathrm{d}\end{array}$ & warm & cold & Italy & $\begin{array}{l}\text { Val } \\
\text { d'Aosta }\end{array}$ & 2115 \\
\hline $40 / 3 / 1$ & $\begin{array}{l}\text { tetraploi } \\
\mathrm{d}\end{array}$ & warm & cold & $\begin{array}{l}\text { Switzerl } \\
\text { and }\end{array}$ & Valais & 1860 \\
\hline $41 / 2 / 2$ & $\begin{array}{l}\text { tetraploi } \\
\text { d }\end{array}$ & warm & cold & Italy & $\begin{array}{l}\text { Val } \\
\text { d'Aosta }\end{array}$ & 2174 \\
\hline $42 / 3 / 2$ & $\begin{array}{l}\text { tetraploi } \\
\text { d }\end{array}$ & warm & cold & $\begin{array}{l}\text { Switzerl } \\
\text { and }\end{array}$ & Valais & 1789 \\
\hline $45 / 1 / 2$ & $\begin{array}{l}\text { tetraploi } \\
\text { d }\end{array}$ & warm & cold & $\begin{array}{l}\text { Switzerl } \\
\text { and }\end{array}$ & Valais & 2400 \\
\hline $47 / 2 / 2$ & $\begin{array}{l}\text { tetraploi } \\
\mathrm{d}\end{array}$ & warm & cold & $\begin{array}{l}\text { Switzerl } \\
\text { and }\end{array}$ & $\begin{array}{l}\text { Graubund } \\
\text { en }\end{array}$ & 2211 \\
\hline $48 / 4 / 2$ & $\begin{array}{l}\text { tetraploi } \\
\text { d }\end{array}$ & warm & cold & $\begin{array}{l}\text { Switzerl } \\
\text { and }\end{array}$ & $\begin{array}{l}\text { Graubund } \\
\text { en }\end{array}$ & 2262 \\
\hline $50 / 2 / 1$ & $\begin{array}{l}\text { tetraploi } \\
\mathrm{d}\end{array}$ & warm & cold & $\begin{array}{l}\text { Switzerl } \\
\text { and }\end{array}$ & $\begin{array}{l}\text { Graubund } \\
\text { en }\end{array}$ & 2322 \\
\hline
\end{tabular}




\begin{tabular}{|c|c|c|c|c|c|c|}
\hline $\begin{array}{l}\text { Sample } \\
\text { ID }\end{array}$ & $\begin{array}{l}\text { Leaf } \\
\text { ploidy }\end{array}$ & $\begin{array}{l}\text { Temperature } \\
\text { Treatment } \\
2016\end{array}$ & $\begin{array}{l}\text { Temperature } \\
\text { Treatment } \\
2017\end{array}$ & Country & Region & Altitude \\
\hline $53 / 3 / 1$ & $\begin{array}{l}\text { tetraploi } \\
\text { d }\end{array}$ & warm & cold & $\begin{array}{l}\text { Switzerl } \\
\text { and }\end{array}$ & $\begin{array}{l}\text { Graubund } \\
\text { en }\end{array}$ & 2456 \\
\hline $54 / 2 / 2$ & $\begin{array}{l}\text { tetraploi } \\
\text { d }\end{array}$ & warm & cold & Italy & Lombardia & 2303 \\
\hline $55 / 3 / 1$ & $\begin{array}{l}\text { tetraploi } \\
\text { d }\end{array}$ & warm & cold & Austria & Tirol & 2557 \\
\hline $58 / 1 / 3$ & $\begin{array}{l}\text { tetraploi } \\
\mathrm{d}\end{array}$ & warm & cold & Italy & $\begin{array}{l}\text { Trentino } \\
\text { Alto } \\
\text { Adige/ } \\
\text { Südtirol }\end{array}$ & 2117 \\
\hline $66 / 2 / 2$ & $\begin{array}{l}\text { tetraploi } \\
\mathrm{d}\end{array}$ & warm & cold & Italy & $\begin{array}{l}\text { Trentino } \\
\text { Alto } \\
\text { Adige/ } \\
\text { Südtirol }\end{array}$ & 2101 \\
\hline $79 / 3 / 3$ & $\begin{array}{l}\text { tetraploi } \\
\text { d }\end{array}$ & warm & cold & $\begin{array}{l}\text { Switzerl } \\
\text { and }\end{array}$ & $\begin{array}{l}\text { Graubund } \\
\text { en }\end{array}$ & 2280 \\
\hline $82 / 3 / 3$ & $\begin{array}{l}\text { tetraploi } \\
\mathrm{d}\end{array}$ & warm & cold & Italy & Lombardia & 2500 \\
\hline $83 / 3 / 1$ & $\begin{array}{l}\text { tetraploi } \\
\text { d }\end{array}$ & warm & cold & Austria & Osttirol & 2271 \\
\hline $84 / 4 / 2$ & $\begin{array}{l}\text { tetraploi } \\
\text { d }\end{array}$ & warm & cold & Austria & Kärnten & 2236 \\
\hline $90 / 2 / 3$ & $\begin{array}{l}\text { tetraploi } \\
\text { d }\end{array}$ & warm & cold & $\begin{array}{l}\text { Switzerl } \\
\text { and }\end{array}$ & Valais & 2477 \\
\hline $96 / 2 / 3$ & $\begin{array}{l}\text { tetraploi } \\
\text { d }\end{array}$ & warm & cold & France & $\begin{array}{l}\text { Provence- } \\
\text { Alpes-Côte } \\
\text { d'Azur }\end{array}$ & 2300 \\
\hline $\begin{array}{l}106 / 2 / \\
3\end{array}$ & $\begin{array}{l}\text { tetraploi } \\
\mathrm{d}\end{array}$ & warm & cold & Italy & $\begin{array}{l}\text { Trentino } \\
\text { Alto } \\
\text { Adige/ } \\
\text { Südtirol }\end{array}$ & 2142 \\
\hline $\begin{array}{l}108 / 3 / \\
3\end{array}$ & $\begin{array}{l}\text { tetraploi } \\
\mathrm{d}\end{array}$ & warm & cold & $\begin{array}{l}\text { Switzerl } \\
\text { and }\end{array}$ & $\begin{array}{l}\text { Graubund } \\
\text { en }\end{array}$ & 2171 \\
\hline $\begin{array}{l}111 / 2 / \\
3\end{array}$ & $\begin{array}{l}\text { tetraploi } \\
\text { d }\end{array}$ & warm & cold & France & $\begin{array}{l}\text { Provence- } \\
\text { Alpes-Côte } \\
\text { d'Azur }\end{array}$ & 2243 \\
\hline
\end{tabular}


Table S2. The parameters, which were chosen for each dye run in RawGeno, with regard to an optimized dataset for each year. Listed are minimum and maximum bin width (bp), Relative Fluorescence Units (RFU), number of bins (nbin), reproducibility threshold (thresh), bin reproducibility (reprd), error rate (ErrBonin) and polymorphy rate (Pol).

\begin{tabular}{cccccccccc}
\hline $\begin{array}{l}\text { Colour } \\
\text { dye }\end{array}$ & $\begin{array}{l}\text { Year of } \\
\text { data }\end{array}$ & minbin & maxbin & rfu & thresh & nbin & BinReprod & ErrBonin & Pol \\
\hline $\begin{array}{c}\text { Blue } \\
\text { (FAM) }\end{array}$ & 2016 & 1.5 & 1.7 & 175 & 75 & 120 & 31.56 & 0.15 & 0.68 \\
& 2017 & 1.6 & 2.1 & 100 & 75 & 198 & 6.51 & 0.05 & 0.38 \\
\cline { 2 - 9 } $\begin{array}{l}\text { Green } \\
\text { (HEX) }\end{array}$ & 2016 & 1.6 & 1.8 & 150 & 75 & 110 & 27.85 & 0.16364 & 0.74 \\
& 2017 & 1.7 & 2.1 & 150 & 75 & 137 & 9.3 & 0.06 & 0.42 \\
\hline $\begin{array}{l}\text { Yellow } \\
\text { (NED) }\end{array}$ & 2016 & 1.7 & 1.8 & 150 & 75 & 105 & 31.67 & 0.15238 & 0.73 \\
\hline
\end{tabular}


Table S3. The arcsine transformed percentages of polymorphic epiloci of the 4 groups for 2016 \& 2017 treatment years. The data in the current table were used for treatment years' boxplots and for pairwise comparisons of the same R. kuepferi individuals through the two treatment years.

\begin{tabular}{|c|c|c|c|c|c|}
\hline Group & Year & SampleID & Externally-methylated & Internally-methylated & Non-methylated \\
\hline D2 & 2017 & 112_1_2 & 2.73 & 3.23 & 3.47 \\
\hline D2 & 2017 & $115 \_4 \_2$ & 2.22 & 3.23 & 1.57 \\
\hline D2 & 2017 & 116_1_3 & 1.86 & 2.32 & 2.45 \\
\hline D2 & 2017 & 116_3_1 & 2.86 & 3.46 & 3.32 \\
\hline D2 & 2017 & 117_3_3 & 2.42 & 2.6 & 1.57 \\
\hline D2 & 2017 & 202_3_3 & 1.96 & 2.82 & 2.63 \\
\hline D2 & 2017 & 203_2_2 & 1.96 & 2.82 & 2.45 \\
\hline D2 & 2017 & 23_3_3 & 2.14 & 0 & 1.57 \\
\hline D2 & 2017 & 233_2_3 & 3.25 & 2.92 & 3.61 \\
\hline D2 & 2017 & 24_1_2 & 3.45 & 0 & 1.57 \\
\hline D2 & 2017 & 25_1_3 & 2.22 & 2.72 & 1.95 \\
\hline D2 & 2017 & 26_4_1 & 2.82 & 3.01 & 3.03 \\
\hline D2 & 2017 & 27_2_2 & 2.94 & 1.93 & 1.95 \\
\hline D2 & 2017 & 28_2_3 & 3.14 & 2.47 & 1.95 \\
\hline D2 & 2017 & 28B_1_2 & 2.36 & 3.09 & 3.14 \\
\hline D2 & 2017 & 29_4_2 & 1.48 & 2.47 & 0.98 \\
\hline D2 & 2017 & 3_2_2 & 0.34 & 2.32 & 2.63 \\
\hline D2 & 2017 & 3_3_2 & 0 & 0 & 2.63 \\
\hline D2 & 2017 & 30_1_2 & 2.97 & 2.47 & 1.57 \\
\hline D2 & 2017 & 31_2_3 & 2.9 & 2.32 & 1.95 \\
\hline D2 & 2017 & $\begin{array}{l}\text { 31B/32B_2 } \\
1\end{array}$ & 1.86 & 2.72 & 1.95 \\
\hline D2 & 2017 & 31B_3_3 & 1.75 & 3.23 & 2.92 \\
\hline D2 & 2017 & 32_3_3 & 2.05 & 2.32 & 0.98 \\
\hline D2 & 2017 & 32B_1_1 & 3.2 & 2.72 & 2.63 \\
\hline D2 & 2017 & 33_4_2 & 2.29 & 3.23 & 0.98 \\
\hline $\mathrm{T} 2$ & 2017 & 106_2_3 & 3.38 & 0 & 1.57 \\
\hline $\mathrm{T} 2$ & 2017 & 108_3_3 & 3.14 & 0 & 1.57 \\
\hline $\mathrm{T} 2$ & 2017 & 111_2_3 & 3.45 & 0 & 1.57 \\
\hline $\mathrm{T} 2$ & 2017 & 17_4_2 & 0.34 & 0.76 & 2.45 \\
\hline $\mathrm{T} 2$ & 2017 & 36_2_1 & 3.86 & 0.76 & 1.57 \\
\hline $\mathrm{T} 2$ & 2017 & 37_4_1 & 3.72 & 0 & 1.57 \\
\hline $\mathrm{T} 2$ & 2017 & 40_3_1 & 2.42 & 1.65 & 1.57 \\
\hline $\mathrm{T} 2$ & 2017 & 41_2_2 & 1.32 & 1.93 & 1.57 \\
\hline $\mathrm{T} 2$ & 2017 & 42_3_2 & 2.29 & 2.6 & 1.57 \\
\hline $\mathrm{T} 2$ & 2017 & 45_1_2 & 2.9 & 1.65 & 1.57 \\
\hline $\mathrm{T} 2$ & 2017 & 47_2_2 & 3.11 & 1.93 & 1.57 \\
\hline
\end{tabular}




\begin{tabular}{|c|c|c|c|c|c|}
\hline Group & Year & SampleID & Externally-methylated & Internally-methylated & Non-methylated \\
\hline $\mathrm{T} 2$ & 2017 & $48 \_4 \_2$ & 2.64 & 1.93 & 1.57 \\
\hline $\mathrm{T} 2$ & 2017 & 50_2_1 & 3.07 & 3.61 & 2.23 \\
\hline $\mathrm{T} 2$ & 2017 & 53_3_1 & 2.54 & 1.93 & 4.05 \\
\hline $\mathrm{T} 2$ & 2017 & $54 \_2 \_2$ & 2.78 & 1.29 & 1.57 \\
\hline $\mathrm{T} 2$ & 2017 & 55_3_1 & 2.36 & 0.76 & 1.57 \\
\hline $\mathrm{T} 2$ & 2017 & 58_1_3 & 2.14 & 2.47 & 1.57 \\
\hline $\mathrm{T} 2$ & 2017 & $66 \_2 \_2$ & 3.11 & 0.76 & 1.57 \\
\hline $\mathrm{T} 2$ & 2017 & 79_3_3 & 3.57 & 3.35 & 1.95 \\
\hline $\mathrm{T} 2$ & 2017 & 82_3_3 & 2.9 & 0 & 1.57 \\
\hline $\mathrm{T} 2$ & 2017 & 83_3_1 & 2.05 & 0 & 1.57 \\
\hline $\mathrm{T} 2$ & 2017 & $84 \_4 \_2$ & 3.25 & 0 & 1.57 \\
\hline $\mathrm{T} 2$ & 2017 & $90 \_2 \_3$ & 3.2 & 0 & 1.57 \\
\hline $\mathrm{T} 2$ & 2017 & 96_2_3 & 3.3 & 0.76 & 1.57 \\
\hline D1 & 2017 & 112_3_1 & 3.4 & 2.32 & 2.63 \\
\hline D1 & 2017 & 112_3_2 & 3.2 & 3.09 & 0.98 \\
\hline D1 & 2017 & 115_3_3 & 3.14 & 2.82 & 2.23 \\
\hline D1 & 2017 & 116_1_1 & 2.97 & 2.6 & 1.57 \\
\hline D1 & 2017 & 116_3_3 & 2.14 & 2.32 & 0.98 \\
\hline D1 & 2017 & 117_3_2 & 1.32 & 2.6 & 0.98 \\
\hline D1 & 2017 & 203_4_3 & 2.42 & 2.32 & 1.95 \\
\hline D1 & 2017 & 23_4_1 & 0.34 & 2.32 & 1.95 \\
\hline D1 & 2017 & 233_2_1 & 1.48 & 2.14 & 4.13 \\
\hline D1 & 2017 & 24_4__3 & 1.13 & 1.93 & 1.57 \\
\hline D1 & 2017 & 25_3_2 & 1.96 & 1.93 & 1.57 \\
\hline D1 & 2017 & 26_3_3 & 3.38 & 1.65 & 2.45 \\
\hline D1 & 2017 & 27_2_1 & 3.01 & 2.82 & 1.95 \\
\hline D1 & 2017 & 28_3_1 & 3.55 & 2.32 & 1.57 \\
\hline D1 & 2017 & 28_3_2 & 1.48 & 1.93 & 1.57 \\
\hline D1 & 2017 & 28B_3_1 & 2.05 & 0.76 & 3.88 \\
\hline D1 & 2017 & 29_1_2 & 2.69 & 1.29 & 4.05 \\
\hline D1 & 2017 & 3_2_3 & 2.22 & 2.92 & 2.23 \\
\hline D1 & 2017 & 30_1_3 & 0.65 & 1.65 & 1.57 \\
\hline D1 & 2017 & 31_3_3 & 1.75 & 3.09 & 3.78 \\
\hline D1 & 2017 & $\begin{array}{l}\text { 31B/32B_2 } \\
2\end{array}$ & 1.62 & 1.65 & 1.57 \\
\hline D1 & 2017 & 31B_1_3 & 1.32 & 1.65 & 1.57 \\
\hline D1 & 2017 & 32_4_2 & 1.13 & 2.47 & 2.23 \\
\hline D1 & 2017 & 32B_1_2 & 1.32 & 2.32 & 1.95 \\
\hline D1 & 2017 & 33_3_3 & 0.34 & 1.65 & 1.57 \\
\hline $\mathrm{T} 1$ & 2017 & 103_4_2 & 2.86 & 2.47 & 1.57 \\
\hline $\mathrm{T} 1$ & 2017 & 106_4_1 & 2.69 & 0.76 & 1.57 \\
\hline $\mathrm{T} 1$ & 2017 & 111_3_2 & 2.9 & 0.76 & 3.78 \\
\hline
\end{tabular}




\begin{tabular}{|c|c|c|c|c|c|}
\hline Group & Year & SampleID & Externally-methylated & Internally-methylated & Non-methylated \\
\hline $\mathrm{T} 1$ & 2017 & 111_3_3 & 2.69 & 0 & 1.57 \\
\hline $\mathrm{T} 1$ & 2017 & 116_4_1 & 3.01 & 0 & 1.57 \\
\hline $\mathrm{T} 1$ & 2017 & 17_4_3 & 3.38 & 2.47 & 2.78 \\
\hline $\mathrm{T} 1$ & 2017 & 208_2_1 & 2.22 & 0 & 1.57 \\
\hline $\mathrm{T} 1$ & 2017 & 34_2_1 & 3.04 & 2.32 & 2.23 \\
\hline $\mathrm{T} 1$ & 2017 & 36_4_1 & 2.69 & 1.65 & 3.83 \\
\hline $\mathrm{T} 1$ & 2017 & 37_1_2 & 1.86 & 0.76 & 1.57 \\
\hline $\mathrm{T} 1$ & 2017 & 38_1_2 & 3.8 & 2.47 & 1.57 \\
\hline $\mathrm{T} 1$ & 2017 & 3B_1_2 & 2.78 & 0 & 1.57 \\
\hline $\mathrm{T} 1$ & 2017 & 41_4_3 & 3.81 & 3.01 & 1.57 \\
\hline $\mathrm{T} 1$ & 2017 & 42_1_2 & 3.45 & 2.92 & 2.23 \\
\hline $\mathrm{T} 1$ & 2017 & 47_3_3 & 2.42 & 1.65 & 1.57 \\
\hline $\mathrm{T} 1$ & 2017 & 51_3_1 & 2.64 & 1.65 & 1.57 \\
\hline $\mathrm{T} 1$ & 2017 & 53_1_3 & 2.48 & 1.65 & 1.57 \\
\hline $\mathrm{T} 1$ & 2017 & 54_2_3 & 1.32 & 1.93 & 1.57 \\
\hline $\mathrm{T} 1$ & 2017 & 58_1_1 & 2.73 & 1.65 & 1.95 \\
\hline $\mathrm{T} 1$ & 2017 & 58_3_3 & 1.96 & 1.65 & 1.95 \\
\hline $\mathrm{T} 1$ & 2017 & 74_1_2 & 2.73 & 1.93 & 1.57 \\
\hline $\mathrm{T} 1$ & 2017 & 78_3_2 & 2.42 & 1.93 & 3.92 \\
\hline $\mathrm{T} 1$ & 2017 & 79_2_3 & 2.42 & 1.65 & 4.09 \\
\hline $\mathrm{T} 1$ & 2017 & 85_4_1 & 2.36 & 1.29 & 1.57 \\
\hline $\mathrm{T} 1$ & 2017 & 88_3_1 & 1.75 & 0.76 & 1.57 \\
\hline D1 & 2016 & 112_3_1 & 1.43 & 2.17 & 2.17 \\
\hline D1 & 2016 & 112_3_2 & 2.33 & 3.13 & 3.13 \\
\hline D1 & 2016 & 115_3_3 & 1.97 & 1.24 & 1.24 \\
\hline D1 & 2016 & 116_1_1 & 1.43 & 1.74 & 1.74 \\
\hline D1 & 2016 & 116_3_3 & 2.08 & 2.6 & 2.6 \\
\hline D1 & 2016 & 117_3_2 & 1.59 & 3.02 & 3.02 \\
\hline D1 & 2016 & 203_4_3 & 1.86 & 3.63 & 3.63 \\
\hline D1 & 2016 & 23_4_1 & 1.59 & 3.71 & 3.71 \\
\hline D1 & 2016 & 233_2_1 & 2.25 & 3.94 & 3.94 \\
\hline D1 & 2016 & $24 \_4 \_3$ & 1.86 & 3.4 & 3.4 \\
\hline D1 & 2016 & 25_3_2 & 1.59 & 3.57 & 3.57 \\
\hline D1 & 2016 & 26_3_3 & 1.73 & 4.23 & 4.23 \\
\hline D1 & 2016 & 27_2_1 & 1.97 & 2.17 & 2.17 \\
\hline D1 & 2016 & 28_3_1 & 1 & 2.9 & 2.9 \\
\hline D1 & 2016 & 28_3_2 & 0.72 & 1.59 & 1.59 \\
\hline D1 & 2016 & 28B_3_1 & 2.33 & 3.5 & 3.5 \\
\hline D1 & 2016 & 29_1_2 & 1.97 & 1.43 & 1.43 \\
\hline D1 & 2016 & 3_2_3 & 2.08 & 4.12 & 4.12 \\
\hline D1 & 2016 & 30_1_3 & 1.59 & 3.45 & 3.45 \\
\hline D1 & 2016 & 31_3_3 & 1.23 & 3.89 & 3.89 \\
\hline
\end{tabular}




\begin{tabular}{|c|c|c|c|c|c|}
\hline Group & Year & SampleID & Externally-methylated & Internally-methylated & Non-methylated \\
\hline D1 & 2016 & $\begin{array}{l}\text { 31B/32B_2 } \\
2\end{array}$ & 2.65 & 4 & 4 \\
\hline D1 & 2016 & 31B_1_3 & 3.78 & 1.74 & 1.74 \\
\hline D1 & 2016 & 32_4_2 & 1.97 & 3.2 & 3.2 \\
\hline D1 & 2016 & 32B_1_2 & 2.08 & 3.2 & 3.2 \\
\hline D1 & 2016 & 33_3_3 & 1.86 & 3.67 & 3.67 \\
\hline $\mathrm{T} 1$ & 2016 & $103 \_4 \_2$ & 3.87 & 3.2 & 3.2 \\
\hline $\mathrm{T} 1$ & 2016 & 106_4_1 & 3.5 & 3.79 & 3.79 \\
\hline $\mathrm{T} 1$ & 2016 & 111_3_2 & 3.92 & 2.76 & 2.76 \\
\hline $\mathrm{T} 1$ & 2016 & 111_3_3 & 2.76 & 3.73 & 3.73 \\
\hline $\mathrm{T} 1$ & 2016 & 116_4_1 & 3.09 & 3.69 & 3.69 \\
\hline $\mathrm{T} 1$ & 2016 & 17_4_3 & 1.59 & 4.38 & 4.38 \\
\hline $\mathrm{T} 1$ & 2016 & 208_2_1 & 3.22 & 3.9 & 3.9 \\
\hline $\mathrm{T} 1$ & 2016 & 34_2_1 & 2.6 & 3.95 & 3.95 \\
\hline $\mathrm{T} 1$ & 2016 & 36_4_1 & 3.13 & 3.65 & 3.65 \\
\hline $\mathrm{T} 1$ & 2016 & 37_1_2 & 3.59 & 3.73 & 3.73 \\
\hline $\mathrm{T} 1$ & 2016 & 38_1_2 & 2.25 & 3.69 & 3.69 \\
\hline $\mathrm{T} 1$ & 2016 & 3B_1_2 & 2.65 & 3.61 & 3.61 \\
\hline $\mathrm{T} 1$ & 2016 & 41_4_3 & 3.31 & 3.67 & 3.67 \\
\hline $\mathrm{T} 1$ & 2016 & 42_1_2 & 3.5 & 3.35 & 3.35 \\
\hline $\mathrm{T} 1$ & 2016 & 47_3_3 & 3.4 & 3.59 & 3.59 \\
\hline $\mathrm{T} 1$ & 2016 & 51_3_1 & 3.19 & 3.84 & 3.84 \\
\hline $\mathrm{T} 1$ & 2016 & 53_1_3 & 3.06 & 3.89 & 3.89 \\
\hline $\mathrm{T} 1$ & 2016 & 54_2_3 & 3.54 & 3.59 & 3.59 \\
\hline $\mathrm{T} 1$ & 2016 & 58_1_1 & 2.85 & 4.12 & 4.12 \\
\hline $\mathrm{T} 1$ & 2016 & 58_3_3 & 3.16 & 3.73 & 3.73 \\
\hline $\mathrm{T} 1$ & 2016 & 74_1_2 & 3.87 & 3.2 & 3.2 \\
\hline $\mathrm{T} 1$ & 2016 & 78_3_2 & 3.16 & 3.94 & 3.94 \\
\hline $\mathrm{T} 1$ & 2016 & 79_2_3 & 2.33 & 3.89 & 3.89 \\
\hline $\mathrm{T} 1$ & 2016 & 85_4_1 & 3.22 & 3.61 & 3.61 \\
\hline $\mathrm{T} 1$ & 2016 & 88_3_1 & 2.71 & 3.8 & 3.8 \\
\hline D2 & 2016 & 112_1_2 & 1.23 & 1.74 & 1.74 \\
\hline D2 & 2016 & 115_4_2 & 2.81 & 3.37 & 3.37 \\
\hline $\mathrm{D} 2$ & 2016 & 116_1_3 & 1.23 & 2.81 & 2.81 \\
\hline D2 & 2016 & 116_3_1 & 1.59 & 3.37 & 3.37 \\
\hline D2 & 2016 & 117_3_3 & 1.73 & 3.57 & 3.57 \\
\hline D2 & 2016 & 202_3_3 & 0.38 & 2.08 & 2.08 \\
\hline D2 & 2016 & 203_2_2 & 2.71 & 3.98 & 3.98 \\
\hline D2 & 2016 & 23_3_3 & 1.86 & 3.69 & 3.69 \\
\hline D2 & 2016 & 233_2_3 & 3.06 & 3.45 & 3.45 \\
\hline D2 & 2016 & 24_1_2 & 2.33 & 3.73 & 3.73 \\
\hline D2 & 2016 & 25_1_3 & 2.47 & 3.61 & 3.61 \\
\hline
\end{tabular}




\begin{tabular}{|c|c|c|c|c|c|}
\hline Group & Year & SampleID & Externally-methylated & Internally-methylated & Non-methylated \\
\hline D2 & 2016 & 26_4_1 & 2.54 & 2.76 & 2.76 \\
\hline D2 & 2016 & 27_2_2 & 3.75 & 2.81 & 2.81 \\
\hline D2 & 2016 & 28_2_3 & 2.47 & 3.87 & 3.87 \\
\hline $\mathrm{D} 2$ & 2016 & 28B_1_2 & 2.17 & 4.16 & 4.16 \\
\hline D2 & 2016 & $29 \_4 \_2$ & 2.4 & 3.52 & 3.52 \\
\hline D2 & 2016 & 3_2_2 & 3.61 & 3.29 & 3.29 \\
\hline D2 & 2016 & 3_3_2 & 3.06 & 3.65 & 3.65 \\
\hline $\mathrm{D} 2$ & 2016 & 30_1_2 & 3.16 & 3.35 & 3.35 \\
\hline D2 & 2016 & 31_2_3 & 2.81 & 3.69 & 3.69 \\
\hline D2 & 2016 & 31B_3_3 & 2.17 & 4.23 & 4.23 \\
\hline D2 & 2016 & 32_3_3 & 1.59 & 2.54 & 2.54 \\
\hline D2 & 2016 & $\begin{array}{l}\text { 32B/31B_2 } \\
1\end{array}$ & 2.54 & 3.65 & 3.65 \\
\hline D2 & 2016 & 32B_1_1 & 2.65 & 3.89 & 3.89 \\
\hline $\mathrm{D} 2$ & 2016 & 33_4_2 & 3.19 & 3.71 & 3.71 \\
\hline $\mathrm{T} 2$ & 2016 & 106_2_3 & 2.71 & 4.01 & 4.01 \\
\hline $\mathrm{T} 2$ & 2016 & 108_3_3 & 2.4 & 4.07 & 4.07 \\
\hline $\mathrm{T} 2$ & 2016 & 111_2_3 & 3.56 & 3.1 & 3.1 \\
\hline $\mathrm{T} 2$ & 2016 & 17_4_2 & 1.97 & 2.98 & 2.98 \\
\hline $\mathrm{T} 2$ & 2016 & 36_2_1 & 3.76 & 3.35 & 3.35 \\
\hline $\mathrm{T} 2$ & 2016 & 37_4_1 & 2.9 & 3.82 & 3.82 \\
\hline $\mathrm{T} 2$ & 2016 & 40_3_1 & 3.37 & 3.35 & 3.35 \\
\hline $\mathrm{T} 2$ & 2016 & 41_2_2 & 3.16 & 3.73 & 3.73 \\
\hline $\mathrm{T} 2$ & 2016 & 42_3_2 & 3.42 & 3.32 & 3.32 \\
\hline $\mathrm{T} 2$ & 2016 & 45_1_2 & 3.06 & 3.45 & 3.45 \\
\hline $\mathrm{T} 2$ & 2016 & 47_2_2 & 3.22 & 3.35 & 3.35 \\
\hline $\mathrm{T} 2$ & 2016 & 48_4_2 & 3.5 & 3.61 & 3.61 \\
\hline $\mathrm{T} 2$ & 2016 & 50_2_1 & 2.76 & 3.8 & 3.8 \\
\hline $\mathrm{T} 2$ & 2016 & 53_3_1 & 2.71 & 3.92 & 3.92 \\
\hline $\mathrm{T} 2$ & 2016 & $54 \_2 \_2$ & 2.81 & 3.75 & 3.75 \\
\hline $\mathrm{T} 2$ & 2016 & 55_3_1 & 3.28 & 3.23 & 3.23 \\
\hline $\mathrm{T} 2$ & 2016 & 58_1_3 & 2.85 & 3.9 & 3.9 \\
\hline $\mathrm{T} 2$ & 2016 & 66_2_2 & 2.6 & 3.73 & 3.73 \\
\hline $\mathrm{T} 2$ & 2016 & 79_3_3 & 2.25 & 4.12 & 4.12 \\
\hline $\mathrm{T} 2$ & 2016 & 82_3_3 & 3.09 & 3.77 & 3.77 \\
\hline $\mathrm{T} 2$ & 2016 & 83_3_1 & 2.65 & 4.19 & 4.19 \\
\hline $\mathrm{T} 2$ & 2016 & $84 \_4 \_2$ & 2.33 & 4.3 & 4.3 \\
\hline $\mathrm{T} 2$ & 2016 & 90_2_3 & 3.28 & 3.8 & 3.8 \\
\hline $\mathrm{T} 2$ & 2016 & 96_2_3 & 2.47 & 4.19 & 4.19 \\
\hline
\end{tabular}




\title{
Chapter 3
}

Phenotypic responses, reproduction mode and epigenetic patterns under temperature treatments in the alpine plant species Ranunculus kuepferi (Ranunculaceae)

Eleni Syngelaki, Mareike Daubert, Simone Klatt and Elvira Hörandl

Published in Biology (2020), 9 (10), 315.

DOI 10.3390/biology9100315

\begin{abstract}
Plant life in alpine habitats is shaped by harsh abiotic conditions and cold climates. Phenotypic variation of morphological characters and reproduction can be influenced by temperature stress. Nevertheless, little is known about the performance of different cytotypes under cold stress and how epigenetic patterns could relate to phenotypic variation. Ranunculus kuepferi, a perennial alpine plant, served as a model system for testing the effect of cold stress on phenotypic plasticity, reproduction mode, and epigenetic variation.
\end{abstract}

Diploid and autotetraploid individuals were placed in climate growth cabinets under warm and cold conditions. Morphological traits (height, leaves and flowers) and the proportion of well-developed seeds were measured as fitness indicators, while flow cytometric seed screening (FCSS) was utilized to determine the reproduction mode. Subsequently, comparisons with patterns of methylation-sensitive amplified fragmentlength polymorphisms (AFLPs) were conducted.

Diploids grew better under warm conditions, while tetraploids performed better in cold treatments. Epigenetic patterns were correlated with the expressed morphological traits. Cold stress reduced the reproduction fitness but did not induce apomixis in diploids.

Overall, our study underlines the potential of phenotypic plasticity for acclimation under environmental conditions and confirms the different niche preferences of cytotypes in natural populations. Results help to understand the pattern of geographical parthenogenesis in the species. 


\subsection{Introduction}

Environment is well known to be a major factor, together with genotype, to influence the expression of a phenotype in living organisms (West-Eberhard, 2008). Alpine habitats are characterized by short growth periods and cold spells, eventually with nocturnal frost during flowering time (spring or summer), which can influence several developmental processes in plants and activate adaptive traits (Körner, 2003; Nagy and Grabherr, 2009; Hedhly, 2011). In that context, phenotypic plasticity is defined as the ability of an organism, as a single genotype, to differentially respond to environmental stimuli (Brandshaw, 1965; Schlichting, 1986). The alterations of the phenotype can be depicted in morphology, in physiology, in gene expression, as single changes, or as a combination of these characteristics of organisms (West-Eberhard, 2008; Price et al., 2003; Whitman and Agrawal, 2009; Munns, 2011; Laland et al., 2015). The effect of phenotypic plasticity on plants, as sessile organisms, seems to be of great importance, regarding the acclimation to environmental conditions (West-Eberhard, 2008; Nicotra et al., 2011; Richards et al., 2017). The adaptive value of phenotypic plasticity should not be considered eminent per se, as adaptation is a complex procedure that is implied by plastic responses that are beneficial and can be transmitted to next generations (Schlichting, 1986; Kopp and Matuszewski, 2013; Chevin and Hoffmann, 2017).

As an immediate response to a change inbiotic or abiotic environmental conditions, individuals often show the capacity of phenotypic accommodation (West-Eberhard, 2003; Whitman and Agrawal, 2009), as well as acclimation to the new conditions, which are established in time (Chevin and Hoffmann, 2017). The latter term is often understood as environmental tolerance, estimated through the phenotypic plasticity of several fitness traits (Merilä and Hendry, 2013; Chevin and Hoffmann, 2017).

In the past few decades, a growing numberof studies approached phenotypic plasticity and its evolutionary aspects on organisms, as well as population level (Via and Lande, 1985; Schlichting, 1986; Sterns, 1989; Pigliucci, 2001; Franks et al., 2013; Laland et al., 2015; Kelly, 2019). A reliable body of them highlighted the triggering role of environmental conditions and changes, which often challenge an organism's survival and reproduction (Angers et al., 2010; Kooke et al., 2015). Studies on the genetic and epigenetic background of phenotypic plasticity (Richards et al., 2017) and its correlation with transcriptional differentiation (Donelson et al., 2017; Kelly, 2019) posed various interesting research questions on plasticity under extreme environmental conditions.

Plastic responses are the way of organisms potentially coping with extreme conditions and, thus, contributing positively to the colonization of novel habitats (Yeh and Price, 2004; Sol et al., 2005) via selection of fitting phenotypes (Schlichting and Pigliucci, 1998; West-Eberhard, 2003; Lande, 2009; Whitman and Agrawal, 2009; Chevin and Lande, 
2010). Several traits could be potentially involved in such procedures (Kopp and Matuszewski, 2013; Kelly, 2019). Nicotra et al. (2010) reviewed several studies on phenotypic plasticity and climate change, trying to highlight the fitness traits that seem to be up- or down regulated as part of the phenotypic response. Such phenotypic traits in plants can be stem height at maturity, flowering time and size at reproduction stage, leaf size and further morphological characteristics, and number/size of seeds (Westoby, 1998; Cornelissen et al., 2003; Metcalf et al., 2003). For alpine plants, a reduction in stem height and dense, cushion-like growth is regarded as acclimation or even adaptation to short vegetation periods, lower temperature, and exposure to freezing (Körner, 2003), while polyploidization and mode of reproduction can be affected by cold stress conditions (Ramsey and Schemske, 1998). Mirouze and Paszkowski (2011) proposed that this plasticity of plants to new environmental and possibly unfavorable conditions is linked to DNA methylation variation, which could regulate growth and reproduction to fit the changes (Lacaze et al., 2009) and may lead to microevolutionary events in plants (Zhang et al., 2013).

Phenotypic plasticity can also occur in the mode of reproduction. Apomixis is defined as asexual reproduction via seeds, i.e. agamospermy (Nogler, 1984). It is a heritable trait (Nogler, 1984; Ozias-Akins and van Dijk, 2007) and occurs in 78 families and more than 290 genera of angiosperms (Hojsgaard et al., 2014). Apomixis is usually facultative, which means that both sexual and apomictic seeds can be produced by the same plant, in variable proportions (Nogler, 1984; Hojsgaard et al., 2014; Schmidt, 2020). Apomictic plants are mostly perennials, and an individual plant may express variation in sexual/apomictic seed formation in different years (Klatt et al., 2018). Apomixis appears to be a consequence of a temporal or spatial deregulation of genes regulating the sexual pathway (Koltunow and Grossniklaus, 2003; Grimanelli, 2012), but its genetic and epigenetic background and the environmental influence on the expression of that trait are rather complicated and remain enigmatic (Schmidt, 2020).

In flowering plants, apomicts are commonly polyploids. Polyploidy is thought to have many effects on vigor, physiology, morphology, and other adaptive traits (te Beest $e$ al., 2012), and genomic changes associated with the formation of polyploid cytotypes were thought to lead to the induction of apomixis (Carman, 1997; Koltunow and Grossniklaus, 2003; Comai, 2005). However, growing evidence suggests that apomixis can originate spontaneously in diploid wild populations in low frequencies (Schinkel et al., 2016) and in diploid populations under cold temperature stress (Klatt et al., 2018). A successful establishment of polyploids is often connected to a niche differentiation of cytotypes (Levin, 1975; Levin, 2003). Apomictic polyploid taxa tend to have environmental tolerances and colonization abilities at high latitudes and altitudes, which are not observed among their diploid and sexual progenitors ("geographical parthenogenesis") (Vandel, 1928; Bierzychudek, 1985; Hörandl, 2006). 
Experimental research suggests that abiotic conditions like temperature and light (Hörandl and Hadacek, 2013; Klat et al., 2016; Klatt et al., 2018; Ulum et al., 2020) can directly alter the mode of reproduction in plants. Specifically, low temperature may trigger apomictic seed formation, albeit at low frequencies (Klatt et al., 2018). Case studies on apomictic clonal dandelions demonstrated the immediate response of plants to abiotic stress conditions, which are linked to methylation patterns and heritability of traits (Verhoeven et al., 2010a, b; Verhoeven and Preite, 2013) and could contribute to differentiation of populations according to latitudinal gradients (Preite et al., 2015).

We hypothesized that cold exposure would influence morphological and reproductive traits; therefore, we used Ranunculus kuepferi Greuter \& Burdet, a high-mountain perennial herb with diploids and autotetraploids as main cytotypes (Cosendai and Hörandl, 2010; Cosendai et al., 2011), as a suitable system to test our hypothesis. The reproduction mode of these cytotypes is predominantly sexual for the diploid plants and facultative apomictic for the autotetraploid plants, with varying proportions of sexual and asexual seeds (Burnier et al., 2009; Schinkel et al., 2016). The species is primarily distributed across the European Alps (as well as the northern Apennines and Corsica) and at altitudes between 1300 and $2800 \mathrm{~m}$ (Burnier et al., 2009; Cosendai and Hörandl, 2010; Cosendai et al., 2011; Kirchheimer et al., 2016; Schinkel et al., 2016). This distribution pattern indicates a pronounced geographical parthenogenesis pattern in the European Alps (Cosendai et al., 2013), where diploid populations are restricted to the southwestern Alps and tetraploid populations have colonized previously glaciated areas, i.e., northern, central, and eastern Alps (Burnier et al., 2009; Cosendai and Hörandl, 2010; Küpfer, 1974). Tetraploids exhibit a pronounced niche shift toward higher elevations and colder temperatures (Kirchheimer et al., 2016; Schinkel et al., 2016), which are associated with their reproduction mode and, in that regard, seem to provide asexual taxa with a distributional advantage (Kirchheimer et al., 2018).

Previous studies on wild populations showed that genetic differentiation between cytotypes is very low, and that within cytotypes is on a similar level ( $\mathrm{F}_{\mathrm{st}} \mathrm{S}$ are around 0.3 for both cytotypes), independent of their reproduction mode (Cosendai et al., 2013). A molecular dating revealed that the tetraploid cytotype originated only 10-80 thousand years ago (Kirchheimer et al., 2018), probably via multiple and recurrent polyploidization events (Cosendai et al., 2011; Schinkel et al., 2017). Epigenetic studies using methylation-sensitive amplified fragment-length polymorphisms (MS-AFLPs) on the species suggested differential profiles in the cytotypes and a connection to abiotic environmental conditions of the epigenetic variation in natural populations and experimental treatments (Schinkel et al., 2020; Syngelaki et al., 2020). This epigenetic variation was further correlated with an elevation in natural populations (Schinkel et al., 2020) and showed higher persistence under cold treatment in experimental conditions (Syngelaki et al., 2020). Thus, we assume a putative epigenetic background of the niche 
shift of tetraploids in the Alps, which helps to understand the geographical parthenogenesis scenario for the species. Additionally, concerning several epigenetic mechanisms, it is indicated that methylation patterns also configure, together with genotype, phenotypic plasticity, under changing environmental and developmental conditions (Bossdorf et al., 2010; Kooke et al., 2015).

The aim of the current study was to investigate the putative temperature sensitivity of morphological responses under the different ploidy levels of individuals, in order to decipher how the two cytotypes cope with different temperature conditions. For that purpose, we exposed diploid and tetraploid plants of $R$. kuepferi to different controlled temperature treatments, to quantify plasticity and their phenotypic response. Furthermore, we explored the effect of treatment on the reproduction mode of the species and more specifically the probability of a positive correlation between cold temperature and induction of apomixis, as previously reported by Klatt et al. (2018).

By assessing methylation variation data of the same year of treatment (Syngelaki et al., 2020), we focused on possible correlations of phenotypic patterns with MS-AFLP profiles. We investigated whether the methylation profiles of vegetative parts differentiate for phenotypic traits according to ploidy and treatment conditions. The results provided us with insights into the potential of R. kuepferi to acclimate to cold conditions during the postglacial establishment of the species in the European Alps.

\subsection{Materials and Methods}

\section{Plant Material and Experimental Design}

Diploid and tetraploid individuals of the species Ranunculus kuepferi were collected at 102 sampling sites throughout the distribution range of the species in the European Alps (Schinkel et al., 2016) during the flowering seasons of 2013 and 2014. Consequently, they were transferred to the Old Botanical Garden of Göttingen University, where they were repotted in garden soil and overwintered outdoors. Their ploidy level was determined via flow cytometry measurements on silica-gel-dried leaf material collected in the field (Schinkel et al., 2016).

During the early spring of 2014 (beginning of sprouting and flowering period), a subset of these individuals (see Table S1, Supplementary Materials) was placed in two climate chambers MC1000E (Snijders Scientific, Tilburg, the Netherlands), which implemented different temperature conditions but all other environmental variables were kept equal (Klatt et al., 2018). The conditions of the cold and warm temperature treatments are presented in Table 1. The current experimental design was favored for the purpose of investigating the temperature preferences of the two cytotypes implied by Schinkel et al. 
(2016) and Kirchheimer et al. (2016), with cold temperature treatments simulating the harsh high alpine temperature conditions of the tetraploid cytotype's typical habitats. The treatment of Klatt et al. (2018) was kept until 2016 and rotated in 2017 before the beginning of the present study (Syngelaki et al., 2020). All measures were taken from 2017 under the conditions specified in Table 1.

Table 1. Temperature treatment conditions during plant growth and seed formation.

\begin{tabular}{|c|c|c|}
\hline & \multirow{2}{*}{ Cold Treatment } & \multirow{2}{*}{ Warm Treatment } \\
\hline \multirow[b]{2}{*}{ Plant Ploidy } & & \\
\hline & Tetraploid & Diploid Tetraploid \\
\hline \multirow{2}{*}{ No.plants } & 164 & 189 \\
\hline & 90 & 92 \\
\hline $\begin{array}{c}\text { Light regime } \\
\left(\mu \mathrm{mol} \mathrm{m}^{-2} \cdot \mathrm{s}^{-1}, \mathrm{PAR}\right)\end{array}$ & \multicolumn{2}{|l|}{ ca. $700^{*}$} \\
\hline Photoperiod & \multicolumn{2}{|c|}{$16 \mathrm{~h} ; 10 \mathrm{~h}$ of full light and $3+3$ of twilight } \\
\hline $\begin{array}{l}\text { Temperature during } \\
\text { the light/dark period } \\
\qquad\left({ }^{\circ} \mathrm{C}\right)\end{array}$ & $\begin{array}{l}+7^{\circ} \mathrm{C} \text { day } /+2^{\circ} \mathrm{C} \text { night; frost } \\
\text { treatment; }-1{ }^{\circ} \mathrm{C} \text { cold shocks for } \\
\text { three nights per week }\end{array}$ & 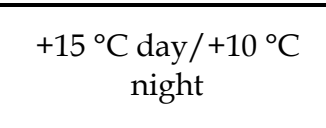 \\
\hline
\end{tabular}

PAR: Photosynthetically active radiation in 400-700nm.

*Measured with a Quantum light meter (Spectrum Technologies Inc., Aurora, IL, USA) during the full light period (100\% intensity) at level of early leaf tips and first buds. Plants were rotated weekly in the cabinet to avoid effects of light and temperature gradients.

In the early spring of 2017, 353 individuals from 63 populations were sampled, targeting as precisely as possible the distribution range of the species in the Alps (see Table S1, Supplementary Materials). The individuals were categorized into four groups regarding their treatment and ploidy: cold diploids, cold tetraploids, warm diploids, and warm tetraploids (CD, CT, WD, and WT, respectively). During the flowering period of 2017, leaf material was collected from all the plants, which was stored in silica gel for further molecular analysis. 
Flowers of the diploid individuals are self-incompatible, and they have fewer carpels and more well-developed stamens than the ones of tetraploids, which are also to some degree self-compatible (Cosendai et al., 2013). Although tetraploids are mainly apomictic, pollen is still needed for endosperm formation, as it fertilizes the polar nuclei (pseudogamy) (Küpfer, 1974; Burnier et al., 2009; Cosendai et al., 2013; Ladinig et al., 2013). Hence, we placed the two cytotypes in separate space sections of the climate chambers and pollinated the individuals manually at least thrice with the pollen of plants belonging to the same ploidy level and treatment. To prevent any unwanted cross-pollination event, flowers were covered with small perforated plastic bags as long as they were blooming.

At the peak of the flowering time, measurements of the vegetative parts of the individuals (153 individuals from both growth chambers, belonging to 50 populations) were conducted during the peak of the flowering period of each chamber, regarding the height of the stem (including flower), the number and length of the leaves, and the number of flowers per individual. These morphological growth variables are most informative according to Schinkel et al. (2016). All measurements took place the same day for each chamber and were handled further in order to investigate any potential ploidy and treatment effect between the groups.

At the late stage of pollinated flowers/early stage of achene formation, stems were sealed tightly with tape in small perforated plastic bags until the harvesting of ripe fruits (single-seeded achenes). Well-developed achenes were separated from the undeveloped achenes manually by using forceps, with the former resisting the pressure because of their properly formatted endosperm and the latter shattering as they were empty (Schinkel et al., 2016; Klatt et al., 2018). Thereupon, the seed set, i.e. the proportion of well-developed achenes of the total number of achenes per flower per individual, was calculated, as a measure of reproductive fitness of both cytotypes under both treatments. Well-developed achenes, after being kept for at least a week at room temperature, were placed into paper bags and stored on silica gel at $4{ }^{\circ} \mathrm{C}$, prior to further analyses.

Methylation-Sensitive Amplified Fragment-Length Polymorphisms (MS-AFLPs)

A subset of 100 randomly selected individuals (25 per group; Table S1, Supplementary Materials), originating from 57 populations, was selected to elucidate the effects of temperature treatments on the DNA methylation. DNA was isolated from the dried leaf material collected in 2017, using the Qiagen DNeasy Plant Mini Kit, and was processed further with a slightly modified protocol of Paun et al. (2012), to investigate the patterns of epigenetic variation through the methylation-sensitive amplified fragment-length polymorphisms (MS-AFLPs). Regarding fragment scoring, the resulted 
electropherograms from the ABI Prism 3700/3730 (Applied Biosystems, Waltham, MA, USA) capillary sequencer went through the following scoring pipeline: Peakscanner v.2 (Applied Biosystems, Life Technologies Corporation, Carlsbad, California, USA), RawGeno 2.0-1 (Arrigo et al., 2009), and MSAP_calc script (Schulz et al., 2013). A detailed wet lab and fragment scoring methodology can be found in Methods S1 (Supplementary Materials), and the DNA methylation study results on the species Ranunculus kuepferi are presented elsewhere (Syngelaki et al., 2020).

\section{Flow Cytometric Seed Screening (FCSS)}

The flow cytometric seed screening (FCSS) method was employed to determine the reproduction mode of each seed (achene) and investigate whether temperature, especially cold stress, affects it, by quantifying the proportion of sexual versus asexual seed formation. FCSS can distinguish the ploidy levels of both endosperm and embryo per single seed and allows the reconstruction of reproductive pathways, by calculating the ratios of endosperm to embryo ploidy levels, which differs between sexual and apomictic seeds (Matzk et al., 2000).

Up to 10 well-developed seeds (when applicable) per individual were analyzed with a slightly modified FCSS protocol (Matzk et al., 2000), initially introduced by Schinkel et al. (2016). Seeds were prepared in separate $2 \mathrm{~mL}$ Eppendorf tubes with two steel beads (Qiagen, Hilden, Germany) $(\varnothing 4 \mathrm{~mm}$ ) for each tube and were ground with Tissue Lyzer II (Qiagen, Hilden, Germany) (stroke rate: $30 \mathrm{~Hz}$ for 7s). Subsequently, nucleus isolation and staining were performed in two steps using the Otto buffers (Otto, 1990; Dolezel and Bartos, 2005; Dolezel et al., 2007). First, $200 \mu \mathrm{L}$ of Otto I buffer wasadded to the ground seed material for a minimum of 30s, to extract the nuclei from the cells. Then, 30 $\mu \mathrm{m}$ mesh filters (CellTrics, Partec $\mathrm{GmbH}$, Münster, Germany) were used to filtrate the mixture into $3.5 \mathrm{~mL}$ plastic tubes $(55 \times 12 \mathrm{~mm}$, Sarstedt, Nümbrecht, Germany) and the plastic tubes containing the filtrate were placed in a dark chamber to proceed with the staining of nuclei. Second, $800 \mu \mathrm{L}$ of Otto II buffer, containing the stain 4',6-diamidino-2phenylindole (DAPI), in a concentration of $300 \mu \mathrm{g} \mathrm{mL}^{-1}$, wasadded to the filtrate and, after an incubation of minimum $5 \mathrm{~min}$ in the dark, the measurement of the final solution was performed on a CyFlow Space flow Cytometer (Sigma-Aldrich, Partec GmbH, Münster, Germany) in the blue fluorescence channel [ultraviolet (UV) light-emitting diode (LED), wavelength $365 \mathrm{~nm}$ ]. A diploid and a tetraploid R. kuepferi plant were used as an external ploidy reference standard to adjust the gain of the UV LED lamp, and parameters were kept equal. Resulting histograms presenting the Gaussian means were obtained and analyzed with the FloMax software, version 2.81 (Quantum Analysis $\mathrm{GmbH}$, Münster, Germany). 
The Gaussian means of the peaks refer to the mean values of the DNA content for every tissue, uncovering the ploidy levels of the embryo and the endosperm of the seed. The peak index of each seed, i.e., the ratio of the mean peak value of the endosperm to the mean peak value of the embryo, was calculated, as it is required for the interpretation of plausible reproductive pathways (see Figure S1, Supplementary Materials). To link peak ratios to reproductive pathways, the studies of Cosendai and Hörandl (2010), Schinkel et al. (2016), and Klatt et al. (2018) on R. kuepferi were utilized (see Table S2, Supplementary Materials). A peak index threshold of 1.65 was set to classify all seeds with lower peak indices as sexual. Seeds with peak indices values of minimum 2.0 were classified as asexual (apomictic) (see Figure S1, Supplementary Materials). The proportions of different reproduction modes of the seeds were quantified for each individual and, thereafter, were pooled for each of the four groups, in order to pairwise compare their reproductive modes.

\section{Statistical Analyses}

Regarding the pairwise comparisons of the Groups (WD, CD, WT, CT), multiway ANOVAs and the nonparametric Wilcoxon and Kruskal-Wallis tests were computed on morphological growth, seed set, and reproduction mode datasets. All datasets mentioned above were handled as table formats in Excel 2016, and percentages of seed set and reproduction mode (sexuality, apomixis, and BIII hybrids) were arcsine transformed to match the normal distribution of the data. Analyses were performed in $\mathrm{R}$ ( $\mathrm{R}$ Core Team, 2020) under R Studio environment (RStudio Team, 2016). The visualization of descriptive statistics was carried out with ggplot2 R package (Wickham, 2009). All data used for descriptive statistics can be found in Table S3 (Supplementary Materials).

To compare the DNA methylation data produced previously (Syngelaki et al., 2020) with the current morphological growth dataset, non-Euclidean, Jaccard distances of DNA methylation data were calculated under vegan 2.5-6 R package (Oksanen et al., 2019) and visualized with ggplot2, with color referring to the morphological growth data and shape to the predefined groups. Linear models (LMs) and generalized linear models (GLMs), produced under R, were also employed to investigate these relationships further and check the hypothesis of morphological growth data being predicted by the different types of epiloci. Group was selected as an extra predictor, as it indicated the ploidy level and the treatment conditions for each individual.

We conducted linear models for morphological traits (stem height and leaf length) which are continuous numerical variables, while for the traits that refer to count data (number of flowers and number of leaves), generalized linear models, assuming Poisson distributions, were employed (Bolker et al., 2009; Zuur et al., 2009). The normal 
distribution of the continuous variables was tested by Shapiro-Wilk's test, prior to linear modeling. For stem height, only the observations that differed from zero were used. As the resulting $p$-values of Shapiro-Wilk's test were not significant, the null hypothesis, i.e. that data follow a normal distribution, could not be rejected, and we didnot need to further transform those variables. Furthermore, we set the intercept, i.e. the expected mean value of $y$ when all $x=0$, to zero, regarding both types of statistical models. Without this step, the coefficients estimated the mean in each group but the difference from a reference group.

\subsection{Results}

\section{Morphological Growth Data}

Overall, the growth of tetraploid plants was affected under warm treatment, as they produced significantly lower numbers of flowers and leaves, as well as significantly shorter leaves and shorter stems in the warm treatment than in the cold one (Figure 1). Paralleling the two ploidy levels under warm treatment, we observed that diploid plants attained significantly higher values for all the morphometric measurements than the tetraploids (Figure 1). Moreover, diploid individuals developed significantly more leaves under the cold treatment than under the warm one. Herein, differences were regarded as highly significant at the $5 \%$ level of probability and slightly/marginal significant at the $10 \%$ level of probability. 

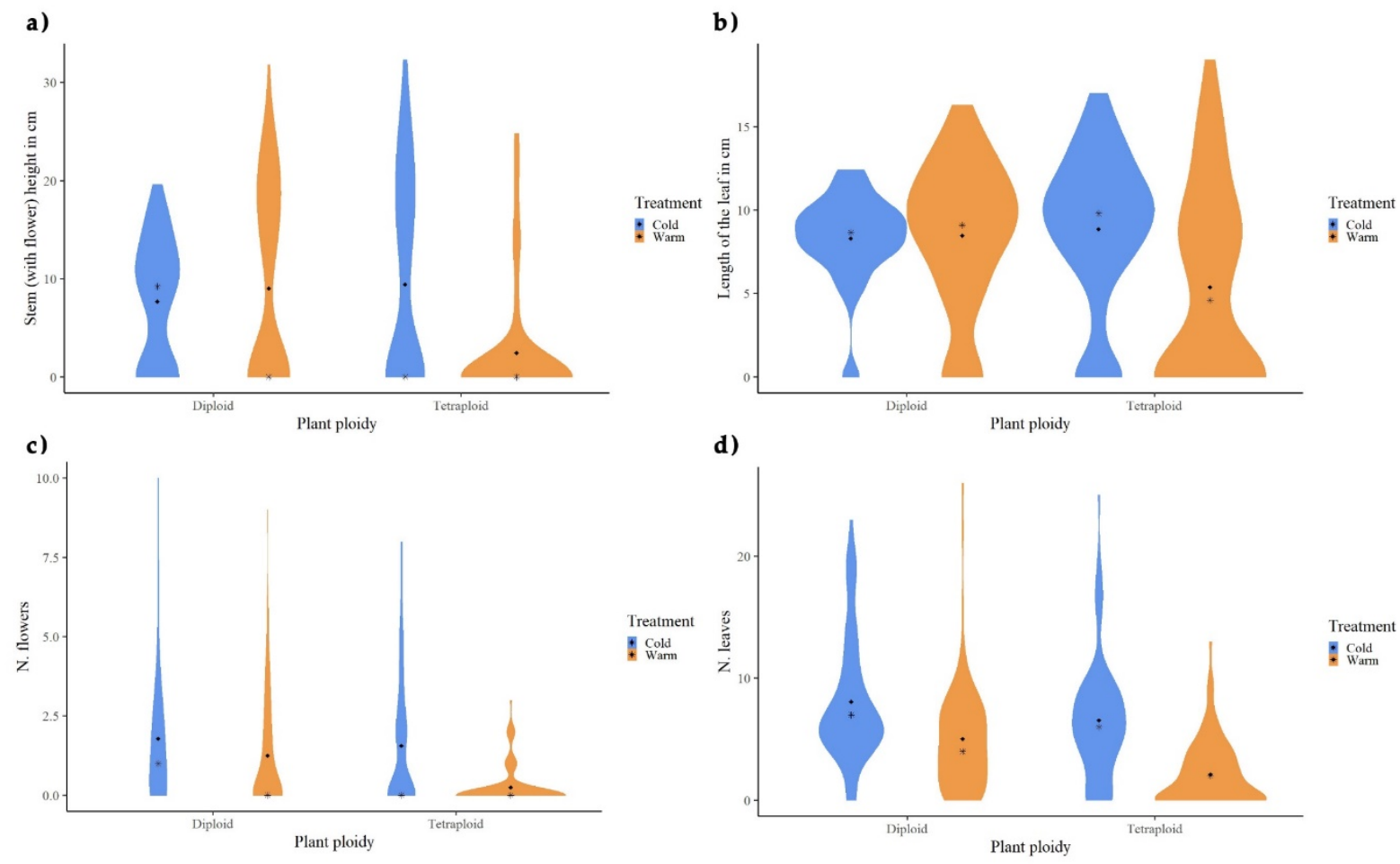

Figure 1. Violin plots of morphological traits of diploid and tetraploid Ranunculus kuepferi individuals under cold (blue) and warm (orange) temperature treatments: (a) stem height (with flower) in $\mathrm{cm}$, (b) length of the longest leaf per plant in $\mathrm{cm}$, (c) total number of flowers per plant, and (d) total number of leaves per plant.

Seed Set (Reproductive Fitness) and Reproduction Mode

A total number of 14,404 seeds were harvested from 143 individuals (49 populations) in both treatment conditions. On average, 20.25\% of them were well-developed (Figure 2), classified among CD, CT, WD, and WT with percentages of $10.97 \%, 4.7 \%, 84.13 \%$, and $0.2 \%$, respectively. Statistical analyses on the seed set data showed that diploids have a significantly higher seed set than tetraploids under both treatments, while diploids produced significantly more well-developed seeds under the warm treatment (Figure 2).

From the 701 FCSS measurements, 688 seeds, collected from 87 individuals, were clearly interpretable, while 13 were excluded from further analyses as there were extreme irregularities in embryo and endosperm development (histograms in Figure S1; reproductive pathways in Table S2; FCSS data in Table S3, Supplementary Materials). Flow cytometric seed screening results confirmed that the sexual mode of reproduction is dominant for the diploid individuals, whereas apomixis is higher expressed in the tetraploid cytotype (see Figure S2, Supplementary Materials). Except for sexual and apomictic seeds, in which the ploidy of the embryo is equal to that of the mother plant, there were cases detected with a ploidy shift in the embryo compared to the mother plant. In such cases, which are defined as BIII hybrids (Nogler, 1984) (Figure S1b, 
Supplementary Materials), an unreduced egg cell was fertilized by reduced pollen, resulting in a higher-ploid embryo. BIII hybrids are considered to perform partial apomixis (i.e., apomeiosis only) and be a potential pathway to polyploidization (Schinkel et al., 2017). Interestingly, a relatively high number of individuals (16) in the WD group displayedpartially apomictic reproduction as they were classified as BIII hybrids (Figure S2).

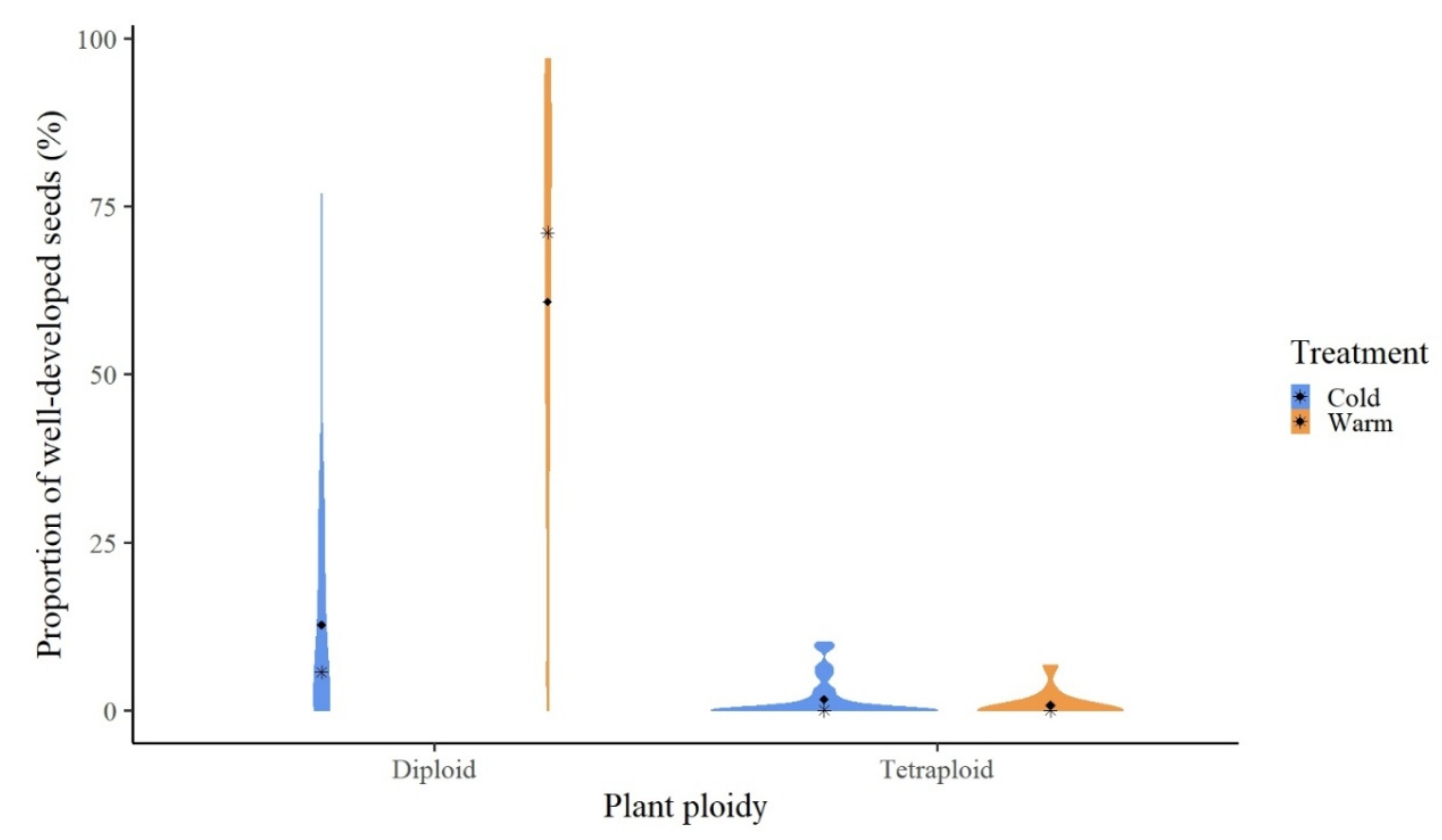

Figure 2. Violin plots of reproduction fitness of diploid and tetraploid Ranunculus kuepferi individuals under cold (blue) and warm (orange) temperature treatments.

Comparison of Morphological Growth Data with MS-AFLP Data

In a previous study, a ploidy effect was confirmed for all three types of epiloci (internally, externally, and nonmethylated) under cold conditions and for externally and internally methylated under warm conditions. Moreover, a treatment effect was observed in diploids regarding the internallymethylated epiloci (Syngelaki et al., 2020). The Jaccard distance matrices of the respective MS-AFLP data for all types of epiloci, calculated separately for each cytotype, were visualized as multidimensional scaling diagrams and present a pronounced variation of the groups and a "relaxed" correlation of the morphological traits with the epigenetic data. Treatments are more sharply separated in the diploid cytotype than in the tetraploid one, as cold diploids are gathered mainly in two clusters, whereas the epigenetic patterns of the tetraploid groups seem to overlap a lot (Figures 3 and 4). 
Concerning the number of flowers for each cytotype, diploids did not seem to form an epigenetic cluster by increasing or decreasing the number of flowers per individual. As already shown by Figure 1c, treatment affects this morphological trait, as the highest values were found in warm diploids, while cold diploids had mostly individuals with zero to one flower (Figure 3a). For the tetraploids, the highest numbers of flowers were found under cold conditions, and these individuals tended to cluster in MS-AFLP patterns toward the $y$-axis (Figure $3 b$ ).
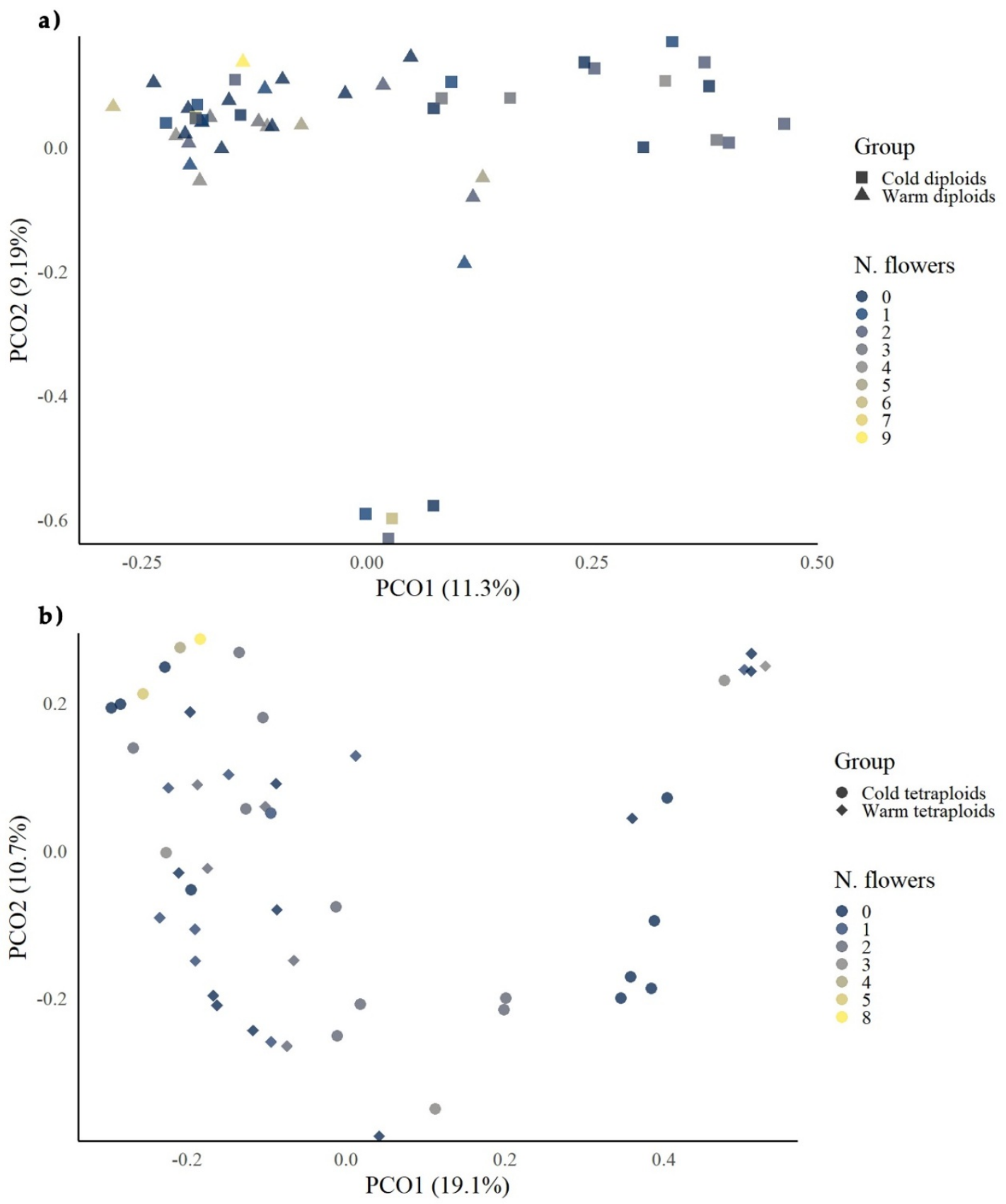
Figure 3. PCoAs of DNA methylation-sensitive amplified fragment-length polymorphisms (MS-AFLPs) against the number of flowers on treatment level of Ranunculus kuepferi diploid and tetraploid individuals: (a) diploid plants; (b) tetraploid plants.

The correlation of epigenetic patterns with the number of leaves was slightly stronger. MSAP patterns, regarding both treatments, tended to gather on "relaxed" clusters along the $x$-axis (toward $y$-axis) for diploid individuals with a higher number of leaves in the warm treatment (Figure 4a), while, in tetraploids, there wasa slight differentiation of leaf number and epigenetic patterns along the $x$-axis, with the highest numbers of leaves in the cold treatment (Figure $4 b$ ). 

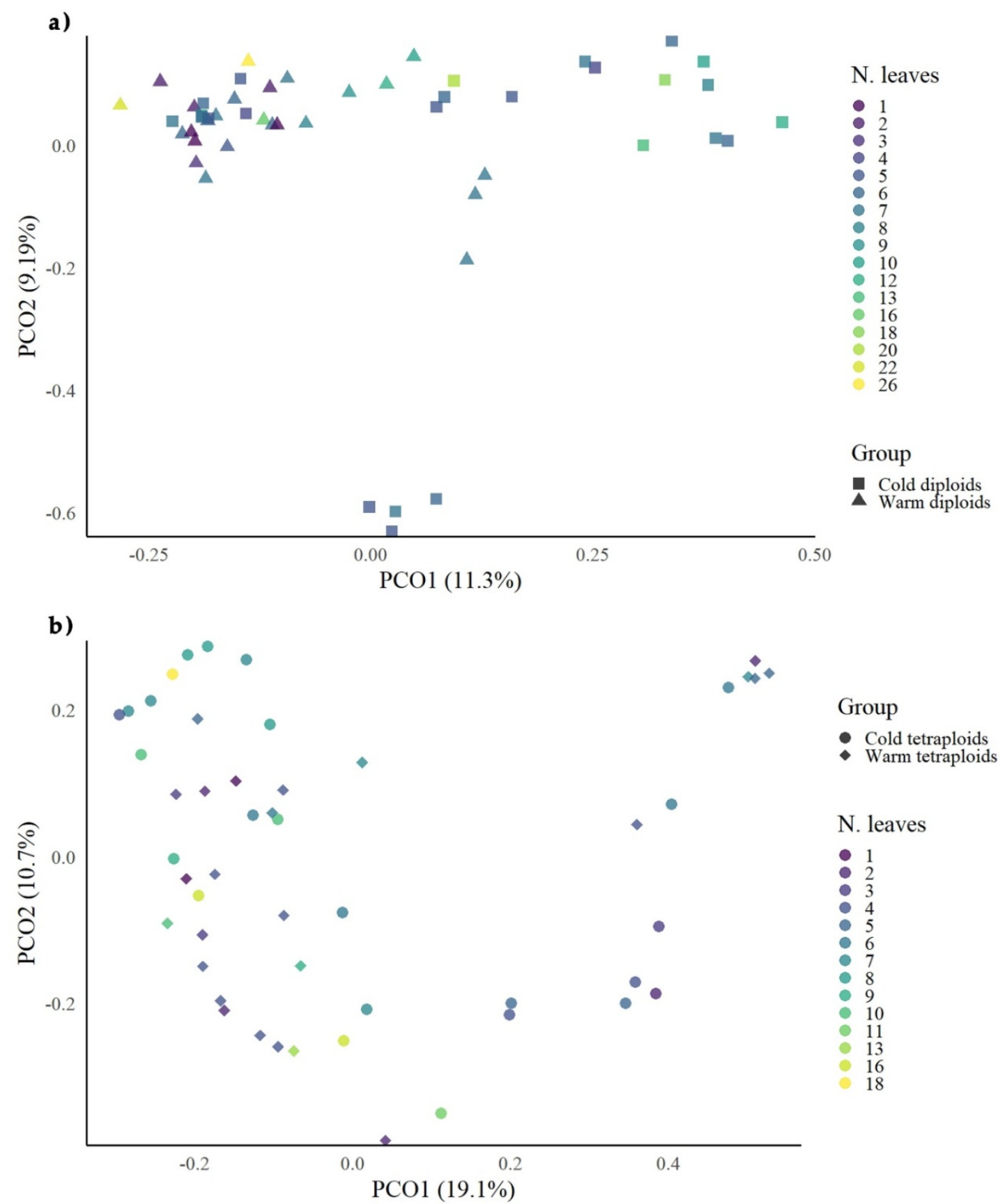

Figure 4. PCoAs of DNA methylation patterns (MS-AFLPs) against the number of leaves on treatment level of Ranunculus kuepferi diploid and tetraploid individuals: (a) diploid plants; (b) tetraploid plants.

Further comparisons of the two datasets via linear models (LMs) and generalized linear models (GLMs) unveiled that non-methylated epiloci (predictor) have a significant and a slightly significant negative correlation with leaf length and number of leaves (responses), respectively (Table 2). Furthermore, modeling results showed that groups were, mostly, highly significant and positively correlated with all different 
morphological traits, except for the case of WT regarding the number of flowers and the externally methylated epiloci (Table 2b). All linear models presented here (Table 2a) had highly significant $p$-values. 
Table 2. Linear model and generalized linear model results, investigating the relationship of morphological traits with DNA methylation (MS-AFLP) patterns and predefined groups. MS-AFLP patterns are reported separately for different types of epiloci (Syngelaki et al., 2020): (a) linear models (model $p$-values < 0.0001); (b) generalized linear models. 


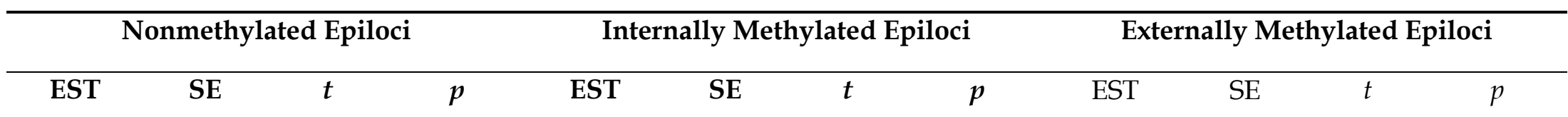

(a) Linear Models (LMs)

\begin{tabular}{|c|c|c|c|c|c|c|c|c|c|c|c|c|}
\hline Stem height & & & & & & & & & & & & \\
\hline Epiloci's arcsin & 0.3109 & 0.9664 & 0.322 & 0.749 & 0.317 & 0.7598 & 0.417 & 0.678 & -0.5181 & 0.7724 & -0.671 & 0.505 \\
\hline Group WD & 21.0011 & 2.4582 & 8.543 & $<0.0001$ & 20.9473 & 2.2096 & 9.48 & $<0.0001$ & 22.7812 & 2.2576 & 10.091 & $<0.0001$ \\
\hline Group WT & 14.9239 & 2.4573 & 6.073 & $<0.0001$ & 15.14 & 1.8074 & 8.376 & $<0.0001$ & 16.9496 & 2.5926 & 6.538 & $<0.0001$ \\
\hline Group CD & 11.3751 & 2.6498 & 4.293 & $<0.0001$ & 11.3147 & 2.3252 & 4.866 & $<0.0001$ & 13.3097 & 2.209 & 6.025 & $<0.0001$ \\
\hline Group CT & 18.653 & 2.3273 & 8.015 & $<0.0001$ & 18.836 & 1.7315 & 10.879 & $<0.0001$ & 20.5472 & 2.4101 & 8.525 & $<0.0001$ \\
\hline \multicolumn{13}{|l|}{ Leaf length } \\
\hline Epiloci's arcsin & 0.7476 & 0.3653 & 2.047 & 0.0435 & -0.0095 & 0.3222 & -0.029 & 0.977 & -0.2165 & 0.3482 & -0.622 & 0.535 \\
\hline Group WD & 8.1467 & 0.9546 & 8.534 & $<0.0001$ & 9.7367 & 0.9122 & 10.674 & $<0.0001$ & 10.1492 & 0.9062 & 11.199 & $<0.0001$ \\
\hline Group WT & 8.9927 & 0.9476 & 9.49 & $<0.0001$ & 10.5581 & 0.7544 & 13.996 & $<0.0001$ & 11.1192 & 1.0916 & 10.186 & $<0.0001$ \\
\hline Group CD & 7.5579 & 0.9898 & 7.636 & $<0.0001$ & 9.2389 & 0.9716 & 9.509 & $<0.0001$ & 9.7112 & 0.9849 & 9.86 & $<0.0001$ \\
\hline Group CT & 9.4605 & 0.8641 & 10.948 & $<0.0001$ & 10.8027 & 0.6849 & 15.772 & $<0.0001$ & 11.371 & 1.0967 & 10.369 & $<0.0001$ \\
\hline
\end{tabular}


(b) Generalized Linear Models (GLMs)

\begin{tabular}{|c|c|c|c|c|c|c|c|c|c|c|c|c|}
\hline \multicolumn{13}{|l|}{ No. of flowers } \\
\hline Epiloci's arcsin & 0.0019 & 0.1519 & 0.012 & 0.9901 & -0.0077 & 0.1327 & -0.058 & 0.9536 & 0.0973 & 0.1514 & 0.643 & 0.5202 \\
\hline Group WD & 2.0764 & 0.4299 & 4.83 & $<0.0001$ & 2.0971 & 0.4089 & 5.128 & $<0.0001$ & 1.8705 & 0.4126 & 4.533 & $<0.0001$ \\
\hline Group WT & 0.836 & 0.3644 & 2.294 & $<0.05$ & 0.8495 & 0.2705 & 3.14 & $<0.01$ & 0.5777 & 0.4362 & 1.324 & 0.1854 \\
\hline Group CD & 1.8357 & 0.4325 & 4.245 & $<0.0001$ & 1.8601 & 0.4206 & 4.423 & $<0.0001$ & 1.6387 & 0.4363 & 3.756 & $<0.001$ \\
\hline Group CT & 1.7965 & 0.381 & 4.715 & $<0.0001$ & 1.8091 & 0.3075 & 5.884 & $<0.0001$ & 1.5369 & 0.4789 & 3.21 & $<0.01$ \\
\hline \multicolumn{13}{|l|}{ No. of leaves } \\
\hline Epiloci's arcsin & -0.5111 & 0.3085 & -1.657 & 0.0975 & -0.3444 & 0.287 & -1.2 & 0.23 & 0.0663 & 0.3181 & 0.208 & 0.835 \\
\hline Group WD & 8.4683 & 0.8596 & 9.852 & $<0.0001$ & 8.1792 & 0.8334 & 9.814 & $<0.0001$ & 7.2984 & 0.8359 & 8.731 & $<0.0001$ \\
\hline Group WT & 5.7235 & 0.7948 & 7.201 & $<0.0001$ & 5.1557 & 0.6189 & 8.331 & $<0.0001$ & 4.4241 & 0.9462 & 4.676 & $<0.0001$ \\
\hline Group CD & 8.8534 & 0.8903 & 9.945 & $<0.0001$ & 8.4953 & 0.896 & 9.482 & $<0.0001$ & 7.5825 & 0.9142 & 8.294 & $<0.0001$ \\
\hline Group CT & 8.6126 & 0.7854 & 10.966 & $<0.0001$ & 8.1359 & 0.6513 & 12.493 & $<0.0001$ & 7.5378 & 1.0138 & 7.436 & $<0.0001$ \\
\hline
\end{tabular}

EST: estimate of each coefficient; SE: standard error of the estimate; $t$ - $t$-value, i.e. the coefficient divided by its standard error; $p$ : $p$-value for the coefficient. 


\subsection{Discussion}

In the current study, the variability of several morphological traits together with shifts of the reproduction mode in two cytotypes of $R$. kuepferi along cold (stress) and warm (control) temperature treatments was explored, simulating natural conditions in the Alps. The results confirmed the correlation of phenotypic responses with the ploidy level and treatment conditions, while, for reproduction mode, only the ploidy effect was confirmed as reported previously (Klatt et al., 2018), as there were no significant differences in treatments.

Furthermore, tetraploids had significantly improved growth under the cold treatment and seemed to suffer under the warm conditions. Comparing the growth response of the two cytotypes under warm conditions, diploids did better than tetraploids. This prominent reaction of the tetraploid cytotype to the cold treatment, in addition to the slightly better performance of the diploid cytotype under warm treatment, strengthens the hypothesis of the ecological background of the geographical parthenogenesis pattern of the species (Schinkel et al., 2016; Kirchheimer et al., 2018). This hypothesis proposes the occurrence of the diploid cytotype in the warmer climate of the southwestern Alps and of the tetraploid cytotype in colder conditions at higher elevations inthe rest of the Alps.

The interaction between morphological traits and DNA methylation patterns, evaluated for different cytotypes, could indicate an aspect of the molecular, more specifically, epigenetic, background of environmental response and/or phenotypic plasticity.

Overall, the treatment shift did affect the phenotypic plasticity of the two cytotypes. A repeated exposure to a condition for several flowering periods may induce acclimation and eventually put adaptive procedures in motion. Below, we attempt to disentangle and interpret all results.

\section{Phenotypic Plasticity and Morphological Traits}

Regarding the response of the four selected morphological traits to the treatments, our findings support the hypothesis of a niche preference depending on the cytotype documented by Kirchheimer et al. (2016; 2018). The observed ploidy effect under warm treatment and the treatment effect for the tetraploids under cold treatment imply a potential of phenotypic plasticity, which could sustain fitness under shifted environmental conditions (Bateson, 2015). In natural environments, plants show phenotypic variation under a wider range of conditions. If such a variation is inherited by next generations, it is a trait, which could be associated with adaptation and evolution (van Kleunen and Fisher, 2003; Bossdorf and Pigliucci, 2009; Miryeganeh and Saze, 2019). This ability could give an advantage to an organism to colonize freshly 
available ecological niches. Under this process, the evolution of several adaptive traits could be expected, in favor of a successful establishment to the new niche (Wyles, 1983; Pfenning and McGee, 2010; Bateson, 2015). Moreover, cytotypes with low genetic divergence (Cosendai et al., 2011; Cosendai et al., 2013) rely on phenotypic variation to manage to colonize different environments (Vrijenhoek and Parker, 2009). Thus, we suggest that the post-glacial colonization of the Alps by tetraploid populations of $R$. kuepferi and the distribution of the two cytotypes was fostered by their phenotypic response to climatic conditions.

Previous studies on morphological traits in natural populations of $R$. kuepferi (Schinkel et al., 2016) showed that tetraploid plants in the Alps often exhibit "alpine dwarfism" as an adaptation to higher elevations and harsh conditions (Körner, 2003). Our results suggest that tetraploids grow best under a cold treatment, which approximates the optimal alpine conditions of the natural habitats for this cytotype, as they do significantly better than those under warm treatment. Our experiments did not include the extreme cold conditions that occur at the highest elevations of the Alps (Schinkel et al., 2016), which explains why we did not observe dwarf growth. Although temperature,as an environmental factor, plays the most decisive role in the ecology of each cytotype (Kirchheimer et al., 2016), the phenotypic response of the tetraploid cytotype under cold conditions may entail a spatiotemporal heterogeneity of several environmental variables, e.g. moisture, $\mathrm{pH}$, and nutrients (Kelly, 2019). Kirchheimer et al. (2016) found a niche shift of tetraploids toward more acidic soils. At the highest elevations in the Alps, nutrient-poor soils may also reduce growth performance (Körner, 2003). Furthermore, we hypothesized that the adaptive effects of polyploidy, e.g. increasing cell size (te Beest et al., 2012) may be expressed in a stronger way in the climate growth chambers, where only temperature varies and the other proxies are kept equal for the scope of current experimental design. For the diploids, our results are consistent with the study on natural populations (Schinkel et al., 2016), as diploids grew better and had more flowers than tetraploids under warm conditions. Our warm treatments appear to match their natural optimal conditions. The higher number of flowers, together with better seed set (Schinkel et al., 2016), resulted in a higher seed yield for diploids and, hence, a fitness advantage in their optimal, warmer climatic niche.

\section{Epigenetic Patterns and Morphological Traits}

The epigenetic background of phenotypic plasticity was noteworthily discussed (Pigliucci, 2001; West-Eberhard, 2003; Mirouze and Paskzowski, 2011; Noble et al., 2014; Bateson, 2015), while the potential of epigenetic inheritance of plastic phenotypic traits in plants was debated by several authors (Johannes et al., 2009; Cortijo et al., 2014; Miryeganeh and Saze, 2019), with cytosine (DNA) methylation being quite important in such procedures (Paskowski and Grossniklaus, 2011). DNA methylation is an epigenetic 
mechanism, which seems to be strongly correlated with phenotypic plasticity to internal and external stimuli (Wyles et al., 1983), which could be advantageous to occupy a wider distribution niche (Pal and Milkos, 1999; Angers et al., 2010). Such stress-induced epigenetic patterns provide rapid responses to fluctuating environmental conditions and could have an impact on individual fitness (Crews et al., 2007; Bossdorf and Pigliucci, 2009; Angers et al., 2010; Castonguay and Angers, 2012; Herrera et al., 2013; Nicotra et al., 2015; Rubenstein et al., 2016: Verhoeven et al., 2016).. In case this phenotypic variation is heritable, DNA methylation could provide a mechanism of adaptive microevolution in plants (Herman and Sultan, 2011; Zhang et al., 2013), which is faster and independent from traditional genetic evolution ( Jablonka and Lamb, 1995; Richards, 2006; Bossdorf and Pigliucci, 2009). Epigenetic variation differed in R. kuepferi between cytotypes, and also varied under climatic conditions, both in natural populations (Schinkel et al., 2020) and under controlled conditions (Syngelaki et al., 2020).

Here, we compared the DNA methylation patterns with all the measured morphological traits per individual, keeping in mind their ploidy level and treatment conditions. Furthermore, we focused on the number of leaves and number of flowers, as they were important for our hypotheses regarding the survival and the fitness of $R$. kuepferi. Concerning the leaves as a morphological trait, it wasintriguing to inspect their interaction with the epigenetic patterns, as they are the main photosynthetic organ of plants (Maugarny-Cales and Laufs, 2018). Tholen et al. (2012) suggested that biomass production of leaves is the main factor influencing photosynthesis, while Yamori et al. (Yamori et al., 2014) appraised the temperature acclimation of photosynthesis, its underlying mechanisms, and their heritable potential. Moreover, photosynthetic plasticity is triggered by stress environmental conditions in cotton cultivars (Aspinwall et al., 2015). In Arabidopsis thaliana, the phenotypic plasticity of leaves has an epigenetic basis and is associated with DNA hypomethylation (Kooke et al., 2015).

The correlation of some morphological traits with the epigenetic patterns, which wasindicated in our study, may refer to the invoked reaction of the individuals toward the shifted conditions after three years (Syngelaki et al., 2020) of being acclimated in previous experimental treatments (Klatt et al., 2018). In particular, our findings showed a stronger correlation of phenotypic plasticity in leaves than in flowers with epigenetic variation, while, for both cytotypes, leaves exhibited higher values under the cold treatment.

Hence, the stress response of individuals was expressed as phenotypic plasticity, which may be controlled by DNA methylation variation, as well as by the genetic background. Such a hypothesis of epigenetic control on the phenotypic plasticity of the species wasfurther supported by the negative correlation of the leaf length and the number of 
leaves with the patterns of non-methylated epiloci for all the predefined groups. The significant relationship of nonmethylated epiloci withleaf length and the number of leaves, in comparison to the non-significant effect of the other types of epiloci, may highlight the importance of this epilocus in the mechanisms of phenotypic response, e.g. the gene expression toward the new temperature conditions. Non-methylated epiloci are often linked with DNA demethylation, which is responsible for variations in phenotypic plasticity, by extending its environmental sensitivity (Kooke et al., 2015), while global demethylation of genomic DNA in response to abiotic environmental stress could regulate gene expression (Steward et al., 2002; Shan et al., 2013). However, the observed non-methylation patterns could also reflect an underlying genetic variation and should rather be regarded as indicative of a high methylation dynamics under stress conditions (Zhang et al., 2018).

The observed variation in some of the morphological traits and the epigenetic patterns seemed to affect the fitness of individuals under the new environmental conditions, thus proposing a Jack-and-master scenario (Richards et al., 2006) for the species. In that scenario, changes in traits can contribute to a higher fitness and/or be opportunistic, e.g. because of epigenetic asymmetry, profiting in such a way the establishment of a species in a new environment. Epigenetic asymmetry is often observed under changing environmental conditions, as stochastic epigenetic changes may result in high levels of plasticity, "weird" phenotypes, and even developmental disturbances (Palmer and Strobeck, 1986; Palmer, 1996; Moller and Swaddle, 1997; Dongen, 2006; Angers et al., 2010; Angers et al., 2020).

Nevertheless, the degree of phenotypic and epigenetic response of the species in fluctuating biotic and abiotic environmental conditions is a rather complicated process, where exposure time may also play a role (Angers et al., 2010). Thus, further studies, which would investigate the mechanisms of phenotypic response and factors that prompt it, e.g. exploring harsher environmental conditions, will help us to address our hypotheses more efficiently.

\section{Reproduction Mode under Temperature Treatments}

Differences in seed set and reproduction mode among the cytotypes confirmed the results of previous studies on the species in natural populations (Cosendai and Hörandl, 2010; Schinkel et al., 2016) and under experimental conditions (Klatt et al., 2018). Seed set is negatively affected by cold conditions, with diploids having significantly lower abortion rates under both temperature conditions, while tetraploids produced only a handful of well-developed seeds under warm conditions. Cold and frost conditions decrease seed set and injure the reproductive tissues of alpine plants, e.g. in Saxifraga bryoides (Ladinig and Wagner, 2007) and Ranunculus hirtellus (Kumar and Singhal, 2011). 
Moreover, Ladinig and Wagner (2007) suggested that the repeated moderate frost treatment, applied also here, mimics temperature conditions occurring in high mountains and provokes frost injury in reproductive shoots, which could also result in full fruit loss. Such damaging effects were observed by Klatt et al. (2018) regarding the present experimental design.

Results of the current study did not imply a significant cold-induced production of apomictic seeds in the diploid cytotype as observed by Klatt et al. (2018), but rather suggest a phenotypic plasticity on reproduction mode from one year to the other in these perennial plants, as observed in the earlier study. In accordance with earlier findings (Syngelaki et al., 2020), we speculate that these results may be correlated with the shift of treatment for the plants, which activated the complex stress responses in plants (Dewitt et al., 1998) such as the plastic development of flowers in R. kuepferi. More specifically, not all individuals produce flowers every year, as they can rest for one or more years. It is also hypothesized that female development takes place before sprouting, asin various alpine plants (Körner, 2003). The severity of stress conditions also plays a role in the plants' response and can underline the cost of plasticity in extreme environmental conditions (Dewitt et al., 1998; Suzuki et al., 2014; Chevin and Hoffmann, 2017). Finally, the occurrence of BIII hybrids, which were detected in the group of WD, confirmed the hypothesis of a "female triploid bridge" as the first step to polyploidization and apomictic mode of reproduction in natural populations (Schinkel et al., 2017).

To summarize, temperature stress does affect phenotypic plasticity of morphological traits in R. kuepferi, with responses linked to DNA methylation patterns. In addition, the phenotypic plasticity of $R$. kuepferi most likely helps to acclimate the cytotypes to their respective climatic niches. If traits were heritable, then they would have an adaptive value and explain the geographical parthenogenesis pattern of the species in the Alps. The putative epigenetic background of phenotypic plasticity suggests that DNA methylation, in comparison to DNA mutations, provides rapid reactions of an organism to variable environmental conditions but does not necessarily ensure the stability of a phenotype. Thus, the high phenotypic variability of asexual organisms could allow for a higher or equal niche dynamic as for sexual plants. Regarding these interactions of DNA methylation and gene regulation, the next step ininvestigating the stress response of $R$. kuepferi would be to identify the gene expression profiles of both cytotypes under stress and controlled conditions. 


\subsection{References}

Angers, B., Castonguay, E., and Massicotte, R. (2010). Environmentally induced phenotypes and DNA methylation: How to deal with unpredictable conditions until the next generation and after. Mol. Ecol., 19, 1283-1295.

Angers, B., Perez, M., Menicucci, T., and Leung, C. (2020). Sources of epigenetic variation and their applications in natural populations. Evol. Appl., 13, 1262-1278.

Arrigo, N., Tuszynski, J.W., Ehrich, D., Gerdes, T., and Alvarez, N. (2009). Evaluating the impact of scoring parameters on the structure of intra-specific genetic variation using RawGeno, an R package for automating AFLP scoring. BMC Bioinform., 10, 10-33.

Aspinwall, M.J., Loik, M.E., De Dios, V.R., Tjoelker, M.G., Payton, P.R., and Tissue, D.T. (2015). Utilizing intraspecific variation in phenotypic plasticity to bolster agricultural and forest productivity under climate change. Plant Cell Environ., 38, 17521764.

Bateson, P. (2015). Why are individuals so different from each other? Heredity, 115, 285292.

Bierzychudek, P. (1985). Patterns in plant parthenogenesis. Experientia, 41, 1255-1264.

Brandshaw, A.D. (1965). Evolutionary significance of phenotypic plasticity in plants. Adv. Genet., 13, 115-155.

Bolker, B., Brooks, M., Clark, C., Geange, S., Poulsen, J., Stevens, H., and White, J.-S. (2009). Generalized Linear Mixed Models: A practical guide for ecology and evolution. Trends Ecol. Evol., 24, 127-135.

Bossdorf, O., and Pigliucci, M. (2009). Plasticity to wind is modular and genetically variable in Arabidopsis thaliana. Evol. Ecol., 23, 669-685.

Bossdorf, O., Arcuri, D., Richards, C.L., and Pigliucci, M. (2010). Experimental alteration of DNA methylation affects the phenotypic plasticity of ecologically relevant traits in Arabidopsis thaliana. Evol. Ecol., 24, 541-553.

Burnier, J., Buerki, S., Arrigo, N., Küpfer, P., and Alvarez, N. (2009). Genetic structure and evolution of Alpine polyploid complexes: Ranunculus kuepferi (Ranunculaceae) as a case study. Mol. Ecol., 18, 3730-3744.

Carman, J.G. (1997). Asynchronous expression of duplicate genes in angiosperms may cause apomixis, bispory, tetraspory and polyembryony. Biol. J. Linn. Soc., 61, 51-94. 
Castonguay, E., and Angers, B. (2012). The key role of epigenetics in the persistence of a sexual lineage. Genet. Res. Int., 534289, 1-9.

Chevin, L.M., and Lande, R. (2010). When do adaptive plasticity and genetic evolution prevent extinction of a density-regulated population? Evolution, 64, 1143-1150.

Chevin, L.M., and Hoffmann, A.A. (2017). Evolution of phenotypic plasticity in extreme environments. Philos. Trans. R. Soc. B Biol. Sci., 372, 20160138.

Comai, L. (2005). The advantages and disadvantages of being polyploid. Nat. Rev. Genet., 6, 836-846.

Cornelissen, J.H.C., Lavorel, S., Garnier, E., Diaz, S., Buchmann, N., Gurvich, D.E., Reich, P.B., te Steege, H., Morgan, H.D., van der Heijden, M.G.A., et al. (2003). A handbook of protocols for standardized and easy measurement of plant functional traits worldwide. Aust. J. Bot., 51, 335-380.

Cortijo, S., Wandenaar, R., Colome-Tatche, M., Gilly, A., Etcheverry, M., Labadie, K., Johannes, F., et al. (2014). Mapping the epigenetic basis of complex traits. Science, 343, 1145-1148.

Cosendai, A.C., and Hörandl, E. (2010). Cytotype stability, facultative apomixis and geographical parthenogenesis in Ranunculus kuepferi (Ranunculaceae). Ann. Bot., 105, 457-470.

Cosendai, A.C., Rodewald, J., and Hörandl, E. (2011). Origin and distribution of autopolyploids via apomixis in the alpine species Ranunculus kuepferi (Ranunculaceae). Taxon, 60, 355-364.

Cosendai, A.C., Wagner, J., Ladinig, U., Rosche, C., and Hörandl, E. (2013). Geographical parthenogenesis and population genetic structure in the alpine species Ranunculus kuepferi (Ranunculaceae). Heredity, 110, 560-569.

Crews, D., Gore, A.C., Hsu, T.S., Dangleben, N.L., Spinetta, M., Schallert, T., Anway, M.D., and Skinner, M.K. (2007). Transgenerational epigenetic imprints and mate preference. Proc. Natl. Acad. Sci. USA, 104, 5942-5946.

Dewitt, T.J., Sih, A., and Wilson, D.S. (1998). Costs and limits of phenotypic plasticity. Trends Ecol. Evol., 13, 77-81.

Dolezel, J., and Bartos, J. (2005). Plant DNA flow cytometry and estimation of nuclear genome size. Ann. Bot., 95, 99-110.

Dolezel, J., Greilhuber, J., and Suda, J. (2007). Estimation of nuclear DNA content in plants using flow cytometry. Nat. Protoc., 2, 2233-2244. 
Donelson, J.M., Salinas, S., Munday, P.L., and Shama, L.N.S. (2017). Transgenerational plasticity and climate change experiments: Where do we go from here? Glob. Chang. Biol., 24, 13-24.

Dongen, S.V. (2006). Fluctuating asymmetry and development instability in evolutionary biology: Past, present and future. J. Evol. Biol., 19, 1727-1743.

Franks, S.J., Weber, J.J., and Aitken, S.N. (2013). Evolutionary and plastic responses to climate change in terrestrial plant populations. Evol. Appl., 7, 123-139.

Grimanelli, D. (2012). Epigenetic regulation of reproductive development and the emergence of apomixis in angiosperms. Curr. Opin. Plant Biol., 15, 57-62.

Hedhly, A. (2011). Sensitivity of flowering plant gametophytes to temperature fluctuations. Environ. Exp. Bot., 74, 9-16.

Herman, J.J., and Sultan, S.E. (2011). Adaptive transgenerational plasticity in plants: Case studies, mechanisms and implications for natural populations. Front. Plant Sci., 2, 102.

Herrera, C.M., and Bazaga, P. (2013). Epigenetic correlates of plant phenotypic plasticity: DNA methylation differs between prickly and nonprickly leaves in heterophyllous Ilex aquifolium (Aquifoliaceae) trees. Bot. J. Linn. Soc., 171, 441-452.

Hojsgaard, D., Greilhuber, J., Pellino, M., Paun, O., Sharbel, T.F., and Hörandl, E. (2014). Emergence of apospory and bypass of meiosis via apomixis after sexual hybridization and polyploidization. New Phytol., 204, 1000-1012.

Hörandl, E. (2006). The complex causality of geographical parthenogenesis. New Phytol., $171,525-538$.

Hörandl, E. and Hadacek, F. (2013). The oxidative damage initiation hypothesis for meiosis. Plant Reprod., 26, 351-367.

Jablonka, E., and Lamb, M.J. (1995). Epigenetic Inheritance and Evolution,Oxford University Press: Oxford, UK.

Johannes, F., Porcher, E., Teixeira, F.K., Saliba-Colombani, V., Simon, M., Agier, N., Bulski, A., Albuisson, J., Heredia, F., Audigier, P., et al.(2009). Assessing the Impact of Transgenerational Epigenetic Variation on Complex Traits. PLoS Genet., 5, e1000530, doi:10.1371/journal.pgen.1000530.

Kelly, M. (2019). Adaptation to climate change through genetic accommodation and assimilation of plastic phenotypes. Philos. Trans. R. Soc. B, 374, 20180176. 
Kirchheimer, B., Schinkel, C.C.-F., Dellinger, A.S., Klatt, S., Moser, D., Winkler, M., Lenoir, J., Caccianiga, M., Guisan, A., Nieto-lugilde, D., et al.(2016). A matter of scale: Apparent niche differentiation of diploid and tetraploid plants may depend on extent and grain of analysis. J. Biogeogr., 43, 716-726.

Kirchheimer, B., Wessely, J., Gattringer, A., Hülber, K., Moser, D., Schinkel, C.C.-F., Appelhans, M., Klatt, S., Caccianiga, M., Dellinger, A., et al.(2018). Reconstructing geographical parthenogenesis: Effects of niche differentiation and reproductive mode on Holocene range expansion of an alpine plant. Ecol. Lett., 21, 392-401.

Klatt, S., Hadacek, F., Hodac, L., Brinkmann, G., Eilerts, M., Hojsgaard, D., and Hörandl, E. (2016). Photoperiod extension enhances sexual megaspore formation and triggers metabolic reprogramming in facultative apomictic Ranunculus auricomus. Front. Plant Sci., 7, 728.

Klatt, S., Schinkel, C.C.-F., Kirchheimer, B., Dullinger, S., and Hörandl, E. (2018). Effects of cold treatments on fitness and mode of reproduction in the diploid and polyploid alpine plant Ranunculus kuepferi (Ranunculaceae). Ann. Bot., 121, 1287-1298.

Koltunow, A.M. and Grossniklaus, U. (2003). Apomixis: A developmental perspective. Annu. Rev. Plant Biol., 54, 547-574.

Kooke, R., Johannes, F., Wardenaar, R., Becker, F., Etcheverry, M., Colot, V., Vreugdenhil, D., and Keurentjes, J.B. (2015). Epigenetic Basis of Morphological Variation and Phenotypic Plasticity in Arabidopsis thaliana. Plant Cell, 27, 337-348.

Kopp, M., and Matuszewski, S. (2013). Rapid evolution of quantitative traits: Theoretical perspectives. Evol. Appl., 7, 169-191.

Körner, C.H. (2003). Alpine Plant Life, 2nd ed., Springel: Berlin, Germany.

Kumar, P., and Singhal, V.K. (2011). Male meiosis, morphometric analysis and distribution pattern of 2x and 4x cytotypes of Ranunculus hirtellus Royle (Ranunculaceae) from the cold regions of northwest Himalayas (India). Comp. Cytogenet., 5, 143-161.

Küpfer, P. (1974). Recherches sur les liens de parente entre la flore orophile des Alpes et celle des Pyrenees. Boissiera, 23, 1-322.

Lacaze, X., Hayes, P.M., and Korol, A. (2009). Genetics of phenotypic plasticity: QTL analysis in barley Hordeum Vulgare. Heredity, 102, 163-173.

Ladinig, U., and Wagner, J. (2007). Timing of sexual reproduction and reproductive success in the high-mountain plant Saxifraga bryoides L. Plant Biol., 9, 683-693. 
Ladinig, U., Hacker, J., Neuner, G., and Wagner, J. (2013). How endangered is sexual reproduction of high-mountain plants by summer frosts? Frost resistance, frequency of frost events and risk assessments. Oecologia, 171, 743-760.

Laland, K.N., Uller, T., Feldman, M.W., Sterelny, K., Müller, G.B., Moczek, A., Jablinka, E., and Odling-Smee, J. (2015). The extended evolutionary synthesis: its structure, assumptions and predictions. Proc. R. Soc. B, 282, 20151019.

Lande, R. (2009). Adaptation to an extraordinary environment by evolution of phenotypic plasticity and genetic assimilation. J. Evol. Biol., 22, 1435-1446.

Levin, D.A. (1975). Minority cytotype exclusion in local plant populations. Taxon, 24, 3543.

Levin, D.A. (2003). The cytoplasmatic factor in plant speciation. Syst. Bot., 28, 5-11.

Matzk, F., Meister, A., and Schubert, I. (2000). An efficient screen for reproductive pathways using mature seeds of monocots and dicots. Plant J., 21, 97-108.

Maugarny-Calès, A., and Laufs, P. (2018). Getting leaves into shape: A molecular, cellular, environmental and evolutionary view. Development, 145, dev161646.

Merilä, J., and Hendry, P. (2013). Climate change, adaptation and phenotypic plasticity: The problem and the evidence. Evol. Appl., 7, 1-14.

Metcalf, J.C., Rose, K., and Rees, M. (2003). Evolutionary demography of monocarpic perennials. Trends Ecol. Evol., 18, 471-480.

Mirouze, M., and Paskzowski, J. (2011). Epigenetic contribution to stress adaptation in plants. Curr. Opin. Plant Biol., 14, 267-274.

Miryeganeh, M., and Saze, H. (2019) Epigenetic inheritance in plant evolution. Popul. Ecol., 62, 17-27.

Moller, A.P., and Swaddle, J.P. (1997). Asymmetry, Developmental Stability and Evolution, Oxford University Press: Oxford, UK.

Munns, R. (2011). Plant adaptations to salt and water stress: Differences and commonalities. Adv. Bot. Res., 57, 1-32.

Nagy, L., and Grabherr, G. (2009). The Biology of Alpine Habitats, Oxford University Press: New York, NY, USA.

Nicotra, A.B., Atkin, O.K., Bonser, S.P., Davidson, A.M., Finnegan, E.J., Mathesius, U., Poot, P., Purugganan, M.D., Richards, C.L., Valladares, F., et al.(2010). Plant phenotypic plasticity in a changing climate. Trends Plant Sci., 15, 684-692. 
Nicotra, A.B., Segal, D.L., Hoyle, G.L., Schrey, A.W., Verhoeven, K.J.F., and Richards, C.L. (2015). Adaptive plasticity and epigenetic variation in response to warming in an alpine plant. Ecol. Evol., 5, 634-647.

Noble, D., Jablonka, E., Joyner, M., Muller, G., and Omholt, S.W. (2014). Evolution evolves: Physiology returns to centre stage. J. Physiol., 592, 2237-2244.

Nogler, G.A. (1984). Gametophytic apomixis. In Embryology of Angiosperms, 1st ed., Johri, B.M., Ed., Springer: Berlin, Germany, 475-518.

Oksanen, J., Blanchet, F.G., Kindt, R., Legendre, P., Minchin, P.R., Ohara, R., et al. (2019). Vegan: Community Ecology Package, version 2.2-1, 2019. Available online: https:/ /CRAN.R-project.org/package=vegan/ (accessed on spring 2019).

Otto, F.J. (1990). DAPI staining of fixed cells for high-resolution flow cytometry of nuclear DNA. Methods Cell Biol., 33, 105-110.

Ozias-Akins, P., and van Dijk, P.J. (2007). Mendelian genetics of apomixis in plants. Annu. Rev. Genet., 41, 509-537.

Pal, C., and Milkos, I. (1999). Epigenetic inheritance, genetic assimilation and speciation. J. Theor. Biol., 200, 19-37.

Palmer, A.R., and Strobeck, C. (1986). Fluctuating asymmetry: Measurement, analysis, patterns. Annu. Rev. Ecol. Syst., 17, 391-421.

Palmer, A.R. (1996). Waltzing with Asymmetry. BioScience, 46, 518-532.

Paskowski, J., and Grossniklaus, U. (2011). Selected aspects of transgenerational epigenetic inheritance and resetting in plants. Curr. Opin. Plant Biol., 14, 195-203.

Paun, O., and Schönswetter, P. (2012). Amplified Fragment Length Polymorphism (AFLP)-An invaluable fingerprinting technique for genomic, transcriptomic and epigenetic studies. Methods Mol. Biol., 862, 75-87.

Pfenning, D.W., and McGee, M. (2010). Resource polyphenism increases species richness: A test of the hypothesis. Philos. Trans. R Soc. Ser. B, 365, 577-591.

Pigliucci, M. (2001). Phenotypic Plasticity: Beyond Nature and Nurture, John Hopkins Press: Baltimore, MD, USA.

Preite, V., Snoek, L., Oplaat, C., Biere, A., Putten, W., and Verhoeven, K.J.F. (2015). The epigenetic footprint of poleward range-expanding plants in apomictic dantelions. Mol. Ecol., 24, 4406-4418. 
Price, T.D., Qvarnström, A., and Irwin, D.E. (2003). The role of phenotypic plasticity in driving genetic evolution. Proc. R. Soc. Lond. Ser. B, 270, 1433-1440.

R Core Team. (2019).R: A Language and Environment for Statistical Computing, $\mathrm{R}$ Foundation for Statistical Computing: Vienna, Austria. Available online: https://www.R-project.org/ (accessed on spring 2019).

Ramsey, J., and Schemske, D.W. (1998). Pathways, mechanisms, and rates of polyploidy formation in flowering plants. Annu. Rev. Ecol. Syst., 29, 467-501.

Richards, C.L., Bossdorf, O., Muth, N.Z., Gurevitch, J., and Pigliucci, M. (2006). Jack of all trades, master of some? On the role of phenotypic plasticity in plant invasions. Ecol. Lett., 9, 981-993.

Richards, E.J. (2006). Inherited epigenetic variation-revisiting soft inheritance. Nat. Rev., 7, 395-402.

Richards, C.L., Alonso, C., Becker, C., Bossdorf, O., Bucher, E., Colome-Tatche, M., Durka, W., Engelhardt, J., Gaspar, B., Gogol-Döring, A., et al.(2017). Ecological plant epigenetics: Evidence from model and non-model species, and the way forward. Ecol. Lett., 20, 1576-1590.

RStudio Team. (2016).RStudio: Integrated Development for $R$, RStudio, PBC: Boston, MA, USA. Available online: http://www.rstudio.com/ (accessed on spring 2019).

Rubenstein, D.R., Skolnik, H., Berrio, A., Champagne, F. A., Phelps, S., and Solomon, J. (2016). Sex-specific fitness effects of unpredictable early life conditions are associated with DNA methylation in the avian glucocorticoid receptor. Mol. Ecol., 25, 1714-1728.

Schinkel, C.C.-F., Kirchheimer, B., Dellinger, A.S., Klatt, S., Winkler, M., Dullinger, S., and Hörandl, E. (2016). Correlations of polyploidy and apomixis with elevation and associated environmental gradients in an alpine plant. AoB Plants, 8, plw064, doi:10.1093/aobpla/plw064.

Schinkel, C.C.-F., Kirchheimer, B., Dullinger, S., Geelen, D., De Storme, N., and Hörandl, E. (2017). Pathways to polyploidy: Indications of a female triploid bridge in the alpine species Ranunculus kuepferi (Ranunculaceae). Plant Syst. Evol., 303, 1093-1108.

Schinkel, C.C.-F., Syngelaki, E., Kirchheimer, B., Dullinger, S., Klatt, S., and Hörandl, E. (2020). Epigenetic patterns and geographical parthenogenesis in the alpine plant species Ranunculus kuepferi (Ranunculaceae). Int. J. Mol. Sci., 21, 3318.

Schlichting, C.D. (1986). The evolution of phenotypic plasticity in plants. Annu. Rev. Ecol. Syst., 17, 667-693. 
Schlichting, C.D., and Pigliucci, M. (1998). Phenotypic Evolution: A Reaction Norm Perspective, Sinauer: Sunderland, MA, USA.

Schmidt, A. (2020). Controlling Apomixis: Shared features and distinct characteristics of gene regulation. Genes, 11, 329.

Schulz, B., Eckstein, R.L., and Durka, W. (2013). Scoring and analysis of methylationsensitive amplification polymorphisms for epigenetic population studies. Mol. Ecol. Resour., 13, 642-653.

Shan, X., Wang, X., Yang, G., Wu, Y., Su, S., Li, S., Liu, H., and Yuan, Y. (2013). Analysis of the DNA Methylation of Maize (Zea mays L.) in response to cold stress Based on methylation-sensitive amplified polymorphisms. J. Plant Biol., 56, 32-38.

Sol, D., Duncan, R.P., Blackburn, T.M., Cassey, P., and Lefebvre, L. (2005). Big brains, enhanced cognition and response of birds to novel environments. Proc. Natl. Acad. Sci. USA, 102, 5460-6465.

Sterns, S. (1989). The evolutionary significance of phenotypic plasticity. Bioscience, 39, 436-445.

Steward, N., Ito, M., Yamaguchi, Y., Koizumi, N., and Sano, H. (2002). DNA methylation in maize nucleosomes and demethylation by environmental stress. J. Biol. Chem., 277, 37741-37746.

Suzuki, N., Rivero, R.M., Shulaev, V., Blumwald, E., and Mittler, R. (2014). Abiotic and biotic stress combinations. New Phytol., 203, 32-43.

Syngelaki, E., Schinkel, C.C.-F., Klatt, S., and Hörandl, E. (2020). Effects of temperature treatments on cytosine-methylation profiles of diploid and autotetraploid plants of the alpine species Ranunculus kuepferi (Ranunculaceae). Front. Plant Sci., 11, 435.

te Beest, M., Le Roux, J.J., Richardson, D.M., Brysting, A.K., Suda, J., Kubesova, M., and Pysck, P. (2012). The more the better? The role of polyploidy in facilitating plant invasions. Ann. Bot., 109, 19-45.

Tholen, D., Boom, C., and Zhu, X.-G. (2012). Opinion: Prospects for improving photosynthesis by altering leaf anatomy. Plant Sci., 197, 92-101.

Ulum, F.B., Castro, C.C., and Hörandl, E. (2020). Ploidy-dependent effects of light stress on the mode of reproduction in the Ranunculus auricomus complex (Ranunculaceae). Front. Plant Sci., 11, 104.

van Kleunen, M., and Fisher, M. (2001). Adaptive evolution of plastic foraging responses in a clonal plant. Ecology, 82, 3309-3319. 
van Kleunen, M., and Fisher, M. (2003). Effects of four generations of densitydependent selection on life history traits and their plasticity in a clonally propagated plant. J. Evol. Biol., 16, 474-484.

Vandel, A. (1928). La parthenogenese geographique: Contribution a l'etude biologique et cytologique de la parthenogenese naturelle. Bull Biol. France Belg., 62, 164-281.

Verhoeven, K.J.F., Jansen, J.J., van Dijk, P.J., and Biere, A. (2010a). Stress-induced DNA methylation changes and their heritability in asexual dandelions. New Phytol., 185, 1108-1118.

Verhoeven, K.J.F., van Dijk, P.J., and Biere, A. (2010b). Changes in genomic methylation patterns during the formation of triploid asexual dandelion lineages. Mol. Ecol., 19, 315-324.

Verhoeven, K.J.F., and Preite, V. (2013). Epigenetic variation in asexually reproducing organisms. Evolution, 68, 644-655.

Verhoeven, K.J.F., von Holdt, B.M., and Sork, V.L. (2016). Epigenetics in ecology and evolution: What we know and what we need to know. Mol. Ecol., 25, 1631-1638.

Via, S., and Lande, R. (1985). Genotype-environment interaction and the evolution of phenotypic plasticity. Evolution, 39, 505-522.

Vrijenhoek, R.C., and Parker, E.D. (2009). Geographical parthenogenesis: General purpose genotypes and frozen niche variation BT. In Lost Sex: The Evolutionary Biology of Parthenogenesis, Schön, I., Martens, K., Dijk, P., Eds., Springer: Dordrecht, The Netherlands, 99-131.

West-Eberhard, M.J. (2003). Developmental Plasticity and Evolution, Oxford University Press: Oxford, UK.

West-Eberhard, M.J. (2008). Phenotypic plasticity. In Encyclopedia of Ecology, Jorgensen, E., Fath, B., Eds., Elsevier Science: Amsterdam, The Netherlands, 2701-2707.

Westoby, M. (1998). A leaf-height-seed (LHS) plant ecology strategy scheme. Plant Soil, 199, 213-227.

Wickham, H. (2009). Ggplot2: Elegant Graphics for Data Analysis. Springer: New York, NY, USA.

Whitman, D.W, and Agrawal, A.A. (2009). What is phenotypic plasticity and why is it important? In Phenotypic Plasticity of Insects, Ananthakrishnan, T.N., Ed., Science Publishers: Enfield, New Hampshire, USA, 1-63. 
Wyles, J.S., Kunkel, J.G., and Wilson, A.C. (1983). Birds, behavior and anatomical evolution. Proc. Natl. Acad. Sci. USA, 80, 4394-4397.

Yamori, W., Hikosaka, K., and Way, D.A. (2014). Temperature response of photosynthesis in $\mathrm{C}_{3}, \mathrm{C}_{4}$, and CAM plants: Temperature acclimation and temperature adaptation. Photsynth. Res., 119, 101-117.

Yeh, P.J., and Price, T.D. (2004). Adaptive phenotypic plasticity and the successful colonization of a novel environment. Am. Nat., 164, 531-542.

Zhang, Y., Fischer, M., Colot, V., and Bossdorf, O. (2013). Epigenetic variation creates potential for evolution of plant phenotypic plasticity. New Phytol., 197, 314-322.

Zhang, H., Lang, Z., and Zhu, J. (2018). Dynamics and function of DNA methylation in plants. Nat. Rev., 19, 489-506.

Zuur, A.F., Ieno, E.N., Walker, N.J., Saveliev, A.A., and Smith, G.M. (2009). Mixed Effects Models and Extensions in Ecology with R, Springer: New York, NY, USA. 


\subsection{Supporting Information}

Table S1. List of individuals placed in the climate chambers. Listed are the sampling ID, ploidy level, treatment, country, province and altitude. The individuals, which were used for the MSAP laboratory work, are highlighted with green (Schinkel et al., 2016; Klatt et al., 2018; Syngelaki et al., 2020).

\begin{tabular}{|c|c|c|c|c|c|c|}
\hline SampleID & $\begin{array}{c}\text { Leaf } \\
\text { ploidy }\end{array}$ & $\begin{array}{c}\text { Temperature } \\
\text { treatment } \\
2017\end{array}$ & Country & Region & Altitude & MSAPs \\
\hline 3_2_3 & diploid & warm & France & Provence-Alpes-Côte d'Azur & 2291 & $\mathrm{Y}$ \\
\hline 3_4_2 & diploid & warm & France & Provence-Alpes-Côte d'Azur & 2291 & $\mathrm{~N}$ \\
\hline 3_4_3 & diploid & warm & France & Provence-Alpes-Côte d'Azur & 2291 & $\mathrm{~N}$ \\
\hline 23_1_2 & diploid & warm & France & Provence-Alpes-Côte d'Azur & 1616 & $\mathrm{~N}$ \\
\hline 23_2_2 & diploid & warm & France & Provence-Alpes-Côte d'Azur & 1616 & $\mathrm{~N}$ \\
\hline 23_2_3 & diploid & warm & France & Provence-Alpes-Côte d'Azur & 1616 & $\mathrm{~N}$ \\
\hline 23_4_1 & diploid & warm & France & Provence-Alpes-Côte d'Azur & 1616 & Y \\
\hline $23 \_4 \_3$ & diploid & warm & France & Provence-Alpes-Côte d'Azur & 1616 & $\mathrm{~N}$ \\
\hline $24 \_2 \_2$ & diploid & warm & France & Provence-Alpes-Côte d'Azur & 1925 & $\mathrm{~N}$ \\
\hline 24_2_3 & diploid & warm & France & Provence-Alpes-Côte d'Azur & 1925 & $\mathrm{~N}$ \\
\hline 24_3_2 & diploid & warm & France & Provence-Alpes-Côte d'Azur & 1925 & $\mathrm{~N}$ \\
\hline 24_4_1 & diploid & warm & France & Provence-Alpes-Côte d'Azur & 1925 & $\mathrm{~N}$ \\
\hline 24_4_3 & diploid & warm & France & Provence-Alpes-Côte d'Azur & 1925 & Y \\
\hline 25_1_2 & diploid & warm & France & Provence-Alpes-Côte d'Azur & 1435 & $\mathrm{~N}$ \\
\hline 25_2_2 & diploid & warm & France & Provence-Alpes-Côte d'Azur & 1435 & $\mathrm{~N}$ \\
\hline 25_2_3 & diploid & warm & France & Provence-Alpes-Côte d'Azur & 1435 & $\mathrm{~N}$ \\
\hline 25_3_2 & diploid & warm & France & Provence-Alpes-Côte d'Azur & 1435 & Y \\
\hline 25_3_3 & diploid & warm & France & Provence-Alpes-Côte d'Azur & 1435 & $\mathrm{~N}$ \\
\hline 25_4_1 & diploid & warm & France & Provence-Alpes-Côte d'Azur & 1435 & $\mathrm{~N}$ \\
\hline 26_1_2 & diploid & warm & France & Provence-Alpes-Côte d'Azur & 1456 & $\mathrm{~N}$ \\
\hline 26_2_1 & diploid & warm & France & Provence-Alpes-Côte d'Azur & 1456 & $\mathrm{~N}$ \\
\hline $26 \_2 \_2$ & diploid & warm & France & Provence-Alpes-Côte d'Azur & 1456 & $\mathrm{~N}$ \\
\hline 26_3_2 & diploid & warm & France & Provence-Alpes-Côte d'Azur & 1456 & $\mathrm{~N}$ \\
\hline 26_3_3 & diploid & warm & France & Provence-Alpes-Côte d'Azur & 1456 & Y \\
\hline $26 \_4 \_3$ & diploid & warm & France & Provence-Alpes-Côte d'Azur & 1456 & $\mathrm{~N}$ \\
\hline 27_1_1 & diploid & warm & France & Rhônes-Alpes & 1449 & $\mathrm{~N}$ \\
\hline 27_1_2 & diploid & warm & France & Rhônes-Alpes & 1449 & $\mathrm{~N}$ \\
\hline 27_2_1 & diploid & warm & France & Rhônes-Alpes & 1449 & Y \\
\hline 27_2_2 & diploid & warm & France & Rhônes-Alpes & 1449 & $\mathrm{~N}$ \\
\hline 27_2_3 & diploid & warm & France & Rhônes-Alpes & 1449 & $\mathrm{~N}$ \\
\hline 27_3_1 & diploid & warm & France & Rhônes-Alpes & 1449 & $\mathrm{~N}$ \\
\hline 27_4_3 & diploid & warm & France & Rhônes-Alpes & 1449 & $\mathrm{~N}$ \\
\hline 28_2_2 & diploid & warm & Italy & Piemonte & 1685 & $\mathrm{~N}$ \\
\hline 28_3_1 & diploid & warm & Italy & Piemonte & 1685 & Y \\
\hline
\end{tabular}




\begin{tabular}{|c|c|c|c|c|c|c|}
\hline SampleID & $\begin{array}{l}\text { Leaf } \\
\text { ploidy }\end{array}$ & $\begin{array}{c}\text { Temperature } \\
\text { treatment } \\
2017 \\
\end{array}$ & Country & Region & Altitude & MSAPs \\
\hline 28_3_2 & diploid & warm & Italy & Piemonte & 1685 & Y \\
\hline 28_4_2 & diploid & warm & Italy & Piemonte & 1685 & $\mathrm{~N}$ \\
\hline 28_4_3 & diploid & warm & Italy & Piemonte & 1685 & $\mathrm{~N}$ \\
\hline 29_1_1 & diploid & warm & Italy & Piemonte & 2020 & $\mathrm{~N}$ \\
\hline 29_1_2 & diploid & warm & Italy & Piemonte & 2020 & $\mathrm{Y}$ \\
\hline $29 \_2 \_2$ & diploid & warm & Italy & Piemonte & 2020 & $\mathrm{~N}$ \\
\hline 29_4_1 & diploid & warm & Italy & Piemonte & 2020 & $\mathrm{~N}$ \\
\hline 30_1_1 & diploid & warm & Italy & Piemonte & 1743 & $\mathrm{~N}$ \\
\hline 30_1_3 & diploid & warm & Italy & Piemonte & 1743 & $\mathrm{Y}$ \\
\hline 31_3_3 & diploid & warm & Italy & Piemonte & 1937 & $\mathrm{Y}$ \\
\hline 31_4_1 & diploid & warm & Italy & Piemonte & 1937 & $\mathrm{~N}$ \\
\hline 31_4_2 & diploid & warm & Italy & Piemonte & 1937 & $\mathrm{~N}$ \\
\hline 32_1_3 & diploid & warm & Italy & Piemonte & 2320 & $\mathrm{~N}$ \\
\hline 32_4_1 & diploid & warm & Italy & Piemonte & 2320 & $\mathrm{~N}$ \\
\hline 32_4_2 & diploid & warm & Italy & Piemonte & 2320 & Y \\
\hline 33_3_2 & diploid & warm & Italy & Piemonte & 2328 & $\mathrm{~N}$ \\
\hline 33_3_3 & diploid & warm & Italy & Piemonte & 2328 & $\mathrm{Y}$ \\
\hline 33_4_3 & diploid & warm & Italy & Piemonte & 2328 & $\mathrm{~N}$ \\
\hline 112_1_3 & diploid & warm & France & Provence-Alpes-Côte d'Azur & 1626 & $\mathrm{~N}$ \\
\hline $112 \_2 \_2$ & diploid & warm & France & Provence-Alpes-Côte d'Azur & 1626 & $\mathrm{~N}$ \\
\hline 112_2_3 & diploid & warm & France & Provence-Alpes-Côte d'Azur & 1626 & $\mathrm{~N}$ \\
\hline 112_3_1 & diploid & warm & France & Provence-Alpes-Côte d'Azur & 1626 & $\mathrm{Y}$ \\
\hline 112_3_2 & diploid & warm & France & Provence-Alpes-Côte d'Azur & 1626 & Y \\
\hline 112_3_3 & diploid & warm & France & Provence-Alpes-Côte d'Azur & 1626 & $\mathrm{~N}$ \\
\hline 115_1_1 & diploid & warm & France & Provence-Alpes-Côte d'Azur & 1891 & $\mathrm{~N}$ \\
\hline 115_1_2 & diploid & warm & France & Provence-Alpes-Côte d'Azur & 1891 & $\mathrm{~N}$ \\
\hline 115_2_2 & diploid & warm & France & Provence-Alpes-Côte d'Azur & 1891 & $\mathrm{~N}$ \\
\hline 115_3_3 & diploid & warm & France & Provence-Alpes-Côte d'Azur & 1891 & Y \\
\hline 115_4_3 & diploid & warm & France & Provence-Alpes-Côte d'Azur & 1891 & $\mathrm{~N}$ \\
\hline 116_1_1 & diploid & warm & France & Provence-Alpes-Côte d'Azur & 1953 & Y \\
\hline 116_1_2 & diploid & warm & France & Provence-Alpes-Côte d'Azur & 1953 & $\mathrm{~N}$ \\
\hline 116_2_1 & diploid & warm & France & Provence-Alpes-Côte d'Azur & 1953 & $\mathrm{~N}$ \\
\hline 116_3_3 & diploid & warm & France & Provence-Alpes-Côte d'Azur & 1953 & $\mathrm{Y}$ \\
\hline 117_1_2 & diploid & warm & France & Provence-Alpes-Côte d'Azur & 1632 & $\mathrm{~N}$ \\
\hline 117_1_3 & diploid & warm & France & Provence-Alpes-Côte d'Azur & 1632 & $\mathrm{~N}$ \\
\hline 117_2_1 & diploid & warm & France & Provence-Alpes-Côte d'Azur & 1632 & $\mathrm{~N}$ \\
\hline 117_3_2 & diploid & warm & France & Provence-Alpes-Côte d'Azur & 1632 & $\mathrm{Y}$ \\
\hline 117_4_1 & diploid & warm & France & Provence-Alpes-Côte d'Azur & 1632 & $\mathrm{~N}$ \\
\hline 117_4_2 & diploid & warm & France & Provence-Alpes-Côte d'Azur & 1632 & $\mathrm{~N}$ \\
\hline 202_1_1 & diploid & warm & France & Provence-Alpes-Côte d'Azur & 1829 & $\mathrm{~N}$ \\
\hline 202_1_2 & diploid & warm & France & Provence-Alpes-Côte d'Azur & 1829 & $\mathrm{~N}$ \\
\hline
\end{tabular}




\begin{tabular}{|c|c|c|c|c|c|c|}
\hline SampleID & $\begin{array}{l}\text { Leaf } \\
\text { ploidy }\end{array}$ & $\begin{array}{c}\text { Temperature } \\
\text { treatment } \\
2017 \\
\end{array}$ & Country & Region & Altitude & MSAPs \\
\hline 202_2_1 & diploid & warm & France & Provence-Alpes-Côte d'Azur & 1829 & $\mathrm{~N}$ \\
\hline 202_4_3 & diploid & warm & France & Provence-Alpes-Côte d'Azur & 1829 & $\mathrm{~N}$ \\
\hline 203_2_3 & diploid & warm & France & Provence-Alpes-Côte d'Azur & 1840 & $\mathrm{~N}$ \\
\hline $203 \_4 \_2$ & diploid & warm & France & Provence-Alpes-Côte d'Azur & 1840 & $\mathrm{~N}$ \\
\hline 203_4_3 & diploid & warm & France & Provence-Alpes-Côte d'Azur & 1840 & Y \\
\hline 233_1_1 & diploid & warm & France & Provence-Alpes-Côte d'Azur & 2185 & $\mathrm{~N}$ \\
\hline 233_2_1 & diploid & warm & France & Provence-Alpes-Côte d'Azur & 2185 & $\mathrm{Y}$ \\
\hline 233_2_2 & diploid & warm & France & Provence-Alpes-Côte d'Azur & 2185 & $\mathrm{~N}$ \\
\hline 233_3_2 & diploid & warm & France & Provence-Alpes-Côte d'Azur & 2185 & $\mathrm{~N}$ \\
\hline 28B_2_1 & diploid & warm & Italy & Piemonte & 1685 & $\mathrm{~N}$ \\
\hline 28B_3_1 & diploid & warm & Italy & Piemonte & 1685 & $\mathrm{Y}$ \\
\hline 28B_4_3 & diploid & warm & Italy & Piemonte & 1685 & $\mathrm{~N}$ \\
\hline 31B_1_1 & diploid & warm & Italy & Piemonte & 1937 & $\mathrm{~N}$ \\
\hline $\begin{array}{c}\text { 31B_1_3 } \\
\text { 31B/32B__ }\end{array}$ & diploid & warm & Italy & Piemonte & 1937 & Y \\
\hline $2 \_2$ & diploid & warm & Italy & Piemonte & 1937 & $\mathrm{Y}$ \\
\hline 32B_1_2 & diploid & warm & Italy & Piemonte & 2320 & Y \\
\hline $\begin{array}{c}\text { 32B } / 31 \mathrm{~B} \_ \\
4 \_3 \\
\end{array}$ & diploid & warm & Italy & Piemonte & 1937 & $\mathrm{~N}$ \\
\hline 16_4_1 & tetraploid & warm & France & Provence-Alpes-Côte d'Azur & 2078 & $\mathrm{~N}$ \\
\hline 17_1_1 & tetraploid & warm & France & Provence-Alpes-Côte d'Azur & 2357 & $\mathrm{~N}$ \\
\hline 17_2_1 & tetraploid & warm & France & Provence-Alpes-Côte d'Azur & 2357 & $\mathrm{~N}$ \\
\hline 17_3_3 & tetraploid & warm & France & Provence-Alpes-Côte d'Azur & 2357 & $\mathrm{~N}$ \\
\hline 17_4_3 & tetraploid & warm & France & Provence-Alpes-Côte d'Azur & 2357 & $\mathrm{Y}$ \\
\hline 34_2_1 & tetraploid & warm & France & Rhônes-Alpes & 2120 & $\mathrm{Y}$ \\
\hline 34_2_3 & tetraploid & warm & France & Rhônes-Alpes & 2120 & $\mathrm{~N}$ \\
\hline 34_4_1 & tetraploid & warm & France & Rhônes-Alpes & 2120 & $\mathrm{~N}$ \\
\hline 36_1_1 & tetraploid & warm & France & Rhônes-Alpes & 2152 & $\mathrm{~N}$ \\
\hline 36_2_3 & tetraploid & warm & France & Rhônes-Alpes & 2152 & $\mathrm{~N}$ \\
\hline 36_4_1 & tetraploid & warm & France & Rhônes-Alpes & 2152 & $\mathrm{Y}$ \\
\hline 36_4_2 & tetraploid & warm & France & Rhônes-Alpes & 2152 & $\mathrm{~N}$ \\
\hline 37_1_2 & tetraploid & warm & Italy & Val d'Aosta & 2115 & $\mathrm{Y}$ \\
\hline 37_2_3 & tetraploid & warm & Italy & Val d'Aosta & 2115 & $\mathrm{~N}$ \\
\hline 37_3_1 & tetraploid & warm & Italy & Val d'Aosta & 2115 & $\mathrm{~N}$ \\
\hline 38_1_2 & tetraploid & warm & France & Rhônes-Alpes & 2182 & $Y$ \\
\hline 40_1_1 & tetraploid & warm & $\begin{array}{c}\text { Switzerla } \\
\text { nd } \\
\text { Switzerla }\end{array}$ & Wallis & 1860 & $\mathrm{~N}$ \\
\hline 40_2_1 & tetraploid & warm & nd & Wallis & 1860 & $\mathrm{~N}$ \\
\hline 40_3_3 & tetraploid & warm & $\begin{array}{l}\text { Switzerla } \\
\text { nd }\end{array}$ & Wallis & 1860 & $\mathrm{~N}$ \\
\hline 40_4_3 & tetraploid & warm & $\begin{array}{l}\text { Switzerid } \\
\text { nd }\end{array}$ & Wallis & 1860 & $\mathrm{~N}$ \\
\hline
\end{tabular}




\begin{tabular}{|c|c|c|c|c|c|c|}
\hline SampleID & $\begin{array}{l}\text { Leaf } \\
\text { ploidy }\end{array}$ & $\begin{array}{c}\text { Temperature } \\
\text { treatment } \\
2017 \\
\end{array}$ & Country & Region & Altitude & MSAPs \\
\hline 41_4_3 & tetraploid & warm & $\begin{array}{c}\text { Italy } \\
\text { Switzerla }\end{array}$ & Val d'Aosta & 2174 & Y \\
\hline 42_1_2 & tetraploid & warm & nd & Wallis & 1789 & Y \\
\hline 42_1_3 & tetraploid & warm & $\begin{array}{l}\text { Switzerla } \\
\text { nd } \\
\text { Switzerla }\end{array}$ & Wallis & 1789 & $\mathrm{~N}$ \\
\hline $42 \_2 \_2$ & tetraploid & warm & $\begin{array}{c}\text { nd } \\
\text { Switzerla }\end{array}$ & Wallis & 1789 & $\mathrm{~N}$ \\
\hline 42_3_3 & tetraploid & warm & $\begin{array}{c}\text { nd } \\
\text { Switzerla }\end{array}$ & Wallis & 1789 & $\mathrm{~N}$ \\
\hline 43_4_1 & tetraploid & warm & $\begin{array}{c}\text { nd } \\
\text { Switzerla }\end{array}$ & Wallis & 2012 & $\mathrm{~N}$ \\
\hline 43_4_3 & tetraploid & warm & $\begin{array}{c}\text { nd } \\
\text { Switzerla }\end{array}$ & Wallis & 2012 & $\mathrm{~N}$ \\
\hline 45_1_3 & tetraploid & warm & $\begin{array}{c}\text { nd } \\
\text { Switzerla }\end{array}$ & Wallis & 2400 & $\mathrm{~N}$ \\
\hline 45_2_2 & tetraploid & warm & $\begin{array}{c}\text { nd } \\
\text { Switzerla }\end{array}$ & Wallis & 2400 & $\mathrm{~N}$ \\
\hline 45_2_3 & tetraploid & warm & $\begin{array}{c}\text { nd } \\
\text { Switzerla }\end{array}$ & Wallis & 2400 & $\mathrm{~N}$ \\
\hline 45_3_2 & tetraploid & warm & $\begin{array}{c}\text { nd } \\
\text { Switzerla }\end{array}$ & Wallis & 2400 & $\mathrm{~N}$ \\
\hline 45_3_3 & tetraploid & warm & nd & Wallis & 2400 & $\mathrm{~N}$ \\
\hline 47_1_1 & tetraploid & warm & $\begin{array}{l}\text { Switzerla } \\
\text { nd }\end{array}$ & Graubünden & 2211 & $\mathrm{~N}$ \\
\hline 47_2_1 & tetraploid & warm & & Graubünden & 2211 & $\mathrm{~N}$ \\
\hline 47_3_2 & tetraploid & warm & $\begin{array}{c}\text { Switzerla } \\
\text { nd }\end{array}$ & Graubünden & 2211 & $\mathrm{~N}$ \\
\hline 47_3_3 & tetraploid & warm & $\begin{array}{c}\text { Switzerla } \\
\text { nd }\end{array}$ & Graubünden & 2211 & Y \\
\hline 48_1_1 & tetraploid & warm & $\begin{array}{c}\text { Switzerla } \\
\text { nd }\end{array}$ & Graubünden & 2262 & $\mathrm{~N}$ \\
\hline $48 \_2 \_2$ & tetraploid & warm & $\begin{array}{l}\text { Switzerla } \\
\text { nd }\end{array}$ & Graubünden & 2262 & $\mathrm{~N}$ \\
\hline 50_1_2 & tetraploid & warm & $\begin{array}{l}\text { Switzerla } \\
\text { nd }\end{array}$ & Graubünden & 2322 & $\mathrm{~N}$ \\
\hline 50_1_3 & tetraploid & warm & $\begin{array}{l}\text { Switzerla } \\
\text { nd }\end{array}$ & Graubünden & 2322 & $\mathrm{~N}$ \\
\hline 50_3_2 & tetraploid & warm & $\begin{array}{l}\text { Switzerla } \\
\text { nd }\end{array}$ & Graubünden & 2322 & $\mathrm{~N}$ \\
\hline 50_3_3 & tetraploid & warm & $\begin{array}{c}\text { Switzerla } \\
\text { nd }\end{array}$ & Graubünden & 2322 & $\mathrm{~N}$ \\
\hline 51_3_1 & tetraploid & warm & Austria & Tirol & 2286 & Y \\
\hline 51_3_3 & tetraploid & warm & $\begin{array}{l}\text { Austria } \\
\text { Switzerla }\end{array}$ & Tirol & 2286 & $\mathrm{~N}$ \\
\hline 53_1_2 & tetraploid & warm & nd & Graubünden & 2456 & $\mathrm{~N}$ \\
\hline 53_1_3 & tetraploid & warm & $\begin{array}{c}\text { Switzerla } \\
\text { nd }\end{array}$ & Graubünden & 2456 & $\mathrm{Y}$ \\
\hline
\end{tabular}




\begin{tabular}{|c|c|c|c|c|c|c|}
\hline SampleID & $\begin{array}{l}\text { Leaf } \\
\text { ploidy }\end{array}$ & $\begin{array}{c}\text { Temperature } \\
\text { treatment } \\
2017 \\
\end{array}$ & Country & Region & Altitude & MSAPs \\
\hline 53_2_1 & tetraploid & warm & $\begin{array}{l}\text { Switzerla } \\
\text { nd } \\
\text { Switzerla }\end{array}$ & Graubünden & 2456 & $\mathrm{~N}$ \\
\hline 53_3_2 & tetraploid & warm & $\begin{array}{c}\text { nd } \\
\text { Switzerla }\end{array}$ & Graubünden & 2456 & $\mathrm{~N}$ \\
\hline 53_4_3 & tetraploid & warm & nd & Graubünden & 2456 & $\mathrm{~N}$ \\
\hline 54_1_1 & tetraploid & warm & Italy & Lombardia & 2303 & $\mathrm{~N}$ \\
\hline 54_2_3 & tetraploid & warm & Italy & Lombardia & 2303 & Y \\
\hline 54_3_1 & tetraploid & warm & Italy & Lombardia & 2303 & $\mathrm{~N}$ \\
\hline 54_4_1 & tetraploid & warm & Italy & Lombardia & 2303 & $\mathrm{~N}$ \\
\hline 58_1_1 & tetraploid & warm & Italy & $\begin{array}{l}\text { Trentino Alto Adige/ } \\
\text { Südtirol } \\
\text { Trentino Alto Adige/ }\end{array}$ & 2117 & Y \\
\hline 58_3_3 & tetraploid & warm & Italy & Südtirol & 2117 & Y \\
\hline 58_4_1 & tetraploid & warm & Italy & $\begin{array}{c}\text { Trentino Alto Adige/ } \\
\text { Südtirol } \\
\text { Trentino Alto Adige/ }\end{array}$ & 2117 & $\mathrm{~N}$ \\
\hline 66_1_3 & tetraploid & warm & Italy & $\begin{array}{l}\text { Südtirol } \\
\text { Trentino Alto Adige/ }\end{array}$ & 2101 & $\mathrm{~N}$ \\
\hline 66_2_1 & tetraploid & warm & Italy & $\begin{array}{c}\text { Südtirol } \\
\text { Trentino Alto Adige/ }\end{array}$ & 2101 & $\mathrm{~N}$ \\
\hline 66_3_2 & tetraploid & warm & Italy & $\begin{array}{c}\text { Südtirol } \\
\text { Trentino Alto Adige/ }\end{array}$ & 2101 & $\mathrm{~N}$ \\
\hline 66_3_3 & tetraploid & warm & Italy & $\begin{array}{c}\text { Südtirol } \\
\text { Trentino Alto Adige/ }\end{array}$ & 2101 & $\mathrm{~N}$ \\
\hline 66_4_2 & tetraploid & warm & Italy & Südtirol & 2101 & $\mathrm{~N}$ \\
\hline 74_1_1 & tetraploid & warm & Austria & Osttirol & 2117 & $\mathrm{~N}$ \\
\hline 74_1_2 & tetraploid & warm & Austria & Osttirol & 2117 & Y \\
\hline 74_2_1 & tetraploid & warm & $\begin{array}{l}\text { Austria } \\
\text { Switzerla }\end{array}$ & Osttirol & 2117 & $\mathrm{~N}$ \\
\hline 75_3_1 & tetraploid & warm & nd & Graubünden & 2678 & $\mathrm{~N}$ \\
\hline 78_3_2 & tetraploid & warm & $\begin{array}{l}\text { Switzerla } \\
\text { nd }\end{array}$ & Wallis & 2000 & Y \\
\hline 79_1_3 & tetraploid & warm & $\begin{array}{l}\text { Switzerla } \\
\text { nd } \\
\text { Switzerla }\end{array}$ & Graubünden & 2280 & $\mathrm{~N}$ \\
\hline 79_2_1 & tetraploid & warm & nd & Graubünden & 2280 & $\mathrm{~N}$ \\
\hline 79_2_3 & tetraploid & warm & $\begin{array}{l}\text { Switzerla } \\
\text { nd }\end{array}$ & Graubünden & 2280 & $\mathrm{Y}$ \\
\hline 79_3_2 & tetraploid & warm & $\begin{array}{l}\text { Switzerla } \\
\text { nd } \\
\text { Switzerla }\end{array}$ & Graubünden & 2280 & $\mathrm{~N}$ \\
\hline 79_4_1 & tetraploid & warm & nd & Graubünden & 2280 & $\mathrm{~N}$ \\
\hline 85_2_1 & tetraploid & warm & Austria & Kärnten & 2184 & $\mathrm{~N}$ \\
\hline 85_4_1 & tetraploid & warm & $\begin{array}{l}\text { Austria } \\
\text { Switzerla }\end{array}$ & Kärnten & 2184 & Y \\
\hline 88_3_1 & tetraploid & warm & nd & Graubünden & 2300 & Y \\
\hline
\end{tabular}




\begin{tabular}{|c|c|c|c|c|c|c|}
\hline SampleID & $\begin{array}{l}\text { Leaf } \\
\text { ploidy }\end{array}$ & $\begin{array}{c}\text { Temperature } \\
\text { treatment } \\
2017 \\
\end{array}$ & Country & Region & Altitude & MSAPs \\
\hline 89_1_2 & tetraploid & warm & $\begin{array}{l}\text { Switzerla } \\
\text { nd } \\
\text { Switzerla }\end{array}$ & Graubünden & 2265 & $\mathrm{~N}$ \\
\hline 89_2_1 & tetraploid & warm & $\begin{array}{c}\text { nd } \\
\text { Switzerla }\end{array}$ & Graubünden & 2265 & $\mathrm{~N}$ \\
\hline $92 \_2 \_2$ & tetraploid & warm & $\begin{array}{c}\text { nd } \\
\text { Switzerla }\end{array}$ & Graubünden & 2260 & $\mathrm{~N}$ \\
\hline 92_3_2 & tetraploid & warm & $\begin{array}{c}\text { nd } \\
\text { Switzerla }\end{array}$ & Graubünden & 2260 & $\mathrm{~N}$ \\
\hline $92 \_4 \_2$ & tetraploid & warm & $\begin{array}{c}\text { nd } \\
\text { Switzerla }\end{array}$ & Graubünden & 2260 & $\mathrm{~N}$ \\
\hline 93_2_2 & tetraploid & warm & nd & Wallis & 2405 & $\mathrm{~N}$ \\
\hline 96_1_1 & tetraploid & warm & France & Provence-Alpes-Côte d'Azur & 2300 & $\mathrm{~N}$ \\
\hline 96_3_1 & tetraploid & warm & France & Provence-Alpes-Côte d'Azur & 2300 & $\mathrm{~N}$ \\
\hline 96_3_3 & tetraploid & warm & France & Provence-Alpes-Côte d'Azur & 2300 & $\mathrm{~N}$ \\
\hline 103_4_1 & tetraploid & warm & Italy & Lombardia & 2290 & $\mathrm{~N}$ \\
\hline 103_4_2 & tetraploid & warm & Italy & Lombardia & 2290 & Y \\
\hline 106_1_2 & tetraploid & warm & Italy & $\begin{array}{l}\text { Trentino Alto Adige/ } \\
\text { Südtirol } \\
\text { Trentino Alto Adige/ }\end{array}$ & 2142 & $\mathrm{~N}$ \\
\hline 106_3_2 & tetraploid & warm & Italy & $\begin{array}{l}\text { Südtirol } \\
\text { Trentino Alto Adige/ }\end{array}$ & 2142 & $\mathrm{~N}$ \\
\hline 106_3_3 & tetraploid & warm & Italy & Südtirol & 2142 & $\mathrm{~N}$ \\
\hline 106_4_1 & tetraploid & warm & Italy & $\begin{array}{c}\text { Trentino Alto Adige/ } \\
\text { Südtirol }\end{array}$ & 2142 & Y \\
\hline 108_4_3 & tetraploid & warm & $\begin{array}{l}\text { Switzerla } \\
\text { nd }\end{array}$ & Graubünden & 2171 & $\mathrm{~N}$ \\
\hline 111_1_3 & tetraploid & warm & France & Provence-Alpes-Côte d'Azur & 2243 & $\mathrm{~N}$ \\
\hline 111_3_2 & tetraploid & warm & France & Provence-Alpes-Côte d'Azur & 2243 & Y \\
\hline 111_3_3 & tetraploid & warm & France & Provence-Alpes-Côte d'Azur & 2243 & $\mathrm{Y}$ \\
\hline 116_4_1 & tetraploid & warm & France & Provence-Alpes-Côte d'Azur & 1953 & Y \\
\hline 116_4_2 & tetraploid & warm & France & Provence-Alpes-Côte d'Azur & 1953 & $\mathrm{~N}$ \\
\hline 208_2_1 & tetraploid & warm & France & Provence-Alpes-Côte d'Azur & 1924 & Y \\
\hline 3B_1_2 & tetraploid & warm & France & Provence-Alpes-Côte d'Azur & 2291 & $\mathrm{Y}$ \\
\hline 3_1_2 & diploid & cold & France & Provence-Alpes-Côte d'Azur & 2291 & $\mathrm{~N}$ \\
\hline 3_1_3 & diploid & cold & France & Provence-Alpes-Côte d'Azur & 2291 & $\mathrm{~N}$ \\
\hline 3_2_2 & diploid & cold & France & Provence-Alpes-Côte d'Azur & 2291 & Y \\
\hline 3_3_2 & diploid & cold & France & Provence-Alpes-Côte d'Azur & 2291 & Y \\
\hline 3_4_1 & diploid & cold & France & Provence-Alpes-Côte d'Azur & 2291 & $\mathrm{~N}$ \\
\hline 23_3_2 & diploid & cold & France & Provence-Alpes-Côte d'Azur & 1616 & $\mathrm{~N}$ \\
\hline 23_3_3 & diploid & cold & France & Provence-Alpes-Côte d'Azur & 1616 & Y \\
\hline $23 \_4 \_2$ & diploid & cold & France & Provence-Alpes-Côte d'Azur & 1616 & $\mathrm{~N}$ \\
\hline 24_1_2 & diploid & cold & France & Provence-Alpes-Côte d'Azur & 1925 & Y \\
\hline 24_3_3 & diploid & cold & France & Provence-Alpes-Côte d'Azur & 1925 & $\mathrm{~N}$ \\
\hline
\end{tabular}




\begin{tabular}{|c|c|c|c|c|c|c|}
\hline SampleID & $\begin{array}{l}\text { Leaf } \\
\text { ploidy }\end{array}$ & $\begin{array}{c}\text { Temperature } \\
\text { treatment } \\
2017 \\
\end{array}$ & Country & Region & Altitude & MSAPs \\
\hline $24 \_4 \_2$ & diploid & cold & France & Provence-Alpes-Côte d'Azur & 1925 & $\mathrm{~N}$ \\
\hline 25_1_3 & diploid & cold & France & Provence-Alpes-Côte d'Azur & 1435 & Y \\
\hline 25_2_1 & diploid & cold & France & Provence-Alpes-Côte d'Azur & 1435 & $\mathrm{~N}$ \\
\hline 25_3_1 & diploid & cold & France & Provence-Alpes-Côte d'Azur & 1435 & $\mathrm{~N}$ \\
\hline $25 \_4 \_2$ & diploid & cold & France & Provence-Alpes-Côte d'Azur & 1435 & $\mathrm{~N}$ \\
\hline 25_4_3 & diploid & cold & France & Provence-Alpes-Côte d'Azur & 1435 & $\mathrm{~N}$ \\
\hline 26_1_3 & diploid & cold & France & Provence-Alpes-Côte d'Azur & 1456 & $\mathrm{~N}$ \\
\hline 26_4_1 & diploid & cold & France & Provence-Alpes-Côte d'Azur & 1456 & Y \\
\hline 27_2_2 & diploid & cold & France & Rhônes-Alpes & 1449 & Y \\
\hline 27_3_2 & diploid & cold & France & Rhônes-Alpes & 1449 & $\mathrm{~N}$ \\
\hline 27_3_3 & diploid & cold & France & Rhônes-Alpes & 1449 & $\mathrm{~N}$ \\
\hline 27_4_1 & diploid & cold & France & Rhônes-Alpes & 1449 & $\mathrm{~N}$ \\
\hline 28_1_2 & diploid & cold & Italy & Piemonte & 1685 & $\mathrm{~N}$ \\
\hline 28_2_1 & diploid & cold & Italy & Piemonte & 1685 & $\mathrm{~N}$ \\
\hline 28_2_3 & diploid & cold & Italy & Piemonte & 1685 & Y \\
\hline 28_3_3 & diploid & cold & Italy & Piemonte & 1685 & $\mathrm{~N}$ \\
\hline 29_1_3 & diploid & cold & Italy & Piemonte & 2020 & $\mathrm{~N}$ \\
\hline 29_2_3 & diploid & cold & Italy & Piemonte & 2020 & $\mathrm{~N}$ \\
\hline 29_3_1 & diploid & cold & Italy & Piemonte & 2020 & $\mathrm{~N}$ \\
\hline 29_4_2 & diploid & cold & Italy & Piemonte & 2020 & Y \\
\hline 30_1_2 & diploid & cold & Italy & Piemonte & 1743 & $\mathrm{Y}$ \\
\hline 31_2_3 & diploid & cold & Italy & Piemonte & 1937 & Y \\
\hline 32_1_2 & diploid & cold & Italy & Piemonte & 2320 & $\mathrm{~N}$ \\
\hline 32_3_2 & diploid & cold & Italy & Piemonte & 2320 & $\mathrm{~N}$ \\
\hline 32_3_3 & diploid & cold & Italy & Piemonte & 2320 & Y \\
\hline 32_4_3 & diploid & cold & Italy & Piemonte & 2320 & $\mathrm{~N}$ \\
\hline 33_1_1 & diploid & cold & Italy & Piemonte & 2328 & $\mathrm{~N}$ \\
\hline 33_3_1 & diploid & cold & Italy & Piemonte & 2328 & $\mathrm{~N}$ \\
\hline 33_4_1 & diploid & cold & Italy & Piemonte & 2328 & $\mathrm{~N}$ \\
\hline 33_4_2 & diploid & cold & Italy & Piemonte & 2328 & Y \\
\hline 112_1_1 & diploid & cold & France & Provence-Alpes-Côte d'Azur & 1626 & $\mathrm{~N}$ \\
\hline 112_1_2 & diploid & cold & France & Provence-Alpes-Côte d'Azur & 1626 & Y \\
\hline 112_2_1 & diploid & cold & France & Provence-Alpes-Côte d'Azur & 1626 & $\mathrm{~N}$ \\
\hline $112 \_4 \_3$ & diploid & cold & France & Provence-Alpes-Côte d'Azur & 1626 & $\mathrm{~N}$ \\
\hline 115_1_3 & diploid & cold & France & Provence-Alpes-Côte d'Azur & 1891 & $\mathrm{~N}$ \\
\hline 115_2_3 & diploid & cold & France & Provence-Alpes-Côte d'Azur & 1891 & $\mathrm{~N}$ \\
\hline 115_3_1 & diploid & cold & France & Provence-Alpes-Côte d'Azur & 1891 & $\mathrm{~N}$ \\
\hline 115_4_1 & diploid & cold & France & Provence-Alpes-Côte d'Azur & 1891 & $\mathrm{~N}$ \\
\hline $115 \_4 \_2$ & diploid & cold & France & Provence-Alpes-Côte d'Azur & 1891 & Y \\
\hline 116_1_3 & diploid & cold & France & Provence-Alpes-Côte d'Azur & 1953 & Y \\
\hline 116_2_2 & diploid & cold & France & Provence-Alpes-Côte d'Azur & 1953 & $\mathrm{~N}$ \\
\hline
\end{tabular}




\begin{tabular}{|c|c|c|c|c|c|c|}
\hline SampleID & $\begin{array}{l}\text { Leaf } \\
\text { ploidy }\end{array}$ & $\begin{array}{c}\text { Temperature } \\
\text { treatment } \\
2017 \\
\end{array}$ & Country & Region & Altitude & MSAPs \\
\hline 116_2_3 & diploid & cold & France & Provence-Alpes-Côte d'Azur & 1953 & $\mathrm{~N}$ \\
\hline 116_3_1 & diploid & cold & France & Provence-Alpes-Côte d'Azur & 1953 & Y \\
\hline 116_3_2 & diploid & cold & France & Provence-Alpes-Côte d'Azur & 1953 & $\mathrm{~N}$ \\
\hline 117_1_1 & diploid & cold & France & Provence-Alpes-Côte d'Azur & 1632 & $\mathrm{~N}$ \\
\hline 117_2_2 & diploid & cold & France & Provence-Alpes-Côte d'Azur & 1632 & $\mathrm{~N}$ \\
\hline 117_2_3 & diploid & cold & France & Provence-Alpes-Côte d'Azur & 1632 & $\mathrm{~N}$ \\
\hline 117_3_3 & diploid & cold & France & Provence-Alpes-Côte d'Azur & 1632 & Y \\
\hline 202_1_3 & diploid & cold & France & Provence-Alpes-Côte d'Azur & 1829 & $\mathrm{~N}$ \\
\hline 202_3_3 & diploid & cold & France & Provence-Alpes-Côte d'Azur & 1829 & $\mathrm{Y}$ \\
\hline 203_2_2 & diploid & cold & France & Provence-Alpes-Côte d'Azur & 1840 & Y \\
\hline 203_4_1 & diploid & cold & France & Provence-Alpes-Côte d'Azur & 1840 & $\mathrm{~N}$ \\
\hline 233_2_3 & diploid & cold & France & Provence-Alpes-Côte d'Azur & 2185 & Y \\
\hline 233_3_1 & diploid & cold & France & Provence-Alpes-Côte d'Azur & 2185 & $\mathrm{~N}$ \\
\hline 233_3_3 & diploid & cold & France & Provence-Alpes-Côte d'Azur & 2185 & $\mathrm{~N}$ \\
\hline 28B_1_1 & diploid & cold & Italy & Piemonte & 1685 & $\mathrm{~N}$ \\
\hline 28B_1_2 & diploid & cold & Italy & Piemonte & 1685 & Y \\
\hline 28B_1_3 & diploid & cold & Italy & Piemonte & 1685 & $\mathrm{~N}$ \\
\hline 28B_2_2 & diploid & cold & Italy & Piemonte & 1685 & $\mathrm{~N}$ \\
\hline 31B_3_3 & diploid & cold & Italy & Piemonte & 1937 & Y \\
\hline $\begin{array}{c}\text { 32B_1_1 } \\
\text { 32B/31B_ }\end{array}$ & diploid & cold & Italy & Piemonte & 2320 & Y \\
\hline $2 \_1$ & diploid & cold & Italy & Piemonte & 2320 & Y \\
\hline 32B_2_3 & diploid & cold & Italy & Piemonte & 2320 & $\mathrm{~N}$ \\
\hline 32B_3_2 & diploid & cold & Italy & Piemonte & 2320 & $\mathrm{~N}$ \\
\hline 17_2_3 & tetraploid & cold & France & Provence-Alpes-Côte d'Azur & 2357 & $\mathrm{~N}$ \\
\hline 17_3_1 & tetraploid & cold & France & Provence-Alpes-Côte d'Azur & 2357 & $\mathrm{~N}$ \\
\hline 17_3_2 & tetraploid & cold & France & Provence-Alpes-Côte d'Azur & 2357 & $\mathrm{~N}$ \\
\hline 17_4_1 & tetraploid & cold & France & Provence-Alpes-Côte d'Azur & 2357 & $\mathrm{~N}$ \\
\hline 17_4_2 & tetraploid & cold & France & Provence-Alpes-Côte d'Azur & 2357 & Y \\
\hline 34_1_1 & tetraploid & cold & France & Rhônes-Alpes & 2120 & Y \\
\hline 34_2_2 & tetraploid & cold & France & Rhônes-Alpes & 2120 & $\mathrm{~N}$ \\
\hline 36_1_2 & tetraploid & cold & France & Rhônes-Alpes & 2152 & $\mathrm{~N}$ \\
\hline 36_1_3 & tetraploid & cold & France & Rhônes-Alpes & 2152 & $\mathrm{~N}$ \\
\hline 36_2_1 & tetraploid & cold & France & Rhônes-Alpes & 2152 & Y \\
\hline $36 \_2 \_2$ & tetraploid & cold & France & Rhônes-Alpes & 2152 & $\mathrm{~N}$ \\
\hline 37_2_2 & tetraploid & cold & Italy & Val d'Aosta & 2115 & $\mathrm{~N}$ \\
\hline 37_3_2 & tetraploid & cold & Italy & Val d'Aosta & 2115 & $\mathrm{~N}$ \\
\hline 37_4_1 & tetraploid & cold & Italy & Val d'Aosta & 2115 & Y \\
\hline 40_1_2 & tetraploid & cold & $\begin{array}{l}\text { Switzerla } \\
\text { nd } \\
\text { Switzerla }\end{array}$ & Wallis & 1860 & $\mathrm{~N}$ \\
\hline 40_2_2 & tetraploid & cold & nd & Wallis & 1860 & $\mathrm{~N}$ \\
\hline
\end{tabular}




\begin{tabular}{|c|c|c|c|c|c|c|}
\hline SampleID & $\begin{array}{l}\text { Leaf } \\
\text { ploidy }\end{array}$ & $\begin{array}{c}\text { Temperature } \\
\text { treatment } \\
2017\end{array}$ & Country & Region & Altitude & MSAPs \\
\hline 40_3_1 & tetraploid & cold & $\begin{array}{c}\text { Switzerla } \\
\text { nd }\end{array}$ & Wallis & 1860 & $\mathrm{Y}$ \\
\hline 40_4_2 & tetraploid & cold & $\begin{array}{c}\text { Switzerla } \\
\text { nd }\end{array}$ & Wallis & 1860 & $\mathrm{~N}$ \\
\hline 41_2_2 & tetraploid & cold & Italy & Val d'Aosta & 2174 & $\mathrm{Y}$ \\
\hline 42_1_1 & tetraploid & cold & $\begin{array}{l}\text { Switzerla } \\
\text { nd } \\
\text { Switzerla }\end{array}$ & Wallis & 1789 & $\mathrm{~N}$ \\
\hline 42_2_3 & tetraploid & cold & nd & Wallis & 1789 & $\mathrm{~N}$ \\
\hline 42_3_2 & tetraploid & cold & $\begin{array}{c}\text { Switzerla } \\
\text { nd }\end{array}$ & Wallis & 1789 & Y \\
\hline 42_4_2 & tetraploid & cold & $\begin{array}{l}\text { Switzerla } \\
\text { nd } \\
\text { Switzerla }\end{array}$ & Wallis & 1789 & $\mathrm{~N}$ \\
\hline 42_4_3 & tetraploid & cold & $\begin{array}{c}\text { nd } \\
\text { Switzerla }\end{array}$ & Wallis & 1789 & $\mathrm{~N}$ \\
\hline 45_1_1 & tetraploid & cold & nd & Wallis & 2400 & $\mathrm{~N}$ \\
\hline 45_1_2 & tetraploid & cold & $\begin{array}{c}\text { Switzerla } \\
\text { nd }\end{array}$ & Wallis & 2400 & Y \\
\hline 45_2_1 & tetraploid & cold & $\begin{array}{l}\text { Switzerla } \\
\text { nd } \\
\text { Switzerla }\end{array}$ & Wallis & 2400 & $\mathrm{~N}$ \\
\hline 45_4_1 & tetraploid & cold & $\begin{array}{c}\text { nd } \\
\text { Switzerla }\end{array}$ & Wallis & 2400 & $\mathrm{~N}$ \\
\hline 47_1_2 & tetraploid & cold & $\begin{array}{c}\text { nd } \\
\text { Switzerla }\end{array}$ & Graubünden & 2211 & $\mathrm{~N}$ \\
\hline 47_1_3 & tetraploid & cold & nd & Graubünden & 2211 & $\mathrm{~N}$ \\
\hline 47_2_2 & tetraploid & cold & $\begin{array}{c}\text { Switzerla } \\
\text { nd }\end{array}$ & Graubünden & 2211 & $\mathrm{Y}$ \\
\hline 47_2_3 & tetraploid & cold & $\begin{array}{l}\text { Switzerla } \\
\text { nd } \\
\text { Switzerla }\end{array}$ & Graubünden & 2211 & $\mathrm{~N}$ \\
\hline 47_4_1 & tetraploid & cold & $\begin{array}{c}\text { nd } \\
\text { Switzerla }\end{array}$ & Graubünden & 2211 & $\mathrm{~N}$ \\
\hline 48_3_2 & tetraploid & cold & nd & Graubünden & 2262 & $\mathrm{~N}$ \\
\hline 48_4_2 & tetraploid & cold & $\begin{array}{l}\text { Switzerla } \\
\text { nd } \\
\text { Switzerla }\end{array}$ & Graubünden & 2262 & Y \\
\hline 50_2_1 & tetraploid & cold & nd & Graubünden & 2322 & Y \\
\hline $50 \_2 \_2$ & tetraploid & cold & $\begin{array}{l}\text { Switzerla } \\
\text { nd } \\
\text { Switzerla }\end{array}$ & Graubünden & 2322 & $\mathrm{~N}$ \\
\hline 50_3_3 & tetraploid & cold & $\begin{array}{c}\text { nd } \\
\text { Switzerla }\end{array}$ & Graubünden & 2322 & $\mathrm{~N}$ \\
\hline 50_4_1 & tetraploid & cold & $\begin{array}{c}\text { nd } \\
\text { Switzerla }\end{array}$ & Graubünden & 2322 & $\mathrm{~N}$ \\
\hline 50_4_3 & tetraploid & cold & $\begin{array}{c}\text { nd } \\
\text { Switzerla }\end{array}$ & Graubünden & 2322 & $\mathrm{~N}$ \\
\hline 53_2_2 & tetraploid & cold & nd & Graubünden & 2456 & $\mathrm{~N}$ \\
\hline
\end{tabular}




\begin{tabular}{|c|c|c|c|c|c|c|}
\hline SampleID & $\begin{array}{l}\text { Leaf } \\
\text { ploidy }\end{array}$ & $\begin{array}{c}\text { Temperature } \\
\text { treatment } \\
2017 \\
\end{array}$ & Country & Region & Altitude & MSAPs \\
\hline 53_2_3 & tetraploid & cold & $\begin{array}{l}\text { Switzerla } \\
\text { nd }\end{array}$ & Graubünden & 2456 & $\mathrm{~N}$ \\
\hline 53_3_1 & tetraploid & cold & $\begin{array}{l}\text { Switzerla } \\
\text { nd }\end{array}$ & Graubünden & 2456 & Y \\
\hline 53_3_3 & tetraploid & cold & $\begin{array}{l}\text { Switzerla } \\
\text { nd }\end{array}$ & Graubünden & 2456 & $\mathrm{~N}$ \\
\hline 54_1_2 & tetraploid & cold & Italy & Lombardia & 2303 & $\mathrm{~N}$ \\
\hline $54 \_2 \_2$ & tetraploid & cold & Italy & Lombardia & 2303 & Y \\
\hline 54_3_3 & tetraploid & cold & Italy & Lombardia & 2303 & $\mathrm{~N}$ \\
\hline $54 \_4 \_2$ & tetraploid & cold & Italy & Lombardia & 2303 & $\mathrm{~N}$ \\
\hline $54 \_4 \_3$ & tetraploid & cold & Italy & Lombardia & 2303 & $\mathrm{~N}$ \\
\hline 55_3_1 & tetraploid & cold & Austria & Tirol & 2557 & Y \\
\hline 58_1_2 & tetraploid & cold & Italy & $\begin{array}{c}\text { Trentino Alto Adige/ } \\
\text { Südtirol }\end{array}$ & 2117 & $\mathrm{~N}$ \\
\hline 58_1_3 & tetraploid & cold & Italy & $\begin{array}{c}\text { Trentino Alto Adige/ } \\
\text { Südtirol }\end{array}$ & 2117 & $\mathrm{Y}$ \\
\hline $58 \_4 \_3$ & tetraploid & cold & Italy & $\begin{array}{l}\text { Trentino Alto Adige/ } \\
\text { Südtirol } \\
\text { Trentino Alto Adige/ }\end{array}$ & 2117 & $\mathrm{~N}$ \\
\hline 66_1_1 & tetraploid & cold & Italy & Südtirol & 2101 & $\mathrm{~N}$ \\
\hline 66_2_2 & tetraploid & cold & Italy & $\begin{array}{c}\text { Trentino Alto Adige/ } \\
\text { Südtirol }\end{array}$ & 2101 & Y \\
\hline 66_2_3 & tetraploid & cold & Italy & $\begin{array}{c}\text { Trentino Alto Adige/ } \\
\text { Südtirol }\end{array}$ & 2101 & $\mathrm{~N}$ \\
\hline $74 \_2 \_2$ & tetraploid & cold & Austria & Osttirol & 2117 & $\mathrm{~N}$ \\
\hline 74_4__2 & tetraploid & cold & $\begin{array}{l}\text { Austria } \\
\text { Switzerla }\end{array}$ & Osttirol & 2117 & $\mathrm{~N}$ \\
\hline 79_3_1 & tetraploid & cold & nd & Graubünden & 2280 & $\mathrm{~N}$ \\
\hline 79_3_3 & tetraploid & cold & $\begin{array}{l}\text { Switzerla } \\
\text { nd }\end{array}$ & Graubünden & 2280 & Y \\
\hline 82_3_3 & tetraploid & cold & Italy & Lombardia & 2500 & Y \\
\hline 83_3_1 & tetraploid & cold & Austria & Osttirol & 2271 & Y \\
\hline 84_1_2 & tetraploid & cold & Austria & Kärnten & 2236 & $\mathrm{~N}$ \\
\hline 84_4_2 & tetraploid & cold & Austria & Kärnten & 2236 & Y \\
\hline 85_3_2 & tetraploid & cold & Austria & Kärnten & 2184 & $\mathrm{~N}$ \\
\hline 85_3_3 & tetraploid & cold & $\begin{array}{l}\text { Austria } \\
\text { Switzerla }\end{array}$ & Kärnten & 2184 & $\mathrm{~N}$ \\
\hline 88_1_1 & tetraploid & cold & $\begin{array}{c}\text { nd } \\
\text { Switzerla }\end{array}$ & Graubünden & 2300 & $\mathrm{~N}$ \\
\hline 88_1_2 & tetraploid & cold & $\begin{array}{c}\text { nd } \\
\text { Switzerla }\end{array}$ & Graubünden & 2300 & $\mathrm{~N}$ \\
\hline 88_2_3 & tetraploid & cold & nd & Graubünden & 2300 & $\mathrm{~N}$ \\
\hline 90_2_3 & tetraploid & cold & $\begin{array}{l}\text { Switzerla } \\
\text { nd }\end{array}$ & Wallis & 2477 & Y \\
\hline 92_2_1 & tetraploid & cold & $\begin{array}{l}\text { Switzerla } \\
\text { nd }\end{array}$ & Graubünden & 2260 & $\mathrm{~N}$ \\
\hline
\end{tabular}




\begin{tabular}{|c|c|c|c|c|c|c|}
\hline SampleID & $\begin{array}{l}\text { Leaf } \\
\text { ploidy }\end{array}$ & $\begin{array}{c}\text { Temperature } \\
\text { treatment } \\
2017\end{array}$ & Country & Region & Altitude & MSAPs \\
\hline 92_4_1 & tetraploid & cold & $\begin{array}{l}\text { Switzerla } \\
\text { nd } \\
\text { Switzerla }\end{array}$ & Graubünden & 2260 & $\mathrm{~N}$ \\
\hline 93_2_1 & tetraploid & cold & $\begin{array}{c}\text { nd } \\
\text { Switzerla }\end{array}$ & Wallis & 2405 & $\mathrm{~N}$ \\
\hline 93_2_3 & tetraploid & cold & $\begin{array}{c}\text { nd } \\
\text { Switzerla }\end{array}$ & Wallis & 2405 & $\mathrm{~N}$ \\
\hline 93_3_3 & tetraploid & cold & nd & Wallis & 2405 & $\mathrm{~N}$ \\
\hline 96_1_3 & tetraploid & cold & France & Provence-Alpes-Côte d'Azur & 2300 & $\mathrm{~N}$ \\
\hline 96_2_3 & tetraploid & cold & France & Provence-Alpes-Côte d'Azur & 2300 & Y \\
\hline 96_3_2 & tetraploid & cold & France & Provence-Alpes-Côte d'Azur & 2300 & $\mathrm{~N}$ \\
\hline $96 \_4 \_2$ & tetraploid & cold & France & Provence-Alpes-Côte d'Azur & 2300 & $\mathrm{~N}$ \\
\hline $96 \_4 \_3$ & tetraploid & cold & France & Provence-Alpes-Côte d'Azur & 2300 & $\mathrm{~N}$ \\
\hline 103_1_2 & tetraploid & cold & Italy & $\begin{array}{c}\text { Lombardia } \\
\text { Trentino Alto Adige/ }\end{array}$ & 2290 & $\mathrm{~N}$ \\
\hline 106_2_1 & tetraploid & cold & Italy & $\begin{array}{l}\text { Südtirol } \\
\text { Trentino Alto Adige/ }\end{array}$ & 2142 & $\mathrm{~N}$ \\
\hline 106_2_2 & tetraploid & cold & Italy & Südtirol & 2142 & $\mathrm{~N}$ \\
\hline 106_2_3 & tetraploid & cold & Italy & $\begin{array}{c}\text { Trentino Alto Adige/ } \\
\text { Südtirol }\end{array}$ & 2142 & Y \\
\hline 106_4_3 & tetraploid & cold & $\begin{array}{c}\text { Italy } \\
\text { Switzerla }\end{array}$ & $\begin{array}{c}\text { Trentino Alto Adige/ } \\
\text { Südtirol }\end{array}$ & 2142 & $\mathrm{~N}$ \\
\hline 108_3_2 & tetraploid & cold & nd & Graubünden & 2171 & $\mathrm{~N}$ \\
\hline 108_3_3 & tetraploid & cold & $\begin{array}{c}\text { Switzerla } \\
\text { nd }\end{array}$ & Graubünden & 2171 & Y \\
\hline 111_1_1 & tetraploid & cold & France & Provence-Alpes-Côte d'Azur & 2243 & $\mathrm{~N}$ \\
\hline 111_1_2 & tetraploid & cold & France & Provence-Alpes-Côte d'Azur & 2243 & $\mathrm{~N}$ \\
\hline 111_2_3 & tetraploid & cold & France & Provence-Alpes-Côte d'Azur & 2243 & $\mathrm{Y}$ \\
\hline
\end{tabular}


Table S2. Reproductive modes (a) and special cases of assumed reproduction modes (b) for diploid and tetraploid Ranunculus kuepferi plants under temperature treatments. The FCSS data for embryo and endosperm ploidy in single seeds presented in (b) were excluded from further analysis.

\begin{tabular}{|c|c|c|c|c|c|c|c|}
\hline & \multirow{2}{*}{$\begin{array}{c}\begin{array}{c}\text { Genome contribution to } \\
\text { embryo/endosperm }\end{array} \\
\begin{array}{c}\text { Egg cell + sperm nucleus/fused } \\
\text { polar nuclei + sperm nucleus } \\
\text { (nuclei) }\end{array}\end{array}$} & \multirow[t]{2}{*}{$\begin{array}{l}\text { Embryo: } \\
\text { endosperm }\end{array}$} & \multirow[t]{2}{*}{$\begin{array}{l}\text { Peak } \\
\text { index }\end{array}$} & \multirow[t]{2}{*}{ Path } & \multicolumn{3}{|c|}{$\begin{array}{c}\text { Number of } \\
\text { observations (seeds, } \\
\text { ssFCSS) }\end{array}$} \\
\hline & & & & & Cold & Warm & Total \\
\hline \multicolumn{8}{|c|}{ a) Reproduction mode } \\
\hline \multicolumn{8}{|c|}{ Diploid plants } \\
\hline Sexual & $1 \mathrm{Cx}(\mathrm{m})+1 \mathrm{Cx}(\mathrm{p}) / 2 \mathrm{Cx}(\mathrm{m})+1 \mathrm{Cx}(\mathrm{p})$ & $2: 3$ & 1.5 & A & 206 & 359 & 565 \\
\hline Apomictic & $2 \mathrm{Cx}(\mathrm{m})+0 \mathrm{Cx}(\mathrm{p}) / 4 \mathrm{Cx}(\mathrm{m})+0 \mathrm{Cx}(\mathrm{p})$ & 2:4 & 2 & B & 1 & 6 & 7 \\
\hline \multirow{5}{*}{$\mathrm{B}_{\text {III }}$ hybrid } & $2 \mathrm{Cx}(\mathrm{m})+0 \mathrm{Cx}(\mathrm{p}) / 4 \mathrm{Cx}(\mathrm{m})+1 \mathrm{Cx}(\mathrm{p})$ & 2:5 & 2.5 & C & 0 & 2 & 2 \\
\hline & $2 \mathrm{Cx}(\mathrm{m})+0 \mathrm{Cx}(\mathrm{p}) / 4 \mathrm{Cx}(\mathrm{m})+2 \mathrm{Cx}(\mathrm{p})$ & 2:6 & 3 & $\mathrm{D}$ & 2 & 0 & 2 \\
\hline & $2 \mathrm{Cx}(\mathrm{m})+1 \mathrm{Cx}(\mathrm{p}) / 4 \mathrm{Cx}(\mathrm{m})+1 \mathrm{Cx}(\mathrm{p})$ & 3:5 & 1.67 & E & 0 & 7 & 7 \\
\hline & $\begin{array}{c}2 \mathrm{Cx}(\mathrm{m})+2 \mathrm{Cx}(\mathrm{p}) / 4 \mathrm{Cx}(\mathrm{m})+2 \mathrm{Cx}(\mathrm{p}) \\
2 \mathrm{Cx}(\mathrm{m})+2 \mathrm{Cx}(\mathrm{p}) /(4 \mathrm{Cx}(\mathrm{m}))^{*} 2+\end{array}$ & 4:6 & 1.5 & $\mathrm{~F}$ & 0 & 1 & 1 \\
\hline & $2 \mathrm{Cx}(\mathrm{p})$ & 4:10 & 2.5 & G & 0 & 8 & 8 \\
\hline \multicolumn{8}{|c|}{ Tetraploid plants } \\
\hline Sexual & $2 \mathrm{Cx}(\mathrm{m})+2 \mathrm{Cx}(\mathrm{p}) / 4 \mathrm{Cx}(\mathrm{m})+2 \mathrm{Cx}(\mathrm{p})$ & 4:6 & 1.5 & $\mathrm{H}$ & 6 & 0 & 6 \\
\hline \multirow[t]{6}{*}{ Apomictic } & $4 \mathrm{Cx}(\mathrm{m})+0 \mathrm{Cx}(\mathrm{p}) / 8 \mathrm{Cx}(\mathrm{m})+0 \mathrm{Cx}(\mathrm{p})$ & $4: 8$ & 2 & I & 2 & 0 & 2 \\
\hline & $4 \mathrm{Cx}(\mathrm{m})+0 \mathrm{Cx}(\mathrm{p}) / 8 \mathrm{Cx}(\mathrm{m})+1 \mathrm{Cx}(\mathrm{p})$ & $4: 9$ & 2.25 & $\mathrm{~J}$ & 3 & 5 & 8 \\
\hline & $4 \mathrm{Cx}(\mathrm{m})+0 \mathrm{Cx}(\mathrm{p}) / 8 \mathrm{Cx}(\mathrm{m})+2 \mathrm{Cx}(\mathrm{p})$ & $4: 10$ & 2.5 & K & 52 & 1 & 53 \\
\hline & $4 \mathrm{Cx}(\mathrm{m})+0 \mathrm{Cx}(\mathrm{p}) / 8 \mathrm{Cx}(\mathrm{m})+3 \mathrm{Cx}(\mathrm{p})$ & $4: 11$ & 2.75 & $\mathrm{~L}$ & 8 & 0 & 8 \\
\hline & $4 \mathrm{Cx}(\mathrm{m})+0 \mathrm{Cx}(\mathrm{p}) / 8 \mathrm{Cx}(\mathrm{m})+4 \mathrm{Cx}(\mathrm{p})$ & $4: 12$ & 3 & M & 11 & 0 & 11 \\
\hline & $4 \mathrm{Cx}(\mathrm{m})+0 \mathrm{Cx}(\mathrm{p}) / 8 \mathrm{Cx}(\mathrm{m})+6 \mathrm{Cx}(\mathrm{p})$ & 4:14 & 3.5 & $\mathrm{~N}$ & 8 & 0 & 8 \\
\hline
\end{tabular}




\begin{tabular}{|c|c|c|c|c|c|c|}
\hline \multicolumn{7}{|c|}{ b) Assumed reproduction mode } \\
\hline \multicolumn{7}{|c|}{ Diploid plants } \\
\hline Apospory with polyspermy & $2 \mathrm{Cx}(\mathrm{m})+0 \mathrm{Cx}(\mathrm{p}) / 4 \mathrm{Cx}(\mathrm{m})+3 \mathrm{Cx}(\mathrm{p})$ & $2: 7$ & 3.5 & 2 & 1 & 3 \\
\hline Apospory with polyspermy & $2 \mathrm{Cx}(\mathrm{m})+1 \mathrm{Cx}(\mathrm{p}) / 4 \mathrm{Cx}(\mathrm{m})+3 \mathrm{Cx}(\mathrm{p})$ & $3: 7$ & 2.33 & 1 & 1 & 2 \\
\hline Apospory with polyspermy & $2 \mathrm{Cx}(\mathrm{m})+1 \mathrm{Cx}(\mathrm{p}) / 4 \mathrm{Cx}(\mathrm{m})+4 \mathrm{Cx}(\mathrm{p})$ & $3: 8$ & 2.67 & 0 & 2 & 2 \\
\hline Apospory with polyspermy & $2 \mathrm{Cx}(\mathrm{m})+2 \mathrm{Cx}(\mathrm{p}) / 4 \mathrm{Cx}(\mathrm{m})+5 \mathrm{Cx}(\mathrm{p})$ & $4: 9$ & 2.25 & 0 & 2 & 2 \\
\hline $\begin{array}{l}\text { Apospory with endosperm } \\
\text { endopolyploidy\& } \\
\text { polyspermy }\end{array}$ & $\begin{array}{c}2 \mathrm{Cx}(\mathrm{m})+2 \mathrm{Cx}(\mathrm{p}) /(4 \mathrm{Cx}(\mathrm{m}))^{*} 2+ \\
8 \mathrm{Cx}(\mathrm{p})\end{array}$ & $4: 16$ & 4 & 0 & 1 & 1 \\
\hline \multicolumn{7}{|c|}{ Tetraploid plants } \\
\hline $\begin{array}{c}\text { Apospory with } \\
\text { endopolyploidy }\end{array}$ & $\begin{array}{c}4 \mathrm{Cx}(\mathrm{m})+0 \mathrm{Cx}(\mathrm{p}) /(8 \mathrm{Cx}(\mathrm{m}))^{*} 2+ \\
2 \mathrm{Cx}(\mathrm{p})\end{array}$ & $4: 18$ & $1: 4.5$ & 2 & 0 & 2 \\
\hline $\begin{array}{l}\text { Hypertetraploid aneuploidy } \\
\text { with autonomous endosperm }\end{array}$ & 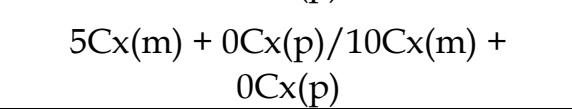 & $5: 10$ & 2 & 1 & 0 & 1 \\
\hline
\end{tabular}

$\mathrm{Cx}$ :ploidy based on DNA content; m: maternal genome contribution; $\mathrm{p}$ : paternal genome contribution. 
Table S3. Vegetative growth data for the measured morphological traits, seed yield data and reproduction mode of the seeds in diploid and tetraploid Ranunculus kuepferi plants under temperature treatments (Supplementary excel file; can be found under the Supplementary data of the published article). 
a)

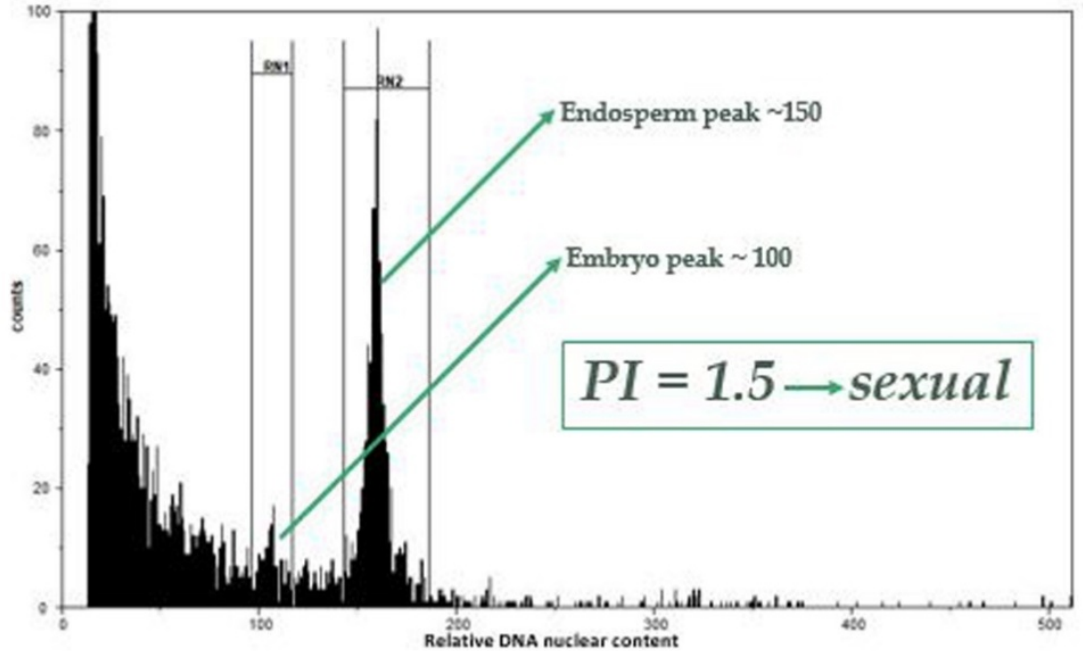

b)

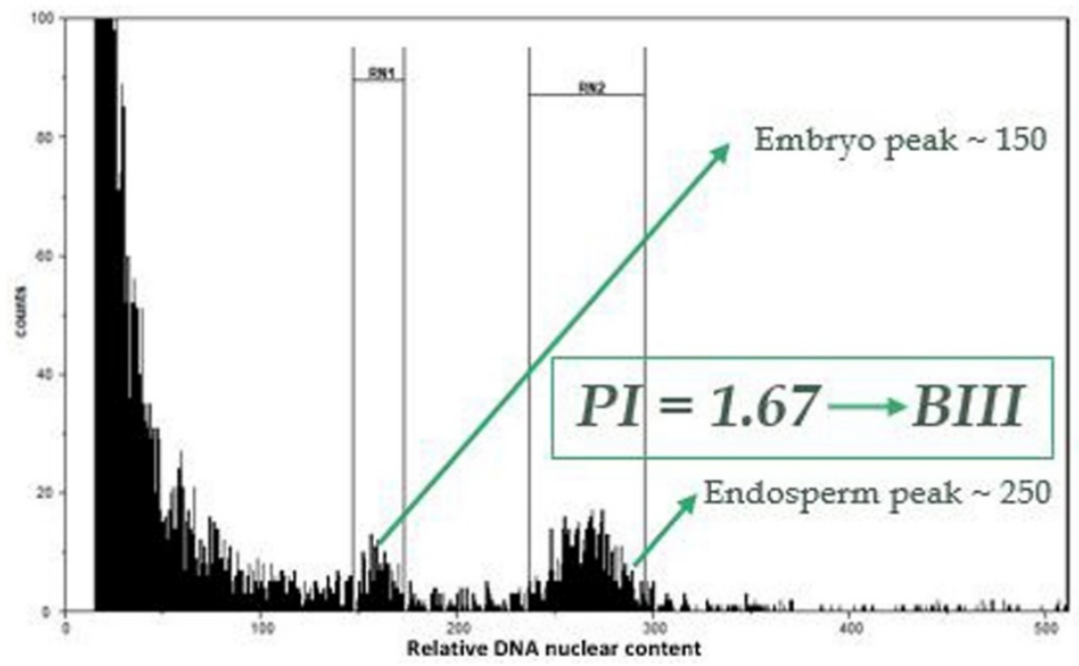

c)

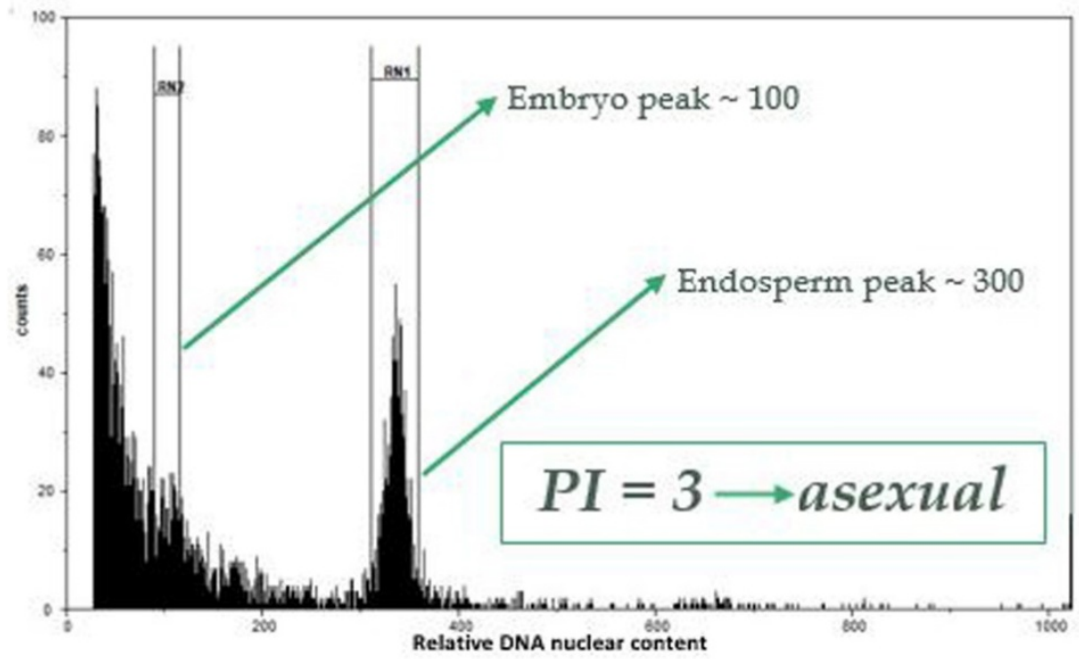

Figure S1. Representative histograms of sexual (a), BIII hybrid (b) and apomictic seeds (c) of Ranunculus kuepferi. All histograms refer to seeds of diploid mother plants. 


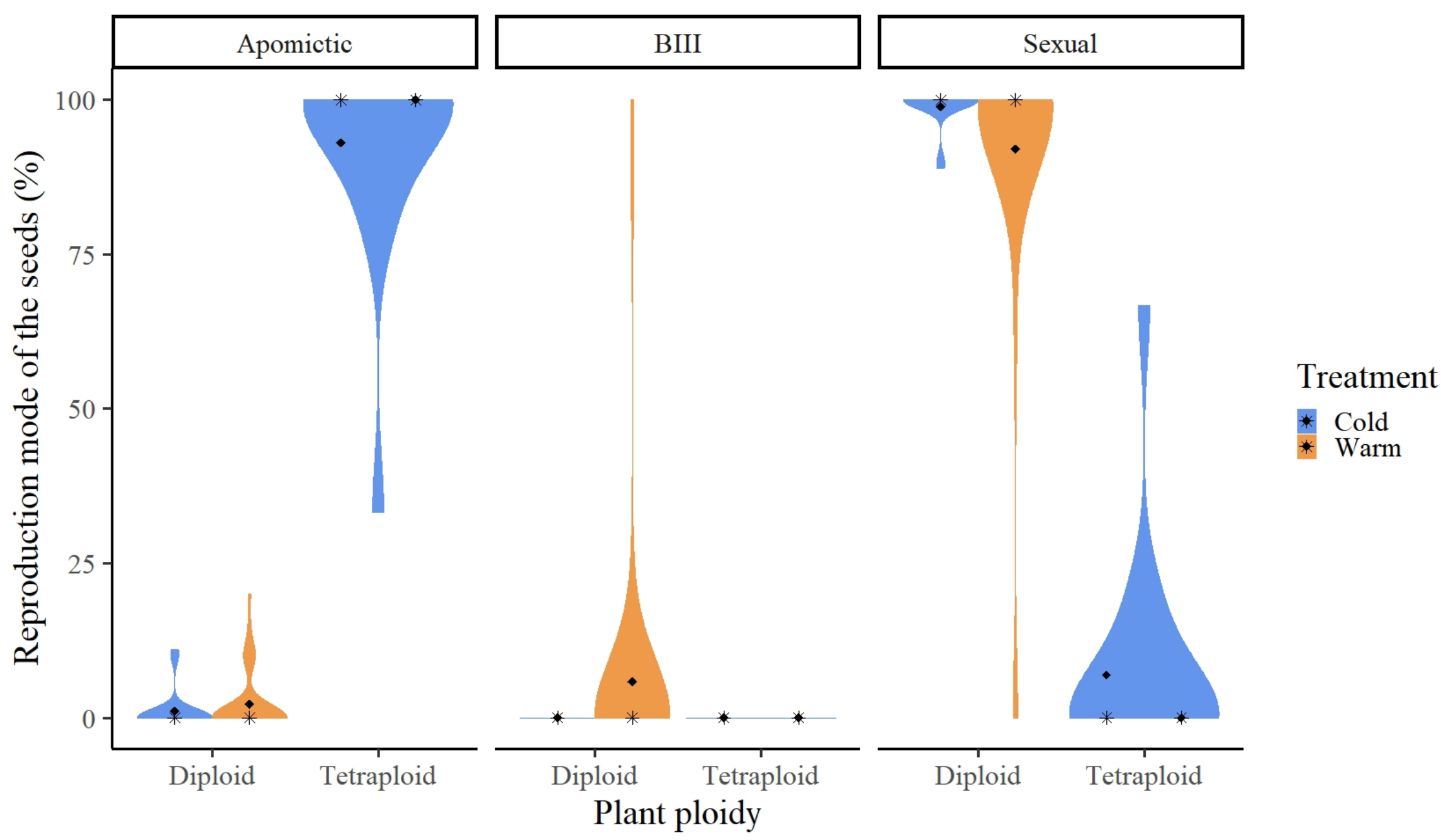


Figure S2. Influence of the temperature treatments on the mode of reproduction in diploid and tetraploid Ranunculus kuepferi plants. Violin plots show the percentages of apomictic seeds, BIII hybrids (partially apomictic seeds) and sexual seeds produced by plants under the cold and warm treatment.

Methods S1. Methylation-sensitive amplified fragment length polymorphisms (MS-AFLPs or MSAPs): Lab protocol and fragments scoring pipeline (Syngelaki et al., 2020).

DNA from the leaf material was isolated using the QiagenDNeasy Plant Mini Kit, with a slightly modified protocol. At the second step, $360 \mu 1$ AP1 Buffer and $40 \mu 1$ PVP 2.6\% were added and incubation time for the elution was prolonged to 30 min. The extracted samples of 100 individuals for each treatment year were screened according to a slightly modified protocol of Paun et al. (2012). Restriction and ligation were carried out in two parallel reactions, each one with a different restriction enzyme. The restriction enzymes, which were used, are MspI \& HpaII. They are methylation sensitive restriction enzymes, i.e. isoschizomers, that recognize the same DNA sequence (CCGG), but differ in the sensitivity regarding the methylation state of $C$, and used as the frequent cutters, while EcoRI is used as the rare cutter. Ligation products were subjected to pre-selective amplification, whereupon selective amplification was performed with a set of three primer combinations with three selective nucleotides to each primer, used before for an AFLP analysis on the species (Cosendai et al., 2011). Ligation, pre-selective and selective amplification products went through a quality and quantity check on a $1.5 \%$ agarose gel and diluted 10-fold dilution prior to pre-selective, selective amplification and fragment analyses, respectively. The final selective-PCR products were prepared with GeneScan ROX 500 (Thermo Fisher Scientific, Waltham, MA, USA) as the internal size standard and fragment analyzed on the ABI Prism 3700/3730 (Applied Biosystems, Waltham, MA, USA) capillary sequencer.

The technical reproducibility of resulting electropherograms was checked by replicating $100 \%$ of accessions, i.e. duplicates were produced for every sample used throughout the MSAP protocol steps, to minimize the false positive fragment peaks. We transformed electropherograms of raw data into a binary dominantmarker matrix. Peak Scanner2 was used to determine the height, width \& the area of all peaks. The output of the Peak Scanner2 was then imported to RawGeno 2.0-1 (Arrigo et al., 2009) to proceed with the binning of detected peaks, the analysis of replication and the filtering of samples of low quality. RawGeno handles a single dye color at a time, so presence/absence of fragments binary matrices were obtained for each of the three dyes (Blue; FAM, Green; HEX, Yellow; NED) and 
then they were merged in a final binary matrix. Fragments between 50 and 600 base pairs were scored.In order to optimize the fragment detection and minimize the risk of false positives, a run of RawGeno with an R script (Arrigo et al., 2009) was performed, which checked stepwise ( $\sim 5760$ steps) the binning and filtering parameters. Going through the resulting table, the optimal combination of the parameters was chosen for each dye and the respective binary matrices were produced. The selection of parameters represent a balance between quality measures, e.g. the error rate and bin reproducibility, and informativity, measured with the data polymorphism.

The merged binary matrix of optimized dataset for each treatment year was dealt with MSAP_calc script in R (Schulz et al., 2013), to distinguish the four possible methylation conditions, using the 'Mixed Scoring 2' approach for scoring the following conditions: I) no methylation (both MspI and HpaII cut the restriction site), II) holo- or hemi-methylation of internal cytosine ( ${ }^{\mathrm{HMe} C G}$ or ${ }^{\mathrm{Me} C G}$; MspI cuts the restriction site), III) hemimethylation of external cytosine (HMeCCG; HpaII cuts the restriction site) and IV) holomethylation of external cytosine or of both cytosines or hemi-methylation of both cytosines or mutations (none of them cuts the restriction site). In 'Mixed Scoring 2' condition I was scored as 100 (nonmethylated), condition II as 010 (internally-methylated), condition III as 001 (externally methylated), and condition IV as '000' and refers to a nondistinguishable situation, e.g. an ambiguous methylation or a mutation status. Condition IV was, therefore, excluded from further statistical analyses. 


\section{Chapter 4}

Gene expression profiles suggest a better cold acclimation of polyploids in the alpine species Ranunculus kuepferi (Ranunculaceae)

Eleni Syngelaki, Claudia Paetzold and Elvira Hörandl

Published in Genes (2021), 12(11), 1818.

DOI 10.3390/genes12111818

Abstract

Alpine habitats are shaped by harsh abiotic conditions and cold climates. Temperature stress can affect phenotypic plasticity, reproduction and epigenetic profiles, which may affect acclimation and adaptation. Distribution patterns suggest that polyploidy seems to be advantageous under cold conditions. Nevertheless, whether temperature stress can induce gene expression changes in different cytotypes, and how the response is initialized through gene set pathways and epigenetic control remain vague for non-model plants.

The perennial alpine plant Ranunculus kuepferi was utilized to investigate the effect of cold stress on gene expression profiles. Diploid and autotetraploid individuals were exposed to cold and warm conditions in climate growth chambers and analyzed via transcriptome sequencing and qRT-PCR.

Overall, cold stress changed gene expression profiles of both cytotypes and induced cold acclimation. Diploids changed more gene set pathways than tetraploids, and suppressed pathways involved in ion/cation homeostasis. Tetraploids mostly activated gene set pathways related to cell wall and plasma membrane. An epigenetic background for gene regulation in response to temperature conditions is indicated.

Results suggest that perennial alpine plants can respond to temperature extremes via altered gene expression. Tetraploids are better acclimated to cold conditions, enabling them to colonize colder climatic areas in the Alps. 


\subsection{Introduction}

Temperature stress is affecting several developmental processes in the life cycle of flowering plants (Hedhly, 2011) and is considered a key constraint to the geographical distribution of species. Aside from distributional ranges, changes in average temperature can affect the phenology, defense capacity, growth and development of plants e.g., (Quint et al., 2016; Gangappa et al., 2017; Lau et al., 2018; Casal \& Balasubramanian, 2019; Fiorucci et al., 2020).

Cold temperature stress is defined as chilling $\left(0-20^{\circ} \mathrm{C}\right)$ or freezing $\left(<0^{\circ} \mathrm{C}\right)$ and represents a major abiotic stress, threatening growth and development e.g., (Chinnusamy et al., 2007; Liu et al., 2017). Most notably, it induces biochemical, physiological, structural and morphological modifications e.g., (Nagy \& Grabherr, 2009; Wani et al., 2013; Wani et al., 2016; Banerjee et al., 2017; Körner, 2021) such as changes in light utilization, ROS production, carbon assimilation, photosynthesis rate, membrane permeability, fluidity and cell wall architecture e.g., (Garsed et al., 1987; Chinnusamy et al., 2007; Sanghera et al., 2011; Theocharis et al., 2012; Longo et al., 2017; Kazemi-Shahandashti \& Maali-Amiri, 2018; Megha et al., 2018).

Flowering plants evolved various adaptation strategies in order to survive and reproduce under adverse temperature conditions, such as plastic responses, which are observed to be positively correlated to colonization of novel habitats e.g., (Yeh \& Prince, 2004; Sol et al., 2005) and subsequent selection of fitting phenotypes over many generations (Schlichting \& Pigliucci, 1998; West-Eberhard, 2003; Lande, 2009; Whitman \& Agrawal, 2009; Chevin \& Lande, 2010). In the past decades, a growing amount of studies have been focused on phenotypic plasticity, one component of which is thought to be changes in gene expression patterns, and its evolutionary aspects e.g., (Via \& Lande, 1985; Schlichting, 1986; Sterns, 1989; Pigliucci, 2001; Franks et al., 2013; Laland et al., 2015; Kelly, 2019). A reliable subset of them focuses on the triggering role of environmental conditions (Angers et al., 2010; Kooke et al., 2015) and the capacity of individuals for phenotypic accommodation (WestEberhard, 2003; Whitman \& Agrawal, 2009) as well as acclimation to the new conditions (Chevin \& Hoffmann, 2017).

The molecular response of plants towards environmental conditions is dynamic and extremely complex, as a typical plant cell possesses more than 30,000 genes (Cramer et al., 2011). Alterations on a phenotype can be depicted in morphology, physiology and gene expression, as single changes or a combination of these (Price et al., 2003; West-Eberhard, 2008; Whitman \& Agrawal, 2009; Munns, 2011; Laland et al., 2015). The genes involved in these procedures can be induced by cold per se or by the relative state of dehydration following cold stress (Griffith \& Yaish, 2004). As plants are sessile organisms, the effects of cold stress seem to be of great importance regarding the acclimation to environmental conditions e.g., (West- 
Eberhard, 2008; Nicotra et al., 2010; Richards et al., 2017), with timing, combination and intensity of the stress parameters presumably playing an important role e.g., (Suzuki et al., 2014).

Cold acclimation, i.e. the acquisition of increased freezing tolerance upon prior exposure to non-lethal low temperatures (Guy, 1990; Thomashow, 1999; Ding et al., 2019), is a sophisticated mechanism plants evolved to endure cold stress. It is moderated via structural and functional remodeling. Profound changes in gene expression profiles affect the composition of the transcriptome, proteome and metabolome e.g., (Chinnusamy et al., 2007; Jammohammadi et al., 2015). Gene expression depicts the way phenotypes are determined under particular environmental conditions (Auld et al., 2010). The combination of environment and genotype influences the expression of a phenotype in a world of continuously changing conditions (West-Eberhard, 2008).

Polyploidy has several effects on vigor, physiology, morphology and other adaptive traits and can result in increased survival fitness in harsher environments (Li et al., 2011; te Beest et al., 2012; Van de Peer et al., 2017; Wei et al., 2019). Polyploids are specifically more abundant in high latitudes and regions with colder climates (Rice et al., 2019). It is hypothesized that under cold temperature conditions polyploid plants are reducing cell numbers and increasing cell size (te Beest et al., 2012), thus adjusting their growth and exposure of reproductive tissues towards the putative adaptive morphology of alpine dwarfism (Körner, 2021). The shift to asexual reproduction modes in some polyploids and epigenetic modifications are suggested to further improve their adaptation to stress conditions (Osborn et al., 2003; Soltis et al., 2014; Körner, 2021).

Epigenetic modifications, such as DNA methylation, histone modifications and chromatin rearrangement can directly or obliquely regulate gene expression e.g., (Bird 2002; Yan et al., 2010; Law \& Jacobsen, 2010; Harris et al., 2018; Xiao et al., 2019). In plants, DNA methylation is a documented epigenetic mechanism, which could mediate phenotypic plasticity within a single generation (Bossdorf et al., 2010) and between generations (Boyko et al., 2010). DNA methylation changes can be induced by environmental stimuli, either biotic or abiotic e.g., (Sherman \& Talbert, 2002; Hu et al., 2011; Dowen et al., 2012), while DNA methylation profiles could be somewhat fixed e.g. for transgenerational inheritance e.g., (Vaughn et al., 2007; Johannes et al., 2009; Finnegan, 2010; Hirsch et al., 2013). Furthermore, DNA methylation changes, e.g. gene silencing, can also be triggered by genomic stresses, such as polyploidization and hybridization, which could also result in genomewide transcriptional rewiring e.g., (Adams \& Wendel, 2005; Grant-Downton \& Dickinson, 2005; Dong et al., 2006; Baubec et al., 2010; Li et al., 2011; Jones, 2012). Thus, DNA methylation can be beneficial in the procedures following 
polyploidization events concerning the re-establishment of genomic balance and structural and functional remodeling (Soltis et al., 2010; Hegarty et al., 2011; Madlung \& Wendel, 2013; Alonso et al., 2016).

Phenotypic plasticity, here defined as the ability of a single genotype to differentially respond to environmental stimuli (Brandshaw, 1965; Schlichting, 1986), is thought to be under genetic and epigenetic control e.g., (Richards et al., 2017) and often correlated with transcriptional differentiation (Donelson et al., 2017; Kelly, 2019). An epigenetic background of phenotypic plasticity suggests that DNA methylation provides a plant with a more rapid reaction to variable environmental conditions compared to DNA mutation. However, the resulting phenotype is not necessarily stable (Angers et al., 2010).

Most studies on gene expression under temperature stress were so far conducted on annual model organisms like Arabidopsis thaliana or on crop plants e.g., (Miura \& Furumoto, 2013; Ding et al., 2019; Zhang et al., 2019). Little is known on the plasticity of perennial plants growing under natural, extreme conditions. Ranunculus kuepferi Greuter \& Burdet is an alpine perennial herb appropriate for studying acclimation to cold conditions. The species is primarily distributed across the European Alps, in altitudes between 1300 - 2800 m (Burnier et al., 2009; Cosendai \& Hörandl, 2010; Cosendai et al., 2011; Kirchheimer et al., 2016; Schinkel et al., 2016) along a pronounced geographical parthenogenesis scenario (Cosendai et al., 2013). Geographical Parthenogenesis in general describes related sexual and asexual organisms having different geographical distributions (Hörandl, 2006). In R. kuepferi, diploid plants are predominantly sexual and restricted to the warmer Southwestern Alps, whereas autotetraploid plants are facultative apomicts (aposporous), with varying proportions of sexual and asexual seeds, and colonize previously glaciated areas, i.e. the Northern, Central and Eastern Alps as well as the northern Apennines and Corsica (Küpfer, 1974; Burnier et al., 2009; Cosendai \& Hörandl, 2010; Schinkel et al., 2016) (Syngelaki et al., 2020a). Tetraploid populations occur at higher elevations in the European Alps than diploids and exhibit a pronounced niche shift towards colder temperatures (Kirchheimer et al., 2016; Schinkel et al., 2016) (Syngelaki et al., 2020a). High alpine habitats are characterized by short growth periods and cold spells, eventually with nocturnal frost during flowering time (spring or summer). It was suggested that the niche differentiation between the cytotypes is associated with a combination of climatic conditions and reproduction mode, with the asexual taxa having a distributional advantage towards cooler conditions (Kirchheimer et al., 2018).

Previous studies revealed that the tetraploid cytotype originated 10 - 80 kyears ago (Kirchheimer et al., 2018), presumably by multiple and recurrent autopolyploidization events (Cosendai et al., 2011; Schinkel et al., 2017). The genetic 
differentiation between cytotypes, regardless of reproduction mode, is very low and on a similar level within cytotypes ( $\mathrm{F}_{\mathrm{st}}$ values $\sim 0.3$ for both cytotypes) (Cosendai et al., 2013). The epigenetic background of the species proposes a differentiation of the cytotypes, but also a correlation of abiotic environmental conditions with the epigenetic variation in natural populations and in experimental conditions (Schinkel et al., 2020; Syngelaki et al., 2020a). Thus, a putative epigenetic background of the niche shift of the tetraploids in the Alps is indicated, with epigenetic variation being associated with elevation in natural populations and higher persistence under cold treatments (Schinkel et al., 2020; Syngelaki et al., 2020a). Syngelaki et al. (2020b) highlighted the potential of phenotypic plasticity, with changes of growth parameters linked to DNA methylation patterns, for acclimation to environmental conditions. These experiments confirmed the different niche preferences of cytotypes in natural populations, as diploids grow better under warm conditions, while tetraploids perform better in cold treatments.

Herein, we employed diploid and tetraploid plants already used by Syngelaki et al. (2020a, b) and exposed them to different controlled temperature treatments, to assess the gene expression profiles of individuals. We aim to investigate whether cold temperature stress has an effect on gene expression and try to get further insights into the expression dynamics. A temperature-sensitivity of gene expression profiles is speculated, which could act as a rapid response towards stressful environments. We also investigated the differentiation of the gene expression profiles according to the ploidy level of the individuals. We hypothesize that the observed niche shift of the tetraploid cytotype has the physiological background of a better cold acclimation. Finally, we associated the gene expression results with DNA methylation, on a transcriptomic level, as a correlation between them would explain the potential of tetraploid R. kuepferi to adapt to cold conditions at higher altitudes during the postglacial recolonization of the European Alps.

\subsection{Materials and Methods}

\section{Plant material and experimental design}

Diploid and tetraploid plants of R. kuepferi utilized in the present study were part of a long-term temperature stress experiment, as described in Klatt et al. (2018) and Syngelaki et al. $(2020 \mathrm{a}, \mathrm{b})$. Plants were collected throughout the distribution range of the species in the European Alps (Kirchheimer et al., 2016) during the growing seasons of 2013 \& 2014. Subsequently, the plants were re-potted in garden soil at the Old Botanical Garden of Göttingen University, where their ploidy level was defined via Flow Cytometry of silica gel dried leaf material collected in the field (Schinkel et al., 2016). For the scope of the current experimental design, which was 
conducted from 2014 onwards, the plants were exposed to different temperature conditions during the sprouting and flowering period, while the rest of the parameters were kept equal. The settings for the transcriptome study were as in Syngelaki et al. (2020a, b) (Table 1). The temperature conditions were simulating the natural environment of the species in the Alps, including freezing during some nights.

Table 1. Temperature treatment conditions during plant growth and sampling collection. Light regime was measured with a Quantum light meter (Spectrum Technologies Inc., Aurora, IL, USA) during the full light period (100\% intensity) at the level of early leaf tips and first buds. Plants were rotated weekly in the cabinet to avoid effects of light and temperature gradients.

\begin{tabular}{|c|c|c|c|c|}
\hline \multirow{2}{*}{ No.Plants } & \multicolumn{2}{|c|}{$\begin{array}{c}\text { Cold Treatment } \\
164\end{array}$} & \multicolumn{2}{|c|}{$\begin{array}{c}\text { Warm Treatment } \\
189\end{array}$} \\
\hline & $\begin{array}{l}\text { Diploid } \\
74\end{array}$ & $\begin{array}{l}\text { Tetraploid } \\
\quad 90\end{array}$ & $\begin{array}{l}\text { Diploid } \\
92\end{array}$ & $\begin{array}{l}\text { Tetraploid } \\
97\end{array}$ \\
\hline $\begin{array}{c}\text { Light regime ( } \mu \mathrm{mol} \\
\left.\mathrm{m}^{-2} \mathrm{~s}^{-1}, \mathrm{SAR}\right)\end{array}$ & \multicolumn{4}{|c|}{$\sim 700$} \\
\hline Photoperiod (h) & \multicolumn{4}{|c|}{$16 ; 10$ of full light and $3+3$ of twilight } \\
\hline \multicolumn{5}{|l|}{$\begin{array}{c}\text { Temperature during } \\
\text { the light } / \text { dark } \\
\text { period }\left({ }^{\circ} \mathrm{C}\right)\end{array}$} \\
\hline Daytime & \multicolumn{2}{|c|}{$\begin{array}{l}7 \\
2\end{array}$} & \multicolumn{2}{|c|}{15} \\
\hline Night & \multicolumn{2}{|c|}{$\begin{array}{l}-1 \text { (cold shocks for three } \\
\text { nights per week) }\end{array}$} & \multicolumn{2}{|c|}{10} \\
\hline
\end{tabular}


Altogether 262 individuals were categorized into four groups corresponding to their ploidy level and treatment: cold diploids (CD, 63 plants), warm diploids (WD, 79 plants), cold tetraploids (CT, 71 plants), and warm tetraploids (WT, 49 plants). At the peak of the flowering season in beginning of summer 2019, leaf tissue was collected simultaneously from three individuals per group, each originating from different natural populations, immediately frozen in liquid nitrogen and stored in $-80^{\circ} \mathrm{C}$. Sample collection localities can be found in Supplementary Table S1.

\section{RNA extraction and sequencing}

Frozen leaf tissue was pulverized in liquid nitrogen and a maximum of $100 \mathrm{mg}$ of powder was used for RNA isolation with the RNAeasy Plant ${ }^{\circledR}$ Mini Kit (QIAGEN, Hilden, Germany) following the provided protocol. RNA quantity and quality were determined with Nanodrop, a Qubit ${ }^{T M}$ with the RNA HS Assay Kit (ThermoFisher Scientific, Waltham, Massachusetts, USA) and an Agilent 2100 Bioanalyzer (Agilent Technologies, Santa Clara, CA, USA). Library preparation and sequencing with HiSeq 4000 (Illumina, San Diego, CA, USA) was conducted at the Transcriptome and Genome Analysis Laboratory of the Microarray \& DeepSequencing Core Facility (UMG, Georg-August-Universität, Göttingen, Germany) producing 50bp single end reads.

\section{Bioinformatics}

The quality of reads was assessed using FastQC v.0.11.4 (Andrews, 2010). Raw reads were trimmed with CutAdapt v.2.3 (Martin, 2011), removing adapters and bases with a phred score below 30 and removing reads shorter than $30 \mathrm{bp}$ after trimming. As there is no available genomic reference for R.kuepferi, the transcriptomes from all diploid individuals were pooled for a de novo assembly with Trinity v.2.8.6 and default parameters, except for max. memory was set to 50Gb (Grabherr et al. 2011, 2013) to produce a pseudoreference. The quality of the resulting assembly was verified with BUSCO v.3.0.2 (Manni et al., 2021; Supplementary Figure S1). TransDecoder v.5.5.0 (Haas et al., 2013) was used to identify the longest Open Reading Frame per assembled contig. Coding sequences were annotated using the blastp algorithm under NCBI-BLAST v.2.10.0 (Johnson et al., 2008) and the December 2020 release of Uniprot as reference. Annotation reports were produced using Trinotate v.3.2.1 (Bryant et al., 2017). Trimmed reads of each sample were mapped against the annotated pseudoreference individually using Bowtie2 v.2.3.5.1 with default parameters (Longread \& Salzberg, 2012).

Raw counts of mapped reads were calculated employing the Rsubread/Subread package v.2.4.0 (Liao et al., 2019) in R/Bioconductor (v.4.0.3 and v.4.1.0/v.3.12 and v.3.13, respectively) ( $\mathrm{R}$ Core Team, 2021) in $\mathrm{R}$ Studio ( $\mathrm{R}$ Studio Team, 2016). Resulting matrices were further analyzed with DESeq2 v.1.30.0 (Love et al., 2014) with a false discovery rate (FDR) threshold of $<0.05$ and the Benjamini-Hochberg 
p-value normalization adjustment (Jafari \& Ansari-Pour, 2019 Loci were identified as differentially expressed regarding the comparison of interest (cytotypes, treatments), with the group of Warm Diploids (WD) used as reference, and were visualized in a heatmap with ggplot2 v.3.3.5 (Wickham, 2009).

ClusterProfiler v.4.0.2 (Yu et al., 2012) was used for Gene Set Enrichment Analysis. This package currently only accepts single organism references via AnnotationDbi v.1.55.1 (Pages et al., 2021). Of the currently accepted reference genomes, A. thaliana is most closely related to $R$. kuepferi (Bell et al., 2010). Consequently, the pseudoreference was annotated again as described above using the updated TAIR 10 release [The Arabidopsis Information Resource (TAIR), http://www.arabidopsis.org; accessed on 11 March 2021] and the resulting annotations were employed in ClusterProfiler for a separate run for each cytotype, checking all subontologies and with a number of 1 Mio. permutations. For these analyses the warm treatment was set as the control condition. Dot plots were generated with enrichplot v.1.13.1 (Yu, 2021).

$q R T-P C R$

Quantitative real time RT-PCR was conducted to validate the differential gene expression revealed by bioinformatic analyses. The annotation reports of the pseudoreference were screened for possible Genes of Interest (GOIs), which are stated to be related, directly or indirectly, to DNA methylation and gene regulation (Finnegan \& Kovac, 2000; Miura \& Furumoto, 2013; Matzke \& Mosher, 2014; Banerjee et al., 2017; Bewick et al., 2017; Lanciano \& Mirouze, 2017; Bräutigam \& Cronk, 2018; Harris et al., 2018; Xiao et al., 2019; Chang et al., 2020; Ritonga \& Chen, 2020) as well as housekeeping genes (Joseph et al., 2018; Yu et al., 2019). Primers were designed for two methyltransferases (CAMT3, PMT2), two demethylases (JM706, JMJ25), the AGO4B gene, which is participating in the RNA-directed DNA methylation (RdDM) pathway in Arabidopsis and rice (Lanciano \& Mirouze, 2017) and the housekeeping gene Actin ( Supplementary Table S2). Primers specificity was tested with a touch-down PCR; products were sequenced and compared to the respective gene in the pseudoreference.

Complementary DNA synthesis and qRT-PCR was performed using QuantiTect Reverse Transcription Kit (QIAGEN, Hilden, Germany) and the Rotor-Gene SYBR Green PCR kit (QIAGEN, Hilden, Germany) in QIAGEN Rotor-Gene Q cycler, equipped with Q-Rex Software and following the instructions of the manufacturer for two cycling steps and a 45 cycles PCR program for three technical replicates per sample. In order to evaluate the differential gene expression, the amplification performance as the log of fold change was calculated with the $\Delta \Delta \mathrm{Ct}$ method (Livak \& Schmittgen, 2001) in Excel 2016, using the housekeeping gene Actin as endogenous control for normalization and warm diploid individuals were considered the reference. 


\subsection{Results}

\section{Pseudoreference and mapping}

In the current study, gene expression profiles of six diploid and six tetraploid individuals of $R$. kuepferi, under cold (stress) and warm (control) temperature treatments were explored. Sequencing of the samples resulted in a mean of $31,918,319$ raw reads per sample with a mean of 31,707,039 reads retained after trimming. The assembly of the pseudoreference resulted in 71,444 transcripts, with 15,224 of them functionally annotated. Through Bowtie2 mapping, we obtained an average mapping rate of $93.08 \%$ per sample (Table 2 ).

Table 2. Summary of sequencing and mapping data for the $R$. kuepferi transcriptomes, against the pseudoreference resulting from Trinity de novo assembly of all reads from diploid samples.

\begin{tabular}{cccccc}
\hline Group $\dagger$ & Sample ID & $\begin{array}{c}\text { Untrimmed } \\
\text { Reads }\end{array}$ & $\begin{array}{c}\text { Total } \\
\text { Trimmed } \\
\text { Reads }\end{array}$ & $\begin{array}{c}\text { Mapped } \\
\text { Reads }\end{array}$ & $\begin{array}{c}\text { Mapped } \\
\text { Reads (\%) }\end{array}$ \\
\hline CD & 30_1_2 & $1,335,657$ & $1,326,485$ & $1,214,557$ & 91.56 \\
CD & $115 \_4 \_2$ & $39,260,122$ & $39,044,345$ & $37,240,848$ & 95.38 \\
CD & 116_3_1 & $46,805,434$ & $46,545,107$ & $43,938,918$ & 94.4 \\
\hline CT & 41_2_2 & $37,813,775$ & $37,625,107$ & $34,877,792$ & 92.7 \\
CT & 90_2_3 & $35,989,875$ & $35,824,317$ & $33,353,051$ & 93.1 \\
CT & 108_3_3 & $36,888,834$ & $36,687,214$ & $33,980,212$ & 92.62 \\
\hline WD & 24_4_3 & $29,197,541$ & $29,058,835$ & $27,467,724$ & 94.52 \\
WD & 29_1_2 & $34,122,764$ & $33,708,095$ & $31,629,139$ & 93.83 \\
WD & 33_3_3 & $29,530,425$ & $29,378,666$ & $27,521,885$ & 93.68 \\
\hline WT & 42_1_2 & $29,277,225$ & $29,108,345$ & $26,919,488$ & 92.48 \\
WT & 74_1_2 & $31,858,591$ & $31,626,671$ & $28,839,855$ & 91.19 \\
WT & 106_4_1 & $30,939,580$ & $30,551,281$ & $27,988,255$ & 91.61 \\
\hline
\end{tabular}

†WD: warm diploid, CD: cold diploid, WT: warm tetraploid, CT: cold tetraploid

\section{Differential gene expression}

A total of 2617 significantly differentially expressed genes were identified between the four predefined groups. Among all groups, more genes were found to be down-regulated compared to up-regulated (Table 3). 
Table 3. Differentially expressed genes of R. kuepferi transcriptomes regarding the comparison of interest (cytotypes, treatments).

\begin{tabular}{ccc} 
& Gene Count & Percentage (\%) \\
\hline Expressed genes & 19,033 & \\
\hline $\begin{array}{c}\text { Differentially expressed } \\
\text { genes }\end{array}$ & 2,617 & 13.75 \\
\hline Up-regulated & 1,055 & 5.5 \\
\hline Down-regulated & 1,562 & 8.2 \\
\hline Outliers & 469 & 2.5 \\
\hline
\end{tabular}

Gene expression was correlated with temperature, while the ploidy level of the plants under the same environmental conditions did not affect the gene expression strongly (Figure 1).

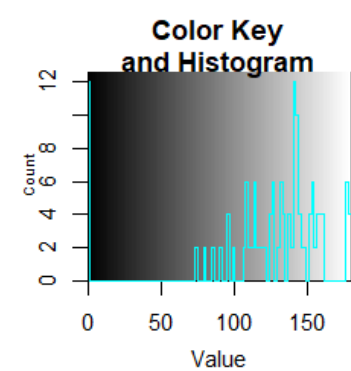

\section{Sample Distance Matrix}
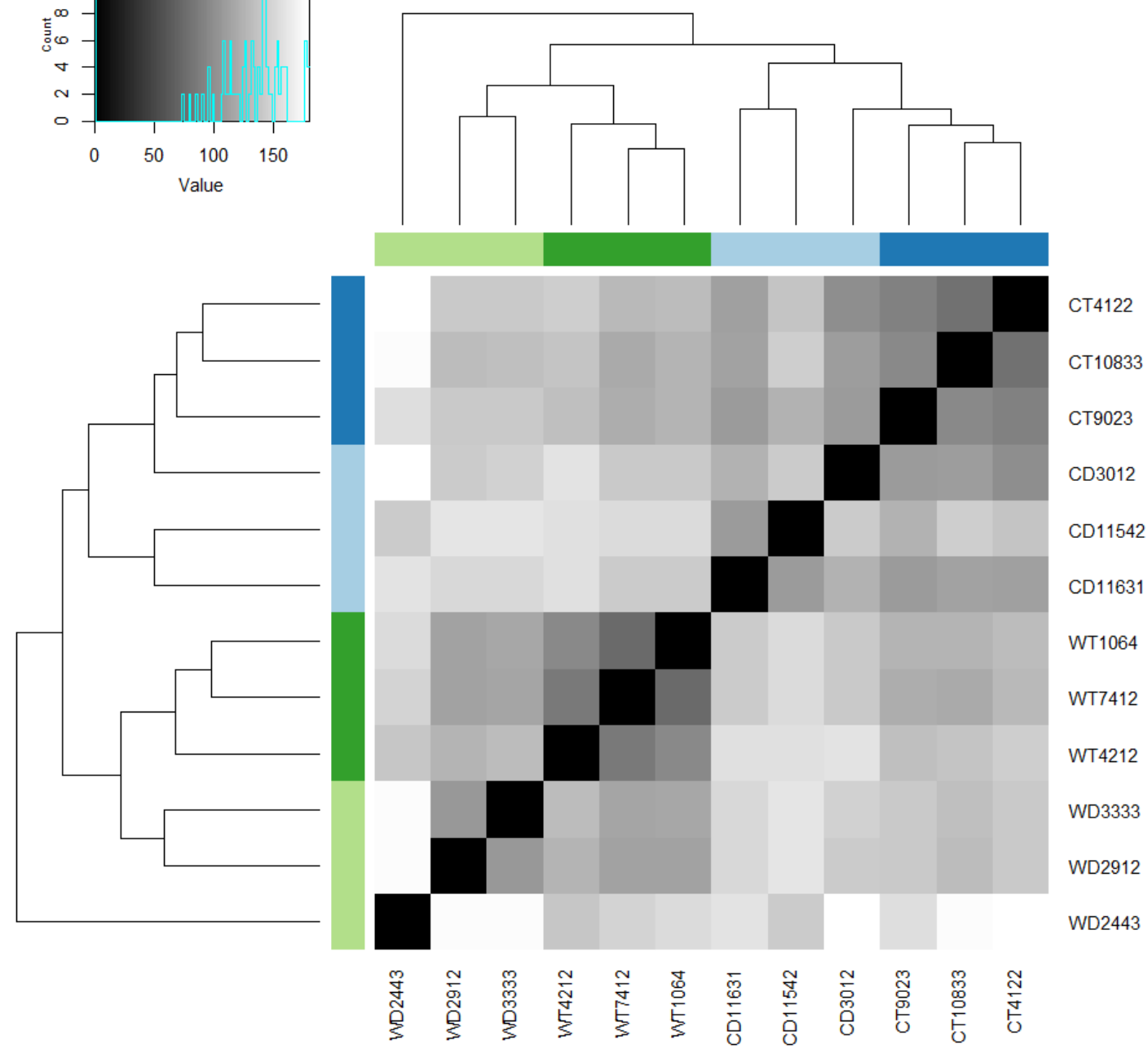
Figure 1. Heat map showing the expression of transcriptomes of diploid and tetraploid R. kuepferi plants under warm (control) and cold (stress) conditions. Regarding the sample IDs the capital letters stand for the predefined groups (WD: warm diploid, CD: cold diploid, WT: warm tetraploid, CT: cold tetraploid) and the numbers stand for the populations in the wild (Supplementary Table S1).

One WD individual (WD2443) seems to present gene expression patterns different from all the other samples. The same individual seems to be an outlier also in the qRT-PCR analysis.

\section{Gene Set Enrichment Analyses}

Gene set enrichment was successfully assigned and statistically significant for 59 pathways in the diploids and 20 pathways in the tetraploids. Enriched gene sets with higher GeneRatios, which in ClusterProfiler are defined as 'count/setSize,' where 'count' is the number of genes that belong to a given gene set, while 'setSize' is the total number of genes in the gene set, are presented in Figures 2 and 3. 


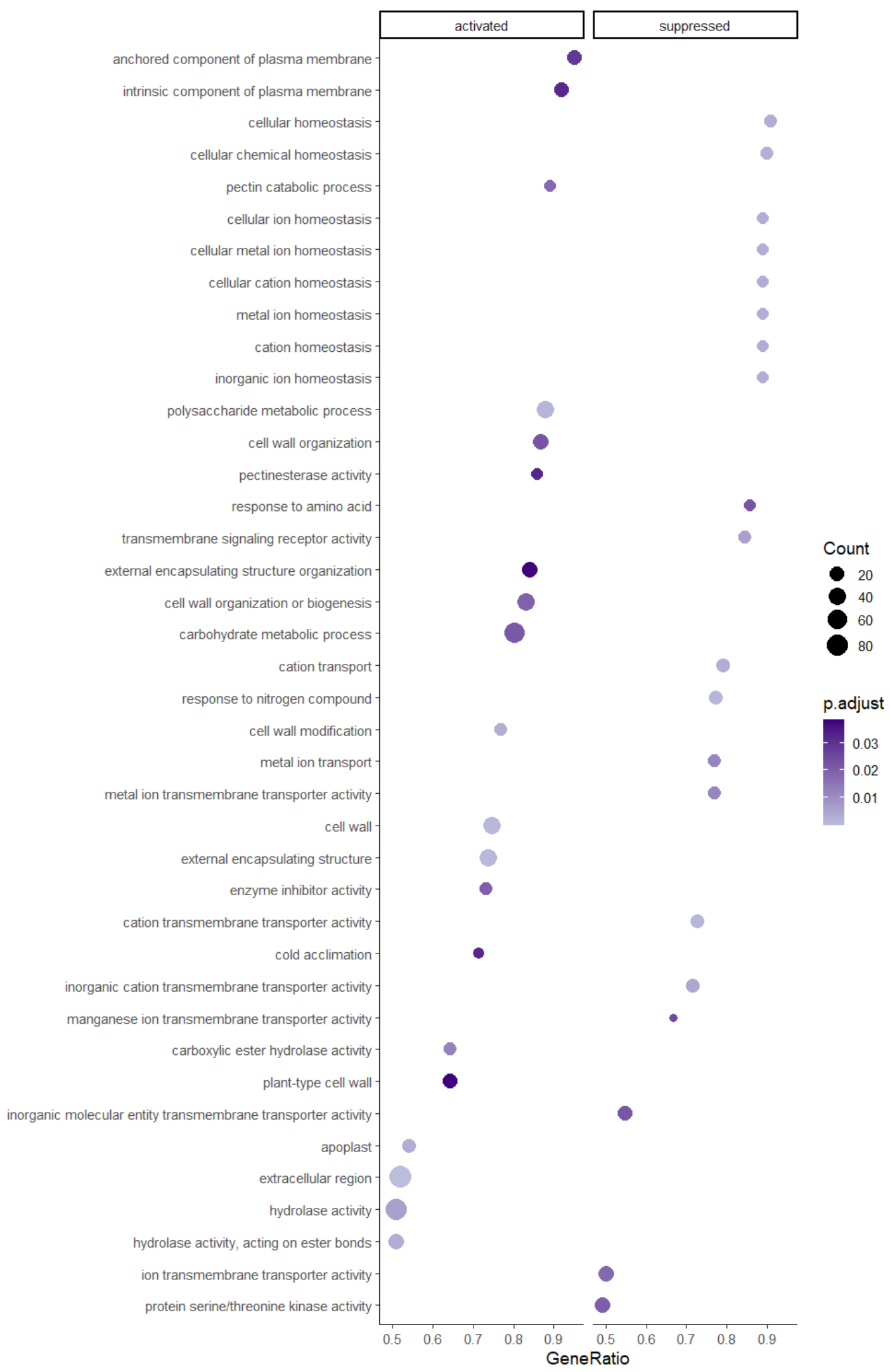

Figure 2. Significantly enriched gene set pathways resulting from the analysis of differentially expressed genes in diploid individuals of $R$. kuepferi. 
Regarding Figure 2, an extract of all resulted enriched pathways is shown due to graphical purposes and a dotplot of all pathways is provided in Supplementary Data (Supplementary Figure S2). Overall, 25 and 13 pathways have been activated in diploid and tetraploid individuals, respectively. Pathways which are linked to the plasma membrane e.g., 'anchored component of plasma membrane', '(cation) transmembrane transporter activity' and the cell wall e.g., 'cell wall organization or biogenesis', 'plant-type cell wall', as well as the 'cold acclimation' and 'hydrolase activity' pathways, are activated in both cytotypes (Figures 2 and 3).

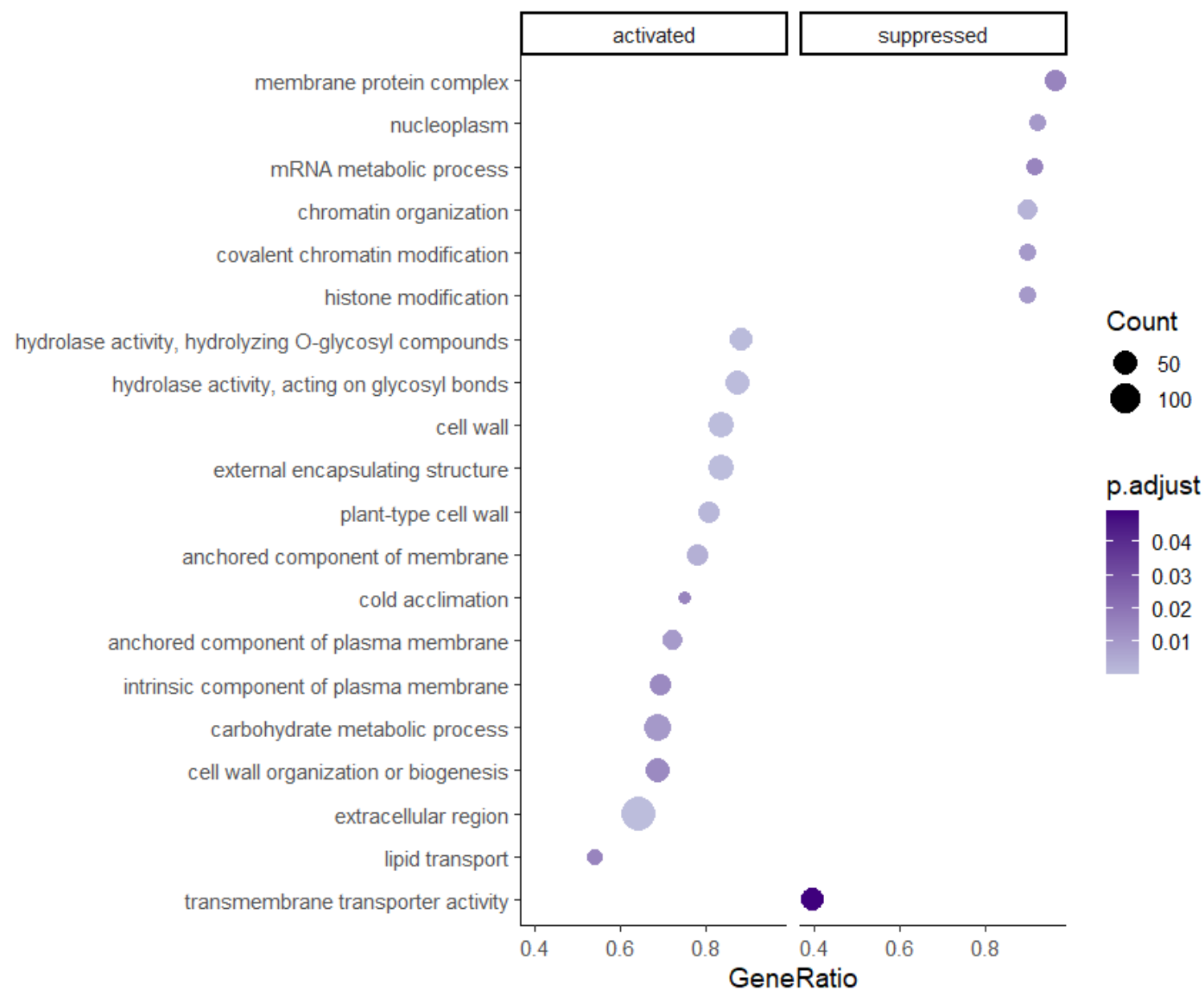

Figure 3. Significantly enriched gene set pathways resulting from the analysis of differentially expressed genes in tetraploid individuals of R. kuepferi.

However, pathways related to ion/cation homeostasis and enzymic activity, such as '(cellular) metal ion homeostasis' and 'protein serine/threonine kinase activity' are enriched only in diploids, while pathways such 'histone/chromatin modification' and 'lipid transport' are enriched only in tetraploid individuals. 
A total of 38 genes of interest, identified by their involvement in DNA methylation, were significantly differentially expressed among the four predefined groups (Table 4).

Table 4. List of differentially expressed genes related to DNA methylation in $R$. kuepferi leaves. Annotation is according to UniProt. The genes which are highlighted are employed as genes of interest (GOIs) for the real-time qRTPCR.

\begin{tabular}{|c|c|c|c|}
\hline GeneID & Organism $\ddagger$ & Function & Regulation \\
\hline AGL15 & BRANA & Agamous-like MADS-box protein & Down \\
\hline AGL62 & ARATH & Agamous-like MADS-box protein & Down \\
\hline AG01A & ORYSJ & Protein argonaute $1 \mathrm{~A}$ & Down \\
\hline AGO4B & ORYSJ & Protein argonaute $4 \mathrm{~B}$ & Down \\
\hline ALKB2 & ARATH & DNA oxidative demethylase & Down \\
\hline AP1 & VITVI & Agamous-like MADS-box protein & Down \\
\hline ATX4 & ARATH & Histone-lysine N-methyltransferase & Up \\
\hline САМТ3 & PETHY & Caffeoyl-CoA O-methyltransferase 3 & Down \\
\hline СMTA3 & ARATH & Calmodulin-binding transcription activator & Down \\
\hline COMT1 & POPKI & Caffeic acid 3-O-methyltransferase & Down \\
\hline DRM1L & ARATH & DNA (cytosine-5)-methyltransferase & Down \\
\hline EPFL2 & ARATH & EPIDERMAL PATTERNING FACTOR-like protein 2 & Down \\
\hline EPFL6 & ARATH & EPIDERMAL PATTERNING FACTOR-like protein 6 & Down \\
\hline EPFL9 & ARATH & EPIDERMAL PATTERNING FACTOR-like protein 9 & Down \\
\hline FDM1 & ARATH & Factor of DNA methylation 1 & Up \\
\hline JM706 & ORYSJ & Lysine-specific demethylase & Down \\
\hline JMJ25 & ARATH & Lysine-specific demethylase & Down \\
\hline LAMT & CATRO & Loganic acid O-methyltransferase & Down \\
\hline MADS1 & VITVI & Agamous-like MADS-box protein & Up \\
\hline MBD2 & ARATH & Methyl-CpG-binding domain-containing protein 2 & Up \\
\hline MBD6 & ARATH & Methyl-CpG-binding domain-containing protein 6 & Down \\
\hline METE & CATRO & $\begin{array}{c}\text { 5-methyltetrahydropteroyltriglutamate-- } \\
\text { homocysteine methyltransferase }\end{array}$ & Down \\
\hline METE2 & ORYSJ & $\begin{array}{l}\text { 5-methyltetrahydropteroyltriglutamate-- } \\
\text { homocysteine methyltransferase } 2\end{array}$ & Down \\
\hline PEAM1 & ARATH & Phosphoethanolamine N-methyltransferase 1 & Down \\
\hline PMT1 & ARATH & Probable methyltransferase PMT1 & Down \\
\hline PMT2 & ARATH & Probable methyltransferase & Down \\
\hline PMT4 & ARATH & Probable methyltransferase & Down \\
\hline PMT7 & ARATH & Probable methyltransferase & Down \\
\hline PMT8 & ARATH & Probable methyltransferase & Down \\
\hline РМТВ & ARATH & Probable methyltransferase & Down \\
\hline PMTD & ARATH & Probable pectin methyltransferase & Down \\
\hline PMTI & ARATH & Probable methyltransferase & Down \\
\hline PMTQ & ARATH & Probable methyltransferase & Down \\
\hline PMTT & ARATH & Probable pectin methyltransferase & Down \\
\hline RP6L1 & ARATH & Protein RRP6-like 1 & $\mathrm{Up}$ \\
\hline RP6L2 & ARATH & Protein RRP6-like 2 & Up \\
\hline RRP8 & ARATH & Ribosomal RNA-processing protein 8 & Up \\
\hline SUVR1 & ARATH & Probable inactive histone-lysine N-methyltransferase & Down \\
\hline
\end{tabular}


‡Abbreviations: ARATH $=$ Arabidopsis thaliana, BRANA $=$ Brassica napus, CATRO $=$ Catharanthus roseus, PETHY = Petunia hybrida, POPKI = Populus kitakamiensis, ORYSJ $=$ Oryza sativa ssp. japonica, VITVI $=$ Vitis vinifera.

The correlation of differential gene expression analysis with epigenetics was validated via qRT-PCR. For almost all individuals the expression of all five of the selected genes was down-regulated (Supplementary Table S3), corresponding to the differential expression analysis results of DESeq2. Only for one individual, an up-regulation of all the genes was detected. This individual is the same that separates from the rest of the samples under cold treatment (Figure 1).

\subsection{Discussion}

Plant acclimation to cold stress induces various cellular processes through a cascade of change in gene expression and protein synthesis e.g., (Smallwood \& Bowles, 2002; Zhu et al., 2007). It is estimated that between $4 \%$ and $12 \%$ of the transcriptome of $A$. thaliana changes after a respective period of several hours, days or weeks of exposure to chilling temperatures (Hannah et al., 2005; Knight \& Knight, 2012). This differentiation in gene expression combined with the observation of different gene clusters being up-regulated during different times of the stress exposure indicates a hierarchy in the functional response, with signaling of harmful conditions or increasing freezing tolerance comes first (Fowler \& Thomashow, 2002; Hannah et al., 2005; Robinson \& Parkin, 2008), while circadian clocks being hypothesized to play an important role in general regulation (Nohales \& Kay, 2016; Ritonga \& Chen, 2020). Polyploidy may affect cold acclimation as polyploids are thought to perform better under cold conditions e.g., (Rice et al., 2019). We analyzed here for the first time gene expression of a perennial alpine plant under different temperature conditions, and evaluated effects of different ploidy levels on the response to cold stress.

\section{Ploidy effects on gene expression and the distribution pattern}

The ploidy level of the individuals per se does not appear to be a significant contributor to the observed differential gene expression (Figure 1). This differs from previous studies on DNA methylation patterns, mode of reproduction, and morphological traits of $R$. kuepferi which revealed significant ploidy effects (Klatt et al., 2018; Syngelaki et al., 2002a, b). The congeneric species of the Ranunculus auricomus complex also showed strong ploidy effects in gene expression profiles of ovules (Pellino et al., 2020). In our study, the main effects in gene expression changes are due to treatments, not to ploidy. In autopolyploids, transcription profiles can be influenced by a multitude of factors, which are caused by genome duplication e.g., dosage effects due to the presence of additional copies of genes (Madlung \& Wendel, 2013). However, autotetraploid rice does seemingly not show a genome-wide dosage effect on gene expression; likely because subfunctionalization maintains the functional pleonasm of duplicated genes and avoids any energy waste (Wagner, 2005; Drummond \& Wilke, 2008; Qian et al., 2010; Zhang et al., 2015). Regarding the WD individual, which is an outlier for both 
the gene expression profiles and qRT-PCR analysis, there was no indication of lower RNA quality during wet and dry lab manipulation of the specimen. Probably, the conditional plasticity and the gene-environment interaction (WestEberhard, 2008; Bateson, 2015) of the individual, as well as the micro site of origin of the natural population, which belongs to the sympatric zone of the two cytotypes (Schinkel et al., 2016), could play the major role for its observed phenotype.To investigate further how the two cytotypes cope with stress conditions, gene set enrichment for each ploidy level was assessed. Several key regulatory pathways and their interactions have been documented previously e.g., (Takahashi et al., 2004; Cramer et al., 2011; Puijalon et al., 2011; Jutsz \& Gnida, 2015; Ritonga \& Chen, 2020).

In R. kuepferi, diploids respond more intensively to temperature treatments compared to the tetraploids, as a higher number of gene sets is significantly differentially expressed (Figures 2 and 3). Hence, diploids appear to be more stressed by cold conditions than tetraploids. The cold stress treatments of our experiments are quite similar to the natural habitat conditions of the tetraploid $R$. kuepferi plants in the Alps (Syngelaki et al., 2020a). As the cold adapted genotypes are thought to have a distinct advantage over non-adapted ones in frost-prone environments, such as high mountain areas (Nagy \& Grabherr, 2009), we hypothesize that the postglacial colonization of the Alps by autotetraploid populations of R. kuepferi (Schinkel et al., 2016) did rely to a large extent on the phenotypic variation towards the climatic conditions, pronounced also as differential gene expression (Vrijenhoek \& Parker, 2009). Thus, the geographical parthenogenesis scenario, which interrelates the cytotypes with different ecological backgrounds (Schinkel et al., 2016; Kirchheimer et al., 2018), is further supported. Results support the simulation study of postglacial recolonization in the Alps, which identified the acclimation/adaptation of tetraploids to a colder climatic niche in higher and more northern parts of the Alps as one decisive character of the geographical parthenogenesis pattern (Kirchheimer et al., 2018). Our results here suggest that this niche shift has a direct physiological background of cold tolerance and is less likely due other characteristics of alpine habitats (like a lower pathogen pressure, among others).

\section{Functional aspects of gene expression related to cold acclimation}

Although some of the differentially expressed gene sets overlap between ploidy levels, there are some characteristics for either group. In diploids, most pathways are linked to ion/cation homeostasis and activity and are suppressed. Additional pathways are connected to the plasma membrane, cell wall, and hydrolase activity. Similar pathways are present in tetraploid individuals, with a greater focus on membranes and cell wall. In contrast to diploids, the tetraploids suppressed only six pathways, mostly related to chromatin and histone modification. In both cytotypes the cold acclimation pathway is activated. 
As access point of the cell, membranes are injured by adverse environmental conditions, yet their stability contributes to cell behavior and activity maintenance (Theocharis et al., 2012; Chen et al., 2018; Ritonga \& Chen, 2020). Pathways related to cell lipid composition, such as the ones activated in the tetraploids, play an important role in the maintenance of plasma membrane functionality e.g., (de Palma et al., 2008; Janska et al., 2010) and are affecting the downstream expression of genes linked to resilience to lower temperature (Dutilleul et al., 2012). Maintenance of plasma membrane functionality is especially important for freezing tolerance in alpine plants, as a fluid membrane allows transfer of water from the protoplast into the intercellular space, where extracellular ice nucleation takes place, leaving the protoplast unfrozen (Körner, 2021). We suppose that our short freezing treatments $\left(-1^{\circ} \mathrm{C}\right.$ during three nights per week) induced these expression changes. However, we observed no apparent damage of leaves in cold treatments (Syngelaki et al., 2020b), and hence both cytotypes are tolerant to shortterm freezing and thawing during the day.

Decreasing membrane fluidity, coupled with its interaction with the cell wall, is considered to be one of the first cold sensors (Murata \& Los, 1997; Martiniere et al., 2011; Ma \& Liu, 2019). The connection of membrane rigidification to cytoskeletal rearrangements, calcium influxes and kinases, acts as trigger for the subsequent low-temperature response e.g., (Orvar et al., 2000; Sangwan et al., 2002).

Changes in the composition of the cell wall can strongly affect plant stress resistance (Zhu, 2016) as stress can up-regulate the expression of e.g., expansins and xyloglycan-modifying enzymes, which are acting on cell wall remodeling (Tenhaken, 2014). The hydrolase activity pathways activated in both ploidy levels in $R$. kuepferi under cold stress may indicate their unique roles in cell wall modification (Sulova et al., 2003; Eklof \& Brumer, 2010). The cytoskeleton is also affected by cold stress (Pokorna et al., 2004; Ma \& Liu, 2019) and its interactions with membranes and the cell wall play a distinctive role in cold stress tolerance (Abdrakhamanova et al., 2003; Kasemi-Shahandashti \& Maali-Amiri, 2018; Ding et al., 2019). The 'cell wall organization or biogenesis' pathway, which is activated in both diploid and tetraploid R. kuepferi individuals (Figures 2 and 3) is relevant to the cytoskeleton and its modifications under cold stress.

The pathways of ion/cation homeostasis and activity, as well as the serine/threonine protein kinase activity are thought to be temporal and spatial events downstream of $\mathrm{Ca}^{2+}$ signaling e.g., (Monroy et al., 1993; Lewis et al., 1997). A change in intracellular calcium ion concentration is one of the earliest signaling events triggering the response of plants to cold stress (Sanders et al., 2002; Knight \& Knight, 2012; Shi et al., 2015) with $\mathrm{Ca}^{2+}$ dynamics being detected within 40 s after cold stress exposure (Zhu et al., 2013). Presumably $\mathrm{Ca}^{2+}$ channels are primary sensors for cooling rate and $\mathrm{Ca}^{2+}$ efflux transporters are absolute temperature sensors (Plieth, 1999; White, 2009), while oscillations of $\mathrm{Ca}^{2+}$ are linked to stomatal closure in Arabidopsis thaliana, as a response to cold stress (Allen et al., 2000). 
Furthermore, the serine/threonine protein kinases are plasma membrane receptorlike kinases (RLKs), several of which are calcium-moderated and promote the expression of cold-responsive genes (COR) through the activation of a mitogenactivated protein kinase (MAPK) cascade (Cheng et al., 2013; Zhu et al., 2016; Ye et al., 2017; Liu et al., 2018).

The intriguing suppression of the latter pathways, especially in diploid R. kuepferi, corroborates the hypotheses of tangled information encoded through $\mathrm{Ca}^{2+}$ kinetics, which are constantly changing as a complex mechanism of stress response and are also influenced by 'cold memory', i.e., former exposure to cold stress conditions (Knight et al., 1996; Knight \& Knight, 2012). We hypothesize that suppressed pathways of ion/cation homeostasis in diploids are probably linked to stomatal closure and consequently reduction of $\mathrm{CO}_{2}$ uptake/carbon gain (Taiz \& Zeiger, 2010). This would explain the lower growth performance of diploids under cold conditions, as observed in the experiments of Syngelaki et al. (2020b).

\section{Gene expression related to DNA methylation}

Deciphering the epigenetic background of plants, which are exposed to abiotic stress, is a constantly developing field e.g., (Richards et al., 2017). DNA methylation is correlated with histone proteins and their post-transcriptional modifications, as the conversion of these modifications to DNA methylation profiles is often thought to be more stable e.g., (Zhu, 2008; Jones, 2012). These interactions are associated with gene expression profiles and gene transcription in general in response to cold stress (Chinnusamy \& Zhu, 2009; Kim et al., 2015) and could encompass changes in chromatin structure and accessibility (Strahl \& Allis, 2000; Lang-Mladek et al., 2010). Chromatin remodeling has a putative function as a plant thermometer, representing a relatively direct connection between cold and gene expression (Kumar \& Wigge, 2010; Kumar et al., 2012). In the present study, the pathways of histone and chromatin modifications are suppressed in the tetraploid individuals (Figure 3). Additionally, several genes, directly or indirectly related to DNA methylation, are significantly differentially expressed in both ploidy levels (Table 4). This result corroborates previous results of methylation-sensitive AFLP screenings that the cytotypes exhibit different methylation profiles (Schinkel et al., 2020; Syngelaki et al., 2020a). The differential expression of genes correlated with DNA methylation is further validated by the qRT-PCR results, where the two methyltransferases (CAMT3, PMT2), two demethylases (JM706, JMJ25) and the argonaute protein AGO4B were all found to be down-regulated, as expected from the bioinformatical analyses of the transcriptomes. This fits the overall pattern of loss of methylated MS-AFLP fragments after dramatic temperature changes (Syngelaki et al., 2020a). Methylation patterns may conserve the transgenerational epigenetic memory of response to cold treatments and hence differential 
acclimation and adaptation of cytotypes (Schinkel et al., 2020, Syngelaki et al. 2020a).

To summarize, the present study demonstrates the responses of diploid and tetraploid R. kuepferi plants towards cold stress in their gene expression patterns. Although both ploidy levels activate genes related to cold acclimation, the gene set pathways differ between cytotypes, suggesting a better cold acclimation of tetraploids than diploids. Consequently, our results strongly support the hypothesis of a physiological background of the observed ecological and geographical differentiation patterns between cytotypes. Altogether, cold stress induces differentially expressed gene profiles and several gene set pathways are involved in the response, either being activated or suppressed. Seemingly, these parallel mechanisms invoke energy conservation and help individuals to survive in novel and/or extreme environments. Lastly, DNA methylation is indicated to contribute to the regulation of gene expression and may preserve a different epigenetic memory for the two cytotypes. 


\subsection{References}

Abdrakhamanova, A., Wang, Q.Y., Khokhlova, L. and Nick, P. (2003). Is microtubule disassembly a trigger for cold acclimation? Plant $\mathcal{E}$ Cell Physiology, 44, 676-686.

Adams, K.L. and Wendel, J.F.(2005). Polyploidy and genome evolution in plants. Current Opinion in Plant Biology, 8, 135-141.

Allen, G.J., Chu, S.P., Schumacher, K., Shimazaki, C.T., Vafeados, D., Kemper, A., Hawke, S.D., Tallman, G., Tsien, R.Y., Harper, J.F. et al.(2000). Alteration of stimulus-specific guard cell calcium oscillations and stomatal closing in Arabidopsis det3 mutant. Science, 289, 2338-2342.

Alonso, C., Balao, F., Bazaga, P. and Perez, R. (2016). Epigenetic contribution to successful polyploidizations: variation in glabal cytosine methylation along an extensive ploidy series in Dianthus broteri (Caryophyllaceae). New Phytologist, 212, 571-576.

Andrews, S. (2010).FastQC: a quality control tool for high throughput sequence data. Available online at: http://www.bioinformatics.bbsrc.ac.uk/projects/fastqc

Angers, B., Castonguay, E. and Massicotte, R. (2010). Environmentally induced phenotypes and DNA methylation: how to deal with unpredictable conditions until the next generation and after. Molecular Ecology, 19, 1283-1295.

Auld, J.R., Agrawal, A.A. and Relyea, R.A. (2010). Re-evaluating the costs and limits of adaptive phenotypic plasticity. Proc. R. Soc. B, 277, 503-511.

Banerjee, A., Wani, S.H. and Roychoudhury, A. (2017). Epigenetic Control of Plant Cold Responses. Frontiers in Plant Science, 8, 1643.

Bateson, P. (2015). Why are individuals so different from each other? Heredity, 115, 285-292.

Baubec, T., Dinh, H.Q., Pecinka, A., Rakic, B., Rozhon, W., Wohlrab, B., von Haeseler, A. and Scheid, O.M. (2010). Cooperation of Multiple Chromatin Modifications Can Generate Unanticipated Stability of Epigenetic States in Arabidopsis. Plant Cell, 22, 34-47.

Bell, C., Soltis, D. and Soltis, P. (2010). The age and diversification of the angiosperms re-visited. American Journal of Botany, 97(8), 1296-1303.

Bewick, A.J., Niederhuth, C.E., Ji, L., Rohr, N.A., Griffin, P.T., Leebens-Mack, J. and Schmitz, R.J. (2017). The evolution of CHROMOMETHYLASES and gene body DNA methylation in plants. Genome Biology, 18, 65. 
Bird, A. (2002). DNA methylation patterns and epigenetic memory. Genes $\mathcal{E}$ Development, 16, 6-21.

Bossdorf, O., Arcuri, D., Richards, C.L. and Pigliucci, M. (2010). Experimental alteration of DNA methylation affects the phenotypic plasticity of ecologically relevant traits in Arabidopsis thaliana. Evolutionary Ecology, 24, 541-553.

Boyko, A., Blevins, T., Yao, Y., Golubov, A., Bilichak, A., Ilnytskyy, Y., Meins, F. and Kovalchuk, I. (2010). Transgenerational Adaptation of Arabidopsis to Stress Requires DNA Methylation and the Function of Dicer-Like Proteins. Plos One, 5,https://doi.org/10.1371/journal.pone.0009514

Brandshaw, A.D. (1965). Evolutionary significance of phenotypic plasticity in plants. Adv. Genet., 13, 115-155.

Bräutigam, K. and Cronk, Q. (2018). DNA Methylation and the Evolution of Developmental Complexity in Plants. Frontiers in Plant Science, 9, 1447.

Bryant, D.M., Johnson, K., DiTommaso, T., Tickle, T., Couger, M.B., PayzinDogru, D., Lee, T.J., Leigh, N.D., Kuo, T.H., Davis, F.G., Bateman, J., Bryant, S., Guzikowski, A.R. et al. (2017). A Tissue-Mapped Axolotl De Novo Transcriptome Enables Identification of Limb Regeneration Factors. Cell Rep., 18(3), 762-776.

Burnier, J., Buerki, S., Arrigo, N., Küpfer, P. and Alvarez, N. (2009). Genetic structure and evolution of Alpine polyploid complexes: Ranunculus kuepferi (Ranunculaceae) as a case study. Molecular Ecology, 18, 3730-3744.

Casal, J.J. and Balasubramanian, S. (2019). Thermomorphogenesis. Annual Review of Plant Biology, 70, 321-346.

Chang, Y.N., Chen, Z., Jiang, J., Zhang, H., Zhu, J.K. and Duan, C.G. (2020). Epigenetic regulation in plant abiotic stress responses. Journal of Intergrative Plant Biology, 62(5), 563-580.

Chen, L., Zhao, Y., Xu, S., Zhang, Z., Xu, Y., Zhang, J. and Chong, K. (2018). Os MADS 57 together with Os TB 1 coordinates transcription of its target Os WRKY 94 and D14 to switch its organogenesis to defense for cold tolerance in rice. J. Exp. Bot., 63, 6467-6480.

Cheng, X., Yan, W., Guo, J., Du, B., Chen, R., Zhu, L. and He, G. (2013). A rice lectin receptor-like kinase that is involved in innate immune responses also contributes to seed germination. Plant J., 76(4), 687-698.

Chevin, L.M. and Lande, R. (2010). When do adaptive plasticity and genetic evolution prevent extinction of a density-regulated population? Evolution, 64, 11431150. 
Chevin, L.M. and Hoffmann, A.A. (2017). Evolution of phenotypic plasticity in extreme environments. Philosophical Transactions of the Royal Society B: Biological Sciences 372(1723), 20160138.

Chinnusamy, V., Zhu, J. and Zhu, J.K. (2007). Cold stress regulation of gene expression in plants. Trends in Plant Science, 12, 444-451.

Chinnusamy, V. and Zhu, J.K. (2009). Epigenetic regulation of stress responses in plants. Current Opinion in Plant Biology, 12, 133-139.

Cosendai, A.C. and Hörandl, E. (2010). Cytotype stability, facultative apomixis and geographical parthenogenesis in Ranunculus kuepferi (Ranunculaceae). Annals of Botany, 105, 457-470.

Cosendai, A.C., Rodewald, J. and Hörandl, E. (2011). Origin and distribution of autopolyploids via apomixis in the alpine species Ranunculus kuepferi (Ranunculaceae). Taxon, 60, 355-364.

Cosendai, A.C., Wagner, J., Ladinig, U., Rosche, C. and Hörandl, E. (2013). Geographical parthenogenesis and population genetic structure in the alpine species Ranunculus kuepferi (Ranunculaceae). Heredity, 110, 560-569.

Cramer, G.R., Urano, K., Delrot, S., Pezzotti, M. and Shinozaki, K. (2011). Effects of abiotic stress on plants: a systems biology perspective. BMC Plant Biology, 11, 163.

de Palma, M., Grillo, S., Massarelli, I., Costa, A., Balong, G., Vigh, L. and Leone, A. (2008). Regulation of desaturase gene expression, changes in membrane lipid composition and freezing tolerance in potato plants. Molecular Breeding, 21, 138-149.

Ding, Y., Shi, Y. and Yang, S. (2019). Advances and challenges in uncovering cold tolerance regulatory mechanisms in plants. New Phytologist, 222, 1690-1704.

Donelson, J.M., Salinas, S., Munday, P.L. and Shama, L.N.S. (2017). Transgenerational plasticity and climate change experiments: Where do we go from here? Global Change Biology, 24, 13-24.

Dong, Z.Y., Wang, Y.M., Zhang, Z.J., Shen, Y., Lin, X.Y., Ou, X.F., Han, F.P. and Liu, B. (2006). Extent and pattern of DNA methylation alteration in rice lines derived from introgressive hybridization of rice and Zizania latifolia Griseb. Theoretical \& Applied Genetics, 113, 196-205.

Dowen, R.H., Pelizzola, M., Schmitz, R.J., Lister, R., Dowen, J.M., Nery, J.R., Dixon, J.E. and Ecker, J.R. (2012). Widespread dynamic DNA methylation in response to biotic stress. Proceedings of the National Academy of Sciences of the United States of America, 109, 2183-2191. 
Drummond, D.A. and Wilke, C.O. (2008). Mistranslation-induced protein misfolding as a dominant constraint on coding-sequence evolution. Cell, 134(4), 341-352.

Dutilleul, C., Benhaissaine-Kesri, G., Demandre, C., Reze, N., Launay, A., Pelletier, S., Renou, J.P., Zachowski, A., Baudouin, E. and Guillas, I. (2012), Phytosphingosine-phosphate is a signal for AtMPK6 action and Arabidopsis response to chilling. New Phytologist, 194, 282-292.

Eklof, J.M. and Brumer, H. (2010). The XTH gene family: an update on enzyme structure, function, and phylogeny in xyloglycan remodeling. Plant Physiology, 153, 456-466.

Finnegan, E.J. and Kovac, K.A. (2000). Plant DNA methyltransferases. Plant Mol. Biol., 43, 189-201.

Finnegan, E.J. (2010). DNA Methylation a Dynamic Regulator of Genome Organization and Gene Expression in Plants.In Plant Developmental Biology Biotechnological Perspectives: vol. 2. (Pua, E-C. and Davey, M.R., eds).Berlin, Germany: Springer-Verlag, 295-323.

Fiorucci, A.S., Galvao, V.C., Ince, Y.C., Boccaccini, A., Goyal, A., Petrolati, L.A., Trevisan, M. and Fankhauser, C. (2020). PHYTOCHROME INTERACTING FACTOR 7 is important for early responses to elevated temperature in Arabidopsis seedlings. New Phytologist, 226, 50-58.

Fowler, S. and Thomashow, M.F. (2002). Arabidopsis transcriptome profiling indicates that multiple regulatory pathways are activated during cold acclimation in addition to the CBF cold response pathway. Plant Cell, 14, 1675-1690.

Franks, S.J., Weber, J.J. and Aitken, S.N. (2013). Evolutionary and plastic responses to climate change in terrestrial plant populations. Evolutionary Applications, 7, 123-139.

Garsed, S., Davey, H. and Galley, D. (1987). The effects of Light and Temperature on the Growth of and Balances of Carbon, Nitrogen and Potassium between Vicia faba L. and Aphis fabae Scop. New Phytologist, 107, 77-102.

Gangappa, S.N., Berriri, S. and Kumar, S.V. (2017) PIF4 coordinates thermosensory growth and immunity in Arabidopsis. Current Biology, 27, 243-249.

Grabherr, M.G., Haas, B.J., Yassour, M., Levin, J.Z., Thompson, D.A., Amit, I., Adiconis, X., Fan, L., Raychowdhury, R., Zeng, Q. et al.(2011). Full-length transcriptome assembly from RNA-Seq data without a reference genome. Nat Biotechnol., 29(7), 644-652. 
Grabherr, M.G., Haas, B.J., Yassour, M., Levin, J.Z., Thompson, D.A., Amit, I., Adiconis, X., Fan, L., Raychowdhury, R., Zeng, Q. et al.(2013). Trinity: reconstructing a full-length transcriptome without a genome from RNA-Seq data. Nat Biotechnol., 29(7), 644-652.

Grant-Downton, R.T. and Dickinson, H.G. (2005). Epigenetics and its implications for Plant Biology: 1. The epigenetic network in plants. Annals of Botany, 96, 11431164.

Griffith, M. and Yaish, M.W.F. (2004). Antifreeze proteins in overwintering plants: a tale of two activities. Trends Plant Sci., 9, 399-405.

Guy, C.L. (1990). Cold acclimation and freezing stress tolerance: role of protein metabolism. Annual Review of Plant Physiology and Plant Molecular Biology, 41, 187223.

Haas, B.J., Delcher, A.L., Mount, S.M., Wortman, J.R., Smith, R.K., Hannick, L.I., Maiti, R., Ronning, C.M., Rusch, D.B., Town, C.D. et al.(2013). Improving the Arabidopsis genome annotation using maximal transcript alignment assemblies. Nucleic Acids Res., 31(19), 5654-5666.

Hannah, M.A., Heyer, A.G. and Hincha, D.K. (2005). A global survey of gene regulation during cold acclimation in Arabidopsis thaliana. PLoS Genet., 1, 179-196.

Harris, C.J., Scheibe, M., Wongpalee, S.P., Liu, W.L., Cornett, E.M., Vaughan, R.M., Li, X.Q., Chen, W., Xue, Y., Zhong, Z.H. et al.(2018). A DNA methylation reader complex that enchances gene transcription. Science, 362, 1182-1186.

Hedhly, A. (2011). Sensitivity of flowering plant gametophytes to temperature fluctuations. Environmental and Experimental Botany, 74, 9-16.

Hegarty, M.J., Batstone, T., Barker, G.L., Edwards, K.J., Abbott, R.J. and Hiscock SJ. (2011). Nonadditive changes to cytosine methylation as a consequence of hybridization and genome duplication in Senecio (Asteraceae). Molecular Ecology, 20, 105-113.

Hirsch, S., Baumberger, R. and Grossniklaus, U. (2013). Epigenetic variation, inheritance, and selection in plant populations. Cold Spring Harbor Symposia on Quantitative Biology, 77, 97-104.

Hörandl, E. (2006). The complex causality of geographical parthenogenesis. New Phytologist, 171(3), 525-538.

Hu, Y., Zhang, L., Zhao, L., Li, J., He, S.B., Zhou, K., Yang, F., Huang, M., Jiang, L. and Li, L.J. (2011). Trichostatin A selectively suppresses the cold-induced transcription of ZmDREB1 gene in maize. PLoS ONE 6, e22132. 
Jafari, M. and Ansari-Pour, N. (2019). Why, When and How to Adjust your P Values? Cell J., 20(4), 604-607.

Janska, A., Marsik, P., Zelenkova, S. and Ovesna, J. (2010). Cold stress and acclimation - what is important for metabolic adjustment? Plant Biology, 12, 395405.

Jammohammadi, M., Zolla, L. and Rinalducci, S. (2015). Low temperature tolerance in plants: Changes at the protein level. Phytochemistry, 117, 76-89.

Johannes, F., Porcher, E., Teixeira, F.K., Saliba-Colombani, V., Simon, M., Agier, N., Bulski, A., Albuisson, J., Heredia, F., Audigier, P. et al.(2009). Assessing the Impact of Transgenerational Epigenetic Variation on Complex Traits. PLoS Genetics, 5(6), e1000530.

Johnson, M., Zaretskaya, I., Raytselis, Y., Merezhuk, Y., McGinnis, S. and Madden, T.L. (2008). NCBI BLAST: a better web interface. Nucleic Acids Research, 36(2), W5-W9.

Jones, P.A. (2012). Functions of DNA methylation: islands, start sites, gene bodies and beyond. Nature Reviews Genetics, 13, 484-492.

Joseph, J.T., Poolakkalody, N.J. and Shah, J.M. (2018). Plant reference gene for development and stress response studies. J Biosci, 43(1), 173-187.

Jutsz, A.M. and Gnida, A. (2015). Mechanisms of stress avoidance and tolerance by plants used in phytoremediation of heavy metals. Arch. Environ. Prot., 41, 104114.

Kazemi-Shahandashti, S.S. and Maali-Amiri, R. (2018). Global insights of protein responses to cold stress in plants: Signaling, defence and degradation. Journal of Plant Physiology, 226, 123-135.

Kelly, M. (2019). Adaptation to climate change through genetic accommodation and assimilation of plastic phenotypes. Phil. Trans. R. Soc. B, 374, 20180176.

Kim, J.M., Sasaki, T., Ueda, M., Sako, K. and Seki, M. (2015). Chromatin changes in response to drought, salinity, heat and cold stresses in plants. Frontiers in Plant Science, 6, 114.

Kirchheimer, B., Schinkel, C.C-F., Dellinger, A.S., Klatt, S., Moser, D., Winkler, M., Lenoir, J., Caccianiga, M., Guisan, A., Nieto-lugilde, D. et al. (2016). A matter of scale: apparent niche differentiation of diploid and tetraploid plants may depend on extent and grain of analysis. Journal of Biogeography, 43, 716-726. 
Kirchheimer, B., Wessely, J., Gattringer, A., Hülber, K., Moser, D., Schinkel, C.CF., Appelhans, M., Klatt, S., Caccianiga, M., Dellinger, A. et al.(2018). Reconstructing geographical parthenogenesis: effects of niche differentiation and reproductive mode on Holocene range expansion of an alpine plant. Ecology Letters, 21, 392-401.

Klatt, S., Schinkel, C.C-F., Kirchheimer, B., Dullinger, S. and Hörandl, E. (2018). Effects of cold treatments on fitness and mode of reproduction in the diploid and polyploid alpine plant Ranunculus kuepferi (Ranunculaceae). Annals of Botany, 121, 1287-1298.

Knight, H., Trewavas, A.J. and Knight, M.R. (1996). Cold calcium signaling in Arabidopsis involves two cellular pools and a change in calcium signature after acclimation. Plant Cell, 8, 489-503.

Knight, M.R. and Knight, H. (2012). Low-temperature perception leading to gene expression and cold tolerance in higher plants. New Phytologist, 195, 737-751.

Kooke, R., Johannes, F., Wardenaar, R., Becker, F., Etcheverry, M., Colot, V., Vreugdenhil, D. and Keurentjes, J.B. (2015). Epigenetic Basis of Morphological Variation and Phenotypic Plasticity in Arabidopsis thaliana. The Plant Cell, 27, 337348.

Körner, C.H. (2021).Alpine plant life $3^{\text {nd }}$ edn. Cham, Switzerland: Springer Switzerland AG.

Kumar, S.V. and Wigge, P.A. (2010). H2A.Z-containing nucleosomes mediate the thermosensory response of Arabidopsis. Cell, 140, 136-147.

Kumar, S.V., Lucyshyn, D., Jaeger, K.E., Alos, E., Harberd, N.P. and Wigge, P.A. (2012). Transcription factor PIF4 controls the thermosensory activation of flowering. Nature, 484, 242-245.

Küpfer, P. (1974). Recherchessurlesliens de parente entre la floreorophile des Alpesetcelle des Pyrenees. Boissiera, 23, 1-322.

Laland, K.N., Uller, T., Feldman, M.W., Sterelny, K., Müller, G.B., Moczek, A., Jablinka, E. and Odling-Smee, J. (2015). The extended evolutionary synthesis: its structure, assumptions and predictions. Proc. R. Soc. B., 282, 20151019

Lanciano, S. and Mirouze, M. (2017). DNA Methylation in Rice and Relevance for Breeding. Epigenomes, 1, 10.

Lande, R. (2009). Adaptation to an extraordinary environment by evolution of phenotypic plasticity and genetic assimilation. J. Evol. Biol., 22, 1435-1446. 
Lang-Mladek, C., Popova, O., Kiok, K., Berlinger, M., Rakic, B., Aufsatz, W., Jonak, C., Hauser, M.T. and Lusching, C. (2010). Transgenerational inheritance and resetting of stress-induced loss of epigenetic gene silencing in Arabidopsis. Mol Plant, 3, 594-602.

Langmead, B. and Salzberg, S.L. (2012). Fast gapped-read alignment with Bowtie2. Nat. Methods, 9(4), 357-359.

Lau, O.S., Song, Z., Zhou, Z., Davies, K.A., Chang, J., Yang, X., Wang, S., Lucyshyn, D., Tay, I.H.Z., Wigge, P.A., et al.(2018). Direct control of SPEECHLESS by PIF4 in the high-temperature response of stomatal development. Current Biology, 28, 1273-1280.e3.

Law, J.A. and Jacobsen, S.E. (2010). Establishing, maintaining and modifying DNA methylation patterns in plants and animals. Nature Reviews Genetics, 11, 204-220.

Lewis, B.D., Karlin-Neumann, G., Davis, R.W. and Spalding, E.P. (1997). Ca ${ }^{2+}$ activated anion channels and membrane depolarizations induced by blue light and cold in Arabidopsis seedlings. Plant Physiology, 114, 1327-1334.

Li, Z.H., Lu, X., Gao, Y., Liu, S.J., Tao, M., Xiao, H., Qiao, Y.Q., Zhang, Y.P. and Luo, J. (2011). Polyploidization and epigenetics. Chinese Science Bulletin, 3, 245-252.

Liao, Y., Smyth, G.K. and Shi, W. (2019). The R package Rsubread is easier, faster, cheaper and better for alignment and quantification of RNA sequencing reads. Nucleic Acids Research, 47, e47.

Liu, T., Li, Y., Duan, W., Huang, F. and Hou, X. (2017). Cold acclimation alters DNA methylation patterns and confers tolerance to heat and increases growth rate in Brassica rapa. Journal of Experimental Botany, 68, 1213-1224.

Liu, Y., Xu, C., Zhu, Y., Zhang, L., Chen, T., Zhou, F., Chen, H. and Lin, Y. (2018). The calcium-dependent kinase OsCPK24 functions in cold stress responses in rice. Journal of Intergrative Plant Biology, 60, 173-188.

Livak, K.J. and Schmittgen, T.D. (2001). Analysis of relative gene expression data using real-time quantitative PCR and the $2^{-\Delta \Delta} \mathrm{C}^{\mathrm{T}}$ method. Methods, 25, 402-408.

Longo, V., Kamran, R.V., Michaletti, A., Toorchi, M., Zolla, L. and Rinalducci, S. (2017). Proteomic and Physiological Response of Spring Barley Leaves to Cold Stress. Int. J Plant Biol. Res., 5, 1-10.

Love, M.I., Huber, W. and Anders, S. (2014). Moderated estimation of fold change and dispersion for RNA-seq data with DESeq2. Genome Biol., 15(12), 550. 
Ma, H. and Liu, M. (2019). The microtubule cytoskeleton acts as a sensor for stress response signaling in plants. Molecular Biology Reports, 46, 5603-5608.

Madlung, A. and Wendel, J.F. (2013). Genetic and Epigenetic Aspects of Polyploid Evolution in Plants. Cytogenetic and Genome Research, 140, 270-285.

Manni, M., Berkeley, M.R., Seppey, M., Simao, F.A. and Zdobnov, E.M. (2021). BUSCO update: novel and streamlined workflows along with broader and deeper phylogenetic coverage for scoring of eukaryotic, prokaryotic, and viral genomes. Available from: http:/ / arxiv.org/abs/2106.11799

Martin, M. (2011). Cutadapt removes adapter sequences from high-throughput sequencing reads. EMBnet.Journal, 17, 10-12.

Martiniere, A., Shvedunova, M., Thomshon, A.J., Evans, N.H., Penfield, S., Runions, J. and McWatters, H.G. (2011). Homeostasis of plasma membrane viscosity in fluctuating temperatures. New Phytologist, 192, 328-337.

Matzke, M.A. and Mosher, R.A. (2014). RNA-directed DNA methylation: an epigenetic pathway of increasing complexity. Nature Reviews. Genetics, 15, 394-408.

Megha, S., Basu, U. and Kav, N.N.V. (2018). Regulation of low temperature stress in plants by microRNAs. Plant, Cell $\mathcal{E}$ Development, 41, 1-15.

Miura, K. and Furumoto, T. (2013). Cold Signaling and Cold Response in Plants. Int. J. Mol. Sci., 14, 5312-5337.

Monroy, A.F., Sarhan, F. and Dhindsa, R.S. (1993). Cold-induced changes in freezing tolerance, protein phosphorylation and gene expression (evidence for a role of calcium). Plant Physiology, 102, 1227-1235.

Munns, R. (2011). Plant adaptations to salt and water stress: differences and commonalities. Advances in Botanical Research, 57, 1-32.

Murata, N. and Los, D.A. (1997). Membrane fluidity and temperature perception. Plant Physiology, 115, 875-879.

Nagy, L. and Grabherr, G. (2009). The biology of alpine habitats. New York, USA: Oxford University Press.

Nicotra, A.B., Atkin, O.K., Bonser, S.P., Davidson, A.M., Finnegan, E.J., Mathesius, U., Poot, P., Purugganan, M.D., Richards, C.L., Valladares, F. and van Kleunen, M. (2010). Plant phenotypic plasticity in a changing climate. Trends in Plant Science, 15, 684-692. 
Nohales, M.A. and Kay, S.A. (2016). Molecular mechanisms at the core of the plant circadian oscillator. Nat. Struct. Mol. Mol. Biol., 23, 1061-1069.

Orvar, B.L., Sangwan, V., Omann, F. and Dhindsa, R. (2000). Early steps in cold sensing by plant cells: the role of actin cytoskeleton and membrane fluidity. The Plant Journal, 23, 785-794.

Osborn, T.C., Pires, J.C., Birchler, J.A., Auger, D.L., Chen, Z.J. et al.(2003). Understanding mechanisms of novel gene expression in polyploids. Trends Genet., 19, 141-147.

Pages, H., Carlson, M., Falcon, S. and Li, N. (2021).AnnotationDbi: Manipulation of SQLite-based annotations in Bioconductor. $\mathrm{R}$ package version 1.55.1, https:// bioconductor.org/packages/AnnotationDbi.

Pellino, M., Hojsgaard, D., Hörandl, E. and Sharbel, T. (2020). Chasing the apomictic factors in the Ranunculus auricomus complex: exploring gene expression patterns in microdissected sexual and apomictic ovules. Genes, 11(7), doi:10.3390/genes11070728

Pigliucci, M. (2001).Phenotypic plasticity: Beyond nature and nurture. Baltimore, MD: John Hopkins Press.

Plieth, C. (1999). Temperature sensing by plants: calcium-permeable channels as primary sensors- a model. Journal of Membrane Biology, 172, 121-127.

Pokorna, J., Schwarzerova, K., Zelenkova, S., Petrasek, J., Janotova, I., Capkova, V. and Opatrny, Z. (2004). Sites of actin filament initiation and reorganization in cold-treated tobacco cells. Plant, Cell E Development, 27, 641-653.

Price, T.D., Qvarnström, A. and Irwin, D.E. (2003). The role of phenotypic plasticity in driving genetic evolution. Proceedings of the Royal Society of London Series B, 270, 1433-1440.

Puijalon, S., Bouma, T.J., Douady, C.J., Groenendael, J.V., Anten, N.P.R., Martel, E., Bornette, G. (2011). Plant resistanse to mechanical stress: Evidence of an avoidance-Tolerance trade-off. New Phytologist, 191, 1141-1149.

Qian, W., Liao, B.Y., Chang, A.Y.F. and Zhang J. (2010). Maintenance of duplicate genes and their functional redundancy by reduced expression. Trends Genet., 26(10), 425-430.

Quint, M., Delker, C., Franklin, K.A., Wigge, P.A., Halliday, K.J. and van Zanten, M. (2016). Molecular and genetic control of plant thermomorphogenesis. Nature Plants, 2, 15190. 
Rice, A., Smarda, P., Novosolov, M., Drori, M., Glick, L., Sabath, N., Meiri, S., Belmaker, J. and Mayrose, I. (2019). The global biogeography of polyploidy plants. Nature Ecology E Evolution, 3, 265-273.

Richards, C.L., Alonso, C., Becker, C., Bossdorf, O., Bucher, E., Colome-Tatche, M., Durka, W., Engelhardt, J., Gaspar, B., Gogol-Döring, A. et al.(2017). Ecological plant epigenetics: Evidence from model and non-model species, and the way forward. Ecology Letters, 20, 1576-1590.

Ritonga, F.N. and Chen, S. (2020). Physiological and Molecular Mechanism Involved in Cold Stress Tolerance in Plants. Plants, 9, 560.

Robinson, S.J. and Parkin, I.A. (2008). Differential SAGE analysis in Arabidopsis uncovers increased transcriptome complexity in response to low temperature. BMC Genomics, 9, 434.

R Core Team (2021). R: A language and environment for statistical computing. $R$ Foundation for Statistical Computing, Vienna, Austria. URL https://www.Rproject.org/

RStudio Team (2016).RStudio: Integrated Development for R. RStudio, PBC, Boston, MA URL http://www.rstudio.com/

Sanders, D., Pelloux, J., Brownlee, C. and Harper, J.F. (2002). Calcium at the crossroads of signaling. Plant Cell, 14, 401-417.

Sanghera, G.S., Wani, S.H., Hussain, W. and Singh, N.B. (2011). Engineering cold stress tolerance in crop plants. Current Genomics, 12, 30-43.

Sangwan, V., Örvar, B.L. and Dhindsa, R.S. (2002).Early events during low temperature signaling. In Plant cold hardiness (Li, C. and Palva, E.T., eds). Dordrecht, The Netherlands: Kluwer Academic Publishers, 43-53.

Schinkel, C.C-F., Kirchheimer, B., Dellinger, A.S., Klatt, S., Winkler, M., Dullinger, S. and Hörandl, E. (2016). Correlations of polyploidy and apomixis with elevation and associated environmental gradients in an alpine plant. $A o B$ PLANTS, 8, plw064.

Schinkel, C.C-F., Kirchheimer, B., Dullinger, S., Geelen, D., De Storme, N. and Hörandl, E. (2017). Pathways to polyploidy: indications of a female triploid bridge in the alpine species Ranunculus kuepferi (Ranunculaceae). Plant Systematics $\mathcal{E}$ Evolution, 303, 1093-1108.

Schinkel, C.C-F., Syngelaki, E., Kirchheimer, B., Dullinger, S., Klatt, S. and Hörandl, E. (2020). Epigenetic patterns and geographical parthenogenesis in the alpine plant species Ranunculus kuepferi (Ranunculaceae). Int J MolSci, 21(9), 3318. 
Schlichting, C.D. (1986). The evolution of phenotypic plasticity in plants. Annu. Rev. Ecol. Syst., 17, 667-693.

Schlichting, C.D. and Pigliucci, M. (1998). Phenotypic evolution: a reaction norm perspective. Sunderland, MA: Sinauer.

Sherman, J.D. and Talbert, L.E. (2002). Vernalization-induced changes of the DNA methylation pattern in winter wheat. Genome, 260, 253-260.

Shi, Y., Ding, Y. and Yang, S. (2015). Cold signal transduction and its interplay with phytohormones during cold acclimation. Plant Cell and Physiology, 56, 7-15.

Smallwood, M. and Bowles, D.J. (2002). Plants in a cold climate. Philos. Trans. R. Soc. Lond. B. Biol., 357, 831-846.

Sol, D., Duncan, R.P., Blackburn, T.M., Cassey, P. and Lefebvre, L. (2005). Big brains, enhanced cognition and response of birds to novel environments. Proc. Natl Acad. Sci. USA, 102, 5460-6465.

Soltis, D.E., Buggs, R.J.A., Doyle, J.J. and Soltis, P.S. (2010). What we still don't know about polyploidy. Taxon, 59, 1387-1403.

Soltis, D.E., Visger, C.J. and Soltis, P.S. (2014). The polyploidy revolution then . . and now: Stebbins revisited. American Journal of Botany, 101, 1057-1078.

Sterns, S. (1989). The evolutionary significance of phenotypic plasticity. Bioscience, $39,436-445$.

Strahl, B.D. and Allis, C.D. (2000). The language of covalent histone modifications. Nature, 403, 41-45.

Sulova, Z., Baran, R. and Farkas, V. (2003). Divergent modes of action on xyloglycan of two isoenzymes of xyloglycan endo-transglycosylase from Tropaelum majus. Plant Physiol. Biochem., 41, 431-437.

Suzuki, N., Rivero, R.M., Shulaev, V., Blumwald, E. and Mittler, R. (2014). Abiotic and biotic stress combinations. New Phytologist, 203, 32-43.

Syngelaki, E., Schinkel, C.C-F., Klatt, S. and Hörandl, E. (2020a). Effects of temperature treatments on cytosine-methylation profiles of diploid and autotetraploid plants of the alpine species Ranunculus kuepferi (Ranunculaceae). Front. Plant Sci., 11, 435.

Syngelaki, E., Daubert, M., Klatt, S. and Hörandl, E. (2020b). Phenotypic responses, reproduction mode and epigenetic patterns under temperature 
treatments in the alpine plant species Ranunculus kuepferi (Ranunculaceae). Biology, 9(10), 315.

Taiz, L. and Zeiger, E. (2010). Plant Physiology. 5th edition Sunderland: Sinauer Associates, Inc.

Takahashi, S., Seki, M., Ishida, J., Satou, M., Sakurai, T., Narusaka, M., Kamiya, A., Nakajima, M., Enju, A., Akiyama, K. et al.(2004). Monitoring the expression profiles of genes induced by hyperosmotic, high salinity, and oxidative stress and abscisic acid treatment in Arabidopsis cell culture using full-length cDNA microarray. Plant Mol. Biol., 56(1), 29-55.

te Beest, M., Le Roux, J.J., Richardson, D.M., Brysting, A.K., Suda, J., Kubesova, M. and Pysck, P. (2012). The more the better? The role of polyploidy in facilitating plant invasions. Annals of Botany, 109, 19-45.

Tenhaken, R. (2014). Cell wall remodeling under abiotic stress. Front. Plant Sci., 5, 771.

Theocharis, A., Clement, C. and AitBarka, E. (2012). Physiolgical and molecular changes in plant growth at low temperatures. Planta, 235, 1091-1105.

Thomashow, M.F. (1999). Plant cold acclimation: freezing tolerance genes and regulatory mechanisms. Annual Review of Plant Physiology and Plant Molecular Biology, 50, 571-599.

Van de Peer, Y., Mizrachi, E. and Marchal, K. (2017). The evolutionary significance of polyploidy. Nature Reviews: Genetics, 18, 411-424.

Vaughn, M.W., Tanurdzic, M., Lippman, Z., Jiang, H., Carrasquillo, R., Rabinowicz, P.D., Dedhia, N., McCombie, W.R., Agier, N., Bulski, A. et al. (2007). Epigenetic Natural Variation in Arabidopsis thaliana. PLoS Biology, 5, 16171629.

Via, S. and Lande, R. (1985). Genotype-environment interaction and the evolution of phenotypic plasticity. Evolution, 39, 505-522.

Vrijenhoek, R.C. and Parker, E.D. (2009). Geographical parthenogenesis: general purpose genotypes and frozen niche variation BT. In Lost sex: The evolutionary biology of parthenogenesis. (Schön, I., Martens, K. and Dijk, P., eds). Dordrecht: Springer, 99-131.

Wagner, A. (2005). Energy constrains on the evolution of gene expression. Mol. Biol. Evol., 22(6), 1365-1374. 
Wani, S.H., Singh, N.B., Haribhushan, A. and Mir, J.I. (2013). Compatible solute engineering in plants for abiotic stress tolerance-Role of glycine betaine. Curr. Gen., 14, 157-165.

Wani, S.H., Sah, S.K., Sanghera, G., Hussain, W. and Singh, N.B. (2016). Genetic engineering for cold stress tolerance in crop plants. In Advances in Genome Science. (Atta-ur-Rahman, eds). London, UK: Betham Science, 173-201.

Wei, N., Cronn, R., Liston, A. and Ashman, T.L. (2019). Functional trait divergence and trait plasticity confer polyploidy advantage in heterogeneous environments. New Phytologist, 221, 2286-2297.

West-Eberhard, M.J. (2003). Developmental Plasticity and Evolution. Oxford, UK: Oxford University Press.

West-Eberhard, M.J. (2008). Phenotypic plasticity. In Encyclopedia of Ecology. (Jorgensen, E. and Fath, B., eds). Amsterdam, Netherlands: Elsevier Science, 27012707.

White, P.J. (2009). Depolarization-activated calcium channels shape the calcium signatures induced by low-temperature stress. New Phytologist, 183, 6-8.

Whitman, D.W. and Agrawal, A.A. (2009). What is phenotypic plasticity and why is it important? In Phenotypic Plasticity of Insects. (Ananthakrishnan, T.N., eds). Science Publishers, 1-63.

Wickham, H. (2009). ggplot2: Elegant Graphics for Data Analysis. New York, USA: Springer-Verlag.

Xiao, X., Zhang, J., Li, T., Fu, X., Satheesh, V., Niu, Q., Lang, Z., Zhu, J.K. and Lei, M. (2019). A group of SUVH methyl-DNA binding proteins regulate expression of the DNA demethylase ROS1 in Arabidopsis. Journal of Intergrative Plant Biology, 61, 110-119.

Yan, H., Kikuchi, S., Neumann, P., Zhang, W., Wu, Y., Chen, F., Jiang, J. and Creek, W. (2010). Genome-wide mapping of cytosine methylation revealed dynamic DNA methylation patterns associated with genes and centromeres in rice. The Plant Journal, 63, 353-365.

Ye, Y., Ding, Y., Jiang, Q., Wang, F. and Sun, J. (2017). The role of receptor-like protein kinases (RLKs) in abiotic stress response in plants. Plant Cell Rep., 36, 235242.

Yeh, P.J. and Price, T.D. (2004). Adaptive phenotypic plasticity and the successful colonization of a novel environment. Am. Nat., 164, 531-542. 
Yu, G., Wang, L.G., Han, Y. and He, Q.Y. (2012). clusterProfiler: an R package for comparing biological themes among gene clusters. OMICS, 16(5), 284-287.

Yu, G. (2021). enrichplot: Visualization of Functional Enrichment Result. R package version 1.13.1, https:/ / yulab-smu.top/biomedical-knowledge-mining-book/.

Yu, Y., Zhang, G., Chen, Y., Bai, Q., Gao, C., Zeng, L., Li, Z., Cheng, Y., Chen, J., Sun, X., Guo, L., Xu, J. and Yan, Z. (2019). Selection of Reference Genes for qPCR Analyses of Gene Expression in Ramie Leaves and Roots across Eleven Abiotic/Biotic Treatment. Scientific Reports, 9, 20004.

Zhang, J., Liu, Y., Xia, E.H., Yao, Q.Y., Liu, X.D. and Gao, L.Z. (2015). Autotetraploid rice methylome analysis reveals methylation variation of transposable elements and their effects on gene expression PNAS, doi: $10.1073 /$ pnas.1515170112.

Zhang, J.Y., Li, X.M., Lin, H.X., Chong, K. and Merchant, S.S. (2019). Crop Improvement Through Temperature Resilience. Annual Review of Plant Biology, 70, 753-780.

Zhu, J., Jeong, J., Zhu, Y., Sokolchik, I., Miyazaki, S., Zhu, J.K., Hasegawa, P.M., Bohnert, H.J., Shi, H., Yun, D.J. et al.(2007). Involvement of Arabidopsis HOS15 in histone deacetylation and cold tolerance. Proc Natl AcadSci USA, 105, 4945-4950.

Zhu, J.K. (2008). Epigenetic sequencing comes of age. Cell, 133, 395-387.

Zhu, J.K. (2016). Abiotic stress signaling and responses in plants. Cell, 167, 313-314.

Zhu, X., Feng, Y., Liang, G., Liu, N. and Zhu, J.K. (2013). Aequorin-based luminescence imaging reveals stimulus- and tissue-specific $\mathrm{Ca}^{2+}$ dynamics in Arabidopsis plants. Molecular plant, 6, 444-455. 


\subsection{Supporting Information}

Table S1. List of individuals used for the laboratory work. Listed are the sample and group IDs, ploidy level, treatment as well as country, province and altitude of origin (Schinkel et al., 2016; Klatt et al., 2018).

\begin{tabular}{|c|c|c|c|c|c|c|}
\hline $\begin{array}{l}\text { Sample } \\
\text { ID }\end{array}$ & Ploidy & $\begin{array}{l}\text { Temperature } \\
\text { Treatment }\end{array}$ & $\begin{array}{l}\text { Grou } \\
\mathrm{p}\end{array}$ & Country & Region & $\begin{array}{l}\text { Altitud } \\
\text { e (m) }\end{array}$ \\
\hline 30_1_2 & diploid & cold & CD & Italy & Piemonte & 1743 \\
\hline 115_4_2 & diploid & cold & $\mathrm{CD}$ & France & $\begin{array}{l}\text { Provence- } \\
\text { Alpes-Côte } \\
\text { d'Azur }\end{array}$ & 1891 \\
\hline 116_3_1 & diploid & cold & $\mathrm{CD}$ & France & $\begin{array}{l}\text { Provence- } \\
\text { Alpes-Côte } \\
\text { d'Azur }\end{array}$ & 1953 \\
\hline $41 \_2 \_2$ & tetraploid & cold & CT & Italy & Val d'Aosta & 2174 \\
\hline 90_2_3 & tetraploid & cold & $\mathrm{CT}$ & Switzerland & Valais & 2477 \\
\hline 108_3_3 & tetraploid & cold & CT & Switzerland & Graubunden & 2171 \\
\hline 24_4_3 & diploid & warm & WD & France & $\begin{array}{l}\text { Provence- } \\
\text { Alpes-Côte } \\
\text { d'Azur }\end{array}$ & 1925 \\
\hline 29_1_2 & diploid & warm & WD & Italy & Piemonte & 2020 \\
\hline 33_3_3 & diploid & warm & WD & Italy & Piemonte & 2328 \\
\hline 42_1_2 & tetraploid & warm & WT & Switzerland & Valais & 1789 \\
\hline 74_1_2 & tetraploid & warm & WT & Austria & Osttirol & 2117 \\
\hline 106_4_1 & tetraploid & warm & WT & Italy & $\begin{array}{l}\text { Trentino } \\
\text { Alto Adige/ } \\
\text { Südtirol }\end{array}$ & 2142 \\
\hline
\end{tabular}


Table S2. List of primers used for qRT-PCR validation.

\begin{tabular}{|c|c|c|}
\hline \multirow{2}{*}{$\begin{array}{l}\text { Gene } \\
\text { ID }\end{array}$} & \multicolumn{2}{|c|}{ Sequence } \\
\hline & Primer 5'-3' & Primer $3^{\prime}-5^{\prime}$ \\
\hline $\mathrm{ACT}$ & TCTCCTTGCTCATTCTGTCG & TTCCCTTTACGCCAGTGGTC \\
\hline AGO4B & GTTGCTCTGAAACTAGAATG & ССАССАСТТСССТТСААС \\
\hline САМТ3 & CTTTCACGATTCAACACTCC & GAACTCAGAGAAATAACAGC \\
\hline JM706 & AGTATGTTTGCATGGCATGTG & TCGGAGTTTGATGGGTAGTG \\
\hline JMJ25 & TTCATCACTGCGCTTCCATTCC & CTTGATGTGGGCACCCTGC \\
\hline PMT2 & GCAGTGATTGGTGTTCTCGG & GTCAGACTCATCCСТACCAGG \\
\hline
\end{tabular}


Table S3. Results of qRT-PCR and Delta-delta analyses. The $\Delta \Delta \mathrm{Ct}$ is calculated as following: $\Delta \mathrm{Ct}$ of the average $\mathrm{Cp}$ for the three runs of each inidividual minus the average $\Delta \mathrm{Ct}$ of all 3 samples of the control group, i.e. the WD group (same setting was used in DESeq2 analysis).

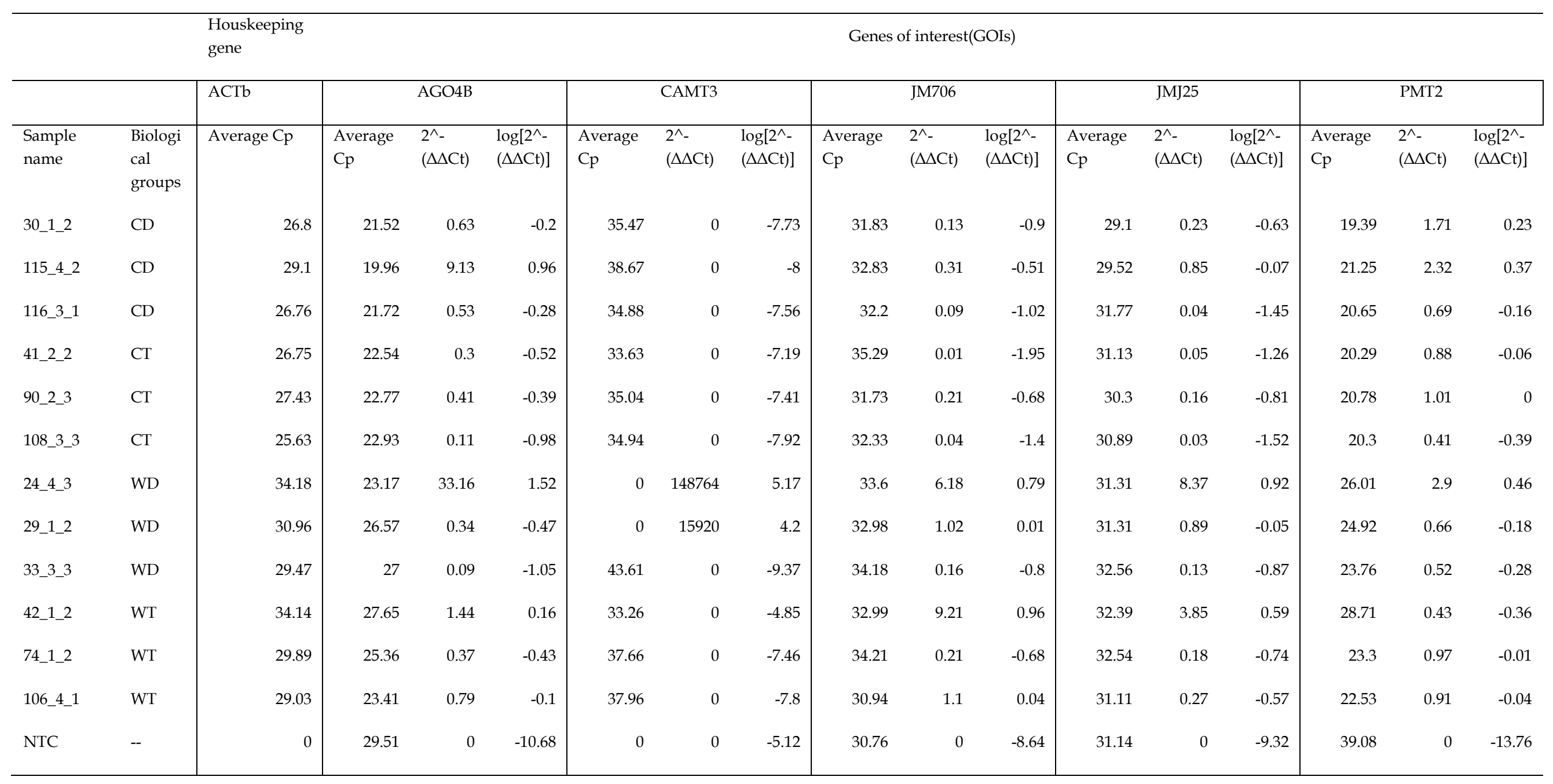




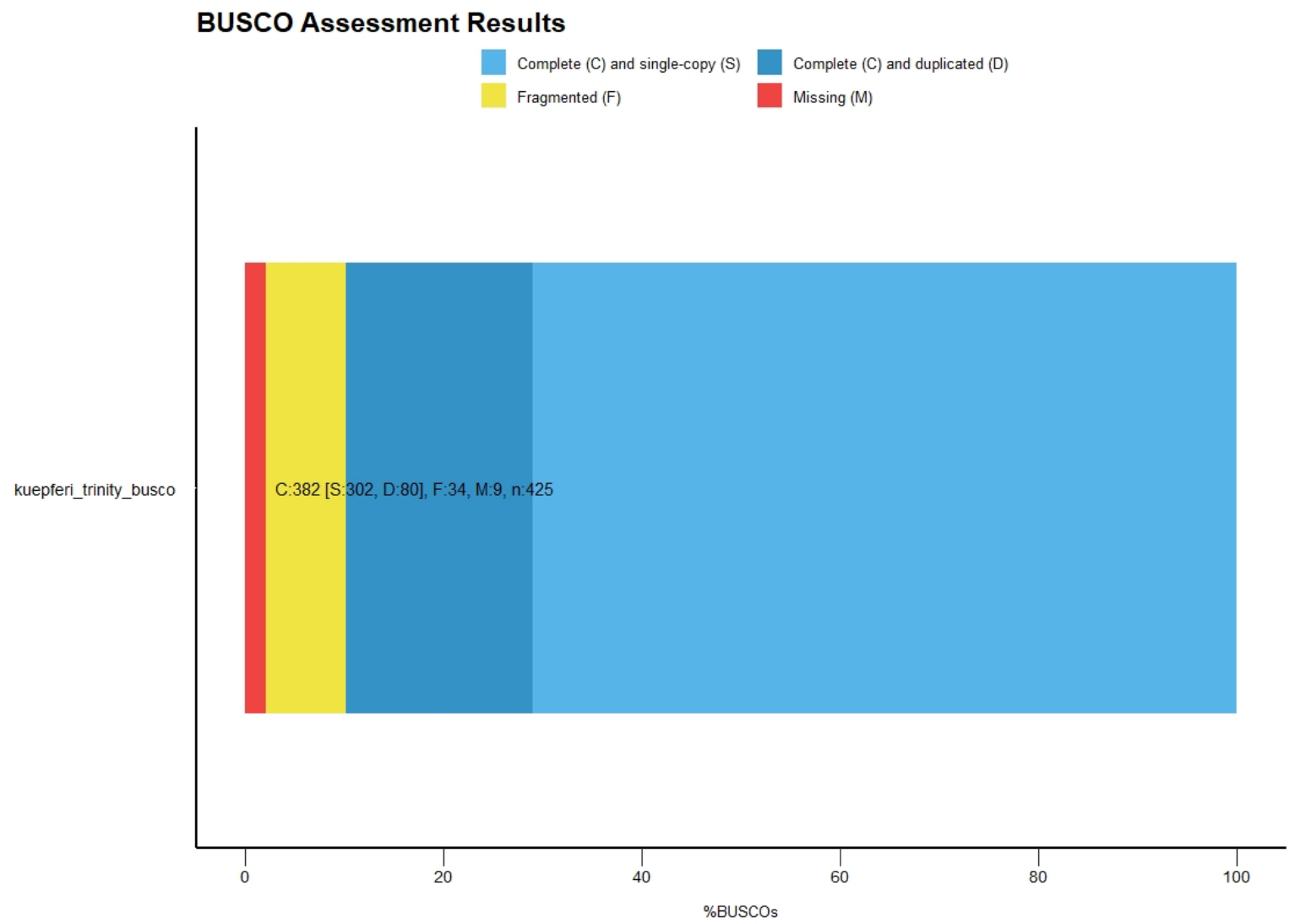

Figure S1. BUSCO (Benchmarking Universal Single-Copy Orthologs) plot of the $R$. kuepferi transcriptome pseudoreference. 


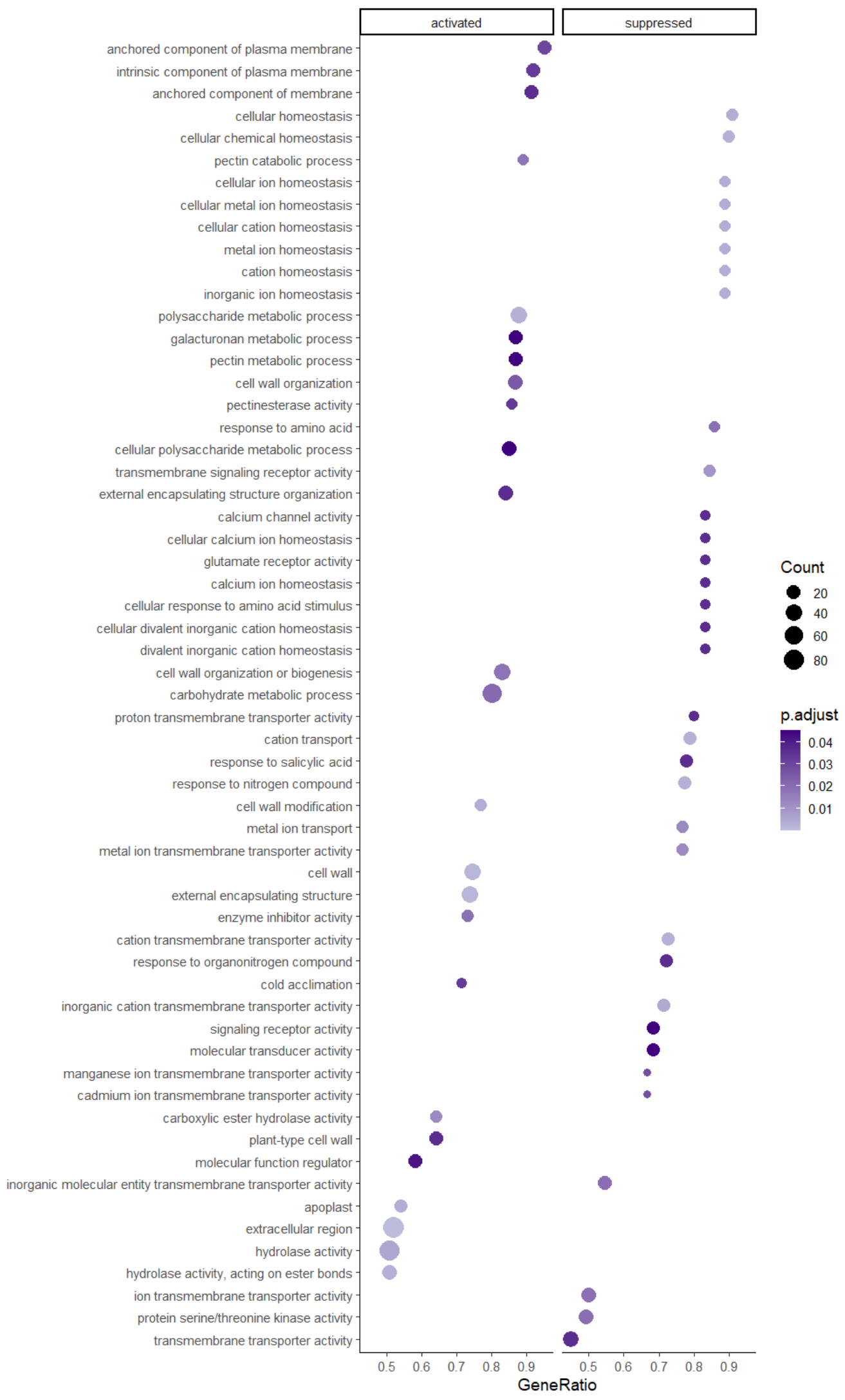

Figure S2. All Gene set pathways significantly enriched from the analysis of differentially expressed genes in diploid individuals of $R$. kuepferi. 
Raw Data Availability

The raw sequences files are stored and available for download in the NCBI Sequence Read Archive (SRA) under BioProject PRJNA756988. 


\section{Discussion}

\subsection{Effects of polyploidy}

In the current session I will discuss how the two cytotypes of $R$. kuepferi react under temperature treatment, and try to entangle any advantageous effects of polyploidy in phenotypic plasticity and acclimation. Such effects will be examined regarding reproductive fitness, mode of reproduction, morphological traits, epigentic and gene expression patterns, as well as gene set pathways. Previous bibliography documented indications of polyploidy could contribute in long-term evolutionary flexibility (e.g. Comai, 2005; Paterson, 2005; van de Peer and Meyer, 2005).

Reproductive fitness of the species, as defined from the seed set measurements, does differentiate among the cytotypes under each temperature treatment, and follows a temperature pattern, i.e. diploids presented significantly lower abortion rates in comparison to tetraploids under both temperature treatments, while tetraploids are doing much better under cold conditions.

Furthermore, it is documented that several alpine species e.g. Saxifraga bryoides and Ranunculus hirtellus are affected by cold and frost conditions, with a decrease in seed sets and injuries of the reproductive tissues (Kumar and Singhal, 2011; Suzuki et al., 2014). These differences in seed set among the cytotypes confirm results of previous studies on the species in natural populations (Cosendai and Hörandl, 2010; Schinkel et al., 2017) and under experimental conditions (Klatt et al., 2018).

The latter study also empowers the hypothesis of a cold-induced production of apomictic seeds in diploid R. kuepferi (Klatt et al., 2018), but this is not supported by my findings. As R. kuepferi is a perennial plant, I would suggest that results from my project reflect the phenotypic plasticity of flower development and reproduction mode from one year to the other and also correlated with the tangled responses of stress (e.g. Dewitt et al., 1998), which were induced from the shift of treatments for the plants, which was performed the same year (2017) of seed collection (Syngelaki et al., 2020a; Chapter 2). Trying to decipher these results regarding the mode of reproduction, I will point to previous studies and observations.

Firstly, in natural populations, a female triploid bridge via unreduced egg

cells was detected as the major pathway towards polyploidization and shift to apomixis in R.kuepferi (Schinkel et al., 2017). Hence, the occurrence of BIII hybrids, which were detected in the warm diploids after the treatment shift, follows such a scenario, as the first step to polyploidization and apomictic mode of reproduction. 
Based on my personal observations, some individuals may rest for one or more years and not develop any parts, or grow only a couple leaves and no flowers, while the lifespan of the plants is unclear. Moreover, embryological analysis on ovules via clearing techniques and DIC microscopy, following the methods of Hojsgaard et al. (2014), implied female development before sprouting, as described for various alpine plants (Körner, 2021). Finally, the molecular mechanisms behind apomixis are rather complicated and remain enigmatic (e.g. Pellino et al., 2013), so further studies are needed to understand their genetic and epigenetic backgrounds, which is proposed by Grimanelli (2012).

The differentiation of the cytotypes is also documented for the measured morphological traits (Syngelaki et al., 2020b; Chapter 3), which implies a potential of phenotypic plasticity and could sustain fitness (van Kleunen and Fisher, 2001) under the shifted temperature conditions. Overall, the hypothesis of niche preference depending on the cytotype is further supported (Kirchheimer et al., 2016; Kirchheimer et al., 2018). Previous studies on these morphological traits in natural populations of $R$. kuepferi showed a phenotypic variation under a wider range of conditions (Schinkel et al., 2017). Results on diploid individuals are consistent with the study on natural populations (Syngelaki et al., 2020b; Chapter 3), as they appear to have a fitness advantage under warm temperature contiditions, which match their natural optimal climatic niche (Kirchheimer et al., 2016; Schinkel et al., 2017; Kirchheimer et al., 2018).

Regarding tetraploid individuals in the Alps, they exhibit "alpine dwarfism" (Schinkel et al., 2017), as an adaptation to higher elevations and harsh conditions (Körner, 2021). However, tetraploids under cold temperature treatment, which simulates the optimal conditions of their natural alpine habitats, do significantly better than under warm temperature treatment. The absence of dwarf growth phenotype in tetraploids is correlated with the absence of the extreme cold conditions at highest elevations of the Alps (Schinkel et al., 2017). Although temperature is stated to be the most decisive environmental factor on the ecology of R. kuepferi cytotypes (Kirchheimer et al., 2016), other environmental variables like $\mathrm{pH}$, nutrients and moisture (Kelly, 2019), may also be important on the phenotypic response towards cold temperature stress. More specifically, growth performance at higher elevations in the Alps is known to be influenced by poor nutrient soils, while tetraploid plants of $R$. kuepferi are showing a niche shift towards more acidic soils. For the scope of the current experimental design, in climate growth chambers only temperature varies and the rest of the proxies are kept equal, allowing the adaptive effects of polyploidy e.g. increasing cell size (te Beest et al., 2012) to be expressed in a stronger way. 
Hypothesizing that such a phenotypic variation of the cytotypes under different temperature conditions could be inherited by the next generations, it is an adaptive trait (e.g. Wyles et al., 1983; van Kleunen and Fisher, 2003; Bossdorf and Pigliucci, 2009; Miryeganeh and Saze, 2019), which could be associated with a successful colonization of different environments (Noble et al., 2014) and an establishment to freshly available ecological niches (van Kleunen and Fisher, 2001; Vrijenhoek and Parker, 2009; Pfenning and McGee, 2010; Miryeganeh and Saze, 2019). Thus, a postglacial colonization of the Alps by tetraploid populations of $R$. kuepferi is suggested, with the phenotypic plasticity of the two cytotypes towards the climatic conditions shaping their distribution.

The epigenetic background of the two cytotypes under the different temperature treatments and the treatment shift of the plants is detected via the methylation approach of MS-AFLPs (Paun et al., 2012). This method is preferred for non-model plants, as their genome has not been sequenced yet, in order to highlight the genome-wide patterns of epigenetic variation (Schrey et al., 2013). Firstly, results showed an epigenetic differentiation between the two cytotypes, for both years of analysis (Syngelaki et al., 2020a; Chapter2), which is in contrast to their very low genetic differentiation in wild populations of the AFLP study of Cosendai et al. $(2011,2013)$. Such an epigenetic differentiation of cytotypes was also observed in methylation patterns studied in wild populations (Schinkel et al., 2020). Moreover, DNA methylation patterns in the wild populations rather followed a temperature gradient than the biogeographical pattern, while they seem to correlate with reproduction mode of each cytotype (Schinkel et al., 2020).

The lack of genetic structure in tetraploids is thought to be a concequence of their recent origin and rapid postglacial colonization of the Alps (Kirchheimer et al., 2018), while the observed variation in DNA methylation patterns over short timescales (Syngelaki et al., 2020a; Chapter 2) could be spontaneous and independent from genetic background (Vidalis et al., 2016). Since tetraploid R.kuepferi is autopolyploid, side-effects of hybridity on methylation patterns can be ruled out (e.g. Chen, 2007).

The epigenetic consequences of polyploidy are well documented prior to the current project, as epigenetic mechanisms such as DNA methylation in allo- and autopolyploids can lead to gene expression alterations (e.g. gene silencing) and genome-wide transcriptional rewiring (e.g. Baubec et al., 2010; Li et al., 2011; Madlung and Wendel, 2013; Song and Chen, 2016). Results on R. kuepferi methylation patterns and their consistency (Syngelaki et al., 2020a; Chapter 2) suggest that polyploidization affects methylation variation independently from genetic background variation and environment, while they could reflect a heritable 
pattern, as ploidy levels are highly stable within natural populations (Cosendai et al., 2010; Schinkel et al., 2016).

Other studies on autopolyploid plants, such as Taraxacum officinale and Dianthus broteri, an endemic species of the Iberian Peninsula, demonstrated that de novo methylation can be triggered (Verhoeven et al., 2010; Alonso et al., 2016), while an increase of the global cytosine methylation in six species of the grass species complex Cymbopogon was observed (Lavania et al., 2012). Autotetraploid cytotypes of $R$. kuepferi in the Alps have an extended biogeographical and altitudinal distribution (Cosendai and Hörandl, 2010; Schinkel et al., 2016; Kirchheimer et al., 2016), but neither geographical structure nor isolation-by-distance appeared in their gene pool (Cosendai et al., 2013) while the cold treatment conditions, which were applied in the experimental design of the climate growth chambers, are quite similar to the natural habitat conditions of the cytotypes in the Alps (Syngelaki et al., 2020a; Chapter 2).

Kirchheimer et al. (2016) suggested that the niche optimum of autotetraploids is placed in the direction of cooler conditions than the one for diploids, presumably due to the change in the reproductive system of an originally warm-adapted species during postglacial re-colonization of higher regions in the Alps (Kearney, 2005; Hörandl, 2006). Thus, tetraploids managed to surmount high elevation barriers and establish new populations throughout a greater distribution range (Kirchheimer et al., 2018), with the shift to facultative apomixis probably being advantageous to rapid colonization (Kirchheimer et al., 2018) (Syngelaki et al., 2020a; Chapter 2).

DNA methylation changes, which are controlled by e.g. hormone signals, may occur at specific genes (Kim et al., 2009) and functional responses may be restricted to this limited number of loci. Thus, the functional interpretation of the data of anonymous MS-AFLP marker loci is unclear. Hence, to capture the stress-induced phenotypic variation of the two cytotypes of R. kuepferi, as well as to try to draw functional interpretation of DNA methylation patterns, a gene expression study under temperature treatment conditions was conducted (Chapter 4).

The results of the latter study, do not advocate per se for polyploidy being a significant contributor to the stress responses, as they were observed by differentiated gene expression patterns, but rather differentiating on the number and characteristics of the Gene Set Enrichment pathways, which are expressed for each group. These findings may indicate that changes in gene expression connected with polyploidy may contribute to heterosis, indicating a variation that may allow adaptive advantages towards novel conditions (Comai, 2005). In general, diploid individuals of R. kuepferi appear to respond more intensively to 
cold temperature treatments than tetraploid ones, as a higher number of Gene Sets Enrichment pathways is significantly differentially expressed in them.

More specifically, most pathways expressed differentially in diploid individuals are linked to ion/cation homeostasis and activity and they were suppressed, while Gene Set Enrichment pathways differentially expressed in tetraploid individuals are mainly focusing on membranes and cell wall, as well as chromatin and histone modification.

The intriguing suppression of the pathways related to ion/cation homeostasis and activity, as well as the serine/threonine protein kinase activity, in diploid individuals of $R$. kuepferi, corroborates the hypotheses of tangled information encoded through $\mathrm{Ca}^{2+}$ kinetics under cold stress conditions (Sanders et al., 2002; Knight \& Knight, 2012; Shi et al., 2015), which could also be influenced by 'cold memory', i.e. former exposure to cold stress conditions (Knight et al., 1996; Knight \& Knight, 2012). I further assume that such pathways in diploids, linked to oscillations of $\mathrm{Ca}^{2+}$ could explain the lower growth performance of diploids under cold conditions, regarding the morphological traits which were measured, as they could provoke the stomatal closure and consequently the reduction of $\mathrm{CO}_{2}$ uptake/carbon gain (Taiz \& Zeiger, 2010). However, temperature treatments seem to be the main factor influencing the gene expression patterns. Previous studies on autotetraploid rice do not seemingly show a genome-wide dosage effect on gene expression patterns (Zhang et al., 2015), empowering the role of subfunctionalization in maintaining the functional pleonasm of duplicated genes and avoiding any energy waste (Wagner, 2005; Drummond \& Wilke, 2008; Qian et al., 2010; Madlung \& Wendel, 2013).

Overall, the post-glacial colonization of the Alps by autotetraploid populations of R. kuepferi (Schinkel et al., 2016) seems to rely, among other factors, on the phenotypic variation, pronounced also as differential gene expression, towards the climatic conditions, with the cold adapted genotypes having a distinct advantage over non-adapted ones in frost-prone environments, such as high mountain areas (Nagy \& Grabherr, 2009; Vrijenhoek \& Parker, 2009). Finally, results of the gene expression study further support the geographical parthenogenesis scenario of the species, towards the ecological niche shift of the two cytotypes (Schinkel et al., 2016; Kirchheimer et al., 2018) and more specifically, the decisive role of acclimation/adaptation of tetraploids to a colder climatic niche in higher and more northern parts of the Alps (Kirchheimer et al., 2018), under a scope of direct physiological background of cold tolerance. 


\subsection{Effects of temperature treatments}

In this session I will discuss how the temperature treatments affect the phenotypic plasticity and acclimation of the cytotypes, regarding the epigenetic and gene expression background. Some of the treatment effects were already discussed in the previous session, as it is thought to be heavily influenced by the ploidy background of the individuals. Altogether, DNA methylation profiles of perennial plants, such as R. kuepferi, do change over their lifetime, independently from environmental influence. However, it is quite unlikely that such a drastic shift from one year to another would just be an effect of ageing, as it occurred synchronously in plants from different origins.

Several studies show that the exposure to biotic or abiotic environmental stresses can trigger epigenetic changes, which seem to persist even after the stress is relieved, resulting, thus, in a stress memory that can be stable throughout the lifetime of an organism or even across generations, especially in plants (e.g. Verhoeven et al., 2010; Dowen et al., 2012; Richards et al., 2012; Verhoeven \& Preite, 2013; Nicotra et al., 2015; Foust et al., 2016). Furthermore, the evolutionary aspects of stress-induced epigenetic variation and putative epigenetic inheritance have been noteworthy discussed (e.g. Wendel and Rapp, 2005; Richards, 2006; Bossdorf et al., 2008; Johannes et al., 2008; Richards et al., 2017).

Regarding the treatment effect on $R$. kuepferi individuals, only after the reciprocal change of treatments we observed significant changes of the methylation profiles for the same individuals. Hereby, the temperature treatment shift happened from 2016 to 2017, concerning the comparison of same individuals for these two years, resulted in less fragments (epiloci) after the shift, i.e. from 754 (2016) to 493 (2017) (Syngelaki et al., 2020a; Chapter 2). Additionally, this epigenetic variation related to the treatment shift, regardless of the treatment's direction, may depict the dynamics of DNA methylation under stress conditions (Bartels et al., 2018; Zhang et al., 2018) and the epigenetic control on the phenotypic plasticity of the species (Zhang et al., 2012; Richards et al., 2017) (Syngelaki et al., 2020a; Chapter 2).

The 2017 results for R. kuepferi (Syngelaki et al., 2020a; Chapter 2) may empower the argument of cold-induced DNA methylation changes, as described by e.g. Song et al. (2015) regarding the alpine to subnivale species Chorispora bungeana, while forest trees set off several epigenetic mechanisms, including DNA methylation, to elicit rapid phenotypic variations in response to environmental changes (Mamadou et al., 2018). Hence, I suggest that the findings of 2016, which represent the $3^{\text {rd }}$ year $(2014$ - 2016) of cultivation in growth chambers under the same conditions, still reflect to a great extent the background methylation profiles from the natural habitats, potentially related to differential cold acclimation of diploids and tetraploids and the dynamics of DNA methylation during cold acclimation 
(Liu et al., 2017) (Syngelaki et al., 2020a; Chapter 2). Moreover, I assume that an extreme change of temperature is needed to alter methylation patterns independently from ploidy variation, such as the extreme temperature shifts occuring under natural weather conditions in the Alps, where temperature fluctuates strongly between day, night and seasons and where extremely low temperatures down to $-24^{\circ} \mathrm{C}$ occur in higher altitudes (Körner, 2021). Thus, the high phenotypic plasticity of $R$. kuepferi regarding methylation patterns, may be responsive to the fluctuating climatic conditions (Syngelaki et al., 2020a; Chapter 2).

Concerning the gene expression profiles of the individuals, they differentiate under treatments (Chapter 4), indicating a cascade of key regulatory pathways provoked by stress conditions (e.g. Takahashi et al., 2004; Cramer et al., 2011; Puijalon et al., 2011; Jutsz \& Gnida, 2015; Ritonga \& Chen, 2020), whereas both cytotypes express gene sets related to cold acclimation, plasma membrane, cell wall and hydrolase activity. I interpret such gene expression changes as a consequence of the short freezing treatments $\left(-1^{\circ} \mathrm{C}\right.$ during three nights per week) taking place in the climate growth chambers. As no apparent damage of leaves in cold treatments was observed (Syngelaki et al., 2020b; Chapter 3), I would further suggest that both cytotypes are tolerant to short-term freezing and thawing during the day.

As access points of the cell, membranes are injured by adverse environmental conditions (e.g. Theocharis et al., 2012). Thus, in order to maintain cell activity and behavior under environmental stress, membrane stability is vital (Chen et al., 2018; Ritonga \& Chen, 2020). Decreasing membrane fluidity, coupled with its interaction with the cell wall, contributes to maintenance of plasma membrane functionality and is considered as one of the first cold sensors (Murata \& Los, 1997; Martiniere et al., 2011; Ma \& Liu, 2019). A fluid membrane in alpine plants, which have to encounter freezing conditions, allows transfer of water from the protoplast into the intercellular space, where extracellular ice nucleation takes place, leaving the protoplast unfrozen (Körner, 2021). 
5.3. Correlations of epigenetic patterns with morphological traits and gene expression patterns

The epigenetic background of phenotypic plasticity, together with cytosine DNA methylation, as an epigenetic mechanism, which seems to be strongly correlated with phenotypic plasticity to internal and external stimuli (Miryeganeh and Saze, 2019), has been notably discussed (e.g. Pigliucci, 2001; van Kleunen and Fisher, 2001; West-Eberhard, 2003; Mirouze and Paskzowski, 2011; Johannes et al., 2009). Stress-induced epigenetic patterns could have an impact on an individual's fitness (e.g. Crews et al., 2007; Angers et al., 2010; Castonguay and Angers, 2012; Herrera and Bazaga, 2013; Nicotra et al., 2015; Rubenstein et al., 2016; Verhoeven et al., 2016; Miryeganeh and Saze, 2019), while it could also be advantageous towards a wider distribution niche (e.g. Pal and Milkos, 1999; Angers et al., 2010).

The potential of epigenetic inheritance of plastic phenotypic traits in plants is argued for by several studies (e.g. Johannes et al., 2009; Paskowski and Grossniklaus, 2011; Cortijo et al., 2014; Miryeganeh and Saze, 2019). In case such phenotypic variation is heritable, DNA methylation could provide a mechanism of adaptive microevolution in plants (e.g. Herman and Sultan, 2011; Zhang et al., 2012), which is faster and independent from traditional genetic evolution (Jablonka and Lamb, 1995; Richards, 2006; Miryeganeh and Saze, 2019).

By comparing the DNA methylation patterns with the morphological traits of leaves and flowers per individual (Syngelaki et al., 2020b; Chapter 3), the hypotheses regarding the survival and the fitness of $R$. kuepferi towards the shifted conditions after three years being acclimated in previous experimental treatments (Klatt et al., 2018; Syngelaki et al., 2020a), are further investigated. A stronger correlation of phenotypic plasticity in leaves than in flowers with epigenetic variation, as it is pronounced by DNA methylation variation, is observed, while for both cytotypes leaves are exhibiting higher values under the cold treatment (Syngelaki et al., 2020b; Chapter 3). The hypothesis of epigenetic control on the phenotypic plasticity of the species is further supported by the negative correlation of the leaf length and the number of leaves with the patterns of non-methylated epiloci for both cytotypes and under both treatments (Syngelaki et al., 2020b; Chapter 3).

These findings indicate an effect on the fitness of individuals under the new environmental conditions, proposing, thus, a Jack-and-master scenario (Richards et al., 2006) for the species. The epigenetic asymmetry, which is proposed from such a scenario, is often observed under changing environmental conditions, as stochastic epigenetic changes may result in high levels of plasticity, "weird" phenotypes and even developmental disturbances (e.g. Palmer and Strobeck, 1986; Palmer, 1996; Moller and Swaddle, 1997; Dongen, 2006; Angers et al., 2010; Angers et al., 2020). 
Such changes may promote the establishment of a species towards freshly available environments, contributing further to the post-glacial colonization of the species in the Alps. However, the correlations of phenotypic plasticity with epigenetic variation of the species in fluctuating biotic and abiotic environmental conditions is a rather complicated process, with time of exposure also playing a role (Angers et al., 2010).

Trying to further explore the mechanisms of phenotypic plasticity and factors that prompt it, I will address the correlations of DNA methylation with the gene expression profiles (Chapter 4). Kooke et al. (2015) proposed that DNA methylation dynamics could extend the environmental sensitivity of the phenotypes and consequently, could regulate gene expression (e.g. Steward et al., 2002; Shan et al., 2013; Rakei et al., 2016), by playing a role in the maintenance of cell stability under stress (Song et al., 2015).

It is further known that DNA methylation profiles under cold stress conditions, together with histone modifications and non-histone proteins, are associated with gene expression profiles (Chinnusamy \& Zhu, 2009; Kim et al., 2015) and could encompass chromatin structure and accessibility (e.g. Strahl \& Allis, 2000; LangMladek et al., 2010; Jones, 2012; Zhang et al., 2018). Moreover, it is proposed that a prolonged cold stress treatment decreases the level of DNA methylation and gene expression is increased after the occurrence of demethylation (Shan et al., 2013), while chromatin remodeling has a putative function as a plant thermometer, indicating, thus, a relatively direct connection between cold and gene expression (Kumar \& Wigge, 2010; Kumar et al., 2012).

Regarding the results of my gene expression study of $R$. kuepferi individuals (Chapter 4), several genes, directly or indirectly related to DNA methylation, are significantly differentially expressed in the tetraploid individuals, while the Gene Set pathways of histone and chromatin modifications are suppressed under the same cytotype. The differential expression of genes correlated to DNA methylation is further validated by the qRT-PCR results. These findings fit the overall pattern of loss of methylated MS-AFLP fragments after dramatic temperature changes (Syngelaki et al., 2020a; Chapter 2) and indicate that DNA methylation patterns could conserve the transgenerational epigenetic memory of cold stress responses towards a differential acclimation cytotypes (Schinkel et al., 2020; Syngelaki et al., 2020a). 


\subsection{Conclusion and Prospects}

To summarize, my thesis demonstrates the temperature and polyploidy effects on the DNA methylation profiles, fitness and mode of reproduction, phenotypic plasticity of several morphological traits and gene expression profiles, as well as their interactions, in R. kuepferi.

More specifically, the DNA methylation differentiation among the two cytotypes and the high epimutational dynamics of the different types of epiloci attest that phenotypic plasticity of epigenetic mechanisms catalyzes the response towards cold stress conditions. Additionally, cold temperature stress induces differentially expressed gene profiles, with several gene set pathways, either activated or suppressed, being involved in the response, with the differentiation of the gene set pathways between cytotypes suggesting a better cold acclimation of tetraploids than of diploids.

This hypothesis is further supported by the correlations of DNA methylation with the morphological traits and the differential gene expression, drawing, thus, an extended concept of rapid reaction to shifted environments, acclimation to cold temperature conditions and a putative epigenetic memory for each cytotype. Interestingly, this acclimation further correlates the cytotypes with their respective climatic niches in the wild, as they were described by Kirchheimer et al. (2016).

Furthermore, if the putative epigenetic background of phenotypic plasticity would be a heritable trait, which could ensure a relative stability of the phenotypes (Angers et al., 2010), it could have an adaptive value and advocate further on the geographical parthenogenesis pattern proposed for the species in the Alps (Kirchheimer et al., 2016; Kirchheimer et al., 2018). Thus, higher DNA methylation differentiation and phenotypic plasticity of asexual organisms could allow for a higher or equal niche dynamics compared to sexual plants. To empower this scenario, a physiological background of the observed ecological and geographical differentiation patterns between cytotypes is suggested by the results of the differential gene expression study. 


\subsection{References}

Alonso, C., Balao, F., Bazaga, P., and Perez, R. (2016). Epigenetic contribution to successful polyploidizations: variation in glabal cytosine methylation along an extensive ploidy series in Dianthus broteri (Caryophyllaceae). New Phytologist, 212, 571-576.

Angers, B., Castonguay, E., and Massicotte, R. (2010). Environmentally induced phenotypes and DNA methylation: How to deal with unpredictable conditions until the next generation and after. Mol. Ecol., 19, 1283-1295.

Angers, B., Perez, M., Menicucci, T., and Leung, C. (2020). Sources of epigenetic variation and their applications in natural populations. Evol. Appl., 13, 1262-1278.

Bartels, A., Han, Q., Nair, P., Stacey, L., Gaynier, H., Mosley, M., Huang, Q. Q., Pearson, J. K., Hsieh, T., An, Y. C., et al. (2018). Dynamic DNA Methylation in Plant Growth and Development. International Journal of Molecular Sciences, 19, 2144. doi:10.3390/ijms19072144.

Baubec, T., Dinh, H. Q., Pecinka, A., Rakic, B., Rozhon, W., Wohlrab, B., von Haeseler, A.,and Scheid, O. M. (2010). Cooperation of Multiple Chromatin Modifications Can Generate Unanticipated Stability of Epigenetic States in Arabidopsis. Plant Cell, 22, 34-47.

Bossdorf, O., Richards, C. L., and Pigliucci, M. (2008). Epigenetics for ecologists. Ecology Letters, 11, 106-115.

Bossdorf, O., and Pigliucci, M. (2009). Plasticity to wind is modular and genetically variable in Arabidopsis thaliana. Evol. Ecol., 23, 669-685.

Castonguay, E., and Angers, B. (2012). The key role of epigenetics in the persistence of a sexual lineage. Genet. Res. Int., 534289, 1-9.

Chen, Z. J. (2007). Genetic and epigenetic mechanisms for gene expression and phenotypic variation in plant polyploids. Annual Review of Plant Biology, 58, 377406.

Chen, L., Zhao, Y., Xu, S., Zhang, Z., Xu, Y., Zhang, J. and Chong, K. (2018). Os MADS 57 together with Os TB 1 coordinates transcription of its target Os WRKY 94 and D14 to switch its organogenesis to defense for cold tolerance in rice. J. Exp. Bot., 63, 6467-6480.

Chinnusamy, V. and Zhu, J.K. (2009). Epigenetic regulation of stress responses in plants. Current Opinion in Plant Biology, 12, 133-139. 
Comai, L. (2005). The advantages and disadvantages of being polyploid. Nature Reviews Genetics, 6, 836-846.

Cortijo, S., Wandenaar, R., Colome-Tatche, M., Gilly, A., Etcheverry, M., Labadie, K., Johannes, F., et al. (2014). Mapping the epigenetic basis of complex traits. Science, 343, 1145-1148.

Cosendai, A. C., and Hörandl, E. (2010). Cytotype stability, facultative apomixis and geographical parthenogenesis in Ranunculus kuepferi (Ranunculaceae). Annals of Botany, 105, 457-470.

Cosendai, A. C., Rodewald, J., and Hörandl, E. (2011). Origin and distribution of autopolyploids via apomixis in the alpine species Ranunculus kuepferi (Ranunculaceae). Taxon, 60, 355-364.

Cosendai, A. C., Wagner, J., Ladinig, U., Rosche, C., and Hörandl, E. (2013). Geographical parthenogenesis and population genetic structure in the alpine species Ranunculus kuepferi (Ranunculaceae). Heredity, 110, 560-569.Cosendai and Hörandl, 2010

Cramer, G.R., Urano, K., Delrot, S., Pezzotti, M. and Shinozaki, K. (2011). Effects of abiotic stress on plants: a systems biology perspective. BMC Plant Biology, 11, 163.

Crews, D., Gore, A.C., Hsu, T.S., Dangleben, N.L., Spinetta, M., Schallert, T., Anway, M.D., and Skinner, M.K. (2007). Transgenerational epigenetic imprints and mate preference. Proc. Natl. Acad. Sci. USA, 104, 5942-5946.

Dewitt, T.J., Sih, A., and Wilson, D.S. (1998). Costs and limits of phenotypic plasticity. Trends Ecol. Evol., 13, 77-81.

Dongen, S.V. (2006). Fluctuating asymmetry and development instability in evolutionary biology: Past, present and future. J. Evol. Biol., 19, 1727-1743.

Dowen, R. H., Pelizzola, M., Schmitz, R. J., Lister, R., Dowen, J. M., Nery, J. R., Dixon, J. E., and Ecker, J. R. (2012). Widespread dynamic DNA methylation in response to biotic stress. Proceedings of the National Academy of Sciences of the United States of America, 109, 2183-2191.

Drummond, D.A. and Wilke, C.O. (2008). Mistranslation-induced protein misfolding as a dominant constraint on coding-sequence evolution. Cell, 134(4), 341-352.

Foust, C. M., Preite, V., Schrey, W., Alvarez, M., Robertson, M. H., Verhoeven, K. J. F., and Richards C. L. (2016). Genetic and epigenetic differences associated with 
environmental gradients in replicate populations of two salt marsh perennials. Molecular Ecology, 25, 1639-1652.

Grimanelli, D. (2012). Epigenetic regulation of reproductive development and the emergence of apomixis in angiosperms. Curr. Opin. Plant Biol., 15, 57-62.

Herman, J.J., and Sultan, S.E. (2011). Adaptive transgenerational plasticity in plants: Case studies, mechanisms and implications for natural populations. Front. Plant Sci., 2, 102.

Herrera, C.M., and Bazaga, P. (2013). Epigenetic correlates of plant phenotypic plasticity: DNA methylation differs between prickly and nonprickly leaves in heterophyllous Ilex aquifolium (Aquifoliaceae) trees. Bot. J. Linn. Soc., 171, 441-452.

Hojsgaard, D., Greilhuber, J., Pellino, M., Paun, O., Sharbel, T.F., and Hörandl, E. (2014). Emergence of apospory and bypass of meiosis via apomixis after sexual hybridisation and polyploidisation. New Phytologist, 204, 1000-1012.

Hörandl, E. (2006). The complex causality of geographical parthenogenesis. New Phytologist, 171, 525-538.

Jablonka, E., and Lamb, M.J. (1995). Epigenetic Inheritance and Evolution,Oxford University Press: Oxford, UK.

Johannes, F., Porcher, E., Teixeira, F. K., Saliba-Colombani, V., Simon, M., Agier, N., Bulski, A., Albuisson, J., Heredia, F., Audigier, P., et al. (2009). Assessing the Impact of Transgenerational Epigenetic Variation on Complex Traits. PLoS Genetics, 5 (6): e1000530. doi: 10.1371/journal.pgen.1000530.

Jones, P. A. (2012). Functions of DNA methylation: islands, start sites, gene bodies and beyond. Nature Reviews Genetics, 13, 484-492.

Jutsz, A.M. and Gnida, A. (2015). Mechanisms of stress avoidance and tolerance by plants used in phytoremediation of heavy metals. Arch. Environ. Prot., 41, 104114.

Kearney, M. (2005). Hybridization, glaciation and geographical parthenogenesis. Trends in Ecology E Evolution, 20, 495-502.

Kelly, M. (2019). Adaptation to climate change through genetic accommodation and assimilation of plastic phenotypes. Philos. Trans. R. Soc. B, 374, 20180176.

Kim, M., Kondo, T., Takada, I., Youn, M.Y., Yamamoto, Y., Takahashi, S., Matsumoto, T., Fujiyama, S., Shirode, Y., and Yamaoka, I. (2009). DNA demethylation in hormone-induced transcriptional derepression. Nature, 461, 10071012. 
Kim, J.M., Sasaki, T., Ueda, M., Sako, K. and Seki, M. (2015). Chromatin changes in response to drought, salinity, heat and cold stresses in plants. Frontiers in Plant Science, 6, 114.

Kirchheimer, B., Schinkel, C. C-F., Dellinger, A. S., Klatt, S., Moser, D., Winkler, M., Lenoir, J., Caccianiga, M., Guisan, A., Nieto-lugilde, D., et al. (2016). A matter of scale: apparent niche differentiation of diploid and tetraploid plants may depend on extent and grain of analysis. Journal of Biogeography, 43, 716-726.

Kirchheimer, B., Wessely, J., Gattringer, A., Hülber, K., Moser, D., Schinkel, C. C-F., Appelhans, M., Klatt, S., Caccianiga, M., Dellinger, A., et al. (2018). Reconstructing geographical parthenogenesis: effects of niche differentiation and reproductive mode on Holocene range expansion of an alpine plant. Ecology Letters, 21, 392-401.

Klatt, S., Schinkel, C. C.-F., Kirchheimer, B., Dullinger, S., and Hörandl, E. (2018). Effects of cold treatments on fitness and mode of reproduction in the diploid and polyploid alpine plant Ranunculus kuepferi (Ranunculaceae). Annals of Botany, 121, 1287-1298.

Knight, H., Trewavas, A.J. and Knight, M.R. (1996). Cold calcium signaling in Arabidopsis involves two cellular pools and a change in calcium signature after acclimation. Plant Cell, 8, 489-503.

Knight, M.R. and Knight, H. (2012). Low-temperature perception leading to gene expression and cold tolerance in higher plants. New Phytologist, 195, 737-751.

Kooke, R., Johannes, F., Wardenaar, R., Becker, F., Etcheverry, M., Colot, V., Vreugdenhil, D., and Keurentjes, J. B. (2015). Epigenetic Basis of Morphological Variation and Phenotypic Plasticity in Arabidopsis thaliana. The Plant Cell, 27, 337348.

Körner, C.H. (2021).Alpine plant life $3^{\text {nd }}$ edn. Cham, Switzerland: Springer Switzerland AG.

Kumar, P., and Singhal, V.K. (2011). Male meiosis, morphometric analysis and distribution pattern of $2 x$ and $4 x$ cytotypes of Ranunculus hirtellus Royle (Ranunculaceae) from the cold regions of northwest Himalayas (India). Comp. Cytogenet., 5, 143-161.

Kumar, S.V. and Wigge, P.A. (2010). H2A.Z-containing nucleosomes mediate the thermosensory response of Arabidopsis. Cell, 140, 136-147. 
Kumar, S.V., Lucyshyn, D., Jaeger, K.E., Alos, E., Harberd, N.P. and Wigge, P.A. (2012). Transcription factor PIF4 controls the thermosensory activation of flowering. Nature, 484, 242-245.

Ladinig, U., and Wagner, J. (2007). Timing of sexual reproduction and reproductive success in the high-mountain plant Saxifraga bryoides L. Plant Biol., 9, 683-693.

Lang-Mladek, C., Popova, O., Kiok, K., Berlinger, M., Rakic, B., Aufsatz, W., Jonak, C., Hauser, M.T. and Lusching, C. (2010). Transgenerational inheritance and resetting of stress-induced loss of epigenetic gene silencing in Arabidopsis. Mol Plant, 3, 594-602.

Lavania, U.C., Srivastava, S., Lavania. S., Basu, S., Misra, N.K., Mukai, Y. (2012). Autopolyploidy differentially influences body sizes in plants, but facilitates enhanced accumulation of secondary metabolites, causing increased cytosine methylation. Plant Journal, 71, 539 - 549.

Li, Z. H., Lu, X., Gao, Y., Liu, S. J., Tao, M., Xiao, H., Qiao, Y. Q., Zhang, Y. P., and Luo J. (2011). Polyploidization and epigenetics. Chinese Science Bulletin, 3, 245-252.

Liu, T., Li, Y., Duan, W., Huang, F., and Hou, X. (2017). Cold acclimation alters DNA methylation patterns and confers tolerance to heat and increases growth rate in Brassica rapa. Journal of Experimental Botany, 68, 1213-1224.

Ma, H. and Liu, M. (2019). The microtubule cytoskeleton acts as a sensor for stress response signaling in plants. Molecular Biology Reports, 46, 5603-5608.

Madlung, A., and Wendel, J. F. (2013). Genetic and Epigenetic Aspects of Polyploid Evolution in Plants. Cytogenetic and Genome Research, 140, 270-285.

Mamadou, D. S., Allona, I., Ambroise, C., Conde, D., Fichot, R., Gribkova, S., Jorge, V., Le-Provost, G., Paques, L., Plomion, C., et al. (2018). "Epigenetic in Forest Trees: State of the Art and Potential Implications for Breeding and Management in a Context of Climate Change" in Advances in Botanical Research: Plant Epigenetics Coming of Age for Breeding Applications, Vol. 88, eds M. Mirouze, E. Bucher and P. Gallusci (London, UK: Academic Press LTD-Elsevier Science LTD), 387-453.

Martiniere, A., Shvedunova, M., Thomshon, A.J., Evans, N.H., Penfield, S., Runions, J. and McWatters, H.G. (2011). Homeostasis of plasma membrane viscosity in fluctuating temperatures. New Phytologist, 192, 328-337.

Mirouze, M., and Paskzowski, J. (2011). Epigenetic contribution to stress adaptation in plants. Curr. Opin. Plant Biol., 14, 267-274. 
Miryeganeh, M., and Saze, H. (2019) Epigenetic inheritance in plant evolution. Popul. Ecol., 62, 17-27.

Moller, A.P., and Swaddle, J.P. (1997). Asymmetry, Developmental Stability and Evolution, Oxford University Press: Oxford, UK.

Murata, N. and Los, D.A. (1997). Membrane fluidity and temperature perception. Plant Physiology, 115, 875-879.

Nagy, L. and Grabherr, G. (2009). The biology of alpine habitats. New York, USA: Oxford University Press.

Nicotra, A. B., Segal, D. L., Hoyle, G. L., Schrey, A. W., Verhoeven, K. J. F., and Richards, C. L. (2015). Adaptive plasticity and epigenetic variation in response to warming in an Alpine plant. Ecology and Evolution, 5, 634-647.

Noble, D., Jablonka, E., Joyner, M., Muller, G., and Omholt, S.W. (2014). Evolution evolves: Physiology returns to centre stage. J. Physiol., 592, 2237-2244.

Pal, C., and Milkos, I. (1999). Epigenetic inheritance, genetic assimilation and speciation. J. Theor. Biol., 200, 19-37.

Palmer, A.R., and Strobeck, C. (1986). Fluctuating asymmetry: Measurement, analysis, patterns. Annu. Rev. Ecol. Syst., 17, 391-421.

Palmer, A.R. (1996). Waltzing with Asymmetry. BioScience, 46, 518-532.

Paskowski, J., and Grossniklaus, U. (2011). Selected aspects of transgenerational epigenetic inheritance and resetting in plants. Curr. Opin. Plant Biol., 14, 195-203.

Paterson, A.H. (2005). Polyploidy, evolutionary opportunity and crop adaptation. Genetica, 123, 191-196.

Paun, O., and Schönswetter, P. (2012). Amplified Fragment Length Polymorphism (AFLP) - an invaluable fingerprinting technique for genomic, transcriptomic and epigenetic studies. Methods in Molecular Biology, 862, 75-87.

Pellino, M., Hojsgraard, D., Schmutzer, T., Scholz, U., Hörandl, E., Vogel, H., and Sharbel, T.F. (2013). Asexual genome evolution in apomictic Ranunculus auricomus complex: examining the effects of hybridization and mutation accumulation. Molecular Ecology, 22, 5908-5921.

Pfenning, D.W., and McGee, M. (2010). Resource polyphenism increases species richness: A test of the hypothesis. Philos. Trans. R Soc. Ser. B, 365, 577-591.

Pigliucci, M. (2001).Phenotypic plasticity: Beyond nature and nurture. Baltimore, MD: John Hopkins Press. 
Puijalon, S., Bouma, T.J., Douady, C.J., Groenendael, J.V., Anten, N.P.R., Martel, E., Bornette, G. (2011). Plant resistanse to mechanical stress: Evidence of an avoidance-Tolerance trade-off. New Phytologist, 191, 1141-1149.

Qian, W., Liao, B.Y., Chang, A.Y.F. and Zhang J. (2010). Maintenance of duplicate genes and their functional redundancy by reduced expression. Trends Genet., 26(10), 425-430.

Rakei, A., Maali-amiri, R., Zeinali, H., and Ranjbar, M.(2016). DNA methylation and physio-biochemical analysis of chickpea in response to cold stress. Protoplasma, $253,61-76$.

Richards, C.L., Bossdorf, O., Muth, N.Z., Gurevitch, J., and Pigliucci, M. (2006). Jack of all trades, master of some? On the role of phenotypic plasticity in plant invasions. Ecol. Lett., 9, 981-993.

Richards, E. J. (2006). Inherited epigenetic variation-revisiting soft inheritance. Nature Reviews, 7, 395-402.

Richards, C. L., Schrey, A. W., and Pigliucci, M. (2012). Invasion of diverse habitats by few Japanese knotweed genotypes is correlated with epigenetic differentiation. Ecology Letters, 15, 1016-1025.

Richards, C. L., Alonso, C., Becker, C., Bossdorf, O., Bucher, E., Colome-Tatche, M., Durka, W., Engelhardt, J., Gaspar, B., Gogol-Döring, A., et al. (2017). Ecological plant epigenetics: Evidence from model and non-model species, and the way forward. Ecology Letters, 20, 1576-1590.

Ritonga, F.N. and Chen, S. (2020). Physiological and Molecular Mechanism Involved in Cold Stress Tolerance in Plants. Plants, 9, 560.

Rubenstein, D.R., Skolnik, H., Berrio, A., Champagne, F. A., Phelps, S., and Solomon, J. (2016). Sex-specific fitness effects of unpredictable early life conditions are associated with DNA methylation in the avian glucocorticoid receptor. Mol. Ecol., 25, 1714-1728.

Sanders, D., Pelloux, J., Brownlee, C. and Harper, J.F. (2002). Calcium at the crossroads of signaling. Plant Cell, 14, 401-417.

Schinkel, C. C-F., Kirchheimer, B., Dellinger, A. S., Klatt, S., Winkler, M., Dullinger, S., and Hörandl, E. (2016). Correlations of polyploidy and apomixis with elevation and associated environmental gradients in an alpine plant. $A o B$ PLANTS, 8, plw064, doi:10.1093/aobpla/plw064.

Schinkel, C. C-F., Kirchheimer, B., Dullinger, S., Geelen, D., De Storme, N., and Hörandl, E. (2017). Pathways to polyploidy: indications of a female triploid bridge 
in the alpine species Ranunculus kuepferi (Ranunculaceae). Plant Systematics $\mathcal{E}$ Evolution, 303, 1093-1108.

Schinkel, C.C-F., Syngelaki, E., Kirchheimer, B., Dullinger, S., Klatt, S., and Hörandl, E. (2020). Epigenetic patterns and geographical parthenogenesis in the alpine plant species Ranunculus kuepferi (Ranunculaceae). Int J MolSci, 21(9), 3318.

Schrey, A. W., Alvarez, M., Foust, C. M., Kilvitis, H. J., Lee, J. D., Liebl, A. L., Martin, L. B., Richards, C. L., and Robertson, M. (2013). Ecological Epigenetics: Beyond MS-AFLP. Integrative and Comparative Biology, 53, 340-350.

Shan, X., Wang, X., Yang, G., Wu, Y., Su, S., Li, S., Liu, H., and Yuan, Y. (2013). Analysis of the DNA Methylation of Maize (Zea mays L.) in response to cold stress Based on methylation-sensitive amplified polymorphisms. J. Plant Biol., 56, 32-38.

Shi, Y., Ding, Y. and Yang, S. (2015). Cold signal transduction and its interplay with phytohormones during cold acclimation. Plant Cell and Physiology, 56, 7-15.

Song, Y., Liu, L., Feng, Y., Wei, Y., Yue, X., He, W., Zhang, H., and An, L. (2015). Chilling- and Freezing-Induced Alterations in Cytosine Methylation and Its Association with the Cold Tolerance of an Alpine Subnival Plant, Chorispora bungeana. PLOS one, doi:10.1371/journal.pone.0135485.

Song, Q., and Chen, Z.J. (2016). Epigenetic and developmental regulation in plant polyploids. CurrentOpinion in Plant Biology, 24, 101-109.

Steward, N., Ito, M., Yamaguchi, Y., Koizumi, N., and Sano, H. (2002). DNA methylation in maize nucleosomes and demethylation by environmental stress. Journal of Biological Chemistry, 277, 37741-37746.

Strahl, B.D. and Allis, C.D. (2000). The language of covalent histone modifications. Nature, 403, 41-45.

Suzuki, N., Rivero, R.M., Shulaev, V., Blumwald, E., and Mittler, R. (2014). Abiotic and biotic stress combinations. New Phytol., 203, 32-43.

Syngelaki, E., Schinkel, C.C-F., Klatt, S. and Hörandl, E. (2020a). Effects of temperature treatments on cytosine-methylation profiles of diploid and autotetraploid plants of the alpine species Ranunculus kuepferi (Ranunculaceae). Front. Plant Sci., 11, 435.

Syngelaki, E., Daubert, M., Klatt, S. and Hörandl, E. (2020b). Phenotypic responses, reproduction mode and epigenetic patterns under temperature treatments in the alpine plant species Ranunculus kuepferi (Ranunculaceae). Biology, 9(10), 315. 
Taiz, L. and Zeiger, E. (2010). Plant Physiology. 5th edition Sunderland: Sinauer Associates, Inc.

Takahashi, S., Seki, M., Ishida, J., Satou, M., Sakurai, T., Narusaka, M., Kamiya, A., Nakajima, M., Enju, A., Akiyama, K. et al.(2004). Monitoring the expression profiles of genes induced by hyperosmotic, high salinity, and oxidative stress and abscisic acid treatment in Arabidopsis cell culture using full-length cDNA microarray. Plant Mol. Biol., 56(1), 29-55.

te Beest, M., Le Roux, J.J., Richardson, D.M., Brysting, A.K., Suda, J., Kubesova, M., and Pysck, P. (2012). The more the better? The role of polyploidy in facilitating plant invasions. Ann. Bot., 109, 19-45.

Theocharis, A., Clement, C. and AitBarka, E. (2012). Physiolgical and molecular changes in plant growth at low temperatures. Planta, 235, 1091-1105.

van de Peer, Y., and Meyer, A. (2005).In The Evolution of the Genome (Gregory, T.R., eds.), San Diego, USA: Elsevier, 330-363.

van Kleunen, M., and Fisher, M. (2001). Adaptive evolution of plastic foraging responses in a clonal plant. Ecology, 82, 3309-3319.

van Kleunen, M., and Fisher, M. (2003). Effects of four generations of densitydependent selection on life history traits and their plasticity in a clonally propagated plant. J. Evol. Biol., 16, 474-484.

Verhoeven, K. J. F., Jansen, J. J., van Dijk, P. J., and Biere, A. (2010). Stressinduced DNA methylation changes and their heritability in asexual dandelions. New Phytologist, 185, 1108-1118.

Verhoeven, K. J. F., and Preite, V. (2013).Epigenetic variation in asexually reproducing organisms. Evolution, 68, 644-655.

Verhoeven, K.J.F., von Holdt, B.M., and Sork, V.L. (2016). Epigenetics in ecology and evolution: What we know and what we need to know. Mol. Ecol., 25, 16311638.

Vidalis, A., Zivkovic, D., Wardenaar, R., Roquis, D., Tellier, A., Johannes, F. (2016). Methylome evolution in plants. Genome Biology, 17, 264.

Vrijenhoek, R.C. and Parker, E.D. (2009). Geographical parthenogenesis: general purpose genotypes and frozen niche variation BT. In Lost sex: The evolutionary biology of parthenogenesis. (Schön, I., Martens, K. and Dijk, P., eds). Dordrecht: Springer, 99-131. 
Wagner, A. (2005). Energy constrains on the evolution of gene expression. Mol. Biol. Evol., 22(6), 1365-1374.

Wendel, J. F., and Rapp, R. A. (2005). Epigenetics and plant evolution. New Phytologist, 168, 81-91.

West-Eberhard, M.J. (2003). Developmental Plasticity and Evolution. Oxford, UK: Oxford University Press.

Wyles, J.S., Kunkel, J.G., and Wilson, A.C. (1983). Birds, behavior and anatomical evolution. Proc. Natl. Acad. Sci. USA, 80, 4394-4397.

Zhang, Y., Fischer, M., Colot, V., and Bossdorf, O. (2012). Epigenetic variation creates potential for evolution of plant phenotypic plasticity. New Phytologist, 197, 314-322.

Zhang, J., Liu, Y., Xia, E.H., Yao, Q.Y., Liu, X.D. and Gao, L.Z. (2015). Autotetraploid rice methylome analysis reveals methylation variation of transposable elements and their effects on gene expression PNAS, doi: 10.1073/pnas.1515170112.

Zhang, H., Lang, Z., and Zhu, J. (2018). Dynamics and function of DNA methylation in plants. Nature Reviews, 19, 489-506. 


\section{List of Publications}

Syngelaki, E., Schinkel, C.C-F., Klatt, S. and Hörandl, E. (2020a). Effects of temperature treatments on cytosine-methylation profiles of diploid and autotetraploid plants of the alpine species Ranunculus kuepferi (Ranunculaceae). Front. Plant Sci., 11, 435.

Schinkel, C.C-F., Syngelaki, E., Kirchheimer, B., Dullinger, S., Klatt, S. and Hörandl, E. (2020). Epigenetic patterns and geographical parthenogenesis in the alpine plant species Ranunculus kuepferi (Ranunculaceae). Int J MolSci., 21(9), 3318.

Syngelaki, E., Daubert, M., Klatt, S. and Hörandl, E. (2020b). Phenotypic responses, reproduction mode and epigenetic patterns under temperature treatments in the alpine plant species Ranunculus kuepferi (Ranunculaceae). Biology, $9(10), 315$.

Syngelaki, E., Paetzold, C., and Hörandl, E. (submitted). Gene expression profiles of diploid and tetraploid plants of the alpine species Ranunculus kuepferi (Ranunculaceae) under cold stress conditions. Submitted to The Plant Journal 


\section{Thesis Declarations}

Chapter 2 - Effects of temperature treatments on cytosine-methylation profiles of diploid and autotetraploid plants of the alpine species Ranunculus kuepferi (Ranunculaceae).

ES, EH designed research; CS, SK, EH collected plant materials; ES, CS, SK performed experiments; ES collected and analyzed data; ES wrote the paper with contributions from EH. All authors commented on and discussed previous versions of the paper.

Chapter 3 -Phenotypic responses, reproduction mode and epigenetic patterns under temperature treatments in the alpine plant species Ranunculus kuepferi (Ranunculaceae).

ES, EH designed research; SK, EH collected plant materials; ES, MD performed experiments; ES collected and analyzed data; ES wrote the paper with contributions from EH. All authors commented on and discussed previous versions of the paper.

Chapter 4-Gene expression profiles of diploid and tetraploid plants of the alpine species Ranunculus kuepferi (Ranunculaceae) under cold stress conditions.

ES, EH designed research; ES performed experiments; ES, CP collected and analyzed data; ES wrote the paper with contributions from EH. All authors commented on and discussed previous versions of the paper. 


\section{Acknowledgements}

I would like to attribute my sincerest thanks to Prof. Dr. Elvira Hörandl, for placing her trust in me to perform this research and providing opportunities to broaden my horizons, as well as her excellent supervision throughout the project. I would also like to express my gradidute to Prof. Dr. Stefan Scheu, for agreeing to be the second reviewer of my dissertation.

Experimental design, wet and dry lab work would be impossible without the support of Simone Klatt, Mareike Daubert, Christoph Schinkel and Claudia Pätzold. The latter two, together with Salvatore Tomasello, I would like to further thank for their invaluable encouragement and the countless discussions that improved the quality of my work.

I would also like to thank all my colleagues for their help and advice towards all kinds of issues occurred during my project, as well as Silvia Friedrich sans Sabine Schmidt for nursing the plants in the climate growth chambers. The current project was financially supported by the German Research Foundation (DFG; Deutsche Forschungsgemeinschaft) [project Ho 4395/1-2] and the Ursula Hofmann Stiftung of the Universitätsbund Göttingen.

Special thanks to Prof. Dr. Christoph Bleidorn and his team for providing me the qRT-PCR facilities at the Department of Animal Evolution and Biodiversity, GeorgAugust-Universität Göttingen.

Finally, I would like to express my gratitude to all my friends in Greece and Berlin, for helping me in various ways to make it to this point, Dr. Ludo Muller for his guidance and help, my therapist for helping me through the stuggle of anxiety and my parents and sister for being always there with their support. 


\section{Curriculum Vitae}

Eleni Syngelaki

*20.04.1991 in Heraklion (Crete)

02/2017-12/2021 PhD-Student at the Albrecht-von-Haller Institute for Plants Sciences, Georg-August-Universität Göttingen, Germany

09/2009-07/2015 Diploma of Science in Biology at Aristotle University of Thessaloniki, Greece

Thesis: Genetic variation of two ecotypes of Thymbra capitata in western Crete

09/2008 - 06/2009 High School Graduation Certificate, 8th Lyceum, Heraklion, Crete

Advanced courses - Biology and Chemistry 